UNIVERSIDADE DE SÃO PAULO

HOSPITAL DE REABILITAÇÃO DE ANOMALIAS CRANIOFACIAIS

TÂNIA MARA DE TASSIS MANDELLI

ALTERAÇÕES DIMENSIONAIS MANDIBULARES E SUA RELAÇÃO COM ATIVIDADE MUSCULAR EM PACIENTES PORTADORES DE PRÓTESES IMPLANTOSSUPORTADAS 



\section{ALTERAÇÕES DIMENSIONAIS MANDIBULARES E SUA RELAÇÃO COM ATIVIDADE MUSCULAR EM PACIENTES PORTADORES DE PRÓTESES IMPLANTOSSUPORTADAS}

Dissertação apresentada ao Hospital de Reabilitação de Anomalias Craniofaciais da Universidade de São Paulo para a obtenção do título de mestre em Ciências da Reabilitação.

Área de Concentração: Fissuras Orofaciais Orientador: Alceu Sérgio Trindade Júnior

\section{BAURU}




\section{UNIVERSIDADE DE SÃO PAULO}

\section{HOSPITAL DE REABILITAÇÃO DE ANOMALIAS CRANIOFACIAIS}

Rua Silvio Marchione, 3-20

Caixa Postal: 1501

17012-900 - Bauru - SP - Brasil

Telefone: (14) 3235-8000

Prof. Dr. Adolpho José Melfi - Reitor da USP

Prof. Dr. José Alberto de Souza Freitas - Superintendente do HRAC - USP

AUTORIZO A REPRODUÇÃO E DIVULGAÇÃO TOTAL OU

PARCIAL DESTE TRABALHO, POR QUALQUER MEIO CONVENCIONAL OU ELETRÔNICO, PARA FINS DE ESTUDO

E PESQUISA, DESDE QUE CITADA A FONTE.

\begin{tabular}{|c|c|}
\hline T185a & $\begin{array}{l}\text { Tassis, Tânia Mara Mandelli } \\
\text { Alterações dimensionais mandibulares e sua relação } \\
\text { com atividade muscular em pacientes portadores de próteses } \\
\text { implantossuportadas. / Tânia Mara de Tassis Mandelli. } \\
\text { Bauru, 2008 } \\
\quad \text { 163p.; il.; } 30 \mathrm{~cm} \text {. }\end{array}$ \\
\hline & $\begin{array}{l}\text { Dissertação (Mestrado - Área de Concentração: Fissuras } \\
\text { Orofaciais) - Hospital de Reabilitação de Anomalias } \\
\text { Craniofaciais, Universidade de São Paulo. }\end{array}$ \\
\hline & Orientador: Alceu Sérgio Trindade Júnior \\
\hline & $\begin{array}{l}\text { 1. Implante dentário endósseo. 2. Eletromiografia. } \\
\text { 3. Reabsorção óssea. }\end{array}$ \\
\hline
\end{tabular}




\section{FOLHA DE APROVAÇÃO}

\section{Tânia Mara de Tassis Mandelli}

Dissertação apresentada ao Hospital de Reabilitação de Anomalias Craniofaciais da Universidade de São Paulo, para obtenção do título de mestre em Ciências da Reabilitação.

Área de Concentração: Fissuras Orofaciais

Aprovado em:

\section{Banca Examinadora}

Prof.(a) Dr.(a)

Instituição Assinatura

Prof.(a) Dr.(a)

Instituição Assinatura

Prof.(a) Dr.(a)

Instituição Assinatura

Prof.(a) Dr.(a)

Instituição Assinatura

Prof.(a) Dr.(a)

Instituição (Orientador)

Prof.(a) Dr.(a)

Presidente da Comissão de Pós-Graduação do HRAC-USP

Data de depósito da dissertação junto à SPG: 1 

13 de fevereiro 1961

Governador Valadares - MG

$1979-1983$

$1986-1986$

$1988-1990$

$1989-1991$

$1995-1995$

$1998-1998$

Associações
Nascimento

Curso de Odontologia na Faculdade de Odontologia de Governador Valadares (FOG) - UNIVALE - Fundação Percival Faquhar

Aperfeiçoamento em Prótese Dentária EAP - ABO - MG

Especialização em Prótese Dentária Faculdade de Odontologia de Bauru USP

Especialização em Periodontia Residência Odontológica - HRAC - USP

Credenciamento Cirúrgico - Protético em Implantes Osseointegrados Brånemark.

Aperfeiçoamento em Prótese sobre Implante Faculdade de Odontologia de Bauru - USP

APCD - Associação Paulista de Cirurgiões-Dentistas

SOBRAPE - Sociedade Brasileira de Periodontia 



\section{DEDICATÓRIA}

A Deus, por me guiar pelos caminhos da vida, me conceder uma família maravilhosa e me proteger, permitindo que eu sinta sua presença em todos os momentos da vida.

Aos meus queridos pais, Eden e Dra. Moreninha, que sempre com muito amor, dedicação e honestidade me educaram e me ensinaram o quanto é importante dar valor às pequenas coisas, aos pequenos gestos e às pessoas. Sei que cada sonho meu realizado, cada degrau da vida conquistado é motivo de imenso orgulho para eles.

Às minhas queridas e amadas filhas, Vitória e Sofia, flores confiadas por Deus a mim, pelo incentivo maior e compreensão das horas roubadas de nossa gostosa convivência.

À minha querida avó, Luzia, mulher ímpar, adorável e maior guerreira que pude conviver nesta existência.

Aos meus queridos irmãos, Vinicius e Éden, talvez a distância e as dificuldades pelas quais passamos na vida tenham nos aproximado ainda mais e reforçado tanto o nosso amor.

Aos meus queridos tios, Aníbal, Dalva, Vera, Amparo, Paulo e Reginaldo, pela carinhosa infância, conduta exemplar e vitoriosa de vida, à qual sempre me espelhei. 



\section{AGRADECIMENTO ESPECIAL}

\section{Aa Praf. Dr. Alceu Sérgia Trindade Júniar}

Renomado mestre, um exemplo de amor à Fisiologia,

todo o meu respeito e minha gratidão pela competente orientação, pela confiança em mim depositada, pelo carinho e desprendimento em compartilhar seus conhecimentos, pela dedicação e disponibilidade sempre demonstradas. 


\section{AGRADECIMENTOS ESPECIAIS}

À Profa. Dra. Maria Lúcia Rubo de Rezende, ícone da Periodontia Contemporânea, agradeço a orientação inicial deste trabalho. Manifesto todo o meu respeito e admiração.

À Dra. Régia Luzia Zanata, competentíssima profissional, amiga de todas as horas, o meu profundo agradecimento pela amizade, incentivo e por me introduzir na vida acadêmica. Sua competência, sua calma e amizade me fizeram chegar até aqui.

À Dra. Ana Cláudia Martins Sampaio Teixeira, do setor de Fisiologia do HRAC, pela grande amizade, minha imensa admiração pela bondade de seu coração, pela competência e por compartilharmos momentos felizes e importantes desta etapa profissional.

Às Dras. Inge Trindade, Ana Paula Fukushiro e Renata Yamashita, do Setor de Fisiologia do HRAC, exemplos de organização e apoio à Ciência, agradeço o incentivo, a paciência e a amizade.

Aos Profs. Drs. José Mauro Xavier, José Adilson Rosa, José Geraldo Frade e Armando Gobira, meus professores da graduação, que com seus profundos conhecimentos e ética profissionais me conduziram nos caminhos iniciais da Odontologia.

Aos Profs. Drs. Valdir Janson, Deoclécio Nahás, Euloir Passanezi e Carlos Araújo, meus professores da pós-graduação latus senso, que despertaram em mim, a importância do contínuo aprendizado.

À Cidinha, do Setor de Genética, sem a qual, esta pesquisa não teria sido realizada.

Ao meu esposo, Urias Mandelli Filho, pelas horas ausentes e apoio. 


\section{AGRADECIMENTOS}

Ao Hospital de Reabilitação de Anomalias Craniofaciais (HRAC-USP), carinhosamente conhecido como Centrinho, que devido ao ideal de um grupo de professores, aqui representados pelo Dr. José Alberto de Souza Freitas, tornou-se referência mundial na arte de reconstruir sorrisos, reabilitando vidas. Aqui, neste local mágico, que transborda ciência, aprendizado e solidariedade, aperfeiçoei meus conhecimentos, fiz grandes amigos e pude compreender que de nada serve ser luz se não for para iluminar os caminhos do demais.

Ao CNPq, Conselho Nacional de Desenvolvimento Científico e Tecnológico, pelo apoio financeiro para o desenvolvimento deste estudo.

À Radiomemory, pela concessão do programa Radiocef 2, utilizado nesta pesquisa.

Aos Drs. Caio Figueiredo, Flávio Amado e Roberta Pires, do Setor de Implantodontia, e ao Dr. Carlos, do Setor de Radiologia, agradeço à colaboração e à amistosa acolhida.

À Ivone Macedo e Roseli, auxiliares odontológicas do Setor de Implantodontia, à Irene, do Setor de Radiologia, ao Edson e ao Neto do Setor de Fotografia, à amizade, ao profissionalismo e à ajuda inestimável para a realização desta pesquisa.

Ao Marcel Taga, estatístico do HRAC-USP, pela análise estatística, amizade sincera e ajuda inestimável para a conclusão desta pesquisa.

À Andréia, Zezé e Rogério, do Setor de Pós-graduação, à Fátima, do Setor de Agendamento, ao Jorge, do Setor de Informática, à Marisa e Lucas, do Setor de Comunicação, à Rose, Alessandra e Denise da UEP, sempre dispostos a ajudar, agradeço a amizade e colaboração. 
Aos amigos do Mestrado e Doutorado, Dr. Mateus Violin, Dr. Gustavo Ducati, Dra. Soraia Maeda, Sílvia Amália, Dra. Cristiane, Simone, Priscila, Ana Celina, Siulan, Trixy, Fabiana, Melissa, Tatiana, Giovana e Janete, pela convivência agradável e amizade sincera, as quais ficarão guardadas para sempre no baú das recordações e também pelas boas risadas que demos juntos. Companheiros inestimáveis desta importante etapa profissional.

Às Dras. Márcia Araújo, Virna Reghini, Elen Moreno e Wolmer Ferreira, companheiros de jornada profissional da Clínica Prodentium, agradeço à amizade, ao apoio e agradável convivência ao longo de todos esses anos.

À Dra. Ivy Trindade, agradeço a ajuda inestimável e à amizade.

Às Dras. Rosa Parolo, Sueli Devides e Rita Lauris, profissionais do Setor Odontológico, pela amizade sincera, pelo apoio ao longo de toda esta jornada.

À Fátima Sandrim, exemplo de ética, agradeço a colaboração no início desta etapa e a amizade sincera.

Aos todos os meus pacientes, que puderam compreender a minha ausência como forma de maior aprendizado.

À minha família bauruense, aqui representada pelo Sr. Urias Carlos Mandelli e Da . Clara, que me acolheram carinhosamente e me ensinaram que o amor é mais que um estado de enamoramento, o amor é uma filosofia de vida.

E finalmente, à Universidade do Vale do Rio Doce, pela minha sólida formação acadêmica, onde tudo começou. 
Um dia, uacê aprende que:

Nãa imparta a que uacê tem na vida, mas quem uacê tem na vida.....

Aprende que nãa imparta aande já chegau, mas para aande está inda... $\mathcal{E}$ descabre que a tempa é alga que nãa se pade valtar atrás...

Os sanhas, ah! Os sanhas sãa para serem realizadas!

Partanta, plante seu jardim e decare sua alma, aa invés de esperar que alguém lhe mande flares...

$\mathcal{E}$ vacê vai descabrir que realmente pade supartar...

Que realmente é forte...

$\mathcal{E}$ que pade ir mais lange, mesma depais de pensar que nãa se pade mais....

Entãa, wacê wai entender que a vida tem valar e que vacê tem valar diante da uida! 



\section{RESUMO}

TASSIS TMM. Alterações dimensionais mandibulares e sua relação com atividade muscular em pacientes portadores de próteses implantossuportadas [dissertação]. Bauru: Hospital de Reabilitação de Anomalias Craniofaciais, Universidade de São Paulo; 2008.

Objetivos: este estudo se propôs avaliar a correlação entre atividade do músculo masseter e alteração óssea mandibular, posterior ao último implante, um ano após a reabilitação com próteses implantossuportadas, em pacientes com fissura labiopalatina já reparada. Material e Método: As alterações dimensionais ósseas foram medidas em radiografias panorâmicas digitalizadas realizadas antes e um ano após a reabilitação de dezessete pacientes. A eletromiografia dos músculos masseteres foi realizada durante a contração voluntária isométrica máxima (CVIM) por $5 \mathrm{~s}$, mastigação habitual de cenoura $(\mathrm{MH})$, mastigação unilateral direita (MUD) e esquerda (MUE) de látex. Resultados: ocorreu aumento ósseo significativo na mandíbula de $1,98 \mathrm{~mm}(\mathrm{p}<0,001)$ para o tipo de prótese inferior overdenture implantossuportada. O lado direito é maior que o esquerdo em $0,9 \mathrm{~mm}$. Um significante aumento da amplitude para a MH $(9 \mu \mathrm{V})$ e para a MUE $(19 \mu \mathrm{V})$ foi observado, independente do tipo de prótese. Um aumento significante para a MUE $(19 \mu \mathrm{V})$ foi observado para a prótese overdenture. Ocorreu um aumento estatisticamente significante para o ato mastigatório durante os três tipos de mastigação ( $\mathrm{MH}=0,13 \mathrm{~s}, \mathrm{MUD}=0,06 \mathrm{~s}, \mathrm{MUE}=0,12 \mathrm{~s}$ ), independente do tipo de prótese. Para o ciclo mastigatório também foi observado aumento estatisticamente significante, independente do tipo de prótese durante a MH $(0,12 \mathrm{~s})$ e MUE $(0,11 \mathrm{~s})$. Conclusão: Ocorreu aposição óssea na região posterior da mandíbula para a prótese overdenture e apesar do aumento da atividade muscular, não foi encontrada correlação estatisticamente significante com a atividade muscular do masseter.

Descritores: implantes endósseos, eletromiografia, reabsorção óssea. 



\begin{abstract}
TASSIS, TMM. Mandibular dimensional changes and its relationship with muscular activity in pacients when implant-supported prosthesis are used [thesis]. Bauru: Hospital for Rehabilitation of Craniofacial Anomalies, University of São Paulo; 2008.

Purpose: The purpose of the present study was to evaluate the correlation between masseter muscle activity and changes occurred in mandibular bone height, posterior to the last implant, one year after implant-supported prosthesis rehabilitation in repared cleft lip and palate patients. Materials and Methods: changes in mandibular bone height were measured in digitalized images of panoramic radiographies taken before and one year after oral rehabilitation of seventeen repared cleft lip and palate patients (Radiocef 2 - Radiomemory). Parameters for electromyography of masseter muscle were: maximum voluntary isometric clench (MVC) for 5s, habitual chewing of carrots (HC) and unilateral right (URL) and left (ULL) chewing of latex. Results: a mean increase in mandibular bone height of $1,98 \mathrm{~mm}$ $(\mathrm{p}<0,001)$ for the implant retained overdenture was observed. Bone apposition was higher in the right side. Significant increase in the amplitude was observed during $\mathrm{HC}(9 \mu \mathrm{V})$ and during ULL $(19 \mu \mathrm{V})$, regardless prosthesis type and side. A significant increase was observed during URL $(19 \mu \mathrm{V})$ for the implant retained overdenture. A significant statistical increase for the masticatory act was observed during the three types of mastication $(\mathrm{HC}=0,13 \mathrm{~s}, \mathrm{URL}=0,06 \mathrm{~s}$, $\mathrm{ULL}=0,12 \mathrm{~s}$ ), regardless prosthesis types. A significant statistical increase was observed for the masticatory cycle during $\mathrm{HC}(0,12 \mathrm{~s})$ and $\mathrm{ULL}(0,11 \mathrm{~s})$, regardless prosthesis type. Conclusion: Mandibular bone apposition in the posterior region to the last implant, in patients using implant retained overdentures and improvement in muscular activity in both types of prosthesis were observed, although no significant correlations were encountered between them.
\end{abstract}

Key words: endosseous implant, electromyography, bone resorption. 



\section{LISTA DE ILUSTRAÇÕES}

Figura 1 - Marcação dos pontos de referência, sobre o papel de acetato transparente, a serem usados na avaliação da altura óssea na região posterior ao último implante

Figura 2 - Negatoscópio com estativa (suporte), máquina fotográfica em posição e máscara de cartão preto.

Figura 3 - Tela inicial do programa Radiocef 2

Figura 4 - Tela de inserção de dados e radiografias do paciente.

Figura 5 - Tela de Calibração da imagem

Figura 6 - Tela de Calibração referencial

Figura 7 - Tela de mensurações dos sítios

Figura 8 - Eletrodos bipolares de superfície.

Figura 9 - Posicionamento dos eletrodos

Figura 10 - Cubos de cenoura e látex.

Figura 11 - Medida da amplitude da contração isométrica máxima dada pelo programa K-6.

Figura 12 - Medida da amplitude da MH, MUD e MUE.

Figura 13 - Calibração da imagem eletromiográfica.

Figura 14 - Medidas do ato e do ciclo mastigatório durante a mastigação habitual de cenoura e durante a mastigação unilateral direita e esquerda de látex

Figura 15 - Medidas da altura óssea vertical segundo os grupos e instantes.

Figura 16 - Medida da Amplitude durante a CVIM e MH segundo o lado, o tipo de prótese inferior e os instantes.

Figura 17 - Medida da Amplitude durante a MUD e MUE segundo o lado, o tipo de prótese inferior e os instantes

Figura 18 - Duração do ato durante a MH, MUD e MUE segundo os grupos e instantes

Figura 19 - Duração do ciclo durante a MH, MUD e MUE segundo os grupos e instantes 



\section{LISTA DE TABELAS}

Tabela 1 - Caracterização da amostra quanto ao gênero e idade média....................... $\quad$ 64

Tabela 2 - Caracterização da amostra quanto ao tipo de fissura e tipos de próteses inferior e superior.

Tabela 3 - Medidas-resumo das medidas verticais do grupo com prótese inferior Overdenture segundo instante, lado e sítio

Tabela 4 - Medidas-resumo das medidas verticais do grupo com prótese inferior Protocolo segundo instante, lado e sítio.

Tabela 5 - Tabela de análise de variância das medidas verticais

Tabela 6 - Comparações post hoc considerando os fatores: Instante e GrupoMedidas verticais.

Tabela 7 - Comparações post hoc dos sítios - Medidas verticais.

Tabela 8 - Comparações post hoc dos lados - Medidas verticais.

Tabela 9 - Medidas-resumo da medida da Amplitude durante a CVIM.

Tabela 10 - Medidas-resumo da medida da Amplitude durante a MH.

Tabela 11 - Medidas-resumo da medida da Amplitude durante a MUD.

Tabela 12 - Medidas-resumo da medida da Amplitude durante a MUE.

Tabela 13 - ANOVAS- Amplitude.

Tabela 14 - Comparações post hoc da medida da Amplitude durante a MH.

Tabela 15 - Comparações post hoc da medida da Amplitude durante a MUD......

Tabela16 - Medidas-resumo da duração do ato durante a MH.

Tabela 17 - Medidas-resumo da duração do ato durante a MUD.

Tabela 18 - Medidas-resumo da duração do ato durante a MUE.

Tabela 19 - ANOVAS-Ato

Tabela 20 - Comparações post hoc-Ato

Tabela 21 - Medidas-resumo da duração do Ciclo durante a MH......

Tabela 22 - Medidas-resumo da duração do Ciclo durante a MUD.

Tabela 23 - Medidas-resumo da duração do Ciclo durante a MUE. 
Tabela 24 - ANOVAS- ciclo......

Tabela 25 - Comparações post hoc da duração do ciclo

Tabela 26 - Valores de $\mathrm{p}$ dos modelos de regressão estratificados por instante e lado entre a média das medidas verticais e cada uma das variáveis

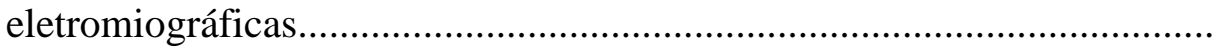

Tabela 27 - Modelos de regressão estratificados por lado entre as diferenças T2-T1 das medidas verticais e as diferenças T2-T1 de cada variável eletromiográfica.

Tabela 28 - Modelos de regressão finais. 
LISTA DE ABREVIATURAS E SIGLAS

PT

3D

EMG

HRAC

USP

DA

DC

CPD

DPI

$\mathrm{cm}$

$\mathrm{mm}$

CVIM

$\mathrm{MH}$

MUD

MUE

$\mu v$

$\mathrm{s}$

Dp

F

M

$\mathrm{O}$

$\mathrm{P}$

W

GB

$\mathrm{ms}$

$\mathrm{Hz}$

vs

LE

LD

Dif
Prótese Total

Três Dimensões

Eletromiografia

Hospital de Reabilitação de Anomalias Craniofaciais

Universidade de São Paulo

Duração do ato mastigatório

Duração do ciclo mastigatório

Centro de Processamento de Dados

Pontos por polegadas

Centímetros

Milímetros

Contração voluntária isométrica máxima

Mastigação Habitual de cenoura

Mastigação Unilateral direita de látex

Mastigação Unilateral Esquerda de látex

Microvolts

Segundos

Desvio-padrão

Feminino

Masculino

Overdenture

Protocolo

Watts

giga bites

Milisegundos

Hertz

versus

Lado Esquerdo

Lado Direito

Diferença 



\section{SUMÁRIO}

1 INTRODUÇÃO

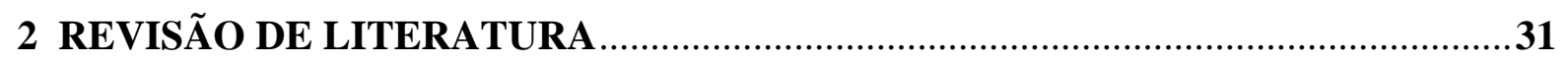

2.1 ALTERAÇÕES DIMENSIONAIS ÓSSEAS MANDIBULARES......................................33

2.1.1 Alterações dimensionais ósseas em pacientes reabilitados com prótese total ..........33

2.1.2 Alterações dimensionais ósseas em pacientes reabilitados com próteses

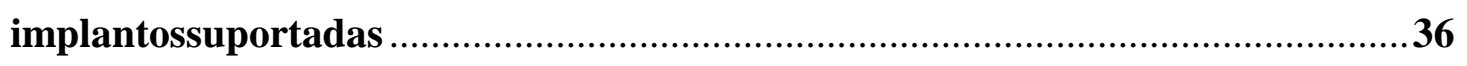

2.2 ATIVIDADE MUSCULAR E ELETROMIOGRAFIA.................................................43

2.3 RADIOLOGIA E PROGRAMAS DE IMAGEM DIGITAL EM IMPLANTODONTIA....52

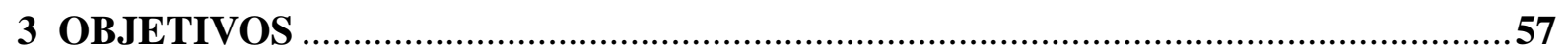

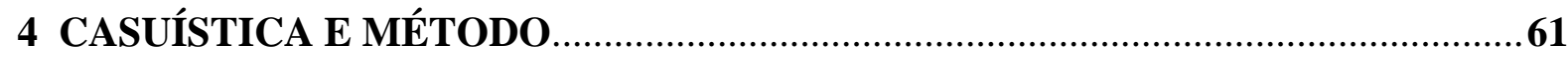

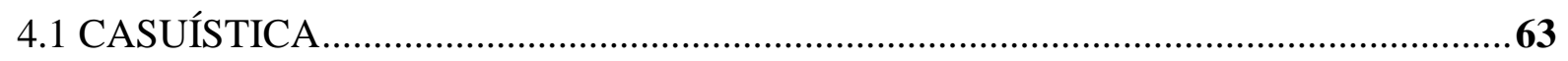

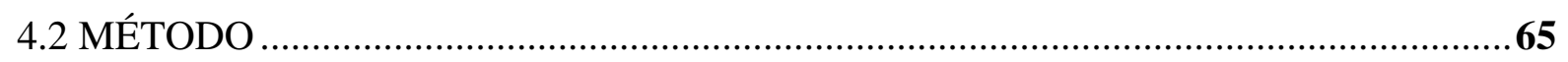

4.2.1 Análise radiográfica ……………………………………………………....65

4.2.1.1 Radiografia Panorâmica .................................................................................65

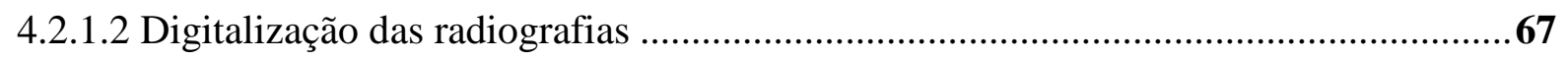

4.2.1.3 Mensurações lineares dos sítios anatômicos ........................................................68

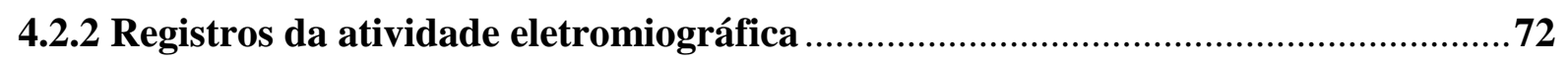

4.2.2.1 Análise do traçado eletromiográfico....................................................................74

4.2.2.1.1 Medida da amplitude durante a Contração Voluntária Isométrica Máxima (CVIM)..75

4.2.2.1.2 Mastigação habitual de cenoura $(M H)$.............................................................75

4.2.2.1.3 Mastigação unilateral direita de látex (MUD)....................................................75

4.2.2.1.4 Mastigação unilateral esquerda de látex (MUE) ................................................76

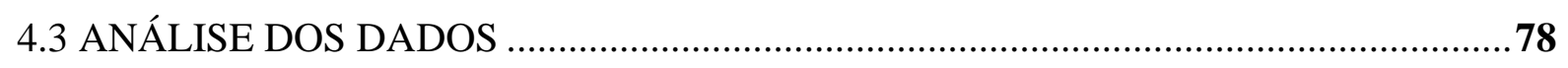

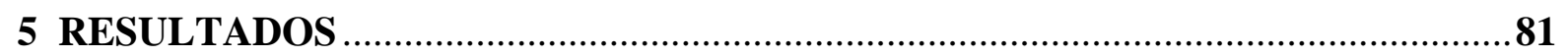

5.1 ESTUDO DA ASSOCIAÇÃO ENTRE A MEDIDA ÓSSEA VERTICAL E OS FATORES: TIPO DE PRÓTESE INFERIOR, INSTANTE, LADO E SÍTIO. .................83

5.2 ESTUDO DA ASSOCIAÇÃO ENTRE AS MEDIDAS DA ATIVIDADE MUSCULAR MASSETÉRICA E OS FATORES: TIPO DE PRÓTESE INFERIOR, INSTANTE E LADO …………………………………………......88

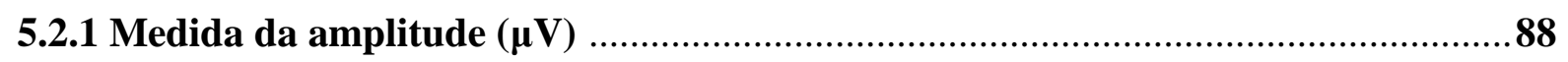


5.2.2 Duração do ato mastigatório(s)

5.2.3 Duração do ciclo mastigatório(s)

5.3 ESTUDO DA ASSOCIAÇÃO ENTRE A MEDIDA ÓSSEA VERTICAL E AS MEDIDAS DE ATIVIDADE MUSCULAR MASSETÉRICA.................................101

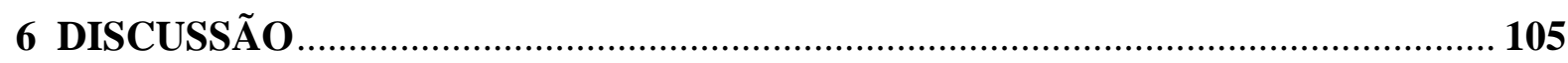

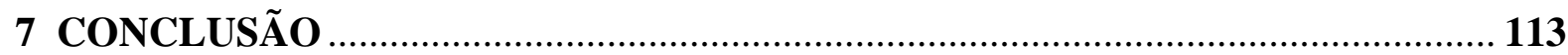

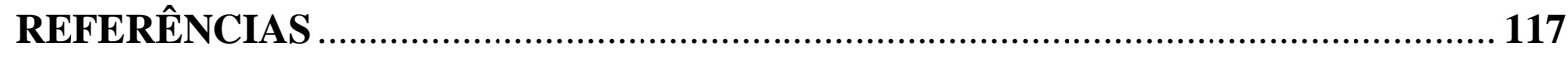

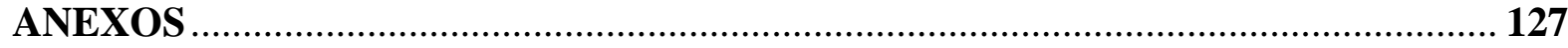





\section{INTRODUÇÃO}

Indivíduos desdentados apresentam alterações da função mastigatória, da fonética e da estética. O edentulismo desses indivíduos, os quais são relatados na literatura como inválidos orais, tem importante repercussão em sua qualidade de vida (Bergman e Carlsson 1985, Stellingsma 2003, Felix 2005).

Os desdentados totais reabilitados com próteses convencionais (prótese total) estão sujeitos ao desconforto mastigatório devido à dor, a não adaptação e à pouca eficiência mastigatória de suas próteses, à dificuldade para se alimentar e falar, bem como à contínua reabsorção de seus rebordos, o que pode dificultar ou mesmo inviabilizar a reabilitação desses indivíduos (Atwood 1971 e 1979, Tallgren 1972, Jahangiri et al 1998).

A reabilitação oral por meio de implantes osseointegrados tem sido o tratamento mais realizado em pacientes edêntulos, com taxa de sucesso de 99\% (Adell et al 1981, Ekelund et al 2003, Jablonski 2004).

Pacientes reabilitados por meio de próteses implantossuportadas melhoram significantemente suas funções orais como mastigação, fonação e deglutição bem como o conforto mastigatório e a estética facial. Além disso, a habilidade e a eficiência mastigatória são mais altas em comparação aos usuários de próteses convencionais causando um impacto psicológico benéfico, aumentando dessa forma, a qualidade de vida dos indivíduos (Haraldson e Ingerval 1979, Lindquist e Carlsson 1985, Feine et al 1994, Fontijn-Tekamp et al 2000, Awad et al 2003, Stellingsma et al 2003, Attard e Zarb 2004, van Kampen et al 2004 e Felix 2005).

A literatura consultada demonstrou que pode ocorrer aposição óssea em áreas subpônticas de pacientes reabilitados com próteses fixas convencionais, bem como, em áreas posteriores ao último implante de pacientes reabilitados com próteses implantossuportada (Taylor 1989, Oikarinem e Siirila 1992, Murphy 1995, Daniels 1997, Wright et al 2002, Reddy et al 2002, Roberts 2005, Lopes 2006).

As pesquisas relacionadas à mensuração da atividade muscular avaliadas por eletromiografia têm sugerido que a força mastigatória e a atividade muscular estão aumentadas em pacientes reabilitados com próteses implantossuportas em comparação com aqueles que foram reabilitados com próteses totais convencionais (Haraldson et al 1979, Lindquist e Carlsson 1985, Fontijn-Tekamp et al 2000, Bakke 2002, Ferrario et al 2004). 
Contudo em indivíduos sem fissuras, bem como naqueles com fissuras congênitas, não há dados consistentes na literatura sobre a atividade muscular do músculo masseter, muito menos correlacionando esta atividade com a aposição óssea pós-reabilitação oral através de prótese implantossuportada.

Este estudo pretendeu quantificar a alteração dimensional óssea do rebordo mandibular, posterior ao último implante e verificar a atividade muscular correlacionando possíveis alterações da atividade muscular com as possíveis alterações dimensionais. O estudo foi realizado em indivíduos com fissuras congênitas reparadas nas modalidades terapêuticas overdenture e protocolo Brånemark implantossuportadas. 
2 REVISÃO DE LITERATURA 



\section{REVISÃO DE LITERATURA}

Com a finalidade de embasar o nosso trabalho, nos aprofundarmos no assunto e para uma melhor compreensão da metodologia, este capítulo foi dividido em tópicos:

\subsection{ALTERAÇÕES DIMENSIONAIS ÓSSEAS MANDIBULARES}

\subsubsection{Alterações dimensionais ósseas em pacientes reabilitados com prótese total}

A mandíbula humana é um osso que exibe um alto grau de variabilidade anatômica e isto ocorre não somente entre os indivíduos ou como resultado da idade, mas também entre lado direito e esquerdo. Após o crescimento ter cessado, o mais importante fator que governa a mudança morfológica deste osso é a presença ou a ausência de dentes.

O contorno e a estrutura de mandíbulas edêntulas são diferentes de mandíbulas dentadas. Na mandíbula edêntula, a largura e altura óssea são reduzidas, a cortical óssea na crista e na superfície anterior é fina ou deficiente e o trabeculado não tem um padrão definido; há uma redução do volume e densidade mineral e as alterações osteoporóticas são comuns no osso alveolar (Lammie 1960).

Por anos, autores como Atwood $(1971,1979)$ e Tallgren (1972) têm escrito sobre a reabsorção contínua e irreversível dos rebordos alveolares de pacientes desdentados, o que poderia dificultar ou inviabilizar a reabilitação desses pacientes por meio de próteses convencionais ou implantossuportadas.

Atwood e Coy (1971) analisaram clínica, cefalométrica e densiométricamente a reabsorção dos rebordos alveolares a partir de 24 pontos anatômicos previamente selecionados, após exodontias múltiplas. Foram selecionados 76 indivíduos (44 homens e 32 mulheres, com idade média de 65,2 \pm 10 anos), divididos em grupos: até 2 anos após as exodontias (grupo 1), de 2 a 10 anos após as exodontias (grupo 2), de 10 a 20 anos após as exodontias (grupo 3) e mais que 20 anos após as exodontias (grupo 4). Os rebordos alveolares foram classificados nas seguintes categorias: categoria III, alto e bem arredondado; categoria IV, em forma de faca; categoria V, baixo mas bem arredondado e VI, depressivo. Após o período de observação reportaram que $68 \%$ dos rebordos maxilares pertenciam à categoria III, dos quais $50 \%$ eram do grupo 4, com mais de 20 anos após as exodontias. Em contraste, na 
mandíbula 54\% dos rebordos pertenciam à categoria IV, dos quais $80 \%$ eram do grupo 1 . Quinze indivíduos (20\%) apresentaram reabsorção óssea de $1 \mathrm{~mm}$ por ano e 1 indivíduo apresentou 2,2mm por ano de perda óssea. Observaram que o processo de reparo ósseo gera alterações marcantes na altura e espessura do rebordo, o qual após determinado tempo, entra em atrofia. Reportaram ainda uma correlação positiva entre a reabsorção óssea e fatores anatômicos (quantidade de rebordo residual, densidade mineral). As reabsorções eram mais evidentes em indivíduos acima de 50 anos, do sexo feminino e relacionadas com o uso prolongado de próteses por mais de 8 horas. Concluíram que, se a média proporcional da reabsorção vertical era de $0,5 \mathrm{~mm}$ por ano, em 10 anos a média da perda seria de $5 \mathrm{~mm}$, resultando em significante perda da dimensão vertical, da estética e do conforto mastigatório. Postularam que novos métodos de prevenção e tratamento da reabsorção do rebordo residual deveriam ser encontrados.

Tallgren (1972) afirmou em um estudo longitudinal de 25 anos que o rebordo alveolar residual de pacientes reabilitados com prótese total possui uma remodelação óssea com constante redução de volume, provavelmente irreversível. Afirmou ainda que, devido à geração de forças promovidas pelo uso contínuo das próteses ocorre uma alteração da morfologia (prognatismo) e comprimento da face devido ao comportamento rotacional da mandíbula, principalmente no primeiro ano de uso das próteses.

Em estudos clínicos longitudinais foi observado que mesmo após a cicatrização das feridas cirúrgicas (pós-extração), o osso alveolar continua a sofrer remodelação catabólica. As dimensões do rebordo ósseo são reduzidas mais rapidamente nos primeiros seis meses, mas a atividade de reabsorção continua ao longo da vida em uma taxa mais baixa resultando na perda de grande quantidade da estrutura óssea mandibular.

Atwood (1979) ainda postulou que havia quatro principais fatores etiológicos para reabsorção alveolar: fator anatômico (como o estado, a altura e a densidade da parte anterior do rebordo), fator protético (distância interoclusal, a retenção, a estabilidade e a coincidência da oclusão cêntrica e relação cêntrica), fator metabólico (idade e sexo, osteoporose) e fator funcional (como o número de horas que a dentadura é usada).

Bergman e Carlsson (1985) realizaram um estudo clínico em 32 usuários de dentaduras completas que foram seguidos por 21 anos. Este estudo incluía exame clínico, questionário e radiografia cefalométrica. No exame clínico reportaram que 2/3 dos pacientes possuíam dimensão vertical de oclusão bastante diminuída e que em 1//3 destes, os dentes estavam severamente desgastados e que 14 pacientes necessitavam de novas dentaduras. $\mathrm{Na}$ 
avaliação da estabilidade, a dentadura inferior era considerada como instável por $42 \%$ dos indivíduos contra $29 \%$ para a dentadura superior. Nos achados cefalométricos, a reabsorção apresentou um alto grau de variação, sendo maior na mandíbula.

Wyatt (1998) em um artigo de revisão da literatura reportou que os usuários de dentaduras tinham em média, um rebordo residual menor que aqueles que não usavam dentaduras e significante perda óssea era encontrada naqueles pacientes que usavam suas dentaduras de dia e de noite. Isto era atribuído à pressão das próteses sobre o rebordo. A perda de osso era mais pronunciada na mandíbula do que na maxila, particularmente nos primeiros 3 meses após a extração, sendo a região posterior da mandíbula mais sujeita à reabsorção. A diferença das forças oclusais entre a região anterior, onde suaves forças para incisar alimentos ocorrem quando comparadas com a região posterior, onde pesadas forças são requeridas para a trituração podem ser as responsáveis. Na avaliação da altura óssea vertical por meio de radiografia após um ano, a média de redução variou de 2 a $4 \mathrm{~mm}$ para a maxila e de 4 a $6 \mathrm{~mm}$ para a mandíbula. Forças parafuncionais podem acelerar a perda óssea em rebordos edêntulos e isto tem sido associado à irritabilidade da mucosa. Contudo, a reabsorção em maxila e mandíbula edêntulas mostra marcada variação entre indivíduos e entre locais num mesmo indivíduo independentemente de idade, sexo, status periodontal pré-extração ou altura do rebordo alveolar. Concluiu que o uso de implantes para suportar próteses fixas ou overdentures têm sido demonstrado que preserva o osso alveolar remanescente.

Perdas dentárias infligem a maior alteração nas forças funcionais. A mandíbula reage com a redução da altura e largura do rebordo alveolar e com a deterioração na qualidade e quantidade de matriz e células ósseas (Murphy 1995).

Um achado constante no estudo de mandíbulas edêntulas é que a altura do rebordo é relacionada à duração do edentulismo: quanto mais longa a duração, maior a reabsorção (Tallgren 1972,1979; Atwood 1979, Bergman e Carlsson 1985; Murphy 1995).

Carlsson (2004) realizou uma revisão de literatura sobre a reabsorção de rebordos edêntulos na resposta para a pressão. Sugeriu que é contínua a reabsorção do rebordo residual para todos os usuários de dentaduras completas, pois uma pressão contínua e excessiva produz reabsorção óssea e há uma grande variação interindividual. Reportou que os fatores considerados e usados na análise de correlação são: gênero, idade, morfologia facial, duração do edentulismo, hábitos do usuário de dentaduras, número de dentes gastos, higiene oral, parafunção, forças oclusais, qualidade da dentadura, nutrição, saúde geral, medicação, doenças sistêmicas e osteoporose, mas os resultados não são conclusivos. Os estudos clínicos 
usando análises multivariadas indicaram que o gênero feminino e fatores sistêmicos são mais importantes que o fator local (uso da dentadura) e anatômico (forma do rebordo). Considerou que a melhor forma de se evitar a reabsorção óssea é evitar a extração de todos os dentes, preservar uns poucos dentes e reabilitar o paciente com overdentures dentossuportadas. Concluiu que, em pacientes edêntulos, a reabilitação com próteses implantossuportadas diminuiu a perda óssea ou mesmo promoveu crescimento ósseo e há necessidade de se aumentar conhecimentos sobre a reabsorção do rebordo residual através de experimentos clínicos e métodos estatísticos, preferencialmente incluindo a colaboração entre pesquisadores cirurgiões-dentistas e médicos.

\subsubsection{Alterações dimensionais ósseas em pacientes reabilitados com próteses implantossuportadas}

Através de relatos experimentais detalhados no início da década de 70, Brånemark et al (1969) demonstraram ser possível reabilitar pacientes edêntulos a partir de implantes de titânio que se osseointegravam ao osso. No relato de seus estudos experimentais, os autores investigaram os fatores que controlavam a cicatrização e a estabilidade a longo prazo de implantes de titânio, inseridos no osso que suportavam próteses em cães. Afirmaram que a integridade de uma boa ancoragem dos implantes requeria um protocolo cirúrgico adequado como: preparação cirúrgica não traumática dos tecidos moles e duros, fechamento primário com retalho mucoperiósteo isolando o implante da cavidade oral, higiene oral para prevenir a inflamação gengival. Após extensas investigações clínicas macroscópicas, esteriomicroscópicas, radiográficas e microcópicas concluíram que os implantes inseridos tinham se incorporado ao tecido ósseo e gengival sem causar nenhuma injúria e que ocorria o crescimento ósseo em volta das roscas dos implantes sem qualquer tecido interposto entre eles. Esta descoberta proporcionou uma nova era na Odontologia, principalmente para os pacientes totalmente edêntulos.

Brånemark et al (1977) após realizarem um controle de 10 anos, com 211 pacientes tratados através de próteses fixas implantossuportadas, por meio da técnica periapical com suporte de Eggen, verificaram que durante a fase de cicatrização houve uma redução óssea perimplantar de 1 a $2 \mathrm{~mm}$ (por volta dos 9 meses). Na fase de remodelação (em torno de 18 meses) ocorria uma perda óssea de 0,2 a $0,3 \mathrm{~mm}$ na altura marginal, atribuindo estes fatos ao estímulo das forças enviadas para o tecido ósseo via implantes. Concluíram que esta força 
parece preservar o tecido ósseo distal ao forame mentoniano na mandíbula e diminuir a reabsorção do rebordo residual.

Adell et al (1981) com o objetivo de confirmar a interface da osseointegração realizaram um estudo durante 15 anos em 2768 implantes instalados por técnica cirúrgica padronizada em 191 maxilas e 219 mandíbulas de 370 pacientes (230 mulheres e 140

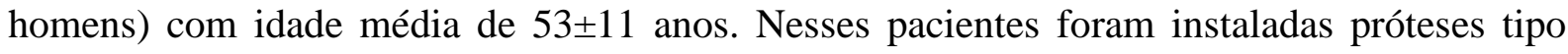
protocolos superiores e inferiores. Os autores avaliaram a altura óssea do rebordo anualmente por meio de radiografias panorâmicas, tendo como parâmetro a medida já conhecida da altura do implante instalado. Nos resultados apresentados, os autores encontraram uma perda óssea marginal no sentido transversal do rebordo perimplantar de $1,2 \mathrm{~mm}$ durante o primeiro ano após a reabilitação, e que posteriormente era de $0,1 \mathrm{~mm}$ anualmente. Afirmaram que a altura óssea marginal dependia da distribuição adequada da força marginal e adequada função da margem gengival, e que, a perda óssea marginal podia ser atribuída a vários fatores como: efeito do trauma cirúrgico (desinserção do periósteo marginal, remoção de osso marginal e dano ósseo devido perfuração), força excessiva no momento de instalação dos implantes, trauma de oclusão, relação desfavorável entre mandíbula e maxila, deflexão da estrutura da prótese sobre o pilar protético, extensão do cantilever e gengivite. Os achados radiográficos mostraram um aumento de radiopacidade em volta dos implantes através dos anos e os autores afirmaram que a força de uma carga oclusal transmitida ao tecido ósseo através dos implantes osseointegrados promovia um estímulo adequado para remodelação do tecido ósseo, mantendo a altura, o volume e eventualmente promovendo aumento da densidade óssea.

Taylor (1989) através de radiografias panorâmicas padronizadas observou um caso de aposição óssea na região posterior da mandíbula de um homem com 50 anos de idade após 2 anos e 8 meses da instalação de uma prótese fixa implantossuportada inferior com 5 implantes tendo como antagonista uma prótese total. O acréscimo foi de $3 \mathrm{~mm}$, confirmados mediante medições das radiografias e usando as angulações dos implantes como parâmetro. $\mathrm{O}$ autor não foi conclusivo quanto à etiologia, sugerindo mais investigações e descartou a possibilidade de bruxismo, pois o paciente relatou dormir sem a prótese superior.

Okarinen e Siirila (1992) a partir de um relato de caso clínico demonstraram que severa atrofia por desuso de uma mandíbula edêntula podia ser substituída por crescimento ósseo reparativo através da restauração da função e habilidade mastigatória usando uma prótese fixa implantossuportada. Os autores relataram que uma paciente de 41 anos 
desdentada por 8 anos, foi reabilitada por prótese fixa colocada sobre 5 implantes endósseos na região da mandíbula. Após 2 anos, as medições em radiografias panorâmicas padronizadas detectaram um aumento em altura no rebordo de $4 \mathrm{~mm}$ na região distal aos últimos implantes de ambos os lados e na região anterior entre os forames de $13 \mathrm{~mm}$. A remodelação óssea reparativa era claramente evidente acima do canal mandibular, mais especialmente do lado esquerdo, onde o osso superior do canal mandibular tinha sido reformado. A cortical óssea da borda inferior da mandíbula tinha sido reforçada. Os autores observaram o crescimento ósseo após 2 anos, de acordo com os achados de Taylor (1989) e conjeturaram que as razões para o reparo poderia ser o marcante uso dos músculos mastigatórios e o hábito de bruxismo da paciente.

Jacobs et al (1992) analisaram a reabsorção óssea da região posterior de mandíbulas reabilitadas com prótese fixa implantossuportadas tipo protocolo Branemark e overdenture implantossuportadas. Para isto avaliaram radiografias panorâmicas de 30 pacientes (21 mulheres e 9 homens) reabilitados com overdenture tipo barra, suportada por dois implantes; 25 pacientes (19 mulheres e 6 homens) reabilitados com prótese fixa tipo protocolo Brånemark e 85 pacientes (69 mulheres e 16 homens) reabilitados com prótese total convencional. As medições das áreas do rebordo foram realizadas por meio de dois pontos anatômicos previamente selecionados. Essas medições foram repetidas num intervalo de 10 dias por 2 examinadores. Na análise dos resultados, os pesquisadores reportaram que houve uma reabsorção anual que variou de $14 \pm 20 \%$ para as próteses overdentures; $10 \pm 19 \%$ para as próteses totais e $4 \pm 6 \%$ para as próteses fixas protocolo. Neste estudo, os autores demonstraram que as reabsorções ósseas posteriores são ligeiramente mais evidentes para as próteses overdentures que para as próteses totais nos primeiros 2 anos, mas que ao longo de 10 anos estes valores se equipararam. Concluíram que a indicação de overdenture para pacientes jovens não tem um prognóstico favorável e que as reabsorções são menos evidentes nos arco reabilitados com próteses fixas implantossuportadas.

Lindquist et al (1996) em um estudo longitudinal de 15 anos reavaliaram 47 pacientes edêntulos reabilitados com próteses fixas implantossuportadas no arco inferior com a finalidade de reportar os resultados clínicos e a perda óssea marginal. Dos 273 implantes inseridos 3 foram perdidos, sendo 2, antes e 1, seis meses após a instalação das próteses fixas, portanto a taxa de sucesso era de 98,9\%. Nenhuma prótese foi perdida e os pacientes estavam com a mesma em função reportando uma taxa de $100 \%$ de sucesso. A perda óssea marginal observada em volta dos implantes era mínima, em média $0,5 \mathrm{~mm}$ durante o primeiro ano e 
após, 0,05 $\mathrm{mm}$ anualmente sendo que esta perda era maior em volta dos implantes anteriores do que nos posteriores. Fatores como o hábito de fumar e pobre higiene oral foram os que mais influenciaram enquanto fatores oclusais como força de mordida máxima, apertamento dental e extensão dos cantilevers foram de menor importância. Concluíram que o tratamento com prótese fixa na mandíbula apresentou sucesso em relação à estabilidade da prótese e que a reabsorção óssea embora mínima, era influenciada por vários fatores, sendo que o hábito de fumar e a pobre higiene oral eram os mais importantes.

Meijer et al (1999) realizaram um estudo longitudinal, prospectivo, por 5 anos com a finalidade de avaliar e comparar os aspectos clínicos e a satisfação em pacientes reabilitados por overdentures implantossuportas (OI) e prótese total convencional (PT). Pacientes foram alocados em dois grupos sendo que 60 pacientes possuíam overdentures implantossuportada por 2 implantes e 61 pacientes possuíam PT. Um ano após a instalação das PTs os pacientes insatisfeitos tinham a oportunidade de serem reabilitados com overdentures. No grupo OI, 4 implantes foram perdidos no primeiro ano e 4 durante os 4 anos seguintes reportando uma taxa de sucesso de 93\%. No grupo da PT, 14 pacientes escolheram a overdenture após um ano. Radiografias panorâmicas foram realizadas 1 e 5 anos após a instalação das overdentures e durante o primeiro ano nenhuma a perda óssea foi reportada para os 55 pacientes sendo que a taxa de satisfação destes pacientes era maior que para o grupo reabilitado por overdenture, mas que em 5 anos esta taxa se equilibrava.

Nakai et al (2000) avaliaram o comportamento ósseo do rebordo alveolar através de radiografias panorâmicas. Para isto, radiografias panorâmicas padronizadas de 27 pacientes (11 mulheres e 16 homens) com mandíbulas edêntulas e reabilitadas com prótese fixa implantossuportadas foram analisadas após 40 meses. A borda inferior da mandíbula foi usada como referência para a mensuração da altura até à crista alveolar. Nas radiografias foram traçadas 10 linhas transversais no rebordo, posterior ao último implante de cada lado, e paralelas à linha que tangencia o processo coronóide da mandíbula. Dos 27 pacientes, 5 apresentaram aumento na crista óssea de 3,3 a 8,6\%, não havendo resultado estatisticamente significante. Os autores atribuíram o crescimento ósseo ao aumento do estresse devido à presença dos implantes endósseos.

Duyck et al (2001) realizaram um estudo experimental em coelhos com a finalidade de avaliar a reação da margem óssea do sítio com implante frente a forças estáticas e dinâmicas. Em cada um dos 10 coelhos adultos foram inseridos 3 implantes Brånemark de $10 \mathrm{~mm}$, na tíbia, do lado direito e esquerdo. Um implante era forçado estaticamente (uma força de $29,4 \mathrm{~N}$ 
ou $3 \mathrm{Kg}$ ), um era forçado dinamicamente (uma força transversa de $14,7 \mathrm{~N}$ ou $1,5 \mathrm{Kg}$, a uma distância de $50 \mathrm{~mm}$ do topo do implante era aplicada 1 vez ao dia), e um implante não era forçado para servir de controle. As forças aplicadas foram padronizadas em um estudo piloto através de um modelo finito 3D e tomografia computadorizada. A análise histológica confirmou a análise clínica, ou seja, todos os implantes estavam osseointegrados, bicorticalmente ancorados e havia formação endóstea ao longo da superfície dos implantes para a medula óssea central em todos os grupos. Uma densidade na cortical do osso lamelar era presente ao redor do pescoço e parte apical do implante, sem sinais de perda óssea para os implantes forçados estaticamente e não forçados. Para os implantes dinamicamente forçados, defeitos em forma de crateras e lacunas de Howship’s eram sinais explícitos de reabsorção óssea na área marginal, contudo havia osso em contato com a superfície do implante. Quando compararam a quantidade de osso formado da área marginal, significante $(\mathrm{p}<0,007)$ menor volume ósseo (densidade) estava presente ao redor dos implantes dinamicamente forçados em comparação com os estaticamente forçados e os implantes controles. Concluíram que o estudo foi capaz de demonstrar que forças dinâmicas excessivas causam defeitos em forma de crateras na lateral dos implantes osseointegrados.

Wrigth et al (2002) através da análise de radiografias panorâmicas, averiguaram o comportamento ósseo do rebordo alveolar posterior de 45 pacientes, sendo 21 indivíduos reabilitados com overdenture implantossuportada e 24 indivíduos reabilitados com prótese fixa sobre implante. Nos pacientes reabilitados com overdenture houve um decréscimo ósseo de aproximadamente de $1,1 \%$ ao ano, enquanto naqueles reabilitados com próteses fixas implantossuportadas houve uma aposição óssea de 1,6\% Os resultados não apresentaram dados que pudessem ser correlacionados com a idade, tempo que o indivíduo ficou desdentado ou altura do rebordo inicial.

Reddy et al (2002) avaliaram o comportamento ósseo de 60 pacientes reabilitados com prótese fixa implantossuportada inferior (protocolo Brånemark) por meio de análises radiográficas realizadas 1, 2, 3, e 4 anos após a reabilitação. Com o objetivo de padronizar as medidas a serem executadas preconizaram pontos fixos na imagem radiográfica de onde partia uma tangente que passava na distal do último implante e linhas paralelas seccionavam o corpo da mandíbula em distâncias de 5, 10, 15 e 20mm e assim eram realizadas as medições, após a correção da magnificação da imagem radiográfica. Os autores concluíram que houve um acréscimo ósseo significativo $(\mathrm{p}<0,05)$ cujo valor médio foi de $0,93 \mathrm{~mm}$ e que este acréscimo ocorria principalmente no primeiro ano após a instalação da prótese. 
Ekelund et al (2003) em uma pesquisa longitudinal estudaram clínica e radiograficamente o comportamento de próteses fixas implantossuportadas tipo protocolo Branemark acompanhadas por 23 anos em 30 pacientes. O objetivo deste trabalho foi reportar o resultado do tratamento de mandíbulas edêntulas reabilitadas por meio de próteses implantossuportadas neste grupo de pacientes. Um total de 273 implantes de $10 \mathrm{~mm}$ foi instalado de acordo com o protocolo de 2 estágios cirúrgicos. Três implantes tinham sido perdidos durante todo o período de investigação e a taxa acumulada de sobrevida era de $98,9 \%$. Todos os pacientes tinham a prótese em função, mas 2 tiveram que refazer as próteses no retorno de 20 anos. Nenhum implante ou prótese foi perdido (a) durante os últimos 5 anos. A média do nível ósseo era 1,6mm abaixo do ponto de referência após 20 anos e a média da perda óssea nos exames entre 15 e 20 anos era de $0,2 \mathrm{~mm}$ sendo que 37 implantes (24\%) mostraram mais que 2 roscas expostas no exame de 15 anos, mas, somente 4 implantes (3\%) apresentaram dor ou perda óssea excedendo uma rosca $(0,6 \mathrm{~mm})$ durante os últimos 5 anos. Concluíram que o resultado do sucesso do tratamento após 15 anos continuava por mais de 20 anos.

Attard e Zarb (2004) reportaram os resultados do tratamento a longo prazo (20 anos) em pacientes edêntulos reabilitados por próteses fixas implantossuportadas tipo protocolo Brånemark que participaram do primeiro estudo clínico sobre implantes na América do Norte. Neste estudo foram avaliados 31 pacientes e 33 próteses. $71 \%$ dos pacientes tinham sido avaliados por 20 anos apresentando $84 \%$ de taxa de sucesso para o planejamento protético e 87\% para a sobrevivência dos implantes. A média da perda óssea ao redor dos implantes após a instalação das próteses era mínima $(0,05 \mathrm{~mm})$, com alta taxa de variação. Pobre higiene oral, hábito de fumar e a posição dos implantes foram os fatores preditores da perda óssea. A longevidade das próteses fixas era de 8,39 $\pm 5,30$ anos. Os autores confirmaram o total sucesso do tratamento a longo prazo em pacientes tratados com próteses fixas implantossuportadas.

Roberts (2005) acompanhou 83 pacientes edêntulos reabilitados com próteses tipo Ramus Frame Implant por 24 anos. Para isto realizou uma detalhada análise da história médica, exames intra-orais e radiografias panorâmicas oriundas de um mesmo aparelho, de magnificação conhecida e as medições foram realizadas por um compasso milimétrico na região de pré-molares. O autor encontrou um crescimento ósseo variando de 1,34mm a 4,413mm (média 2,87mm $\pm 2,17 \mathrm{~mm}$ ) e concluiu que após a colocação das próteses, os músculos da mastigação são capazes de trabalhar mais eficientemente na aplicação das forças necessárias para o processo mastigatório sem causar dor ao paciente. 
Melo (2005) avaliou as possíveis alterações dimensionais na região posterior ao último implante através de radiografias panorâmicas de 10 pacientes com fissura congênita labiopalatina reabilitados com próteses implantossuportadas tipo protocolo inferior e 10 pacientes reabilitados com overdenture inferior e por meio de medições de cada um dos lados analisando-as no programa Radioimp (Radiomemory). Essas alterações ósseas observadas pelo autor foram da ordem de $0,19 \mathrm{~mm}$ para pacientes reabilitados com prótese tipo protocolo e da ordem de $1,03 \mathrm{~mm}$ para os reabilitados com próteses tipo overdentures. O autor concluiu que os indivíduos com fissuras apresentaram alterações ósseas mínimas, sugerindo que os mecanismos de aposição e reabsorção óssea nessas regiões estão equilibrados.

Lopes (2006) avaliou as alterações dimensionais mandibulares e sua correlação com atividade muscular massetérica em 10 indivíduos. Este estudo foi realizado em 10 pacientes com fissura labiopalatina já reparada e reabilitados por prótese fixas implantossuportadas. As alterações dimensionais foram mensuradas em radiografias panorâmicas digitalizadas através do programa para planejamento em Implantodontia Radioimp (Radiomemory, BH, MG) realizadas antes e 1 ano após a reabilitação. A autora reportou a ocorrência de aposição óssea para o lado direito de $0,52 \pm 0.96 \mathrm{~mm}$ e reabsorção de $0,05 \pm 0,78$ para o lado esquerdo e quando

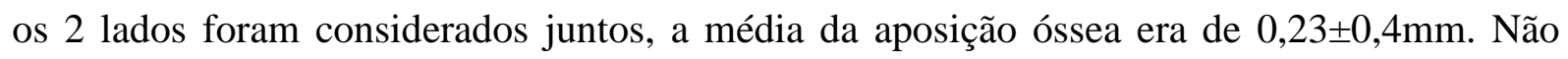
foram encontradas diferenças estatisticamente significante para a atividade muscular.

Chung et al (2007) realizaram uma análise retrospectiva dos fatores que pudessem afetar a perda óssea tardia. Analisaram 339 implantes inseridos em 69 pacientes entre abril de 1981 e 2002. Somente implantes com mais de três anos foram analisados e categorizados, baseados nos seguintes fatores: característica da superfície (lisa x rugosa), altura [curto $(<10 \mathrm{~mm}) x$ longo $(\geq 10 \mathrm{~mm})$ ], plataforma [estreita $(<3,75 \mathrm{~mm})$, regular $(3,75 \mathrm{e} 4 \mathrm{~mm})$, larga ( $>$ $4 \mathrm{~mm}$ )], quantidade de mucosa ceratinizada ( $\geq$ ou $\leq 2 \mathrm{~mm}$ ), localização (anterior x posterior; maxila x mandíbula), tipo de prótese ( fixa x removível), e tipo de dentição oposta. Os efeitos desses fatores sobre os parâmetros clínicos, especialmente a média anual de perda óssea foram avaliados clínica e radiograficamente. Para a análise da média anual de perda óssea utilizaram radiografias panorâmicas e periapicais e concluíram não haver diferença estatisticamente significante entre os dois tipos. A média da perda óssea para a prótese fixa implantossuportada $(0,1 \mathrm{~mm})$ era quase 2 vezes maior do que para a overdenture $(0,7 \mathrm{~mm})$, que fumantes apresentavam quase 3 vezes mais perda óssea que não fumantes $(0,32 \mathrm{~mm} x$ $0,12 \mathrm{~mm}$ ). Concluíram que fatores como implantes largos e curtos, localizados na maxila, 
prótese fixa implantossuportada e fumantes foram os que mais afetaram a perda óssea e que a altura do implante era o fator mais crítico para a manutenção do nível ósseo.

Tawil (2007) em um relato de caso demonstrou que força oclusal excessiva pode causar perda óssea tardia. Uma paciente de 57 anos reabilitada com prótese fixa implantossuportada na região dos dentes 14,15 e 16 e prótese provisória removível repondo os dentes 24,25 e 26 a 9 anos, apresentou severa perda óssea quando da análise radiográfica de rotina. A prótese provisória encontrava-se muito instável. Dessa forma, a conduta realizada foi a confecção de próteses fixas provisórias esplintadas para as regiões dos dentes 14,15 e 16 e 24, 25 e 26. A higiene oral foi reforçada e a condição perimplantar era avaliada a cada 3 meses por meio de radiografias periapicais. A lesão óssea começou a cicatrizar por volta de 3 meses após a eliminação da oclusão traumática. Aos 6 meses, 1,5mm de ganho ósseo vertical foi observado. Aos 12 meses a cicatrização se completou. Radiografias periapicais realizadas 4 anos mais tarde confirmaram a estabilidade da situação.

Alsaadi et al (2008) realizaram um estudo retrospectivo a fim de avaliarem a influência dos fatores sistêmicos e locais que pudessem afetar a perda óssea 2 anos após a conexão das próteses. Dados de 412 pacientes com 1514 implantes inseridos foram analisados. A coleta e a análise de dados eram focadas para os fatores endógenos como: hipertensão, problemas de coagulação, osteoporose, hipo e hipertireoidismo, quimioterapia, radioterapia, diabete tipo I e II, doença de Crohn e alguns fatores locais: qualidade e quantidade óssea, altura, diâmetro e localização do implante, tipo de edentulismo, valores para o Periotest (PTV) e quebra do protocolo de esterelização durante a cirurgia. Na análise reportaram que a radioterapia, implantes de plataforma de 5mm, localizados na região posterior da maxila afetavam significantemente a perda óssea tardia. Concluíram que a radioterapia, a localização e o diâmetro do implante eram os fatores predominantes na ocorrência da perda óssea tardia e que fatores como o hábito de fumar e fatores sistêmicos não eram proeminentes.

\subsection{ATIVIDADE MUSCULAR E ELETROMIOGRAFIA}

Moyers (1949) propôs o uso da eletromiografia como intuito de mensurar a atividade dos músculos elevadores (masseter e temporal) da mandíbula. Neste estudo ele comparou a atividade eletromiográfica de indivíduos com características normais de oclusão e indivíduos portadores de má oclusão classe II, divisão 1 de Angle. $\mathrm{O}$ autor demonstrou que havia 
diferenças significativas entre os grupos, mas que ocorria a equiparação de valores após a correção da má oclusão.

Haraldson et al (1979) realizaram um estudo sobre a função mastigatória de 13 mulheres entre 42 e 59 anos com um dos arcos reabilitado por prótese fixa sobre implante (tipo protocolo) tendo com antagonistas dentes naturais contra um grupo controle de 10 mulheres com dentes naturais ou com prótese fixas dento-suportadas. As pacientes foram questionadas quanto à qualidade de suas próteses e quanto à mastigação. Foram realizados testes de atividade eletromiográfica durante a mastigação de amêndoas e medidas da contração voluntária isométrica máxima (amplitude em $\mu \mathrm{V}$ ). Os autores encontraram satisfação das pacientes quanto à qualidade da mastigação. Para o grupo com implantes, as médias dos resultados eletromiográficos para a amplitude mastigatória durante a mastigação de amêndoas e contração voluntária isométrica máxima foram respectivamente de $8,3 \mu \mathrm{v}$ (de 0 a $27,9 \mu \mathrm{v}$ ) e $39 \mu \mathrm{v}$ (de $13 \mu \mathrm{v}$ a $93 \mu \mathrm{v}$ ); e as médias do grupo controle para os resultados eletromiográficos de amplitude mastigatória e contração voluntária isométrica máxima foram de $8,6 \mu \mathrm{v}(1,5$ a $15,2 \mu \mathrm{v})$ e $31 \mu \mathrm{v}$ (variando de 8 a $230 \mu \mathrm{v}$ ) respectivamente, sendo estes dados não diferentes estatisticamente $(\mathrm{p}<0,05)$. Os autores também concluíram que não havia correlação entre força mastigatória e idade e que o tempo de instalação das próteses implantossuportadas podia ter correlação positiva com a força mastigatória e ainda que, indivíduos reabilitados com prótese protocolo inferior possuíam função mastigatória equivalente à de indivíduos com dentição normal.

Nagasawa et al (1988) defenderam o exame eletromiográfico com sendo eficaz para o estudo da função dos músculos da mastigação permitindo a reprodutibilidade dos dados mediante conhecimento do coeficiente de variação dos parâmetros de tempo (ato/atividade mastigatória e intervalo/relaxamento muscular). Os autores afirmaram que a eletromiografia pode quantificar a atividade muscular como um todo, resultando em um melhor entendimento da fisiologia do complexo estomatognático, onde a análise da função neuromuscular é realizada por meio de potenciais de ação que precedem a contração muscular. Este trabalho colaborou para uma argumentação favorável ao uso da eletromiografia como parâmetro de avaliação da função mastigatória.

Jacobs e van Steenberghe (1993) avaliaram a fadiga do músculo masseter durante o apertamento sustentado em sujeitos com dentaduras completas, próteses implantossuportadas e dentes naturais. Os pacientes foram divididos em 4 grupos a fim de estabelecer se o grupo com próteses implantossuportadas influenciava os parâmetros dos sinais eletromiográficos. $\mathrm{O}$ 
grupo NT consistia de 8 pacientes dentados, com idade média variando entre 26 e 64 anos (média de 46 anos), para servir como controle. O grupo FD (dentaduras completas) consistia de 16 pacientes com idade entre 33 a 67 anos (média 50 anos), reabilitados com dentaduras em ambos os arcos. O grupo ODi (overdenture implantossuportada) consistia de 20 pacientes com idade entre 46 e 82 anos (média de 60 anos), sendo o arco antagonista reabilitado por meio de dentaduras completas. O grupo FFPi (prótese fixa implantossuportada) consistia de 9 pacientes com idade entre 52 e 74 anos (média de 65 anos). Sendo o arco oposto reabilitado por meio de dentaduras completas. Pacientes do grupo FD, ODi, e FFPi tinham sido edêntulos por mais de 10 anos e foram avaliados somente após 1 ano a fim de se evitar a variação devido á adaptação funcional. A média do período após a reabilitação era de 4 anos para o grupo ODi, de 6 anos para o gripo FFPi e de 15 anos para o grupo de FD. Neste estudo os seguintes parâmetros foram analisados: a variação da amplitude (AMP) e a frequiência média da potência (MPF). A AMP representou a amplitude máxima de pico a pico do sinal e a MPF correspondeu à freqüência na qual 50\% da potência era acumulada. Para comparar valores de parâmetros absolutos o teste ANOVA foi realizado (variável independente: grupo de pacientes). Este procedimento também era usado para comparar idade e tempo de duração para diferentes modalidades de tratamento. Um teste t pareado foi realizado em cada grupo de pacientes para detectar se a AMP tempo/dependente ou mudanças MPF diferiam de zero. Na análise dos resultados observaram uma grande variação intersujeitos sendo que alguns sinais eletromiográficos apresentavam comportamento diferente para os 4 grupos analisados. Este achado podia ser relacionado com as diferenças na morfologia craniofacial, diferenças no nível de força ou variações no tipo de composição das fibras musculares. Uma significante amplitude era obtida para o grupo com dentes naturais. Durante a contração voluntária submáxima uma diminuição dos valores foram notados para todos os grupos, exceto para os reabilitados com prótese fixas implantossuportadas. Os grupos NT (dentados) e ODi (overdenture) mostraram significante diminuição da amplitude da contração voluntária isométrica (AMP) após 60 segundos. Para a freqüência média da contração voluntária isométrica (MPF) houve significante diminuição após 120 segundos para o grupo de dentados sendo que para os grupos de usuários de dentaduras e overdentures a diminuição ocorreu após 150 segundos. Concluíram que a eletromiografia oferece informações quantitativas importantes a respeito da performance mastigatória e que os dados destes achados eletromiográficos indicam que as próteses implantossuportadas melhoram marcadamente o comportamento muscular na mastigação quando comparados com os usuários de dentaduras completas. 
Feine et al (1994) com o objetivo de comparar a eficiência mastigatória entre pacientes reabilitados com prótese fixa implantossuportada e overdenture realizou um estudo clínico transversal entre sujeitos. Para isso 16 pacientes, com idade entre 30 e 62 anos, que tinham sido edêntulos por mais de 10 anos foram avaliados. Oito pacientes foram reabilitados com prótese fixa implantossuportada e oito reabilitados com overdenture implantossuportada. As próteses fixas e as overdentures foram manufaturadas juntas, com o mesmo tipo de dente, angulação, dimensão vertical de oclusão e replicadas. Após 2 meses, para fim de adaptação, os pacientes realizavam testes de mastigação para 5 tipos de alimentos e a atividade eletromiográfica dos músculos masseteres, suprahioideo e infrahioideo eram registrados. As próteses eram então trocadas (os sujeitos que tinham sido reabilitados com prótese fixa recebiam prótese overdenture e vice-versa) e o mesmo período de adaptação e testes eram realizados. Reportaram que o tempo da mastigação era menor para pão, queijo e salsicha quando os indivíduos estavam usando overdentures e a amplitude vertical dos golpes mastigatórios era significantemente menor com a overdenture para todos os tipos de comida, exceto cenoura. A duração do ciclo era mais longa com overdenture, para salsicha e cenoura. Concluíram que ao contrário do que se esperava, a prótese overdenture implantossuportada parecia ser mais eficiente do que a prótese fixa implantossuportada para a mastigação de pão, salsicha e queijo e os dados sugeriam que o paciente era capaz de adaptar seus movimentos mastigatórios para as características das duas próteses.

Jacobs et al (1995) avaliaram a contração voluntária isométrica máxima do masseter de 7 pacientes reabilitados com prótese fixa tipo protocolo e de 10 pacientes reabilitados com prótese overdenture implantossuportada. O estudo foi realizado no primeiro e segundo ano após a reabilitação. As médias dos resultados para os lados direito e esquerdo juntos foram de: grupo overdenture logo após a reabilitação foi de $175 \mu \mathrm{V}$, um ano após foi de $160 \mu \mathrm{V}$ e dois anos após foi de $175 \mu \mathrm{V}$. As médias para o grupo protocolo logo após a reabilitação foram de $160 \mu \mathrm{V}$; um ano após $190 \mu \mathrm{V}$ e dois anos após $260 \mu \mathrm{V}$. Os autores concluíram que não houve diferença estatisticamente significante entre os tipos de próteses e que os pacientes desempenharam uma atividade com valores inferiores para a prótese protocolo por receio de fraturá-la.

Sampaio (1997) realizou um estudo onde foram obtidos dados sobre o ciclo e o ato mastigatório dos músculos masseteres de pacientes com fissuras labiopalatinas, já operados. Foram comparados 12 pacientes com fissuras operadas com idade variando entre 13 e 30 anos e 11 indivíduos sem fissura com idade variando entre 19 e 24 anos. Foi solicitado aos 
indivíduos realizar 6 ciclos mastigatórios com um tubo de látex de $0,7 \mathrm{~cm}$ de diâmetro e $1 \mathrm{~cm}$ de comprimento. A duração média do ato mastigatório do músculo masseter direito foi de $443,29 \pm 148,33 \mathrm{~ms}$ e do esquerdo foi de 441,51 $\pm 107,40 \mathrm{~ms}$ para os indivíduos com fissuras. Para os sem fissura a média foi de $330,21 \pm 79,5 \mathrm{~ms}$ para o lado direito e $345,19 \pm 94,84 \mathrm{~ms}$ para o lado esquerdo. Os valores médios para o ciclo mastigatório dos pacientes com fissuras foram $821,22 \pm 175,22 \mathrm{~ms}$ para o lado direito e $787,48 \pm 157,03 \mathrm{~ms}$ para o lado esquerdo. Para o grupo controle encontrou-se $845,42 \pm 174,18 \mathrm{~ms}$ para o lado direito e $828,16 \pm 165,38 \mathrm{~ms}$ para o lado esquerdo. A autora concluiu que os indivíduos com fissura apresentam o ato mastigatório maior que os pacientes sem fissuras, indicando que os músculos analisados permaneceram em maior estado de contração durante o ato mastigatório.

A mastigação envolve um padrão de impactos cíclicos, rápidos, mas periódicos que forçam tanto os componentes do implante quanto a interface osso-implante, mas devido à viscoelasticidade do osso, a alta taxa de força pode aumentar a efetiva dureza funcional na interface. Esta dureza pode ser acompanhada por uma combinação de propriedades materiais locais, como o aumento da massa óssea e mudança na orientação e conectividade do suporte trabecular (Standford e Brand 1999).

Bresin (2001) analisou a correlação entre função muscular e crescimento ósseo em ratos. Ratos jovens foram submetidos a dietas com várias consistências e receberam um dispositivo interoclusal a fim de aumentar a dimensão vertical de oclusão. Por meio de radiografias e videodensiometria analisou a adaptação dentoesqueletal concluindo que uma dieta líquida reduz o crescimento ósseo na região angular da mandíbula e que houve diminuição da função muscular do masseter, resultando em deformidades ósseas mandibulares tanto no sentido transversal quanto sagital. $\mathrm{O}$ autor afirmou ainda que, cargas reduzidas nos molares e em outras regiões resultam em menor estimulação da cadeia osteoblástica, resultando em um trabeculado ósseo menos intensificado, inibindo dessa forma a aposição óssea na região angular, diminuindo a dimensão vertical e a secção transversal dentoalveolar.

Barco (2002) realizou uma análise comparativa entre pacientes com fissuras e sem fissuras com o objetivo de avaliar a atividade eletromiográfica do masseter para os seguintes parâmetros: a duração da fase de elevação mandibular, fase oclusal e fase de abertura maxilomandibular, a duração do ato e ciclo mastigatório e a duração do período de silêncio durante a mastigação de alimentos de consistência dura (cenoura). A amostra constituí-se de 9 pacientes com fissura transforame unilateral já reparada, com idade de 17 a 30 anos e 
indivíduos sem fissura com a mesma idade. Para os indivíduos sem fissura a duração do ato mastigatório para o masseter direito foi de $301,48 \mathrm{~ms}$ e para o masseter esquerdo foi de $306,34 \mathrm{~ms}$. A duração do ciclo mastigatório foi de 646,34 ms para o masseter direito e de 643,10ms para o esquerdo. Nos indivíduos com fissura, o ato mastigatório para o masseter direito foi de 370,26 ms e para o esquerdo de 379,98ms. A duração do ciclo mastigatório para o masseter direito foi de $723,19 \mathrm{~ms}$ e para o esquerdo foi de 743,04ms. Apesar da tendência de maiores valores para $\mathrm{o}$ ato e ciclo mastigatórios dos pacientes com fissura não houve diferença estatisticamente significante e a autora concluiu que mais estudos precisavam ser realizados.

Karkasis (2002) realizou um estudo comparativo da atividade mastigatória dos masseteres de 6 pacientes com idade média de 57 anos e reabilitados por prótese implantosssuportada tipo overdenture com pacientes que possuíam dentição normal. Os parâmetros analisados foram o ato e o ciclo mastigatório da mastigação habitual com cubos de cenoura. Os valores médios encontrados para o ato e ciclo mastigatório dos pacientes reabilitados com prótese implantossuportada overdenture foram respectivamente $0,36 \pm 64 \mathrm{~s}$ e $0,70 \pm 100$ s, respectivamente. $\mathrm{O}$ autor concluiu que os pacientes reabilitados com próteses implantossuportadas possuem uma atividade eletromiográfica massetérica maior do que os pacientes com dentição natural, e que isto colabora para uma melhor função mastigatória e melhor conforto.

Van Kampem et al (2004) com o objetivo de pesquisar se o tipo de conexão protética (o'ring, magneto ou barra-clip) infuenciava a retenção e a estabilidade das próteses overdentures implantossuportadas analisaram 18 pacientes (17 homens e 1 mulher), com idade média de 51,6 anos que foram alocados em 6 grupos de 3 pacientes que receberam diferentes sequências de conexões protéticas. A performance mastigatória, a eficiência mastigatória e a deglutição foram mensuradas. Os autores concluíram que a função mastigatória melhorou significantemente após o tratamento com overdenture implantossuportada para cada um dos 3 tipos de conexão. A performance mastigatória foi melhor para a barra clipe e o'ring que para magneto. O número de ciclos mastigatórios diminuiu após o tratamento com overdentures.

Pantaleón (2004) realizou um estudo da atividade muscular de 5 pacientes com próteses totais inferiores e logo após a instalação de próteses fixas implantossuportadas inferiores. Ele analisou o ato e o ciclo mastigatório desses pacientes para a mastigação unilateral direita e esquerda com látex. As médias, em segundos, encontradas para o ato 
mastigatório unilateral direito dos pacientes reabilitados com prótese total foram de $0,59 \mathrm{~s}$ para o masseter direito e $0,76 \mathrm{~s}$ para o masseter esquerdo; após a instalação das próteses implantossuportadas as médias foram de $0,40 \mathrm{~s}$ para o masseter direito e $0,43 \mathrm{~s}$ para o masseter esquerdo. As médias, em segundos, encontradas para o ato mastigatório unilateral esquerdo dos pacientes reabilitados com prótese total foram de $0,54 \mathrm{~s}$ para o masseter direito e $0,43 \mathrm{~s}$ para o masseter esquerdo; após a instalação das próteses fixas implantossuportadas as médias foram $0,47 \mathrm{~s}$ para o masseter direito e 0,41 s para o masseter esquerdo. As médias da duração do ciclo mastigatório durante a mastigação unilateral direita nos pacientes com prótese total foram de 0,90s para o masseter direito e esquerdo, para os pacientes após a instalação das próteses implantossuportadas foram de 0,93s para o masseter direito e esquerdo. As médias da duração do ciclo mastigatório durante a mastigação unilateral esquerda para os pacientes reabilitados com prótese total foram de $0,85 \mathrm{~s}$ para o masseter direito, 0,96 s para o masseter esquerdo; nos pacientes após a instalação das próteses implantossuportadas o resultado encontrado foi de $0,89 \mathrm{~s}$ para o masseter direito e $0,92 \mathrm{~s}$ para o masseter esquerdo. $\mathrm{O}$ autor concluiu que as próteses implantossuportadas oferecem melhores condições mastigatórias que as próteses totais.

Ferrario et al (2004) compararam as características eletromiográficas dos músculos mastigatórios (temporal e masseter) em pacientes reabilitados com próteses fixas implantossuportadas e overdentures implantossuportadas. Dezenove sujeitos com idade de 45 a 79 anos foram examinados. Sete pacientes tinham sido reabilitados com próteses fixas implantossuportadas, sete com overdentures implantossuportadas e cinco indivíduos tinham dentição natural. A atividade eletromiográfica foi realizada durante a mastigação unilateral direita e esquerda com chicletes. Para cada paciente foram computados os dados referentes à freqüência mastigatória e a confidência elíptica das diferenças simultâneas entre lados direito e esquerdo dos músculos masseter e temporal.

A confidência elíptica foi a ferramenta estatística usada para avaliar a repetibilidade do modelo de contração do músculo durante a execução de movimentos padronizados como a mastigação unilateral. A análise eletromiográfica mostrou que o índice de simetria entre os músculos masseteres não era estatisticamente diferente para os 3 grupos, contudo os pacientes-controle e os reabilitados com próteses fixas implantossuportadas apresentaram um índice maior. $\mathrm{Na}$ contração voluntária isométrica máxima $(\mu \mathrm{V} / \mu \mathrm{V} s \%)$ os valores apresentaram pequena variabilidade sendo 104, 112 e 104,9 $\mu \mathrm{V}$ para os grupos com prótese fixa implantossuportada, overdenture implantossuportada e indivíduos-controle, 
respectivamente. Uma maior atividade do lado de não trabalho comparada ao lado de trabalho do músculo masseter foi encontrada para 4 pacientes reabilitados com overdenture e 3 pacientes com próteses fixas tipo protocolo. Uma significante atividade eletromiográfica mais baixa para os 2 grupos reabilitados com próteses implantossuportadas foi encontrada quando comparada à dos indivíduos-controle. Afirmaram que, após a reabilitação por meio de implantes osseointegrados, os pacientes usavam mais os músculos para tarefas como contração voluntária máxima e mastigação unilateral, mas que essa performance não era bem coordenada e a mastigação para os lados direitos e esquerdos eram menos simétricos que para indivíduos controle. Concluíram que as overdentures e as próteses fixas implantossuportadas são funcionalmente equivalentes, contudo inferiores à dentição natural.

Felix e al (2005) avaliaram a atividade eletromiográfica do músculo masseter durante a mastigação habitual de folha de parafina, pão, maçã, banana, e castanha de caju em 25 pacientes de ambos os gêneros com disfunção temporomandibular (DTM), cujos dados foram confrontados com um grupo controle sem DTM de 15 indivíduos. Foi utilizado o programa computadorizado Myo-Tronics Inc., K6-1 no modo de processamento eletromiográfico para análise do ato e do ciclo mastigatório. Não foram encontradas diferenças estatísticas entre os grupos, concluindo-se que o comportamento dos músculos mastigatórios em indivíduos com DTM durante a mastigação habitual é semelhante à verificada em indivíduos sem disfunção.

Lopes (2006) realizou um estudo com o propósito de verificar as alterações dimensionais mandibulares e a relação destas alterações com a atividade muscular massetérica. Dez pacientes (três homens e 7 mulheres), com idade entre 25 e 69 anos reabilitados com próteses fixas implantossuportadas foram avaliados. Radiografias panorâmicas foram digitalizadas e o registro da atividade eletromiográfica do masseter foi realizado. A fim de mensurar a alteração dimensional mandibular, 5 sítios foram demarcados nas imagens radiográficas a 5, 10, 15, 20 e 20mm a partir de uma tangente que passava na distal do último implante. Em cada sítio, em ambos os lados e em todas as radiografias, a distância foi medida da base da mandíbula à crista do rebordo por meio do software para planejamento em Implantodontia, Radioimp (Radiomemory, BH, MG). A diferença entre os valores obtidos após a instalação e um ano depois, representou a alteração dimensional ocorrida neste período. A atividade muscular do masseter foi registrada para os seguintes parâmetros: contração voluntária isométrica máxima (CVIM), mastigação habitual com cenoura (MH), mastigação unilateral direita (MUD) e esquerda com látex(MUE). A autora reportou uma aposição óssea para o lado direito $(0,52 \pm 0,96 \mathrm{~mm})$ e uma reabsorção óssea para 
o lado esquerdo $(-0,05 \pm 0,78 \mathrm{~mm})$ e quando os dois lados foram considerados juntos, o aumento ósseo médio era de $0,23 \pm 0,4 \mathrm{~mm}$. Não houve diferença estatisticamente significante para a CVIM, mas reportou valores de $83,40 \pm 75,39 \mu \mathrm{V}$ para o lado direito e de $50 \pm 29,43 \mu \mathrm{V}$ para o lado esquerdo. Considerando a amplitude, o ato e o ciclo mastigatório não foram encontradas diferenças estatisticamente significante para nenhum dos três exercícios musculares (MH, MUD e MUE). Somente houve correlação positiva entre a atividade muscular massetérica e a aposição óssea em duas comparações: entre a aposição óssea do lado direito e o ato mastigatório direito durante a $\mathrm{MH}$ e entre a reabsorção óssea do lado esquerdo e o ato mastigatório esquerdo durante a MUD. A autora concluiu que a correlação entre a atividade muscular do masseter e as alterações dimensionais não puderam ser estabelecidas.

Van der Bilt et al (2006) com a finalidade de confirmarem a hipótese que próteses overdentures implantossuportadas melhoravam a função mastigatória avaliaram 18 pacientes com idade média de 51,6 anos. Os pacientes receberam 2 implantes, uma nova overdenture, e sucessivamente 3 diferentes tipos de conexão protética: magneto, o'ring e barra clipe. Quantificaram o processo mastigatório por meio dos movimentos realizados durante a mastigação e por meio da eletromiografia dos músculos masseter e temporal em 5 momentos: com as antigas dentaduras, com as novas dentaduras não conectadas às conexões, com as novas dentaduras conectadas a magneto, com as novas dentaduras conectadas ao o'ring e à barra clipe. Os resultados revelaram um valor menor para a CVIM nas novas dentaduras não suportadas $(637 \mu \mathrm{V}$ para as antigas dentaduras e $466 \mu \mathrm{V}$ para as novas) e no o músculo masseter nenhuma diferença estatisticamente significante entre as antigas dentaduras e as novas dentaduras foi observada. A duração do ciclo foi significante mais longo para Optocal do que para a mastigação de bolo (0,77s para bolo, 0,86s para Optocal). Concluíram que os pacientes mastigavam mais eficientemente após o tratamento com implantes.

Van der Bilt et al (2008) realizaram um estudo para medir a força de mordida e a atividade muscular por meio de eletromiografia durante a contração voluntária isométrica máxima bilateral e unilateral. Oitenta e um pacientes dentados, sendo 13 homens com média

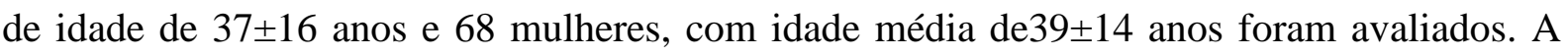
análise dos resultados revelou uma força de mordida maior para homens $(652 \mathrm{~N})$ que para mulheres $(490 \mathrm{~N})$. Na eletromiografia, durante a contração voluntária isométrica máxima bilateral o músculo masseter apresentou os seguintes valores: $246 \mu \mathrm{V}$ para masseter direito e $251 \mu \mathrm{V}$ para o esquerdo; durante a contração máxima unilateral direita o masseter direito apresentou o valor de $187 \mu \mathrm{V}$ e para o esquerdo de $179 \mu \mathrm{V}$; durante a contração unilateral 
esquerda, o valor para o masseter direito foi de $184 \mu \mathrm{V}$ e para o esquerdo de $192 \mu \mathrm{V}$. Concluíram que a mordida de força e a atividade muscular era 30\% maior para a contração bilateral que para a contração unilateral e que a atividade muscular durante a contração unilateral era simétrica para os músculos masseter.

\subsection{RADIOLOGIA E PROGRAMAS DE IMAGEM DIGITAL EM IMPLANTODONTIA}

Para a realização do planejamento do caso em Implantodontia, o exame radiográfico é de fundamental importância, sendo seus objetivos: permitir a visualização global do complexo maxilomandibular, a orientação sobre possíveis regiões a serem implantadas, a avaliação da qualidade dos tecidos, a proservação e a documentação de cada caso.

Para muitos autores a radiografia panorâmica tem especial papel na Implantodontia e faz parte dos protocolos para planejamento em implantes. $\mathrm{O}$ fato de se utilizar um único filme para observar a relação do conjunto de dentes, osso alveolar, articulação temporomandibular, seios maxilares e estruturas contíguas, aliado à simplicidade e rapidez da operação, pequena dose de radiação, baixo custo e boa aceitação por parte dos pacientes, principalmente aqueles que não toleram filmes intrabucais, conferem às radiografias panorâmicas alguma vantagem sobre as demais técnicas. É de fundamental importância o conhecimento da magnitude das distorções ao se examinar uma radiografia panorâmica. Conhecendo-se o índice de distorção esperado para aquele aparelho utilizado, pode-se, por exemplo, melhor avaliar a morfologia do objeto estudado e sua relação com estruturas adjacentes e estabelecer medidas nas imagens radiográficas (Tyndall et al 2000, Dula et al 2001, Chilvarquer 2002).

Ávila (1996) realizou um estudo a fim de comparar e analisar os índices de distorção da imagem produzida em diferentes aparelhos panorâmicos. Para isso, pesquisou a imagem obtida de um crânio adulto, no qual foram fixados fios de chumbo em oito regiões anatômicas e comparou com imagens realizadas no aparelho Panex EC e Rotograph 230 EUR. A partir da comparação entre as medidas reais do crânio com as imagens produzidas nos dois aparelhos a autora encontrou para o aparelho Rotograph um índice de distorção de 19,59\% enquanto que para o aparelho Panex era de 20,4\% e concluiu que, desde que o índice de distorção da imagem produzida pelo aparelho seja conhecido é possível realizar medidas lineares.

Em 2000, a AAOMR (American Academy of Oral and Maxillofacial Radiology) fez uma revisão da literatura a respeito das modalidades radiográficas disponíveis na avaliação pré-cirúrgica do local receptor de implantes e recomendou a utilização da radiografia 
panorâmica em todos os casos para a avaliação do local dos implantes (desde espaços unitários até áreas edêntulas). A tomografia computadorizada, por requerer uma alta dose de radiação e elevado custo financeiro deve ser realizada para casos especiais e pacientes edêntulos (Tyndall et al).

Vasconcelos (2000) realizou um estudo a fim de comparar a confiabilidade e a confiança de traçados cefalométricos pelos seguintes métodos: manual, traçado cefalométrico computadorizado da Radiomemory e do Dentofacial Planner. Para isso, avaliou medidas lineares e angulares de 50 radiografias laterais de boa qualidade concluindo que o programa de traçado cefalométrico da Radiomemory pode ser confiavelmente utilizado como recurso no diagnóstico, plano de tratamento, acompanhamento e avaliação de tratamento na clínica e ou pesquisa.

Dula et al (2001) realizaram um estudo no qual consideram a radiografia panorâmica um exame com visão abrangente que permite a visualização de várias estruturas anatômicas oferecendo possibilidade de medições verticais com confiabilidade, desde que seja conhecida a magnificação do aparelho.

Em workshop organizado pelos membros da Associação Européia de Osseointegração e Harris et al (2002) foram determinadas diretrizes que possibilitassem a condução do processo diagnóstico através de imagens para implantodontia de forma sistemática e eficaz. Os autores elaboraram um guia que apóia o uso de radiografia panorâmica, mesmo diante das limitações e alerta que o uso da tomografia computadorizada de forma indiscriminada resulta em aumento de radiação para o paciente.

Chilvarquer (2002), dentro do protocolo para implantes osseointegrados incluiu a radiografia panorâmica com traçado radiográfico como técnica pré-operatória necessária para uma visualização globalizada do complexo maxilimandibular. Tal técnica visa delinear os principais reparos anatômicos e estimar medidas das distâncias anatômicas de interesse.

Segundo Langland (2002) as radiografias panorâmicas estão recomendadas nas seguintes circunstâncias: como parte da avaliação para tratamento ortodôntico, avaliação de lesões periapicais ou dentes não irrompidos, previamente a uma cirurgia bucomaxilofacial, avaliação do suporte ósseo periodontal, da posição dos terceiros molares, fraturas de ossos da mandíbula e maxila, lesões do seio maxilar (particularmente do assoalho e paredes posteriores e medianas), lesões da ATM e medidas verticais do osso alveolar como parte do planejamento pré-implante. 
Chuenchompoonut et al (2003) com a finalidade de confirmarem a acurácia da radiografia panorâmica e TC na avaliação das dimensões das lesões mandibulares analisaram 115 casos, os quais foram divididos em quatro tipos: Tipo I - cisto com margem esclerótica; Tipo II- cisto sem margem esclerótica; Tipo III- ameloblastoma e Tipo IV- carcinoma de célula escamosa. Os casos foram avaliados pela distância máxima mesiodistal e a altura máxima superoinferior nas radiografias panorâmicas (Lpmax e Hpmax) e nas tomografias computadorizadas (Lcmax e Hcmax), respectivamente e os resultados foram comparados. Os autores concluíram que a radiografia panorâmica é acurada para avaliar as dimensões de lesões mandibulares quando as margens estão bem definidas.

Costa et al (2004) descreveram um protocolo de trabalho abordando diferentes técnicas radiográficas e enfatizaram o uso de radiografia panorâmica, mesmo considerando que a tomografia computadorizada é o exame radiográfico ideal para tratamento com implantes e que deve ser indicado quando se planejam mais que sete implantes.

Vasquez et al (2008) com o objetivo comprovarem a eficácia do uso da radiografia panorâmica como técnica radiográfica para planejamento pré-operatório em Implantodontia, avaliaram os distúrbios sensoriais permanentes do nervo alveolar inferior após a instalação de implantes na mandíbula. Este estudo incluiu 2584 implantes inseridos na região posterior da mandíbula de 1527 pacientes parcial ou totalmente edêntulos. Com o auxílio de uma régua graduada fornecida pelo fabricante do implante, os autores mediram na radiografia panorâmica a altura óssea pré-operatória da crista alveolar até a borda superior do canal mandibular e subtraiu $2 \mathrm{~mm}$ para determinar a altura do implante a ser inserido. Nenhum distúrbio sensorial permanente do nervo alveolar foi observado. Houve 2 casos de parestesia pós-operatória, representando 2 de 2584 implantes, o que representava uma taxa de 0,08\% implantes inseridos no seguimento posterior da mandíbula ou 2 de 1527 pacientes, o que representava uma taxa de $0,13 \%$. Concluíram que a radiografia panorâmica para análise préoperatória pode ser considerada um método satisfatório de avaliação devido à rapidez, simplicidade, baixo custo e baixa dose de radiação, quando $2 \mathrm{~mm}$ acima do canal mandibular forem respeitados.

Os constantes avanços tecnológicos na área da computação, aliados aos avanços científicos na área da Radiologia Odontológica resultaram no desenvolvimento de programas de imagem destinados a efetuar os traçados para planejamento pré-cirúrgico de implantes, a fim de se garantir a qualidade e precisão das medições, aliadas á facilidade e rapidez da operação. 
Os programas de imagem possibilitam a realização de medições necessárias e sugestões de tipos e tamanho de implantes em imagens capturadas por escaneres, câmeras digitais ou obtidos por sensores ou placas ópticas. Eles oferecem várias ferramentas de desenho, efeitos, tratamento de imagem e mensurações. A padronização dos relatórios, emitidos no formato de fichas, possibilita o arquivamento de dados de forma mais organizada e acessível. Além disso, os programas possuem sistemas de calibração da magnificação da imagem, a fim de garantir a precisão das medidas.

Costa et al (2004) consideram que a aplicação de desenhos anatômicos na avaliação radiográfica do planejamento pré-cirúrgico de implantes auxilia a observação dos resultados e poder ser manual ou computadorizado. O desenho manual é o tipo de apresentação mais freqüente, onde por meio de folhas de acetato sobrepostas à radiografia e com auxílio de um negatoscópio, são efetuados os contornos anatômicos da região, seguidos por mensurações de altura e espessura. O desenho computadorizado é realizado após a digitalização das radiografias e a aplicação dos programas de computador destinados ao planejamento (Radioimp-Radiocef, Simplant, Imagelab, Preview). Após as mensurações e simulações, estes resultados podem ser impressos, gravados em CD ou enviados aos cirurgiões-dentistas por meio da Internet, criando-se interatividade dos exames.

Fontão (2004) realizou análise comparativa de medidas lineares de 50 radiografias panorâmicas com pontos de referência previamente determinados pelos métodos direto e indireto (digitalizadas por scanner e máquina digital). Utilizou os métodos de mensuração manual linear (paquímetro) e digital através dos programas Radioimp-Radiomemory e Planimp 2000-CDT e concluiu que não há diferença significativa entre os métodos de obtenção de valores lineares em radiografias panorâmicas.

Melo (2005) avaliou as alterações dimensionais ósseas na região posterior da mandíbula, em pacientes com fissura labiopalatina já reparadas, reabilitados por overdentures e próteses fixas implantossuportadas. Através de radiografias panorâmicas digitalizadas realizou mensurações por meio do programa para planejamento em Implantodontia, Radioimp (Radiomemory, BH, MG). Relatou que a facilidade e rapidez com que as medidas foram realizadas e a possibilidade de calibração das imagens eram as melhores vantagens do uso desse tipo de programa.

Lopes (2006) analisou a atividade muscular massetérica e as alterações ósseas dimensionais mandibulares na região posterior de pacientes com fissuras labiopalatinas congênitas, já reparada, em pacientes que tinham sido reabilitados por próteses fixas 
implantossuportadas. As mensurações foram realizadas em radiografias panorâmicas e eletromiogramas digitalizados através do programa para planejamento em Implantodontia Radiomp (Radiomemory, BH, MG). Reportou a facilidade e a rapidez, bem como a possibilidade de calibração das imagens reforçando opiniões favoráveis para o uso desse programa.

O programa de imagem Radioimp (Radiocef - Radiomemory, Belo Horizonte, Minas Gerais, Brasil), lançado no mercado no ano 2000, foi desenvolvido especialmente para planejamento pré-cirúrgico em Implantodontia. Através de imagens capturadas por meio de escaner, câmera digital, sensores ou placas ópticas, o programa possibilita a realização das medições necessárias e sugestões de tipos e tamanhos de implantes. Com o programa é possível calcular distâncias, ângulos, fazer indicações e evidenciar particularidades anatômicas por meio de ferramentas de desenho (seta, asterisco, retângulo, elipse, etc.). Além disso, existem recursos de melhoramento da imagem: controle simultâneo de brilho e contraste, pseudocoloração, zoom, filtro médio, negativo/positivo, histograma e textura. Ao usar uma ferramenta, o programa faz o legendamento automático, numerando ou colorindo o objeto e relacionando-o às descrições do laudo. Ele disponibiliza um cadastro com os pinos mais usados pelos implantodontistas, podendo incluir novos pinos. Os laudos podem ser totalmente personalizados, as cores, o tipo de legendas, de letra, a logomarca, cabeçalho e rodapé são totalmente configuráveis. Todos esses recursos permitem a emissão de laudos com alto padrão estético, podendo ser salvos em arquivos digitais, impressos ou enviados via internet. Esse programa também possui um sistema de calibração da magnificação da imagem. A calibração pode ser realizada de duas maneiras, por meio da resolução (dpi) com que foi escaneada a radiografia, ou por meio do sistema referencial, com base em uma medida conhecida. No sistema referencial, basta clicar em dois pontos da imagem de uma medida conhecida. Normalmente utiliza-se como referência a imagem de uma régua que foi escaneada juntamente à radiografia. Para completar o processo de calibração da magnificação da imagem é preciso informar o fator de magnificação do aparelho panorâmico ou tomográfico utilizado. Com base nessas informações, o programa realiza a calibração automaticamente. As radiografias devem ser obtidas sob rígidas condições de padronização, incluindo técnica e processamento radiográficos adequados, conforme as instruções do fabricante. Atualmente o programa foi atualizado permitindo a análise de exames tomográficos em 3D. 
3 OBJETIVOS 



\section{OBJETIVOS}

Os objetivos deste estudo foram:

- Avaliar se ocorre alteração óssea vertical na mandíbula, posterior ao último implante, de pacientes reabilitados com prótese fixa implantossuportada tipo protocolo Brånnemark ou overdenture implantossuportada;

- Comparar as próteses protocolo Brånnemark e overdenture quanto à atividade muscular;

- Verificar se há correlação entre as eventuais alterações mandibulares e atividade muscular através de eletromiografia. 




\section{CASUÍSTICA E MÉTOdO}

O presente estudo foi aprovado pelo Comitê de Ética em Pesquisa do Hospital de Reabilitação de Anomalias Craniofaciais - Universidade de São Paulo (HRAC-USP) conforme ofício nọ 380/2006. (Anexos 1, 2 e 3).

\subsection{CASUÍSTICA}

À Central de Processamento de Dados (CPD-USP) e ao Setor de Implantes do Centro Odontológico (HRAC-USP) foi solicitada uma relação dos pacientes com fissura labiopalatina que tinham sido reabilitados com próteses implantossuportadas, o que resultou em uma lista de 189 pacientes, dos quais foram selecionados 20.

Os critérios de inclusão foram:

- Histórico de mandíbulas completamente edêntulas reabilitadas com prótese fixa sobre implantes tipo protocolo Brånemark ou overdenture implantossuportada no arco inferior e reabilitados com prótese total ou overdenture implantossuportada no arco superior;

- Coincidência dos valores das imagens radiográficas dos implantes nas duas radiografias, antes ou logo após a instalação da prótese (T1) e após um ano (T2);

- Ausência de sinais e sintomas de disfunção craniomandibular ou qualquer outra enfermidade sistêmica que pudesse afetar o sistema mastigatório;

- Estar satisfeito quanto à eficiência mastigatória de suas próteses;

- Confirmação de que o ajuste oclusal foi realizado de acordo a obter contatos bilaterais em relação cêntrica;

- Disponibilidade de documentação radiográfica regular.

Desses 20 pacientes apenas 17 (14 mulheres e 3 homens) com idade média de 48,41+12,53 anos (variando de 17 a 72 anos) compareceram ao HRAC-USP como parte do protocolo de rotina para controle e manutenção dessas próteses, durante o período de coleta 
dos dados para esta pesquisa (Tabela 1). Desses, 8 pacientes eram reabilitados por próteses overdentures implantossuportadas inferior e 9 eram reabilitados por protocolo Brånemark, tendo como antagonista prótese total $(\mathrm{PT})$ ou overdenture implantossuportada. Em relação à fissura, 9 pacientes possuíam fissura transforame bilateral, 1 possuía fissura transforame unilateral direita, 3 possuíam fissura transforame unilateral esquerda, 1 possuía fissura préforame incisivo e 3 possuíam fissuras pós-forame incisivo. (Tabela 2)

Tabela 1 - Caracterização da amostra quanto ao gênero e idade média.

\begin{tabular}{cc}
\hline Sexo & Idade \\
\hline F & 66 \\
F & 49 \\
F & 52 \\
F & 50 \\
F & 52 \\
F & 43 \\
M & 17 \\
F & 72 \\
M & 26 \\
M & 54 \\
F & 52 \\
F & 50 \\
F & 49 \\
F & 47 \\
F & 43 \\
F & 53 \\
F & 48 \\
\hline Média & 48,41 \\
\hline Dp & 12,53 \\
\hline &
\end{tabular}

F- feminino, M- masculino, Dp- desvio padrão 
Tabela 2 - Caracterização da amostra quanto ao tipo de fissura e tipos de próteses inferior e superior.

\begin{tabular}{ccc}
\hline $\begin{array}{c}\text { tipo de } \\
\text { fissura }\end{array}$ & $\begin{array}{c}\text { prótese } \\
\text { inferior }\end{array}$ & $\begin{array}{c}\text { prótese } \\
\text { superior }\end{array}$ \\
\hline 1 & $\mathrm{O}$ & $\mathrm{PT}$ \\
1 & $\mathrm{O}$ & $\mathrm{O}$ \\
3 & $\mathrm{O}$ & $\mathrm{O}$ \\
1 & $\mathrm{O}$ & $\mathrm{PT}$ \\
1 & $\mathrm{P}$ & $\mathrm{PT}$ \\
1 & $\mathrm{O}$ & $\mathrm{PT}$ \\
1 & $\mathrm{O}$ & $\mathrm{O}$ \\
1 & $\mathrm{P}$ & $\mathrm{O}$ \\
1 & $\mathrm{O}$ & $\mathrm{O}$ \\
5 & $\mathrm{P}$ & $\mathrm{O}$ \\
2 & $\mathrm{P}$ & $\mathrm{O}$ \\
1 & $\mathrm{P}$ & $\mathrm{O}$ \\
3 & $\mathrm{P}$ & $\mathrm{O}$ \\
5 & $\mathrm{O}$ & $\mathrm{O}$ \\
4 & $\mathrm{P}$ & $\mathrm{O}$ \\
3 & $\mathrm{P}$ & $\mathrm{O}$ \\
5 & $\mathrm{P}$ & $\mathrm{O}$ \\
\hline
\end{tabular}

1- tranforame bilateral, 2- transforame unilateral direita, 3- transforame unilateral esquerda, 4- pré- forame incisivo, 5- pós-forame incisivo; O- overdenture, P- protocolo, PT- prótese total

\subsection{MÉTODO}

\subsubsection{Análise radiográfica}

\subsubsection{Radiografia Panorâmica}

Com a finalidade de avaliar as eventuais alterações ósseas mandibulares foram analisadas as radiografias panorâmicas de cada paciente, antes da instalação da prótese ou logo após a instalação (T1) e após um ano ou mais (T2). Para isto, foi solicitado ao Setor de Radiologia do HRAC-USP, o exame radiográfico de cada paciente selecionado.

As radiografias foram obtidas de acordo com o padrão técnico e de processamento radiográfico, conforme instruções para o aparelho Panex EC e para a revelação em processador automático Macrotec ${ }^{\circledR}$ MX-2 (Macrotec Ind. e Equipamentos Ltda., São Paulo/SP, Brasil). A seleção das radiografias da fase T2, para cada paciente, teve como base a 
coincidência dos valores das medidas dos implantes nas radiografias da fase T1, respeitandose o índice de magnificação do aparelho (distorção) correspondente a 20,4\% ou 1,2 (Ávila 1996). Dessa forma, se o comprimento real do implante era $13 \mathrm{~mm}$, nas duas radiografias a imagem deveria ser de $15,65 \mathrm{~mm}$.

Para evitar danos à documentação, foi utilizado papel de acetato transparente sobre as radiografias para as marcações dos sítios. As análises radiográficas foram realizadas em sala escura, com uso de negatoscópio e em número máximo de cinco por dia, para evitar fadiga visual do pesquisador.

Para a análise radiográfica, foram adaptados os critérios descritos por Reddy et al (2002). Assim sendo, distâncias de 5, 10, 15, 20 e 25mm a partir do último implante foram definidas para mensurar a alteração da altura óssea mandibular, da base à crista do rebordo alveolar. Essas distâncias foram delimitadas com marcador para retroprojetor no papel transparente colocado sobre as radiografias, a partir de uma tangente que passava na distal do último implante (Figura 1). A união dos pontos da base com os da crista alveolar determinou a altura da mandíbula em cada sítio, sendo:

Sítio 0 - correspondeu à linha que tangenciou a face distal do implante mais posterior;

Sítio 1 - correspondeu à linha que passou pelos dois pontos determinados a $5 \mathrm{~mm}$ de distância dos pontos que definiram o sítio 0 ;

Sítio 2 - correspondeu à linha que passou pelos dois pontos determinados a $10 \mathrm{~mm}$ de distância dos pontos que definiram o sítio 0 ;

Sítio 3 - correspondeu à linha que passou pelos dois pontos determinados a $15 \mathrm{~mm}$ de distância dos pontos que definiram o sítio 0 ;

Sítio 4 - correspondeu à linha que passou pelos dois pontos determinados a $20 \mathrm{~mm}$ de distância dos pontos que definiram o sítio 0 ;

Sítio 5 - correspondeu à linha que passou pelos dois pontos determinados a $25 \mathrm{~mm}$ de distância dos pontos que definiram o sítio 0 .

Este procedimento foi realizado bilateralmente em todas as radiografias, totalizando-se dez medidas em cada uma delas. 


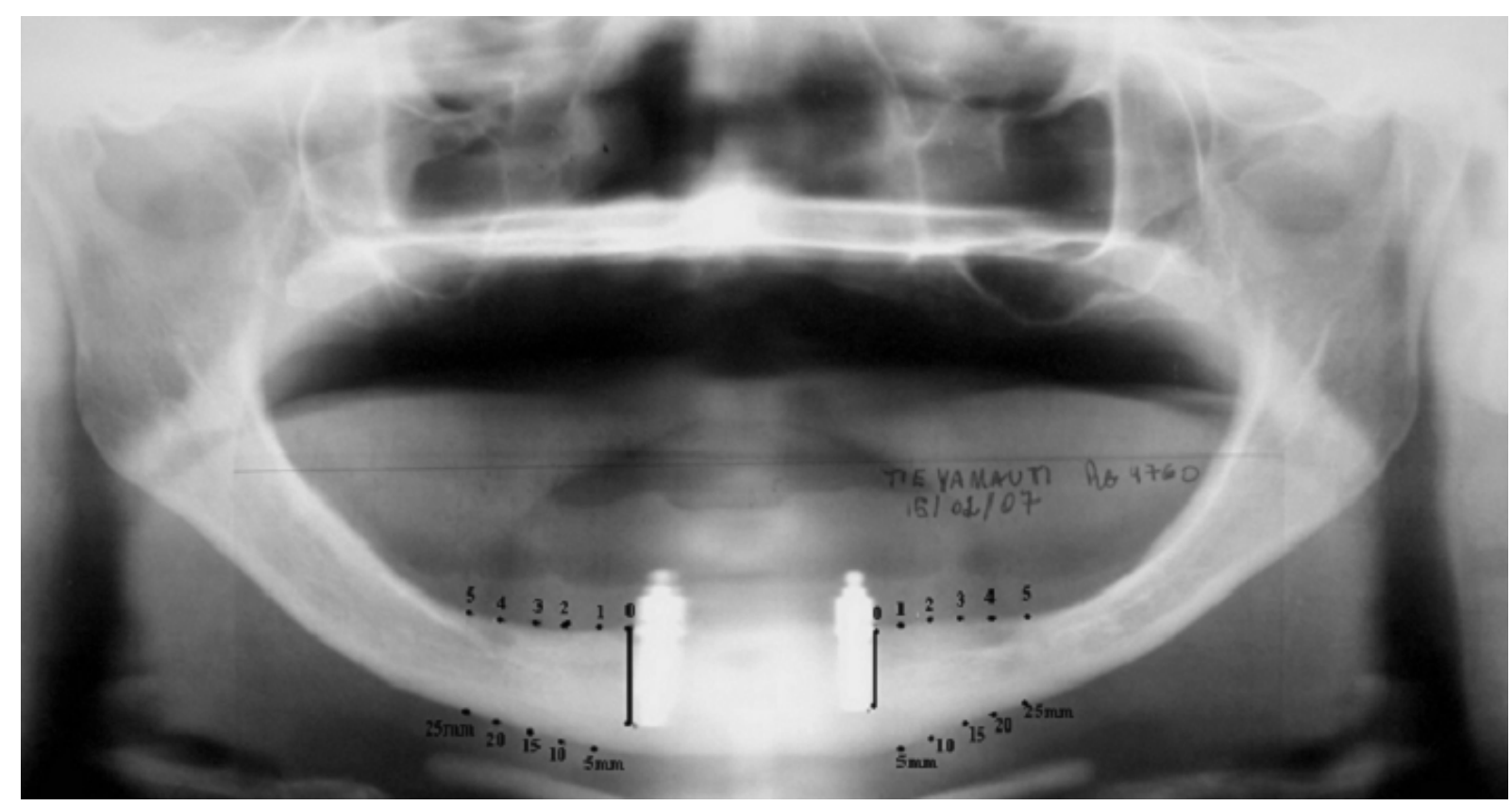

Figura 1 - Marcação dos pontos de referência, sobre o papel de acetato transparente, a serem usados na avaliação da altura óssea na região posterior ao último implante.

\subsubsection{Digitalização das radiografias}

A aquisição das imagens foi realizada com câmera fotográfica digital Nikon 995 , (Nikon Corporation, Japan), resolução de 3,1 megapixel, zoom óptico de 4x, distância lente filme de 50cm (Fontão 2004) e salvas em computador no formato FINE JPEG (FINE 2304 x 1728).

Durante a captura das imagens foi utilizado um negatoscópio especialmente projetado, contendo, em seu interior, quatro lâmpadas fluorescentes de 36w (Osram Dulux F-36 w/21840) Máscara de papel cartão preto emoldurou a radiografia com o objetivo de regular a luminosidade do negatoscópio (Figura 2).

A câmera digital permaneceu em posição perpendicular ao negatoscópio tanto no sentido vertical quanto no sentido horizontal, a 50cm de distância (Fontão 2004). Uma régua foi colocada junto às radiografias durante a captura das imagens para servir de referência no momento da calibração da imagem, pelo programa Radiocef 2 (Radiomemory, Belo Horizonte/MG, Brasil). A digitalização das radiografias foi realizada em um único tempo. 


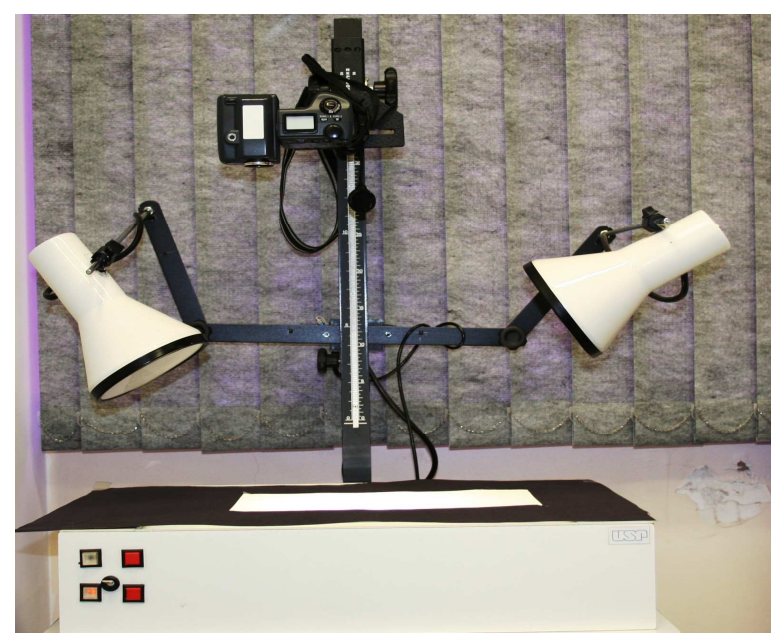

Figura 2 -.Negatoscópio com estativa (suporte), máquina fotográfica em posição e máscara de cartão preto.

\subsubsection{Mensurações lineares dos sítios anatômicos}

O processamento dos dados foi obtido com o programa de imagem para traçado radiográfico e planejamento em Implantodontia Radiocef 2 (Radiomemory, Belo Horizonte, MG, Brasil). A escolha do programa Radiocef 2 deveu-se às pesquisas anteriormente realizadas, atestando a confiabilidade das medidas e a facilidade de uso deste programa (Fontão 2004, Melo 2005, Lopes 2006).

Na sequência, os dados foram anotados em fichas próprias de avaliação (Anexos 4 e 5) e transportados para uma planilha do Excel 2000 (Microsoft @ C Corporation, Richmound, VA, USA), a fim de receber tratamento estatístico.

As imagens digitalizadas foram transferidas para um laptop AMD Turion $64 \times 2$, com hd 120 GB, 1GB, ddr2, onde a licença do Radiocef 2 (Radiomemory, BH) foi instalada para a realização deste estudo.

Após a abertura do programa, clicou-se 2 vezes no ícone do programa, os dados de identificação do paciente foram inseridos, sendo aberta uma tela onde foram incluídos os arquivos de fotos, radiografias, eletromiografias, etc (Figuras 3 e 4). Clicou-se no arquivo (por ex: de rx) e a imagem foi inserida. A imagem foi salva para posterior acesso às medições. $\mathrm{O}$ ícone implante ficou accessível, clicou-se nele para acesso à tela de medições. Após tais procedimentos, foi possível realizar a calibração da imagem (Figura 5). Optou-se por calibragem referencial, a qual permite corrigir o índice de magnificação do aparelho do qual foram obtidas as radiografias (Panex EC). 
A calibração da imagem foi realizada marcando-se 2 pontos entre os números 13 e 15 da régua digitalizada com a radiografia, resultando em uma distância de 20mm (Fontão 2004). Deduziu-se assim, o índice de magnificação do aparelho Panex EC que é de 20,4\% ou 1,2 (Ávila 1996). No campo da janela do programa intitulado "Distância entre dois pontos", digitou-se o valor de 16,66 que é o resultado da divisão de 20 (20mm) por 1,2, em seguida, realizou-se a calibração, selecionando-se calibrar com o mouse (Figura 6).

Em seguida, clicou-se no ícone tela cheia e, assim, foi dado início às medições (Figura 7).

Cada uma das radiografias foi medida 3 vezes em 3 tempos diferentes pelo mesmo pesquisador, obtendo-se dessa forma, 10 valores para cada medição, sendo utilizado como valor final, a média das 3 medições.

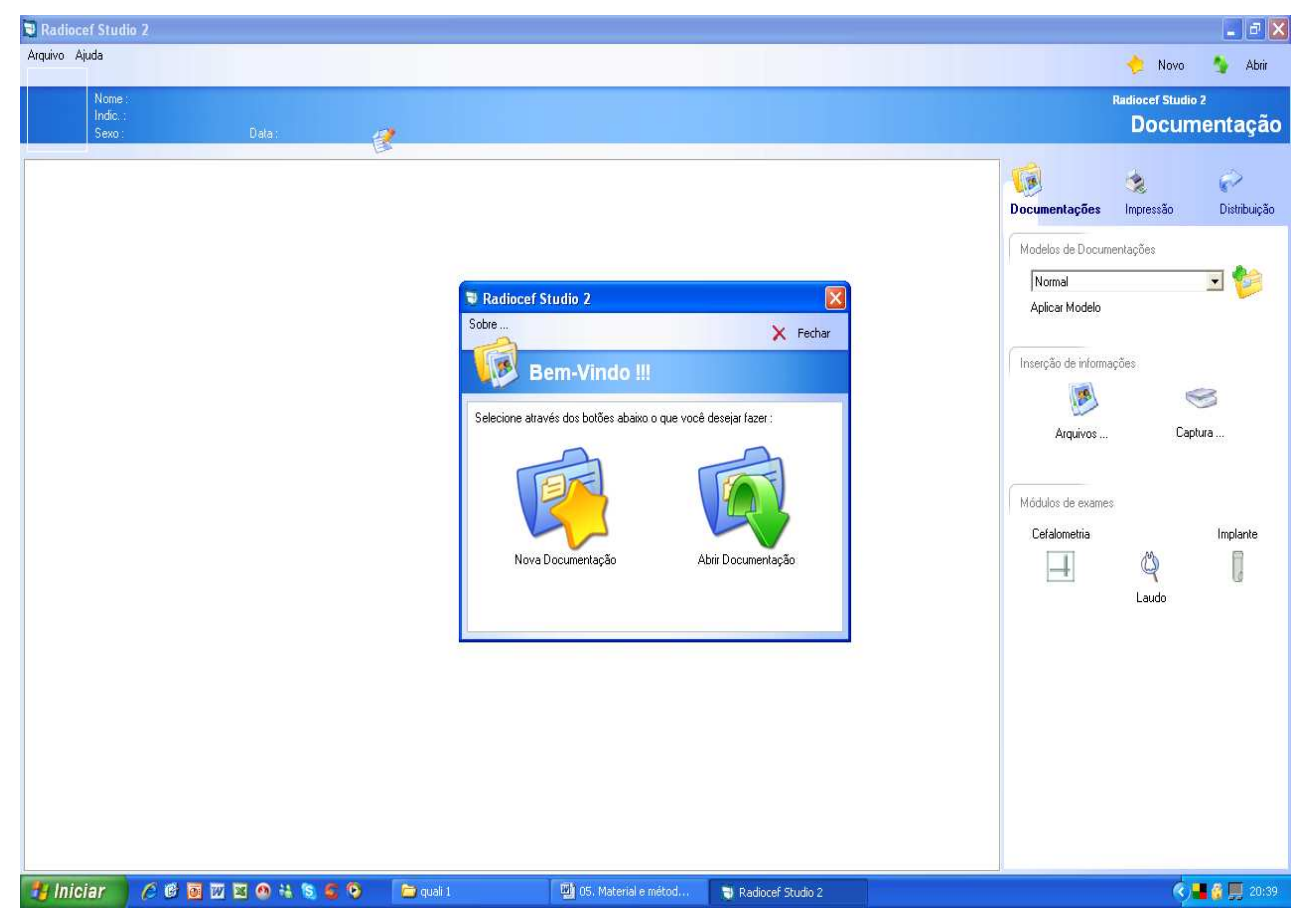

Figura 3 - Tela inicial do programa Radiocef 2. 


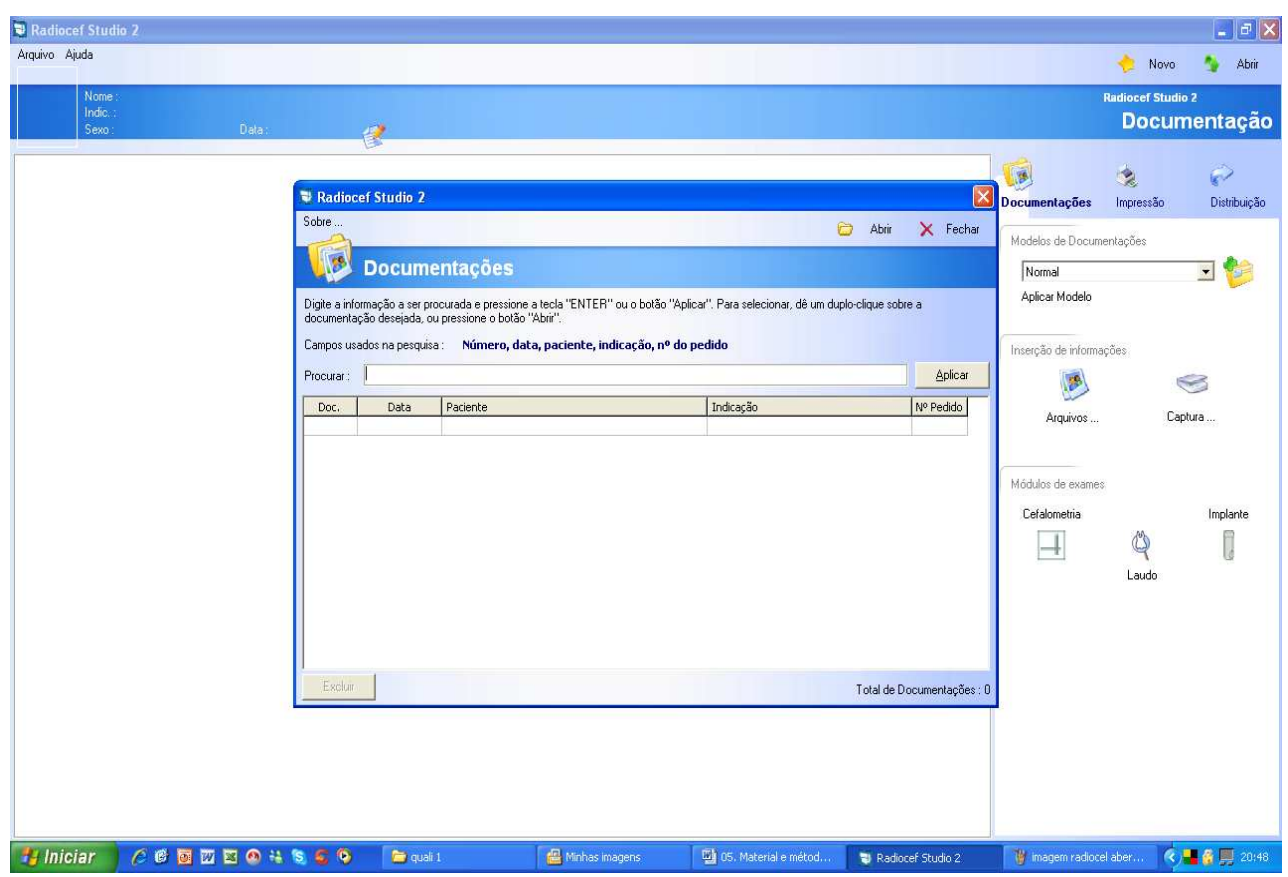

Figura 4 - Tela de inserção dos dados e radiografias do paciente.

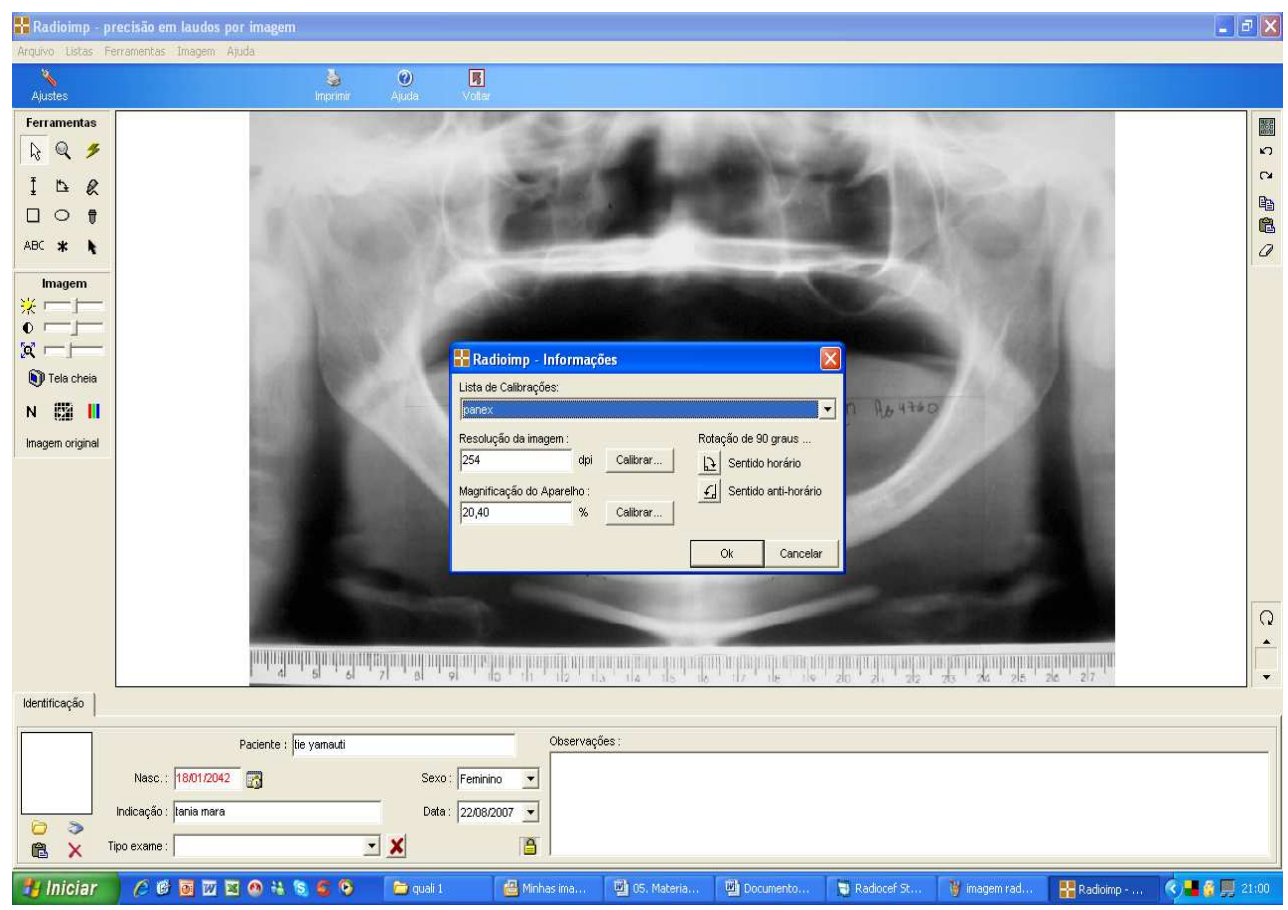

Figura 5 - Tela de calibração da imagem. 


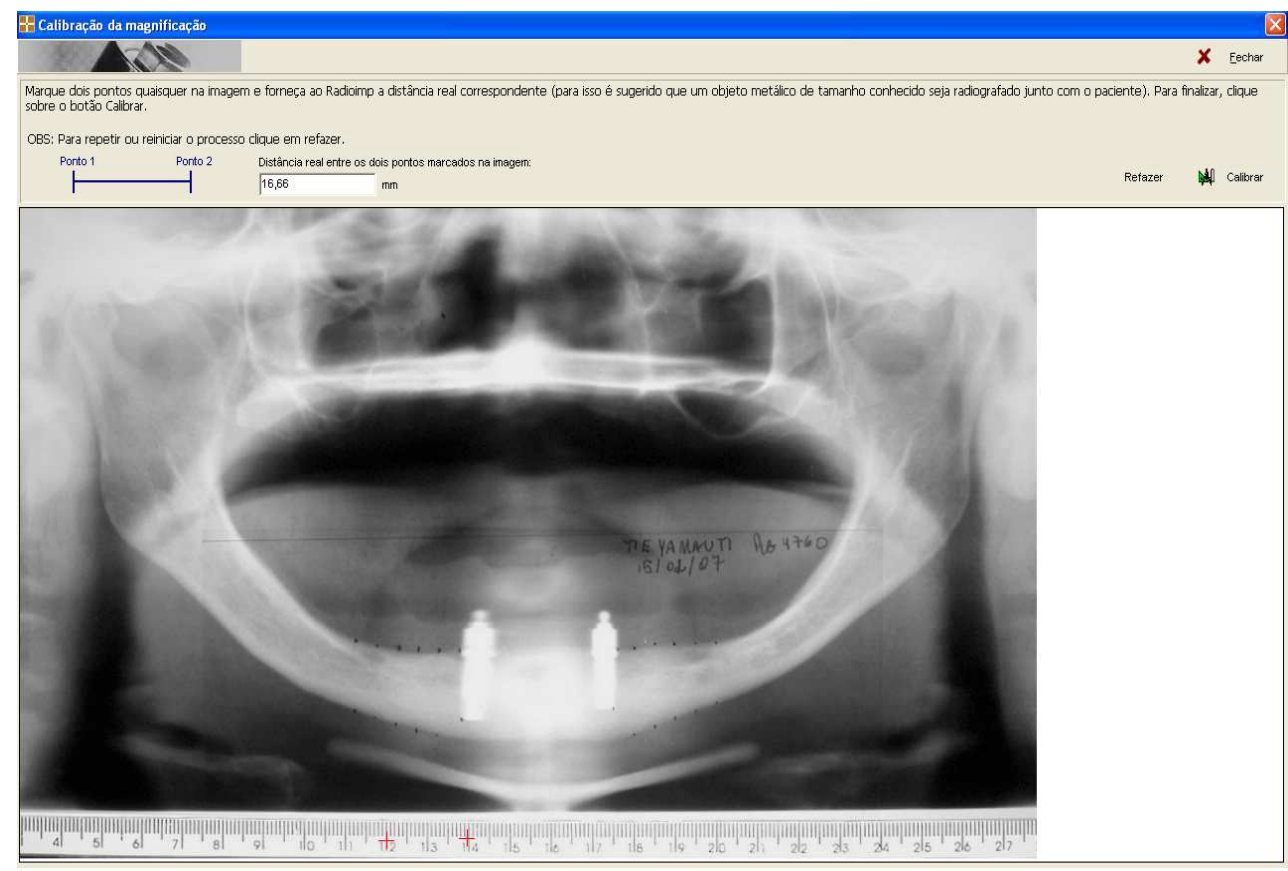

Figura 6 - Tela de calibração referencial.

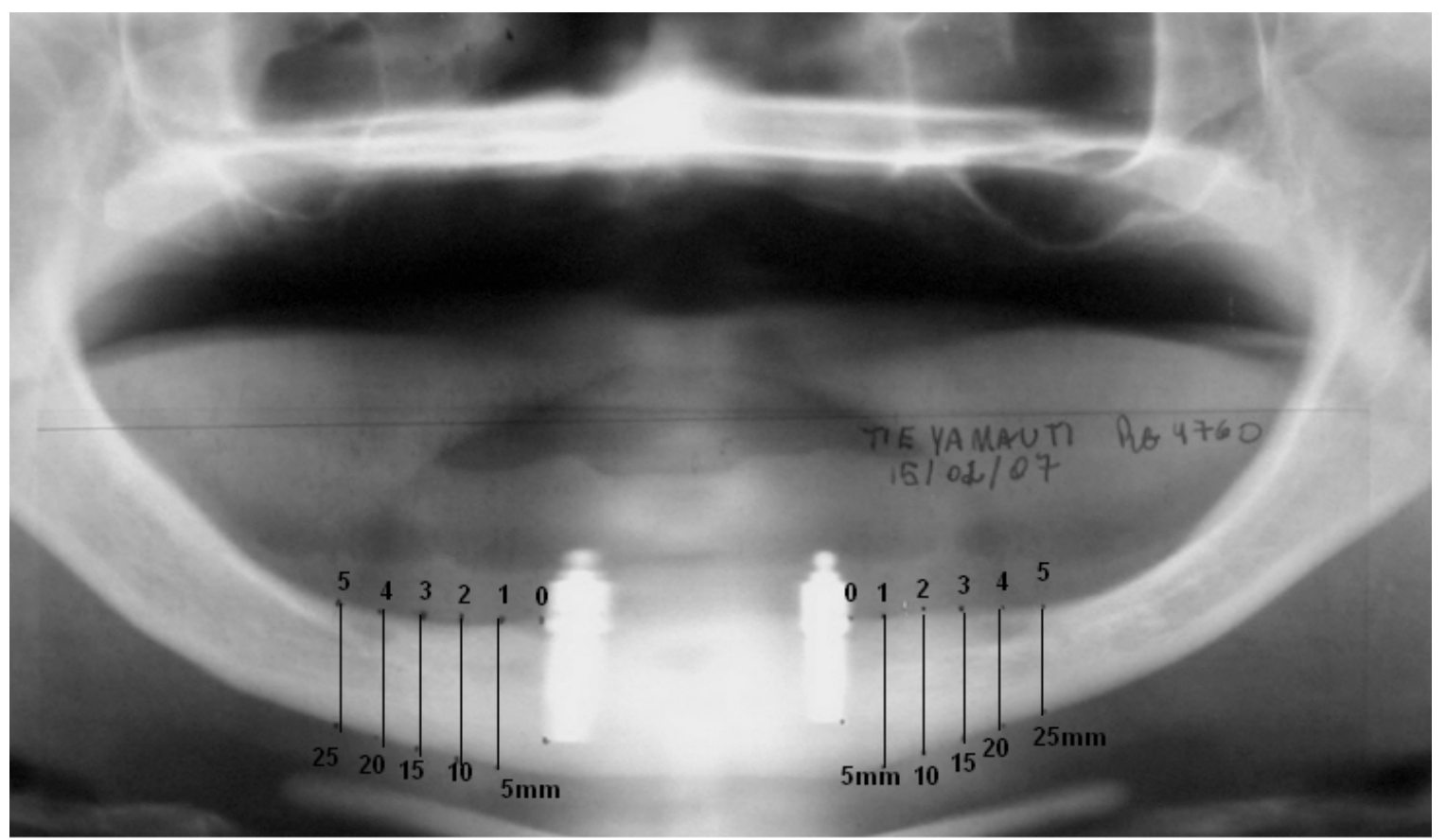

Figura 7 - Tela de mensurações dos sítios. 


\subsubsection{Registros da atividade eletromiográfica}

Para os registros da atividade eletromiográfica dos músculos masseteres foi utilizado um eletromiógrafo modelo K6-I Diagnostic System ® (Myo-Tronics Inc. Seattle, WA - USA) de oito canais, no modo de processamento eletromiográfico. O equipamento foi regulado com as seguintes especificações: freqüência de amostragem de $4000 \mathrm{~Hz}$; resolução do conversor A/D de 10 bits; filtro "passa alta" de 10Hz; filtro "passa baixa" de $2000 \mathrm{~Hz}$; ganho de 5000 vezes; faixa de visualização do sinal entre (+) 1000 e (-) $1000 \mu \mathrm{V}$ e velocidade de deslocamento do feixe de 0,15 s/divisão.

Os registros eletromiográficos foram realizados em 2 tempos distintos: T1, 2 meses após a instalação da prótese e T2, 1 ano ou mais após a instalação das mesmas.

Para a realização dos registros, seguiu-se o protocolo do Setor de Fisiologia do HRAC-USP: indivíduos sentados confortavelmente em cadeira odontológica, com a cabeça apoiada ao encosto e orientada segundo o plano de Frankfurt, de modo que o corpo da mandíbula apresentasse um ângulo de $45^{\circ}$ com o solo. A seguir, a pele na região dos músculos masseteres direito e esquerdo foi limpa com gaze umedecida em álcool $\left(70^{\circ} \mathrm{GL}\right)$, com o objetivo de remover o excesso de oleosidade e contribuir para a melhora da condução do sinal eletromiográfico. Com o intuito de se evitar interferência eletromagnética e para a proteção do paciente, um eletrodo terra (Skintact, CE, Áustria) foi fixado sobre a região do músculo esternocleidomastóideo do lado direito do paciente, após a limpeza da pele com gaze e álcool.

A atividade eletromiográfica dos músculos masseteres foi captada por meio de eletrodos bipolares e circulares com $8 \mathrm{~mm}$ de diâmetro e $1 \mathrm{~cm}$ de distância entre eles (BioTrode, BioResearch, USA). O polo superior do eletrodo foi posicionado paralelamente às fibras musculares dos masseteres, no ponto de intersecção de uma linha que partiu do canto externo do olho até o ramo da mandíbula com uma linha que partiu da comissura labial até o tragus da orelha (Figuras 8 e 9). 


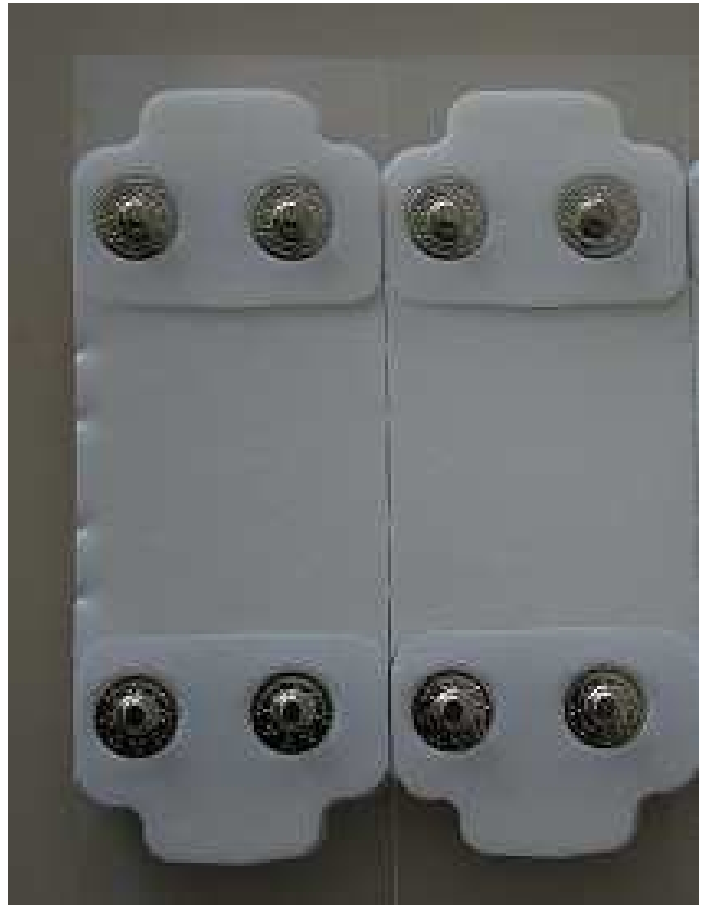

Figura 8 - Eletrodos bipolares de superfície.

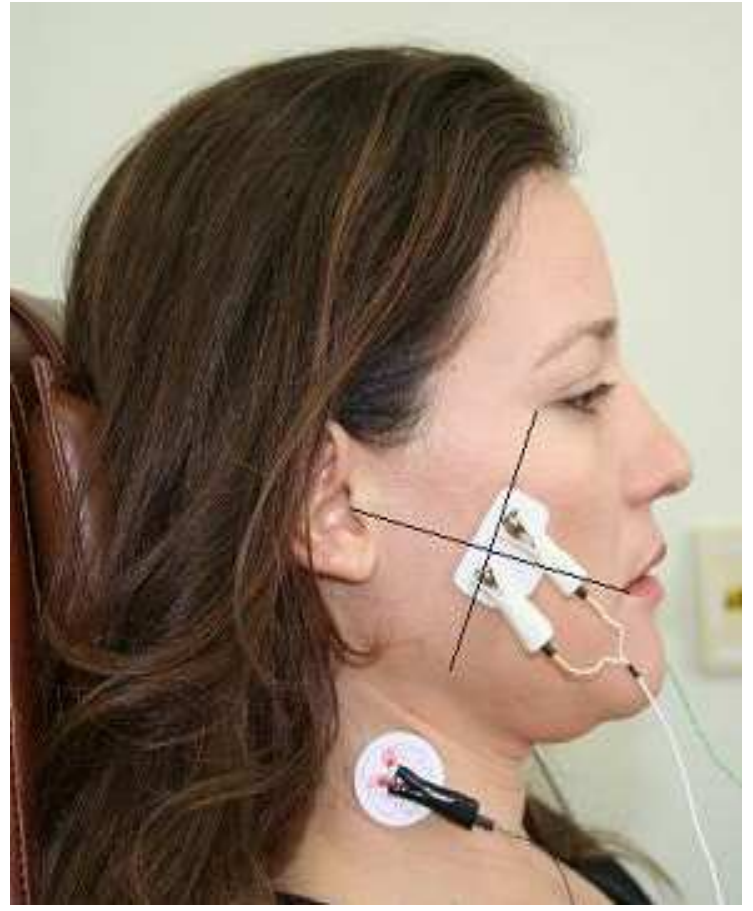

Figura 9 - Posicionamento dos eletrodos.

A atividade eletromiográfica dos músculos masseteres foi registrada durante os seguintes procedimentos:

- Contração voluntária isométrica máxima (CVIM) durante 5 segundos (s),

- Mastigação habitual de cubos de cenoura (MH),

- Mastigação unilateral direita de látex (MUD),

- Mastigação unilateral esquerda de látex (MUE).

- Contração Voluntária Isométrica Máxima (CVIM) durante 5s: foi solicitado ao paciente, o apertamento máximo dos dentes por $5 \mathrm{~s}$, com descanso de $60 \mathrm{~s}$, a fim de evitar a fadiga muscular. Este procedimento foi realizado três vezes.

- Mastigação Habitual de cubos de cenoura (MH): foi solicitado ao paciente, mastigar de forma habitual, respeitando seu próprio padrão mastigatório, um cubo de cenoura fresca $(1 \mathrm{~cm} \times 1 \mathrm{~cm})$, crua e descascada (Figura 10), até que o paciente se sentisse confortável para deglutir. Este procedimento foi realizado três vezes, com descanso de $60 \mathrm{~s}$ entre cada mastigação.

- Mastigação Unilateral Direita de látex (MUD): foi solicitado ao paciente, que mordesse unilateralmente, um pedaço de látex de $0,5 \mathrm{~cm}$ de diâmetro $\mathrm{x} 1 \mathrm{~cm}$ de comprimento (Figura 10), respeitando o seu padrão mastigatório durante um sequiência de 
8 ciclos iniciada pelo lado direito. Este procedimento foi realizado três vezes, com descanso de 60s entre cada mastigação.

- Mastigação Unilateral Esquerda de látex (MUE): Procedimento equivalente ao MUD, realizado do lado esquerdo.

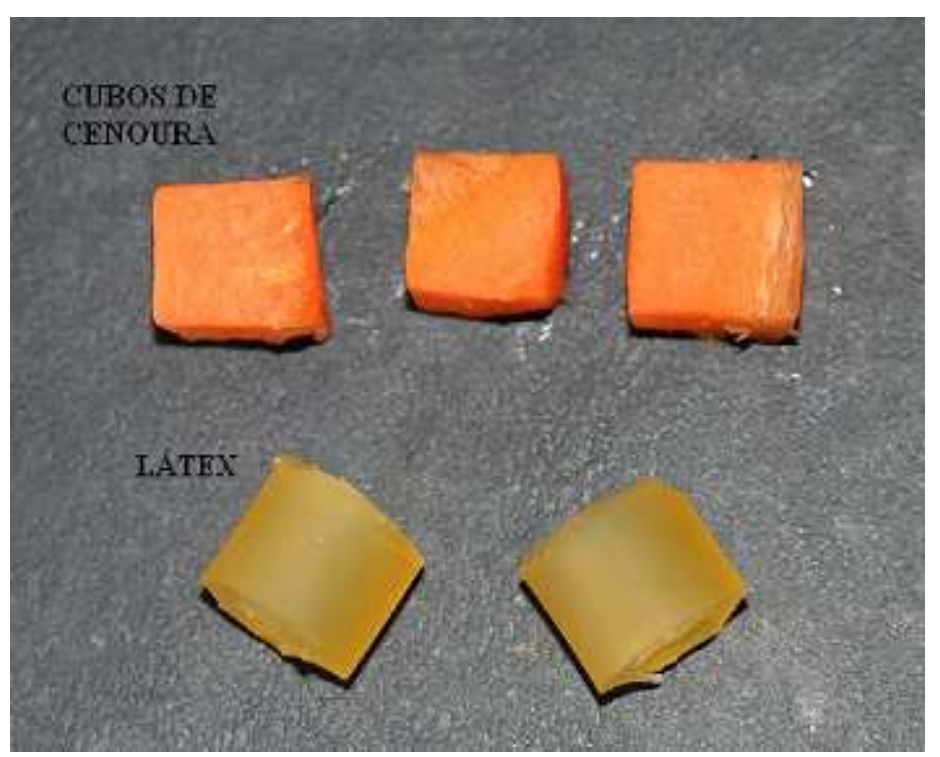

Figura 10 - Cubos de cenoura e látex.

\subsubsection{Análise do traçado eletromiográfico}

Para a análise dos registros eletromiográficos, seguiu-se a metodologia de pesquisas anteriormente realizadas, nas quais o primeiro ato e ciclo foram desprezados por considerar eventual receio dos pacientes em exercitar suas atividades mastigatórias sendo medidos os 8 atos e ciclos consecutivos. (Melo 2005, Lopes 2006)

Para todas as medidas de amplitude em microvolts $(\mu \mathrm{v})$, foram consideradas as medidas médias apresentadas pelo programa K6-I Diagnostic System, no modo de processamento EMG (Myo-Tronics, Inc., Seatle, Wa. USA) (Figuras 11 e 12).

Para as medidas da duração (em segundos) do ato e do ciclo mastigatório durante a mastigação habitual de cenoura e durante mastigação unilateral direita e esquerda de látex, utilizou-se o programa de imagem para traçado radiográfico e planejamento em Implantodontia, Radiocef 2 (Radiomemory, Belo Horizonte, MG, Brasil). A calibração do traçado eletromiográfico foi realizada demarcando-se dois pontos de distância conhecida $(10 \mathrm{~mm})$ na imagem digitalizada. Digitou-se esse mesmo valor no campo "valor real" e clicou-se na opção calibrar. A partir daí, foram realizadas as mensurações (Figuras 13 e 14). 


\subsection{Medida da amplitude durante a Contração Voluntária Isométrica Máxima (CVIM)}

Medida do pico de maior atividade muscular, em microvolts $(\mu \mathrm{V})$, durante 5 segundos, dos lados direito e esquerdo. Foi utilizada a média de 3 contrações isométricas máximas, realizadas em 3 tempos distintos (Figura 11).

\subsection{Mastigação habitual de cenoura $(\mathrm{MH})$}

- Amplitude durante a $\mathrm{MH}$, em $\mu \mathrm{V}$ : foram medidos 8 ciclos, de ambos os lados, em 3 tempos distintos. Para a análise foi considerada a média dos 8 ciclos (Figura 12).

- Ato mastigatório durante a MH em segundos (s): foi medido o período entre o início e o fim da atividade muscular. Para a análise considerou-se a média de 8 atos, medidos durante a $\mathrm{MH}$, em 3 tempos distintos, para ambos os lados (Figura 14).

- Ciclo mastigatório durante a MH em s: foi medido o período entre o início da atividade muscular até o início da próxima atividade, incluindo-se o período de relaxamento muscular. Para análise considerou-se a média de 8 ciclos, medidos durante a MH, em 3 tempos distintos, para ambos os lados (Figura 14).

\subsection{Mastigação unilateral direita de látex (MUD)}

- Amplitude durante a MUD, em $\mu \mathrm{V}$ : foram medidos 8 ciclos, de ambos os lados, realizada em 3 tempos distintos. Para a análise foi considerada a média dos 8 ciclos (Figura 12).

- Ato mastigatório durante a MUD em s: foi medido o período entre o início e o fim da atividade muscular. Para a análise considerou-se a média de 8 atos, medidos durante a MUD, em 3 tempos distintos, para ambos os lados (Figura14).

- Ciclo mastigatório durante a MUD em s: foi medido o período entre o início da atividade muscular até o início da próxima atividade, incluindo-se o período de relaxamento muscular. Para a análise considerou-se a média de 8 ciclos, medidos durante a MUD, em 3 tempos distintos, para ambos os lados (Figura 14). 


\subsection{Mastigação unilateral esquerda de látex (MUE)}

- Amplitude durante a MUE, em $\mu \mathrm{V}$ : foram medidos 8 ciclos, de ambos os lados, realizada em 3 tempos distintos. Para análise foi considerada a média dos 8 ciclos (Figura 12).

- Ato mastigatório durante a MUE, em s: foi medido o período entre o início e o fím da atividade muscular. Para a análise foi considerou-se a média de 8 atos, medidos durante a MUE, em 3 tempos distintos, para ambos os lados (Figura 14).

- Ciclo mastigatório durante a MUE, em s: foi medido o período entre o início da atividade muscular até o início da próxima atividade, incluindo-se o período de relaxamento muscular. Para a análise considerou-se a média de 8 ciclos, medidos durante a MUE, em 3 tempos distintos, para ambos os lados (Figura 14).

Os dados foram anotados em fichas próprias (Anexo 6) e transportados para planilhas do programa Excel 2003 (Microsoft Corporation, Richmound VA, USA) para posteriormente receberem tratamento estatístico.

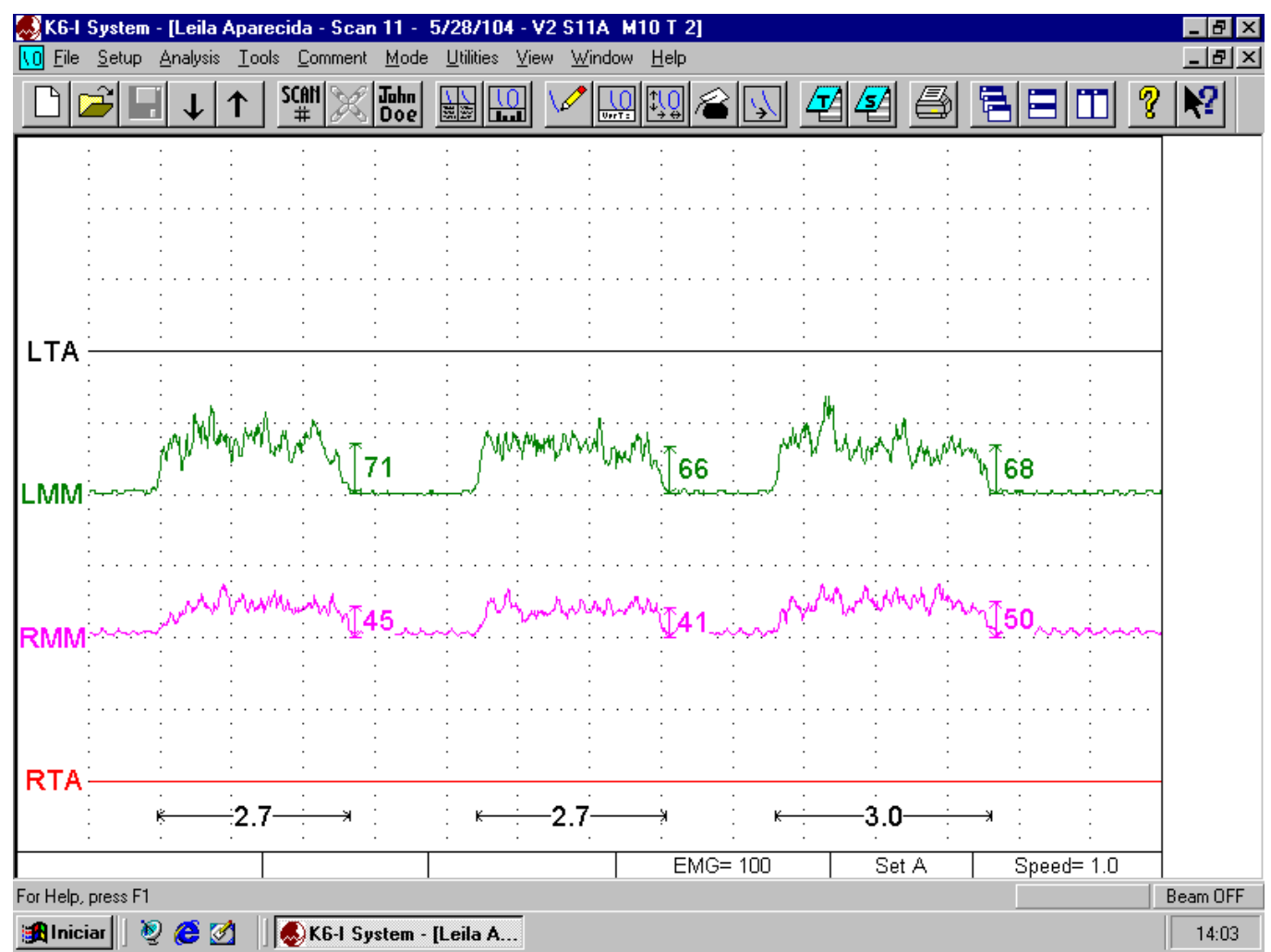

Figura 11 - Medida da amplitude da contração isométrica máxima dada pelo programa K-6. 


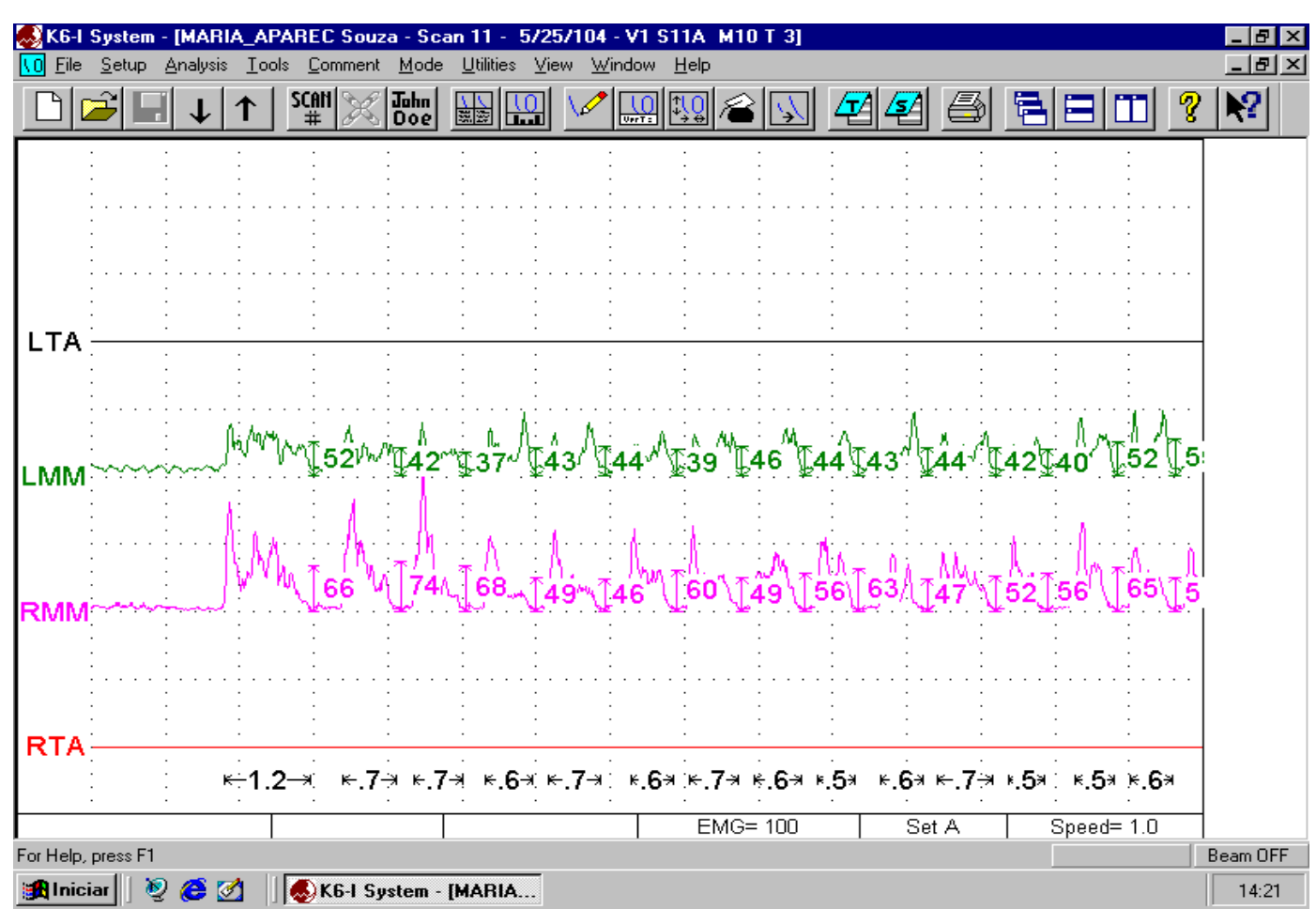

Figura 12 - Medida da amplitude da MH, MUD e MUE.

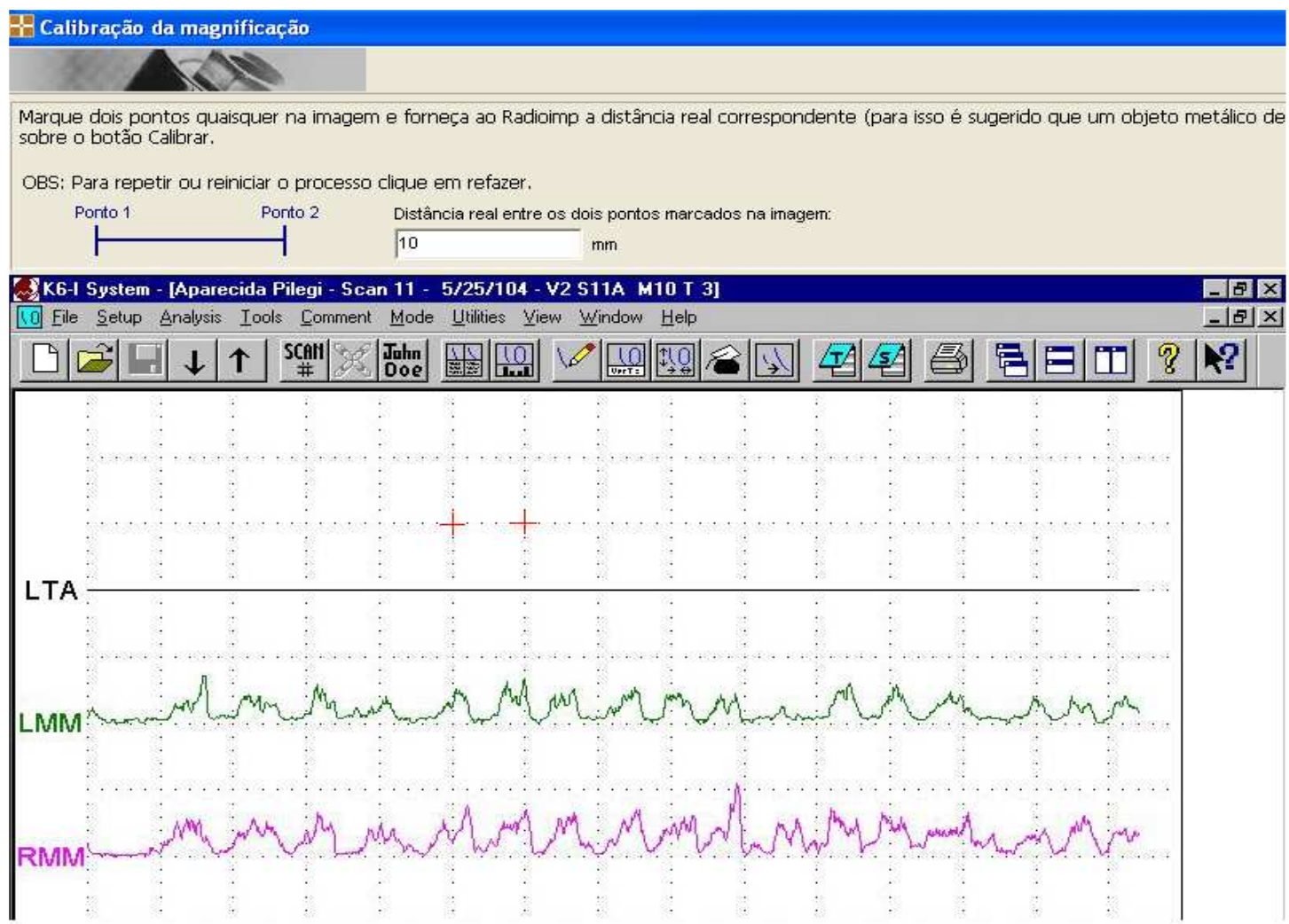

Figura 13 - Calibração da imagem eletromiográfica. 


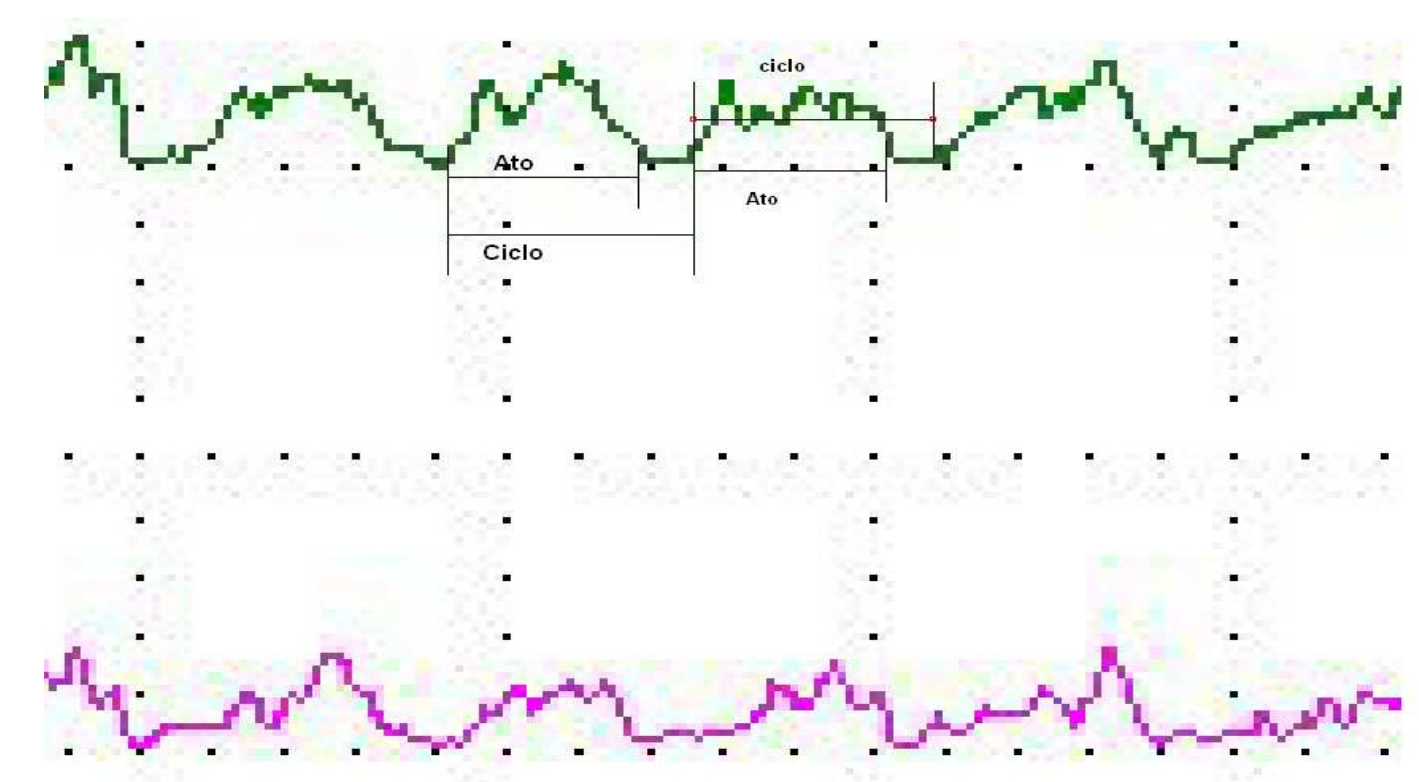

Figura 14 - Medidas do ato e do ciclo mastigatório durante a mastigação habitual de cenoura e durante a mastigação unilateral direita e esquerda de látex.

\subsection{ANÁLISE DOS DADOS}

Para estudar a associação da medida óssea vertical com os fatores: tipo de prótese inferior, lado, sítio e instante, foi utilizado um modelo de análise de variância com medidas repetidas (Verbek e Molenbergs, 1997). O mesmo modelo foi utilizado para estudar a associação entre cada uma das medidas de atividade muscular (amplitude, ato, ciclo) para CVIM, MH, MUD e MUE, e os fatores: tipo de prótese inferior, lado e instante. Para fazer as comparações post hoc, foi utilizada a correção de Tukey (Neter et al 1996).

Para estudar a associação entre as medidas ósseas verticais e as medidas de amplitude, ato e ciclo, foi utilizado um modelo de regressão linear (Neter et al 1996), considerando como variáveis resposta a média das medidas ósseas verticais dos 5 sítios do lado direito e a média das medidas ósseas verticais do lado esquerdo. Para cada lado e para cada instante, foi ajustado um modelo de regressão linear, considerando como variáveis independentes: o tipo de prótese inferior, a variável de interesse e a interação entre o tipo de prótese inferior e a variável de interesse.

O mesmo procedimento foi utilizado considerando-se como variável resposta a diferença entre T2 e T1 das médias das medidas verticais para cada lado e, considerando como variáveis de interesse as diferenças entre T1 e T2 da amplitude, ato e ciclo de cada tipo de mastigação. 
Nos modelos de regressão estatisticamente significantes, foi utilizado o método de "backward" (Neter et al 1996) para determinar, em cada caso, o modelo de regressão final. 

5 RESULTADOS 



\section{RESULTADOS}

\subsection{ESTUDO DA ASSOCIAÇÃO ENTRE A MEDIDA ÓSSEA VERTICAL E OS FATORES: TIPO DE PRÓTESE INFERIOR, INSTANTE, LADO E SÍTIO}

Os valores médios das medidas ósseas verticais (medidas-resumo) para Overdenture e para Protocolo, nos instantes T1 (antes ou logo após a instalação das próteses) e T2 (um ano após a instalação), podem ser vistas nas Tabela 3 e 4, respectivamente.

Tabela 3 - Medidas-resumo das medidas verticais do grupo com prótese inferior Overdenture segundo instante, lado e sítio.

\begin{tabular}{|c|c|c|c|c|c|c|c|c|}
\hline Lado & Sítio & Instante & $\mathrm{N}$ & Média & Desvio-padrão & Mínimo & Mediana & Máximo \\
\hline \multirow{10}{*}{ Direito } & \multirow{2}{*}{1} & $\mathrm{~T} 1$ & 8 & 20,5 & 4,9 & 10,9 & 21,6 & 25,7 \\
\hline & & $\mathrm{T} 2$ & 8 & 21,9 & 4,7 & 15,2 & 22,3 & 28,2 \\
\hline & \multirow{2}{*}{2} & $\mathrm{~T} 1$ & 8 & 19,6 & 4,5 & 10,9 & 21,1 & 23,9 \\
\hline & & $\mathrm{T} 2$ & 8 & 21,2 & 4,7 & 14,4 & 21,9 & 26,8 \\
\hline & \multirow{2}{*}{3} & $\mathrm{~T} 1$ & 8 & 18,7 & 4,2 & 10,7 & 20,0 & 23,0 \\
\hline & & $\mathrm{T} 2$ & 8 & 20,2 & 4,7 & 13,4 & 21,0 & 25,8 \\
\hline & \multirow{2}{*}{4} & $\mathrm{~T} 1$ & 8 & 17,7 & 4,1 & 9,8 & 18,6 & 21,7 \\
\hline & & $\mathrm{T} 2$ & 8 & 19,5 & 4,3 & 13,5 & 20,1 & 24,3 \\
\hline & \multirow{2}{*}{5} & $\mathrm{~T} 1$ & 8 & 16,5 & 3,9 & 9,3 & 17,8 & 21,1 \\
\hline & & $\mathrm{T} 2$ & 8 & 19,1 & 4,9 & 13,1 & 19,0 & 25,4 \\
\hline \multirow{10}{*}{ Esquerdo } & \multirow{2}{*}{1} & $\mathrm{~T} 1$ & 8 & 19,2 & 4,7 & 9,7 & 20,4 & 24,3 \\
\hline & & $\mathrm{T} 2$ & 8 & 21,5 & 4,8 & 14,5 & 23,1 & 27,5 \\
\hline & \multirow{2}{*}{2} & $\mathrm{~T} 1$ & 8 & 18,4 & 4,2 & 9,4 & 19,9 & 22,2 \\
\hline & & $\mathrm{T} 2$ & 8 & 20,7 & 4,6 & 14,3 & 21,9 & 27,0 \\
\hline & \multirow{2}{*}{3} & $\mathrm{~T} 1$ & 8 & 17,3 & 4,1 & 9,0 & 18,8 & 21,3 \\
\hline & & $\mathrm{T} 2$ & 8 & 19,7 & 4,2 & 14,1 & 19,7 & 25,6 \\
\hline & \multirow{2}{*}{4} & $\mathrm{~T} 1$ & 8 & 16,2 & 4,5 & 8,3 & 17,8 & 20,6 \\
\hline & & $\mathrm{T} 2$ & 8 & 18,5 & 4,2 & 12,9 & 18,1 & 25,7 \\
\hline & \multirow{2}{*}{5} & $\mathrm{~T} 1$ & 8 & 15,5 & 5,1 & 8,0 & 17,0 & 21,5 \\
\hline & & $\mathrm{T} 2$ & 8 & 17,1 & 3,9 & 12,5 & 16,9 & 24,0 \\
\hline
\end{tabular}


Tabela 4 - Medidas-resumo das medidas verticais do grupo com prótese inferior Protocolo segundo instante, lado e sítio.

\begin{tabular}{|c|c|c|c|c|c|c|c|c|}
\hline Lado & Sítio & Instante & $\mathrm{N}$ & Média & Desvio-padrão & Mínimo & Mediana & Máximo \\
\hline \multirow{10}{*}{ Direito } & \multirow{2}{*}{1} & $\mathrm{~T} 1$ & 9 & 23,4 & 4,1 & 15,7 & 24,4 & 30,2 \\
\hline & & $\mathrm{T} 2$ & 9 & 24,0 & 4,3 & 16,7 & 24,7 & 30,8 \\
\hline & \multirow{2}{*}{2} & $\mathrm{~T} 1$ & 9 & 22,8 & 4,1 & 15,3 & 23,7 & 29,3 \\
\hline & & $\mathrm{T} 2$ & 9 & 23,0 & 4,0 & 16,1 & 23,3 & 29,3 \\
\hline & \multirow{2}{*}{3} & $\mathrm{~T} 1$ & 9 & 21,7 & 4,1 & 14,7 & 22,1 & 28,1 \\
\hline & & $\mathrm{T} 2$ & 9 & 22,0 & 3,8 & 15,5 & 22,0 & 27,5 \\
\hline & \multirow{2}{*}{4} & $\mathrm{~T} 1$ & 9 & 21,3 & 4,1 & 14,5 & 21,3 & 28,5 \\
\hline & & $\mathrm{T} 2$ & 9 & 21,2 & 3,6 & 15,2 & 21,4 & 26,1 \\
\hline & \multirow{2}{*}{5} & $\mathrm{~T} 1$ & 9 & 20,5 & 3,7 & 14,4 & 20,7 & 28,3 \\
\hline & & $\mathrm{T} 2$ & 9 & 20,8 & 3,4 & 15,0 & 20,7 & 26,2 \\
\hline \multirow{10}{*}{ Esquerdo } & \multirow{2}{*}{1} & $\mathrm{~T} 1$ & 9 & 23,1 & 4,9 & 12,1 & 23,3 & 29,6 \\
\hline & & $\mathrm{T} 2$ & 9 & 23,1 & 4,0 & 15,2 & 22,1 & 29,2 \\
\hline & \multirow{2}{*}{2} & $\mathrm{~T} 1$ & 9 & 22,3 & 5,1 & 10,9 & 22,4 & 28,8 \\
\hline & & $\mathrm{T} 2$ & 9 & 22,6 & 4,4 & 14,1 & 22,2 & 28,4 \\
\hline & \multirow{2}{*}{3} & $\mathrm{~T} 1$ & 9 & 21,6 & 5,1 & 10,7 & 21,5 & 27,2 \\
\hline & & $\mathrm{T} 2$ & 9 & 21,2 & 4,7 & 12,8 & 20,3 & 26,8 \\
\hline & \multirow{2}{*}{4} & $\mathrm{~T} 1$ & 9 & 20,5 & 4,9 & 10,9 & 19,9 & 26,5 \\
\hline & & $\mathrm{T} 2$ & 9 & 19,9 & 5,0 & 11,4 & 18,9 & 26,8 \\
\hline & \multirow{2}{*}{5} & $\mathrm{~T} 1$ & 9 & 19,7 & 4,6 & 11,8 & 19,2 & 26,1 \\
\hline & & $\mathrm{T} 2$ & 9 & 19,3 & 4,8 & 11,3 & 18,5 & 25,8 \\
\hline
\end{tabular}


Os boxplots das medidas verticais ósseas segundo os fatores: tipo de prótese inferior, instante, lado e sítio podem ser vistos na Figura 15.
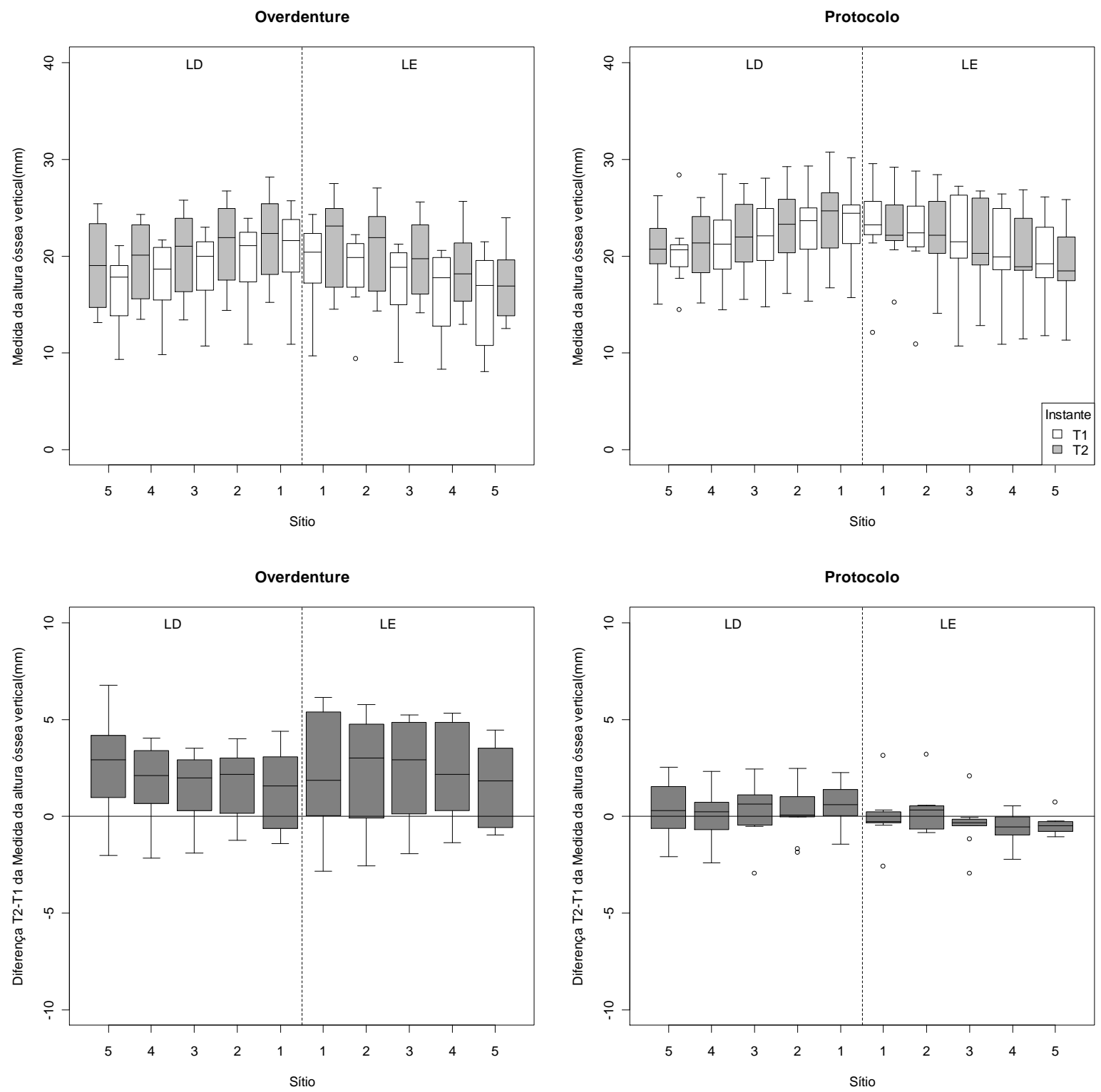

Figura 15 - Medidas da altura óssea vertical segundo os grupos e os instantes. 
Os resultados da análise de variância (ANOVA) indicados na Tabela 5 demonstram que os fatores: lado, sítio e a interação entre tipo de prótese inferior e instante são estatisticamente significantes ( $\mathrm{p}<0,001$, em todos os casos).

Tabela 5 - Tabela de análise de variância das medidas verticais.

\begin{tabular}{lc}
\hline \multicolumn{1}{c}{ Fator } & $\mathrm{p}$ \\
\hline Tipo de prótese inferior & 0,195 \\
Lado & $\mathbf{< 0 , 0 0 1}$ \\
Sítio & $\mathbf{< 0 , 0 0 1}$ \\
Instante & 0,000 \\
Interação entre tipo de prótese inferior e Lado & 0,386 \\
Interação entre tipo de prótese inferior e Sítio & 0,934 \\
Interação entre tipo de prótese inferior e Instante & $\mathbf{< 0 , 0 0 1}$ \\
Interação entre Lado e Sítio & 0,620 \\
Interação entre Lado e Instante & 0,849 \\
Interação entre sítio e instante & 0,990 \\
Interação entre tipo de prótese inferior, Lado e Sítio & 0,999 \\
Interação entre tipo de prótese inferior, Lado e Instante & 0,169 \\
Interação entre tipo de prótese inferior, Sítio e Instante & 0,928 \\
Interação entre Lado, Sítio e Instante & 0,806 \\
Interação entre Tipo de prótese inferior, Lado, Sítio e Instante & 0,895 \\
\hline
\end{tabular}

As comparações post hoc considerando a interação entre os fatores Tipo de prótese inferior e Instante, podem ser vistas na Tabela 6.

Apesar de não ocorrerem diferenças estatisticamente significantes entre os tipos de prótese inferior tanto no instante $\mathrm{T} 1$, como no instante $\mathrm{T} 2$, as mesmas comparações permitem afirmar que ocorre um aumento médio estatisticamente significante das medidas ósseas verticais em média de 1,98mm ( $\mathrm{p}<0,001$ ), com intervalo de confiança (IC) de 1,36 a 2,60mm para o Tipo de prótese inferior Overdenture. 
Tabela 6 - Comparações post hoc considerando os fatores: Instante e Grupo - Medidas verticais.

\begin{tabular}{cccccc}
\hline \multirow{2}{*}{ Comparações } & \multirow{2}{*}{ Estimativas } & \multirow{2}{*}{$\mathrm{p}^{*}$} & \multicolumn{2}{c}{ Intervalo de confiança (95\%)* } \\
\cline { 5 - 6 } & & & Limite inferior & Limite superior \\
\hline \multirow{2}{*}{ T2-T1 } & Overdenture & 1,98 & $<\mathbf{0 , 0 0 1}$ & 1,36 & 2,60 \\
& Protocolo & 0,02 & $>0,999$ & $-0,56$ & 0,61 \\
\hline Overdenture - & T1 & $-3,72$ & 0,260 & $-8,96$ & 1,52 \\
Protocolo & T2 & $-1,77$ & 0,820 & $-7,01$ & 3,48 \\
\hline
\end{tabular}

* Com correção de Tukey

Com relação aos sítios, notamos que ocorre uma diminuição estatisticamente significante das médias conforme nos afastamos dos sítios centrais (Tabela 7).

Tabela 7 - Comparações post hoc dos sítios - Medidas verticais.

\begin{tabular}{ccccc}
\hline \multirow{2}{*}{ Diferenças } & Estimativa & \multirow{2}{*}{$\mathrm{p}^{*}$} & \multicolumn{2}{c}{ Intervalo de confiança (95\%)* } \\
\cline { 4 - 5 } & & & Limite inferior & Limite superior \\
\hline S1-S2 & 0,8 & 0,033 & 0,0 & 1,5 \\
S1-S3 & 1,8 & $<0,001$ & 1,1 & 2,5 \\
S1-S4 & 2,7 & $<0,001$ & 2,0 & 3,5 \\
S1-S5 & 3,5 & $<0,001$ & 2,8 & 4,2 \\
S2-S3 & 1,0 & 0,001 & 0,3 & 1,7 \\
S2-S4 & 2,0 & $<0,001$ & 1,3 & 2,7 \\
S2-S5 & 2,8 & $<0,001$ & 2,1 & 3,5 \\
S3-S4 & 1,0 & 0,002 & 0,3 & 1,7 \\
S3-S5 & 1,8 & $<0,001$ & 1,0 & 2,5 \\
S4-S5 & 0,8 & 0,023 & 0,1 & 1,5 \\
\hline
\end{tabular}

* com correção de Tukey

Com relação ao lado, concluímos que o lado direito é estatisticamente maior que o lado esquerdo em média em 0,9mm com IC de 0,6 a 1,2mm (Tabela 8)

Tabela 8 - Comparações post hoc dos lados - Medidas verticais.

\begin{tabular}{ccccc}
\hline \multirow{2}{*}{ Diferenças } & \multirow{2}{*}{ Estimativa } & \multirow{2}{*}{$\mathrm{p}^{*}$} & \multicolumn{2}{c}{ Intervalo de confiança (95\%)* } \\
\cline { 4 - 5 } & & Limite inferior & Limite superior \\
\hline Direito - Esquerdo & 0,9 & $<\mathbf{0 , 0 0 1}$ & 0,6 & 1,2 \\
\hline
\end{tabular}


5.2 ESTUDO DA ASSOCIAÇÃO ENTRE AS MEDIDAS DA ATIVIDADE MUSCULAR MASSETÉRICA E OS FATORES: TIPO DE PRÓTESE INFERIOR, INSTANTE E LADO

\subsubsection{Medida da Amplitude $(\mu \mathrm{V})$}

As medidas-resumo da medida da Amplitude durante a CVIM, MH, MUD e MUE podem ser vistas nas Tabelas 9, 10 e11 e Tabela 12, respectivamente.

Tabela 9 - Medidas-resumo da medida da Amplitude durante CVIM.

\begin{tabular}{|c|c|c|c|c|c|c|c|c|}
\hline $\begin{array}{l}\text { Tipo de } \\
\text { prótese } \\
\text { inferior }\end{array}$ & Lado & Instante & $\mathrm{N}$ & Média & $\begin{array}{c}\text { Desvio- } \\
\text { padrão }\end{array}$ & Mínimo & Mediana & Máximo \\
\hline \multirow{4}{*}{ Overdenture } & \multirow{2}{*}{ Direito } & $\mathrm{T} 1$ & 8 & 44,1 & 29,8 & 15,0 & 39,3 & 108,7 \\
\hline & & $\mathrm{T} 2$ & 8 & 54,8 & 25,6 & 26,0 & 49,2 & 100,7 \\
\hline & \multirow{2}{*}{ Esquerdo } & $\mathrm{T} 1$ & 8 & 32,5 & 18,4 & 14,7 & 27,7 & 64,7 \\
\hline & & $\mathrm{T} 2$ & 8 & 48,9 & 28,7 & 25,0 & 39,3 & 100,0 \\
\hline \multirow{4}{*}{ Protocolo } & \multirow{2}{*}{ Direito } & $\mathrm{T} 1$ & 9 & 70,1 & 35,2 & 34,7 & 56,3 & 139,0 \\
\hline & & $\mathrm{T} 2$ & 9 & 65,5 & 31,8 & 36,0 & 49,0 & 117,2 \\
\hline & \multirow{2}{*}{ Esquerdo } & $\mathrm{T} 1$ & 9 & 66,2 & 24,4 & 26,3 & 71,0 & 107,0 \\
\hline & & $\mathrm{T} 2$ & 9 & 76,0 & 30,3 & 27,0 & 82,4 & 108,0 \\
\hline
\end{tabular}

Tabela 10 - Medidas-resumo da medida da Amplitude durante a MH.

\begin{tabular}{|c|c|c|c|c|c|c|c|c|}
\hline $\begin{array}{l}\text { Tipo de } \\
\text { prótese } \\
\text { inferior }\end{array}$ & Lado & Instante & $\mathrm{N}$ & Média & $\begin{array}{c}\text { Desvio- } \\
\text { padrão }\end{array}$ & Mínimo & Mediana & Máximo \\
\hline \multirow{4}{*}{ Overdenture } & \multirow{2}{*}{ Direito } & $\mathrm{T} 1$ & 8 & 37,7 & 18,5 & 13,8 & 35,7 & 66,0 \\
\hline & & $\mathrm{T} 2$ & 8 & 44,9 & 22,4 & 15,4 & 38,5 & 72,8 \\
\hline & \multirow{2}{*}{ Esquerdo } & $\mathrm{T} 1$ & 8 & 33,5 & 12,6 & 17,9 & 33,3 & 56,0 \\
\hline & & $\mathrm{T} 2$ & 8 & 48,2 & 22,5 & 22,3 & 48,4 & 81,3 \\
\hline \multirow{4}{*}{ Protocolo } & \multirow{2}{*}{ Direito } & $\mathrm{T} 1$ & 9 & 47,1 & 23,2 & 22,0 & 36,8 & 89,1 \\
\hline & & $\mathrm{T} 2$ & 9 & 61,7 & 30,7 & 33,1 & 61,0 & 117,9 \\
\hline & \multirow{2}{*}{ Esquerdo } & $\mathrm{T} 1$ & 9 & 56,7 & 25,5 & 29,9 & 56,0 & 95,6 \\
\hline & & $\mathrm{T} 2$ & 9 & 55,2 & 26,3 & 21,3 & 48,4 & 110,0 \\
\hline
\end{tabular}


Tabela 11 - Medidas-resumo da medida da Amplitude durante a MUD.

\begin{tabular}{|c|c|c|c|c|c|c|c|c|}
\hline $\begin{array}{l}\text { Tipo de } \\
\text { prótese } \\
\text { inferior }\end{array}$ & Lado & Instante & $\mathrm{N}$ & Média & $\begin{array}{c}\text { Desvio- } \\
\text { padrão }\end{array}$ & Mínimo & Mediana & Máximo \\
\hline \multirow{4}{*}{ Overdenture } & \multirow{2}{*}{ Direito } & $\mathrm{T} 1$ & 8 & 34,2 & 18,2 & 15,5 & 29,7 & 70,6 \\
\hline & & $\mathrm{T} 2$ & 8 & 54,6 & 28,6 & 29,0 & 44,1 & 116,0 \\
\hline & \multirow{2}{*}{ Esquerdo } & T1 & 8 & 29,3 & 10,5 & 15,6 & 26,5 & 45,8 \\
\hline & & $\mathrm{T} 2$ & 8 & 47,0 & 22,2 & 18,0 & 40,4 & 89,6 \\
\hline \multirow{4}{*}{ Protocolo } & \multirow{2}{*}{ Direito } & T1 & 9 & 49,4 & 28,5 & 15,0 & 41,1 & 95,9 \\
\hline & & $\mathrm{T} 2$ & 9 & 55,9 & 20,9 & 34,5 & 53,0 & 100,9 \\
\hline & \multirow{2}{*}{ Esquerdo } & T1 & 9 & 51,5 & 28,9 & 21,9 & 45,8 & 107,1 \\
\hline & & $\mathrm{T} 2$ & 9 & 50,4 & 20,7 & 25,6 & 46,3 & 94,1 \\
\hline
\end{tabular}

Tabela 12 - Medidas-resumo da medida da Amplitude durante a MUE.

\begin{tabular}{|c|c|c|c|c|c|c|c|c|}
\hline $\begin{array}{l}\text { Tipo de } \\
\text { prótese } \\
\text { inferior }\end{array}$ & Lado & Instante & $\mathrm{N}$ & Média & $\begin{array}{c}\text { Desvio- } \\
\text { padrão }\end{array}$ & Mínimo & Mediana & Máximo \\
\hline \multirow{4}{*}{ Overdenture } & \multirow{2}{*}{ Direito } & $\mathrm{T} 1$ & 8 & 29,7 & 12,5 & 14,4 & 29,5 & 49,3 \\
\hline & & $\mathrm{T} 2$ & 8 & 54,9 & 26,6 & 25,5 & 47,6 & 102,5 \\
\hline & \multirow{2}{*}{ Esquerdo } & $\mathrm{T} 1$ & 8 & 28,3 & 12,5 & 14,4 & 25,5 & 48,5 \\
\hline & & $\mathrm{T} 2$ & 8 & 57,9 & 36,9 & 14,9 & 50,6 & 125,9 \\
\hline \multirow{4}{*}{ Protocolo } & \multirow{2}{*}{ Direito } & $\mathrm{T} 1$ & 9 & 57,5 & 27,1 & 24,8 & 53,3 & 93,4 \\
\hline & & $\mathrm{T} 2$ & 9 & 63,7 & 23,6 & 31,9 & 60,3 & 112,6 \\
\hline & \multirow{2}{*}{ Esquerdo } & $\mathrm{T} 1$ & 9 & 47,8 & 19,5 & 20,5 & 49,0 & 85,8 \\
\hline & & $\mathrm{T} 2$ & 9 & 63,9 & 26,9 & 31,4 & 60,9 & 103,4 \\
\hline
\end{tabular}

Os boxplots da amplitude da CVIM, MH podem ser vistos na Figura 16 e os boxplots da amplitude da MUD e da MUE encontram-se na Figura 17. 

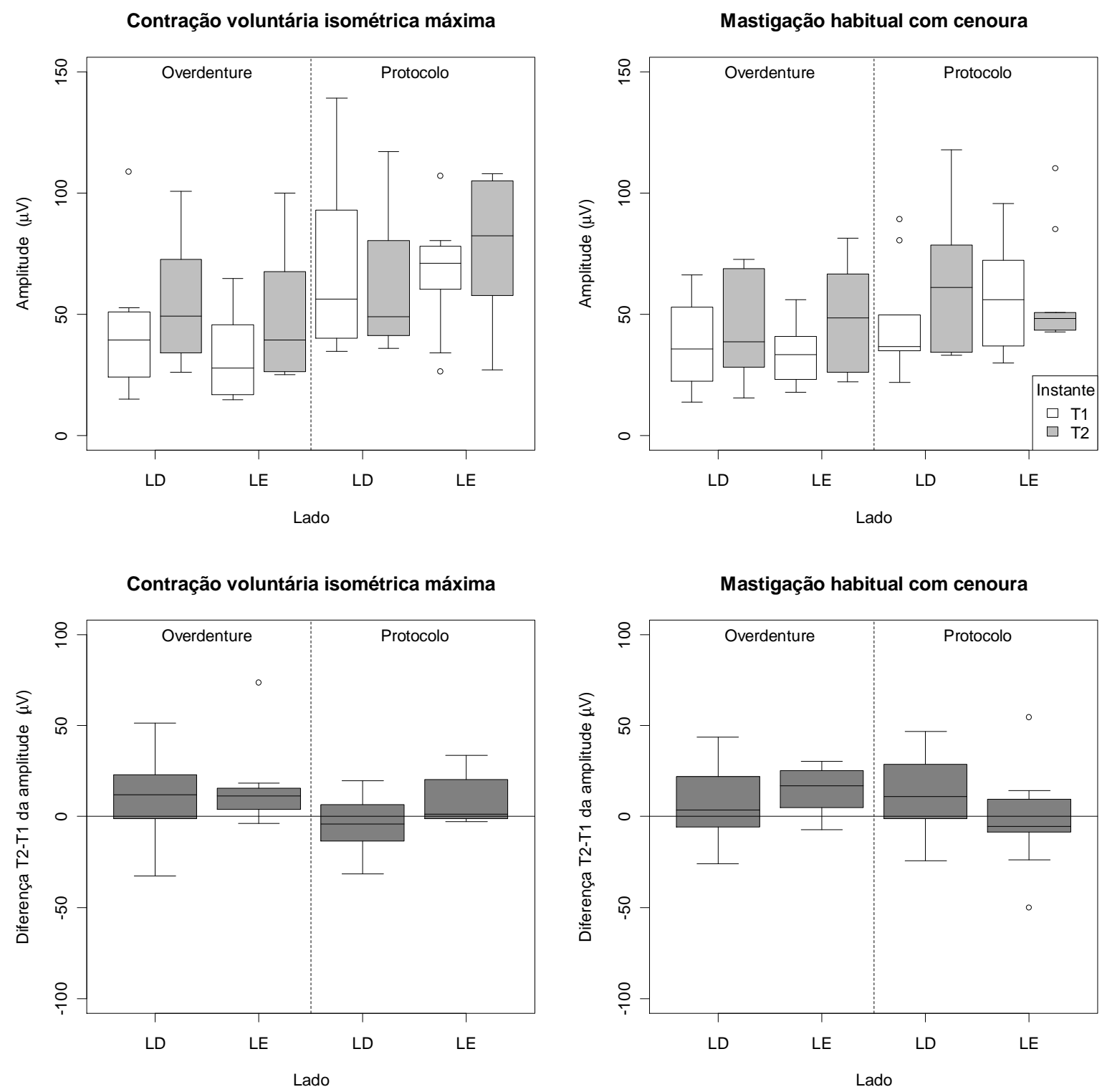

Figura 16 - Medida da Amplitude durante a CVIM e MH segundo o lado, o tipo de prótese inferior e os instantes. 

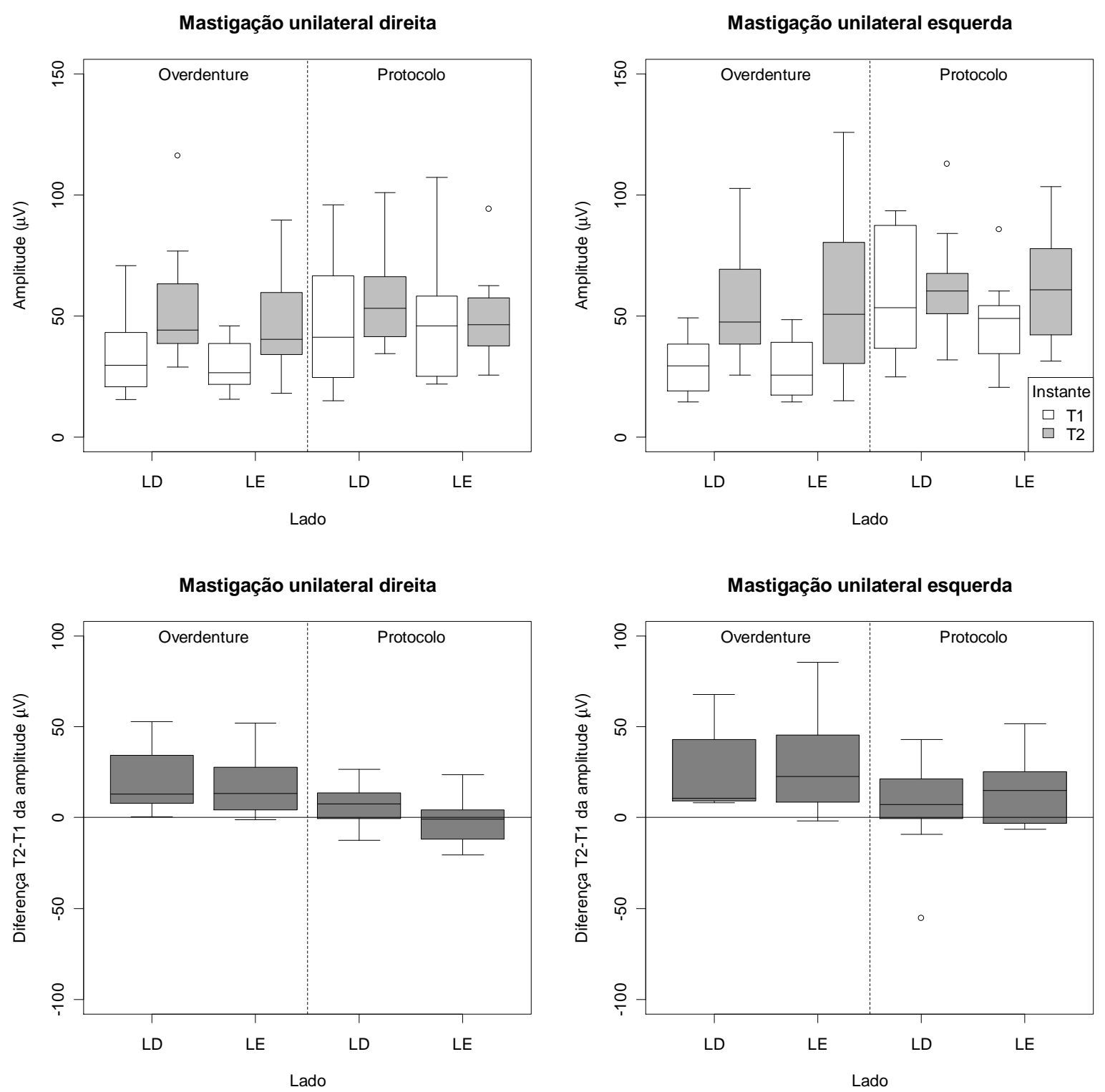

Figura 17 - Medida da Amplitude durante a MUD e MUE segundo o lado, o tipo de prótese inferior e os instantes. 
Os resultados das ANOVAS da medida da Amplitude durante a CVIM, MH, MUD e MUE, encontram-se na Tabela 13.

Tabela 13 - ANOVAS - Amplitude.

\begin{tabular}{lcccc}
\hline \multicolumn{1}{c}{ Fator } & CVIM & MH & MUD & MUE \\
\hline Tipo de prótese inferior & 0,057 & 0,145 & 0,316 & 0,105 \\
Lado & 0,521 & 0,886 & 0,168 & 0,666 \\
Instante & 0,060 & $\mathbf{0 , 0 3 1}$ & $<0,001$ & $<\mathbf{0 , 0 0 1}$ \\
Interação entre Tipo de prótese e Lado & 0,156 & 0,795 & 0,424 & 0,535 \\
Interação entre Tipo de prótese e Instante & 0,197 & 0,582 & $\mathbf{0 , 0 0 6}$ & 0,076 \\
Interação entre Lado e Instante & 0,236 & 0,587 & 0,359 & 0,428 \\
Interação entre Tipo de prótese, Lado e Instante & 0,604 & 0,142 & 0,666 & 0,766 \\
\hline
\end{tabular}

Para a medida da amplitude durante a CVIM, nenhum fator foi estatisticamente significante. Para $\mathrm{MH}$ e MUE, apenas o fator Instante foi estatisticamente significante ( $\mathrm{p}=0,031$ e $\mathrm{p}<0,001$, respectivamente). Portanto, não é possível afirmar que ocorre diferença estatisticamente significante da medida da amplitude média ao compararmos os tipos de prótese inferior para CVIM, MH e MUE. Só é possível afirmar que ocorreu uma mudança dos valores médios entre os instantes T1 e T2 da amplitude média durante a MH e MUE. Abaixo, encontram-se as comparações entre os instantes T1 e T2 para MH e MUE (Tabela 14)

Tabela 14 - Comparações post hoc da medida da Amplitude durante a MH.

\begin{tabular}{|c|c|c|c|c|}
\hline \multirow{2}{*}{$\begin{array}{c}\text { Tipo de } \\
\text { mastigação }\end{array}$} & \multirow{2}{*}{$\begin{array}{c}\text { Dif. estimada } \\
\text { T2-T1 }\end{array}$} & \multirow{2}{*}{$\mathrm{p}$} & \multicolumn{2}{|c|}{ Intervalo de confiança (95\%) } \\
\hline & & & Limite inferior & Limite superior \\
\hline MH & 9 & 0,031 & 1 & 17 \\
\hline MUE & 19 & $<0,001$ & 10 & 28 \\
\hline
\end{tabular}

Com relação à duração da amplitude durante a MUD, verifica-se que o fator de interação entre o Tipo de prótese inferior e Instante é estatisticamente significante ( $\mathrm{p}=0,006$ Tabela 13). Fazendo as comparações post hoc (Tabela 14) não encontramos diferença estatisticamente significante entre os grupos, tanto no instante $\mathrm{T} 1 \quad \mathrm{p}=0,300)$ quanto ao instante T2 (p=0,996). Porém é possível afirmar que ocorre aumento estatisticamente significante da medida da amplitude durante a MUD para o tipo de prótese inferior overdenture em média de $19 \mu$ com IC de 8 a $30 \mu \mathrm{V}$. 
Tabela 15 - Comparações post hoc da medida da Amplitude durante a MUD.

\begin{tabular}{lcccc}
\hline \multirow{2}{*}{ Comparações } & \multirow{2}{*}{ Dif. estimada } & \multirow{2}{*}{$\mathrm{p}^{*}$} & \multicolumn{2}{c}{ Intervalo de confiança (95\%)* } \\
\cline { 5 - 6 } & & & Limite inferior & Limite superior \\
\hline Overdenture T2-T1 & 19 & $<\mathbf{0 , 0 0 1}$ & 8 & 30 \\
Protocolo T2-T1 & 3 & 0,892 & -8 & 13 \\
Overdenture - Protocolo T1 & -19 & 0,300 & -47 & 9 \\
Overdenture - Protocolo T2 & -2 & 0,996 & -31 & 26 \\
\hline
\end{tabular}

*com correção de Tukey

\subsubsection{Duração do Ato mastigatório(s)}

As medidas-resumo da duração do ato durante a MH, MUD e MUE podem ser vistas na Tabela 16, Tabela 17 e Tabela 18, respectivamente.

Tabela 16 - Medidas-resumo da duração do ato durante a MH.

\begin{tabular}{|c|c|c|c|c|c|c|c|c|}
\hline $\begin{array}{c}\text { Tipo de } \\
\text { prótese inferior }\end{array}$ & Lado & Instante & $\mathrm{N}$ & Média & $\begin{array}{l}\text { Desvio- } \\
\text { padrão }\end{array}$ & Mínimo & Mediana & Máximo \\
\hline \multirow{4}{*}{ Overdenture } & \multirow{2}{*}{ Direito } & $\mathrm{T} 1$ & 8 & 0,46 & 0,09 & 0,32 & 0,47 & 0,60 \\
\hline & & $\mathrm{T} 2$ & 8 & 0,60 & 0,27 & 0,13 & 0,59 & 1,04 \\
\hline & \multirow{2}{*}{ Esquerdo } & $\mathrm{T} 1$ & 8 & 0,48 & 0,14 & 0,23 & 0,52 & 0,63 \\
\hline & & $\mathrm{T} 2$ & 8 & 0,62 & 0,22 & 0,32 & 0,62 & 1,03 \\
\hline \multirow{4}{*}{ Protocolo } & \multirow{2}{*}{ Direito } & $\mathrm{T} 1$ & 9 & 0,46 & 0,07 & 0,35 & 0,44 & 0,56 \\
\hline & & $\mathrm{T} 2$ & 9 & 0,56 & 0,08 & 0,46 & 0,53 & 0,69 \\
\hline & \multirow{2}{*}{ Esquerdo } & $\mathrm{T} 1$ & 9 & 0,46 & 0,08 & 0,33 & 0,48 & 0,61 \\
\hline & & $\mathrm{T} 2$ & 9 & 0,61 & 0,12 & 0,48 & 0,62 & 0,86 \\
\hline
\end{tabular}


Tabela 17 - Medidas-resumo da duração do ato durante a MUD.

\begin{tabular}{|c|c|c|c|c|c|c|c|c|}
\hline $\begin{array}{l}\text { Tipo de prótese } \\
\text { inferior }\end{array}$ & Lado & Instante & $\mathrm{N}$ & Média & $\begin{array}{l}\text { Desvio- } \\
\text { padrão }\end{array}$ & Mínimo & Mediana & Máximo \\
\hline \multirow{4}{*}{ Overdenture } & \multirow{2}{*}{ Direito } & $\mathrm{T} 1$ & 8 & 0,52 & 0,11 & 0,33 & 0,51 & 0,67 \\
\hline & & $\mathrm{T} 2$ & 8 & 0,58 & 0,20 & 0,20 & 0,61 & 0,83 \\
\hline & \multirow{2}{*}{ Esquerdo } & $\mathrm{T} 1$ & 8 & 0,51 & 0,07 & 0,43 & 0,50 & 0,61 \\
\hline & & $\mathrm{T} 2$ & 8 & 0,59 & 0,24 & 0,23 & 0,60 & 0,92 \\
\hline \multirow{4}{*}{ Protocolo } & \multirow{2}{*}{ Direito } & $\mathrm{T} 1$ & 9 & 0,54 & 0,10 & 0,37 & 0,55 & 0,66 \\
\hline & & $\mathrm{T} 2$ & 9 & 0,56 & 0,05 & 0,50 & 0,54 & 0,64 \\
\hline & \multirow{2}{*}{ Esquerdo } & $\mathrm{T} 1$ & 9 & 0,52 & 0,09 & 0,37 & 0,52 & 0,66 \\
\hline & & $\mathrm{T} 2$ & 9 & 0,59 & 0,07 & 0,50 & 0,62 & 0,69 \\
\hline
\end{tabular}

Tabela 18 - Medidas-resumo da duração do ato durante a MUE.

\begin{tabular}{|c|c|c|c|c|c|c|c|c|}
\hline $\begin{array}{l}\text { Tipo de } \\
\text { prótese } \\
\text { inferior }\end{array}$ & Lado & Instante & $\mathrm{N}$ & Média & $\begin{array}{c}\text { Desvio- } \\
\text { padrão }\end{array}$ & Mínimo & Mediana & Máximo \\
\hline \multirow{4}{*}{ Overdenture } & \multirow{2}{*}{ Direito } & $\mathrm{T} 1$ & 8 & 0,45 & 0,15 & 0,31 & 0,42 & 0,76 \\
\hline & & $\mathrm{T} 2$ & 8 & 0,57 & 0,21 & 0,13 & 0,61 & 0,81 \\
\hline & \multirow{2}{*}{ Esquerdo } & $\mathrm{T} 1$ & 8 & 0,45 & 0,16 & 0,23 & 0,48 & 0,65 \\
\hline & & $\mathrm{T} 2$ & 8 & 0,67 & 0,23 & 0,30 & 0,72 & 0,95 \\
\hline \multirow{4}{*}{ Protocolo } & \multirow{2}{*}{ Direito } & $\mathrm{T} 1$ & 9 & 0,53 & 0,15 & 0,35 & 0,48 & 0,83 \\
\hline & & $\mathrm{T} 2$ & 9 & 0,59 & 0,11 & 0,41 & 0,57 & 0,74 \\
\hline & \multirow{2}{*}{ Esquerdo } & $\mathrm{T} 1$ & 9 & 0,51 & 0,15 & 0,32 & 0,50 & 0,71 \\
\hline & & $\mathrm{T} 2$ & 9 & 0,58 & 0,16 & 0,27 & 0,66 & 0,78 \\
\hline
\end{tabular}

Os boxplots da duração do ato durante a MH, MUD e MUE encontram-se na Figura 18. 

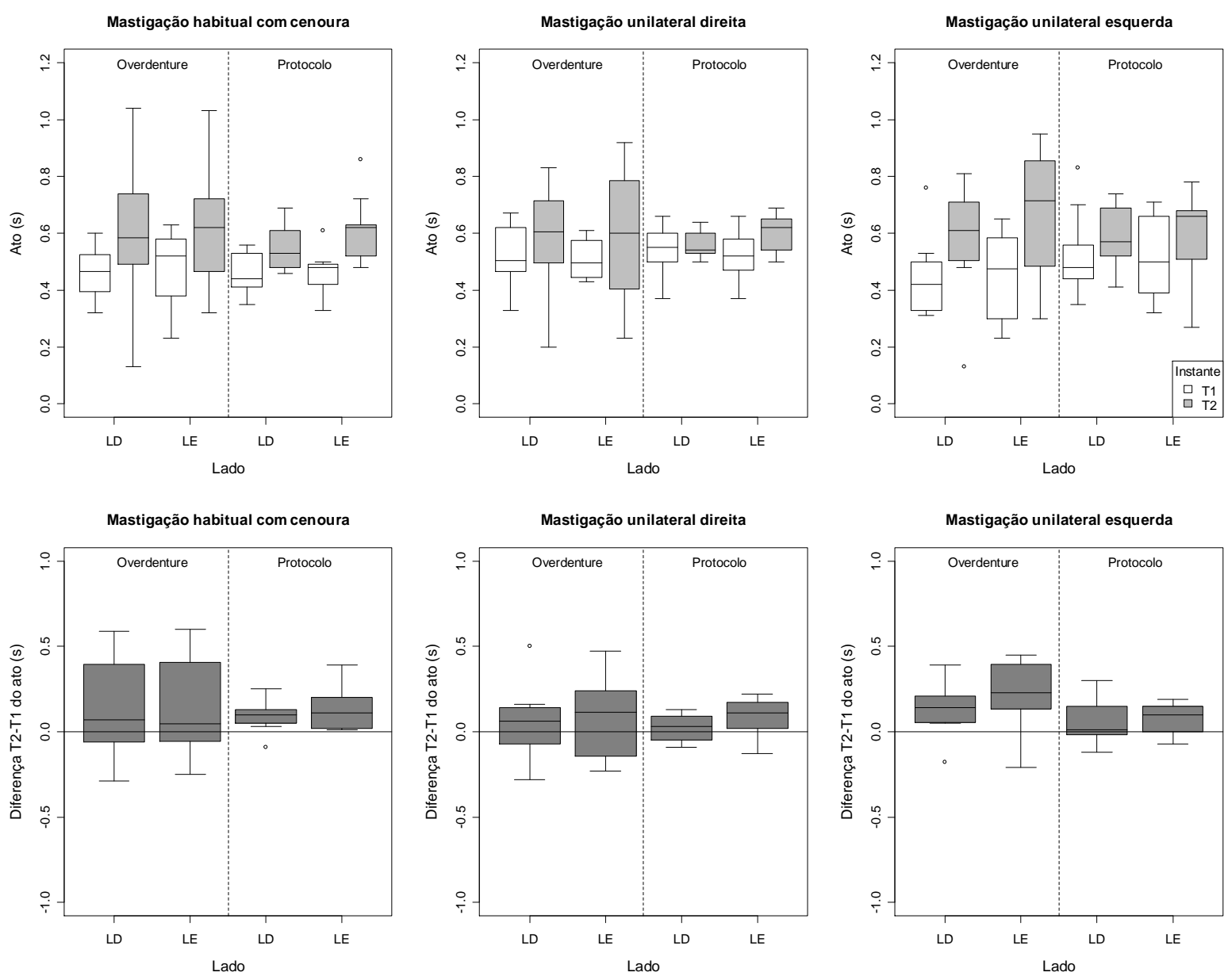

Figura 18 - Duração do ato durante a MH, MUD e MUE segundo os grupos e os instantes. 
Os resultados das ANOVAS para a duração do ato durante a MH, MUD e MUE, encontram-se na Tabela 19. Apenas o fator Instante foi estatisticamente significante em todos os casos (MH, MUD e MUE), ou seja, só é possível afirmar que ocorreu uma mudança da duração do Ato para cada tipo de mastigação, entretanto, não é possível afirmar que ocorreram diferenças entre os tipos de prótese inferior.

Tabela 19 - ANOVAS - Ato

\begin{tabular}{lccc}
\hline \multicolumn{1}{c}{ Fator } & MH & MUD & MUE \\
\hline Tipo de prótese inferior & 0,675 & 0,950 & 0,788 \\
Lado & 0,520 & 0,907 & 0,545 \\
Instante & $\mathbf{< , 0 0 1}$ & $\mathbf{0 , 0 3 3}$ & $\mathbf{< 0 , 0 0 1}$ \\
Interação entre Tipo de prótese e Lado & 0,930 & 0,836 & 0,229 \\
Interação entre Tipo de prótese e Instante & 0,784 & 0,684 & 0,054 \\
Interação entre Lado e Instante & 0,631 & 0,530 & 0,328 \\
Interação entre Tipo de prótese, Lado e Instante & 0,673 & 0,826 & 0,485 \\
\hline
\end{tabular}

As comparações post hoc entre os instantes T1 e T2 para a duração do ato para cada tipo de mastigação, encontram-se na Tabela 20. Em todos os casos, houve aumento médio da duração do ato estatisticamente significante.

Tabela 20 - Comparações post hoc - Ato.

\begin{tabular}{|c|c|c|c|c|}
\hline \multirow{2}{*}{ Tipo de mastigação } & \multirow{2}{*}{ Dif. estimada T2-T1 } & \multirow{2}{*}{$\mathrm{p}^{*}$} & \multicolumn{2}{|c|}{ Intervalo de confiança $(95 \%) *$} \\
\hline & & & Limite inferior & Limite superior \\
\hline $\mathrm{MH}$ & 0,13 & $<0,001$ & 0,07 & 0,20 \\
\hline MUD & 0,06 & 0,033 & 0,01 & 0,12 \\
\hline MUE & 0,12 & $<0,001$ & 0,06 & 0,17 \\
\hline
\end{tabular}

*com correção de Tukey 


\subsubsection{Duração do Ciclo Mastigatório(s)}

As medidas-resumo da duração do ciclo durante a MH, MUD e MUE podem ser vistas nas Tabelas 21, 22 e 23 respectivamente.

Tabela 21 - Medidas-resumo da duração do Ciclo durante a MH.

\begin{tabular}{|c|c|c|c|c|c|c|c|c|}
\hline $\begin{array}{l}\text { Tipo de } \\
\text { prótese } \\
\text { inferior }\end{array}$ & Lado & Instante & $\mathrm{N}$ & Média & $\begin{array}{c}\text { Desvio- } \\
\text { padrão }\end{array}$ & Mínimo & Mediana & Máximo \\
\hline \multirow{4}{*}{ Overdenture } & \multirow{2}{*}{ Direito } & $\mathrm{T} 1$ & 8 & 0,68 & 0,15 & 0,44 & 0,72 & 0,89 \\
\hline & & $\mathrm{T} 2$ & 8 & 0,81 & 0,40 & 0,20 & 0,75 & 1,48 \\
\hline & \multirow{2}{*}{ Esquerdo } & $\mathrm{T} 1$ & 8 & 0,70 & 0,19 & 0,32 & 0,75 & 0,89 \\
\hline & & $\mathrm{T} 2$ & 8 & 0,82 & 0,33 & 0,47 & 0,74 & 1,37 \\
\hline \multirow{4}{*}{ Protocolo } & \multirow{2}{*}{ Direito } & $\mathrm{T} 1$ & 9 & 0,64 & 0,10 & 0,50 & 0,66 & 0,79 \\
\hline & & $\mathrm{T} 2$ & 9 & 0,76 & 0,14 & 0,58 & 0,77 & 0,95 \\
\hline & \multirow{2}{*}{ Esquerdo } & $\mathrm{T} 1$ & 9 & 0,65 & 0,14 & 0,47 & 0,63 & 0,95 \\
\hline & & $\mathrm{T} 2$ & 9 & 0,77 & 0,12 & 0,62 & 0,80 & 0,91 \\
\hline
\end{tabular}

Tabela 22 - Medidas-resumo da duração do Ciclo durante a MUD.

\begin{tabular}{|c|c|c|c|c|c|c|c|c|}
\hline $\begin{array}{l}\text { Tipo de prótese } \\
\text { inferior }\end{array}$ & Lado & Instante & $\mathrm{N}$ & Média & $\begin{array}{c}\text { Desvio- } \\
\text { padrão }\end{array}$ & Mínimo & Mediana & Máximo \\
\hline \multirow{4}{*}{ Overdenture } & \multirow{2}{*}{ Direito } & $\mathrm{T} 1$ & 8 & 0,80 & 0,23 & 0,58 & 0,73 & 1,29 \\
\hline & & $\mathrm{T} 2$ & 8 & 0,86 & 0,39 & 0,25 & 0,81 & 1,62 \\
\hline & \multirow{2}{*}{ Esquerdo } & $\mathrm{T} 1$ & 8 & 0,79 & 0,12 & 0,65 & 0,77 & 0,97 \\
\hline & & $\mathrm{T} 2$ & 8 & 0,82 & 0,39 & 0,32 & 0,78 & 1,57 \\
\hline \multirow{4}{*}{ Protocolo } & \multirow{2}{*}{ Direito } & $\mathrm{T} 1$ & 9 & 0,71 & 0,12 & 0,53 & 0,67 & 0,90 \\
\hline & & $\mathrm{T} 2$ & 9 & 0,75 & 0,07 & 0,67 & 0,73 & 0,86 \\
\hline & \multirow{2}{*}{ Esquerdo } & $\mathrm{T} 1$ & 9 & 0,72 & 0,10 & 0,59 & 0,71 & 0,87 \\
\hline & & $\mathrm{T} 2$ & 9 & 0,78 & 0,10 & 0,69 & 0,74 & 0,95 \\
\hline
\end{tabular}


Tabela 23 - Medidas-resumo da duração do Ciclo durante a MUE.

\begin{tabular}{|c|c|c|c|c|c|c|c|c|}
\hline $\begin{array}{l}\text { Tipo de } \\
\text { prótese } \\
\text { inferior }\end{array}$ & Lado & Instante & $\mathrm{N}$ & Média & $\begin{array}{c}\text { Desvio- } \\
\text { padrão }\end{array}$ & Mínimo & Mediana & Máximo \\
\hline \multirow{4}{*}{ Overdenture } & \multirow{2}{*}{ Direito } & T1 & 8 & 0,76 & 0,21 & 0,54 & 0,69 & 1,19 \\
\hline & & $\mathrm{T} 2$ & 8 & 0,81 & 0,33 & 0,21 & 0,89 & 1,32 \\
\hline & \multirow{2}{*}{ Esquerdo } & $\mathrm{T} 1$ & 8 & 0,71 & 0,16 & 0,48 & 0,69 & 0,95 \\
\hline & & $\mathrm{T} 2$ & 8 & 0,90 & 0,33 & 0,43 & 0,92 & 1,39 \\
\hline \multirow{4}{*}{ Protocolo } & \multirow{2}{*}{ Direito } & T1 & 9 & 0,67 & 0,15 & 0,43 & 0,65 & 0,93 \\
\hline & & $\mathrm{T} 2$ & 9 & 0,76 & 0,12 & 0,58 & 0,81 & 0,95 \\
\hline & \multirow{2}{*}{ Esquerdo } & T1 & 9 & 0,64 & 0,16 & 0,42 & 0,63 & 0,89 \\
\hline & & $\mathrm{T} 2$ & 9 & 0,74 & 0,22 & 0,27 & 0,83 & 0,96 \\
\hline
\end{tabular}


Os boxplots da duração do Ciclo durante a MH, MUD e MUE, podem ser vistos na Figura .
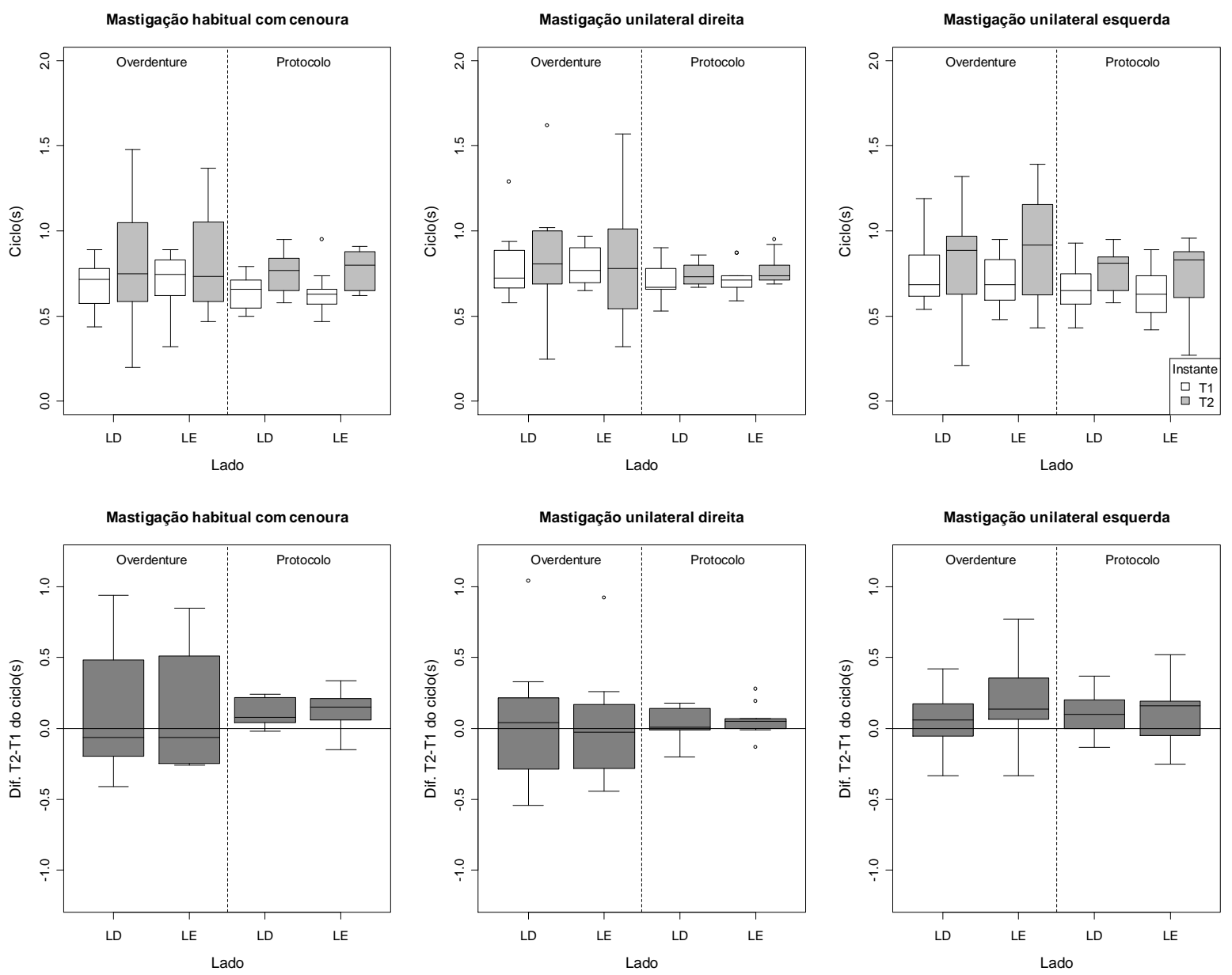

Figura 19 - Duração do ciclo durante a MH, MUD e MUE segundo os grupos e os instantes. 
As ANOVAS da duração do Ciclo durante a MH, MUD e MUE, podem ser vistas na Tabela 24.

Tabela 24 - ANOVAS - Ciclo.

\begin{tabular}{lccc}
\hline \multicolumn{1}{c}{ Fator } & MH & MUD & MUE \\
\hline Tipo de prótese inferior & 0,486 & 0,267 & 0,294 \\
Lado & 0,763 & 0,970 & 0,920 \\
Instante & $\mathbf{0 , 0 1 0}$ & 0,370 & $\mathbf{0 , 0 0 5}$ \\
Interação entre Tipo de prótese e Lado & 0,950 & 0,659 & 0,539 \\
Interação entre Tipo de prótese e Instante & 0,998 & 0,955 & 0,747 \\
Interação entre Lado e Instante & 0,956 & 0,987 & 0,341 \\
Interação entre Tipo de prótese, Lado e Instante & 0,967 & 0,778 & 0,417 \\
\hline
\end{tabular}

Os resultados indicaram associação estatisticamente significante entre a duração do ciclo durante a MH e o Instante $(\mathrm{p}=0,010)$, e entre a duração do ciclo durante a MUE e o Instante $(\mathrm{p}=0,005)$. Dessa forma, não é possível afirmar que existe diferença estatisticamente significante entre os tipos de prótese inferior. Só é possível afirmar que houve um aumento médio da duração do ciclo durante a MH e durante a MUE. As comparações post hoc da duração do ciclo durante a MH e durante a MUE encontram-se na Tabela 25.

Tabela 25 - Comparações post hoc da duração do ciclo.

\begin{tabular}{ccccc}
\hline \multirow{2}{*}{ Tipo de mastigação } & \multirow{2}{*}{ Dif. estimada T2-T1 } & \multirow{2}{*}{$\mathrm{p}^{*}$} & \multicolumn{2}{c}{ Intervalo de confiança (95\%)* } \\
\cline { 4 - 5 } & & & Limite inferior & Limite superior \\
\hline MH & 0,12 & 0,010 & 0,03 & 0,22 \\
MUE & 0,11 & 0,005 & 0,03 & 0,19 \\
\hline
\end{tabular}

* com correção de Tukey 


\subsection{ESTUDO DA ASSOCIAÇÃO ENTRE A MEDIDA ÓSSEA VERTICAL E AS MEDIDAS DE ATIVIDADE MUSCULAR MASSETÉRICA}

Os gráficos de dispersão podem ser vistos no Anexo 7 e os perfis individuais podem ser vistos no Anexo 8.

O modelo utilizado para estudar as associações pode ser escrito da seguinte forma:

$$
E[Y]=b 0+b 1 . X+b 2 . T P I+b 3 . X . T P I
$$

onde:

Y: média dos 5 sítios de determinado instante e lado;

$\mathrm{E}[\mathrm{Y}]$ : valor esperado de $\mathrm{Y}$

X: variável de interesse;

TPI: Tipo de prótese inferior (cujos valores são: 0 para Overdenture e 1 para Protocolo);

Exemplo: para o instante T1, o lado direito e a variável CVIM como a variável de interesse, temos:

$\mathrm{E}[$ Média dos 5 sítios LD T1] = b0+b1.CVIM LD T1 +b2. CVIM LD T1 . TPI

Os níveis descritivos dos testes para cada modelo podem ser vistos na Tabela para os modelos estratificados por instante e lado, e na Tabela quando consideramos as associações entre as diferenças T2 e T1. 
Tabela 26 - Valores de p dos modelos de regressão estratificados por instante e lado entre a média das medidas verticais e cada uma das variáveis eletromiográficas.

\begin{tabular}{|c|c|c|c|c|c|}
\hline \multirow{3}{*}{\multicolumn{2}{|c|}{$\begin{array}{l}\text { Variável utilizada para construir o } \\
\text { modelo de regressão }\end{array}$}} & \multicolumn{4}{|c|}{ Estratos considerados } \\
\hline & & \multicolumn{2}{|c|}{$\mathrm{T} 1$} & \multicolumn{2}{|c|}{$\mathrm{T} 2$} \\
\hline & & LD & $\mathrm{LE}$ & LD & LE \\
\hline \multirow{4}{*}{ Amplitude } & CVIM & 0,440 & $\mathbf{0 , 0 3 7}$ & 0,853 & 0,288 \\
\hline & MH & 0,287 & 0,141 & 0,866 & 0,895 \\
\hline & MUD & 0,263 & 0,191 & 0,822 & 0,518 \\
\hline & MUE & 0,144 & 0,242 & 0,858 & 0,789 \\
\hline \multirow{3}{*}{ Ato } & MH & 0,303 & 0,440 & 0,211 & 0,023 \\
\hline & MUD & 0,048 & 0,070 & 0,098 & 0,561 \\
\hline & MUE & 0,412 & 0,439 & 0,657 & 0,538 \\
\hline \multirow{3}{*}{ Ciclo } & MH & 0,389 & 0,255 & 0,432 & 0,259 \\
\hline & MUD & 0,153 & 0,102 & 0,034 & 0,447 \\
\hline & MUE & 0,451 & 0,328 & 0,735 & 0,527 \\
\hline
\end{tabular}

Tabela 27 - Modelos de regressão estratificados por lado entre as diferenças T2-T1 das medidas verticais e as diferenças T2-T1 de cada variável eletromiográfica.

\begin{tabular}{cccc}
\hline \multirow{2}{*}{$\begin{array}{c}\text { Variável utilizada para construir o modelo de } \\
\text { regressão das diferenças T2-T1 }\end{array}$} & \multicolumn{2}{c}{ Estratos } \\
\cline { 2 - 3 } & CVIM & 0,119 & 0,133 \\
Amplitude & MH & 0,262 & $\mathbf{0 , 0 3 4}$ \\
& MUD & 0,143 & 0,098 \\
& MUE & 0,132 & 0,068 \\
\hline \multirow{3}{*}{ Ato } & MH & 0,383 & 0,135 \\
& MUD & 0,380 & 0,134 \\
Ciclo & MUE & 0,259 & $\mathbf{0 , 0 0 2}$ \\
\hline \multirow{3}{*}{} & MH & 0,419 & 0,131 \\
& MUD & 0,328 & 0,060 \\
& MUE & 0,249 & $\mathbf{0 , 0 0 7}$ \\
\hline
\end{tabular}


$\mathrm{Na}$ tabela 28, encontram-se os modelos finais obtidos pelo método backward (Neter at al., 1996) dos modelos que foram estatisticamente significantes.

Tabela 28 - Modelos de regressão finais.

\begin{tabular}{llccc}
\hline $\begin{array}{l}\text { Variável resposta vs } \\
\text { Variável de interesse }\end{array}$ & \multicolumn{1}{c}{ Coeficientes } & Estimativa & Erro-padrão & $\mathrm{p}$ \\
\hline \multirow{2}{*}{ Média LE T1 vs CVIM } & Intercepto & 22,3 & 3,0 & 0,000 \\
LE T1 & Tipo de prótese inferior & $-0,15$ & 0,08 & 0,087 \\
& Interação entre o tipo de & $-8,2$ & 5,1 & 0,132 \\
& prótese e CVIM LE T1 & 0,26 & 0,10 & 0,022 \\
\hline Média LE T2 vs Ato & Intercepto & 30,1 & 3,3 & 0,000 \\
MH LE T2 & Ato MH LE T2 & $-15,7$ & 5,3 & 0,009 \\
\hline Média LD T1 vs Ato & Intercepto & 8,9 & 5,1 & 0,101 \\
MUD LD T1 & Ato MUD LD T1 & 21,6 & 9,5 & 0,037 \\
\hline Dif. T2-T1 LE vs Dif. & Intercepto & 2,2 & 0,6 & 0,004 \\
T2-T1 MH LE & Tipo de prótese inferior & $-2,4$ & 0,9 & 0,015 \\
Amplitude & Intercepto & $-0,5$ & 0,5 & 0,338 \\
\hline Dif. T2-T1 LE vs Dif. & Dif. T2-T1 MUE LE Ato & 9,5 & 2,1 & 0,000 \\
T2-T1 MUE LE Ato & Intercepto & 1,5 & 0,6 & 0,034 \\
\hline \multirow{2}{*}{ Dif. T2-T1 LE vs Dif. } & Dif. T2-T1 MUE LE Ciclo & 3,5 & 1,5 & 0,033 \\
T2-T1 MUE LE Ciclo & Tipo de prótese inferior & $-2,1$ & 0,8 & 0,018 \\
\hline
\end{tabular}

Interpretação dos modelos acima:

- Estudo da associação entre a média das medidas ósseas verticais do lado esquerdo no instante T1 (Média LE T1) com a CVIM do lado esquerdo no instante T1(CVIM LE T1): como o fator de interação entre a CVIM e o tipo de prótese inferior foi estatisticamente significante $(\mathrm{p}=0,022)$, sabemos que a relação entre a média das medidas ósseas verticais e a CVIM do lado esquerdo no instante T1 são diferentes para os dois tipos de prótese. Para o tipo de prótese inferior overdenture sabemos que é esperado uma diminuição de $0,15 \mathrm{~mm}$ da média da medida óssea vertical quando ocorre aumento de 1 unidade da CVIM do lado esquerdo no instante T1. Para o tipo de prótese Protocolo, é esperado um aumento de $0,11 \mathrm{~mm}$ da média da medida óssea vertical quando ocorre aumento de 1 unidade da CVIM do lado esquerdo no instante $\mathrm{T} 1$; 
- Estudo da associação entre a média das medidas ósseas verticais do lado esquerdo no instante T2 (Média LE T2) com o ato da mastigação habitual do lado esquerdo no instante T2 (Ato MH LE T2): é esperada uma diminuição de $1,57 \mathrm{~mm}$ da média da medida óssea vertical com o aumento do ato em $0,1 \mathrm{~s}$. Observe que neste caso, não foi constatada diferença entre os tipos de prótese inferior;

- Estudo da associação entre média das medidas ósseas verticais do lado direito no instante T1 (Média LD T1) com o ato da mastigação unilateral direita do lado direito no instante T1 (Ato MUD LD T1): é esperado um aumento de 2,16mm da média da medida óssea vertical com o aumento do ato da mordida unilateral direita no instante $\mathrm{T} 1 \mathrm{em} 0,1 \mathrm{~s}$;

- Estudo da associação entre a diferença da média das medidas ósseas verticais no instante T2 do lado esquerdo e a média das medidas ósseas verticais no instante T1 do lado esquerdo (Dif. T2-T1 LE) com a diferença T2-T1 da amplitude da mastigação habitual do lado esquerdo (Dif. T2-T1 MH LE Amplitude): não houve associação estatisticamente significante;

- Estudo da associação entre a diferença da média das medidas ósseas verticais no instante T2 do lado esquerdo e a média das medidas ósseas verticais no instante T1 do lado esquerdo (Dif. T2-T1 LE) com a diferença T2-T1 do ato da mastigação unilateral esquerda do lado esquerdo (Dif. T2-T1 MUE LE Ato): se o ato aumentar em $0,1 \mathrm{~s}$ do instante $\mathrm{T} 1$ para o instante $\mathrm{T} 2$, é esperado um aumento de 0,95mm da diferença T2-T1 entre as médias das medidas ósseas verticais;

- Estudo da associação entre a diferença da média das medidas ósseas verticais no instante T2 do lado esquerdo e a média das medidas ósseas verticais no instante T1 do lado esquerdo (Dif. T2-T1 LE) com a diferença T2-T1 do ciclo da mastigação unilateral esquerda do lado esquerdo (Dif. T2-T1 MUE LE Ciclo): é esperado um aumento de 0,35mm da diferença T2-T1 entre as médias das medidas ósseas verticais com o aumento de 0,1s da diferença T2-T1 do ciclo da MUE do lado esquerdo. 



\section{DISCUSSÃO}

Por anos, os autores têm escrito sobre a reabsorção contínua e irreversível do rebordo alveolar em pacientes edêntulos. Esta reabsorção pode dificultar ou mesmo inviabilizar a reabilitação protética desses pacientes (Tallgren 1972, Atwood 1971 e 1979, Jahangiri 1998 e Carlsson 2004). Contudo, após o advento dos implantes, através de controles radiográficos contínuos, aposição óssea na mandíbula, posterior ao último implante, têm sido reportada na literatura (Reddy 1992, Robert 2005).

Essa aposição óssea não tem sido relacionada a nenhuma causa específica, mas tem sido parcialmente explicada pelo aumento da atividade muscular que age dinamicamente na remodelação óssea (Lanyon 1984). Estudos experimentais têm demonstrado que a diminuição da função muscular do masseter resulta em deformidades ósseas mandibulares tanto no sentido transversal quanto no sentido sagital, o que pode inibir a aposição óssea nesta região (Bresin 2001). Dessa forma, este estudo foi realizado com a finalidade de avaliar se após um ano, ocorria alteração óssea vertical posterior ao último implante, em pacientes reabilitados com 2 tipos de próteses implantossuportadas, overdenture e protocolo Brånemark, e se esta possível alteração se correlacionava com a atividade muscular do masseter.

Nossos resultados da análise de variância (ANOVA) mostraram que a associação entre a medida óssea vertical e os fatores: tipo de prótese inferior e instante, lado e sítio foram estatisticamente significantes $(\mathrm{p}<0,001)$ (Tabela 5$)$.

As comparações post hoc considerando os fatores: instante (T2-T1) e o tipo de prótese (overdenture e protocolo) permitiram afirmar que houve um aumento médio das medidas ósseas verticais (ganho ósseo) de 1,98mm (p<0,001) com intervalo de confiança de 1,36 a 2,60mm para a prótese overdenture (Tabela 6).

Em relação aos sítios, as comparações post hoc permitiram afirmar que ocorreu uma diminuição estatisticamente significante das médias ósseas verticais, conforme nos afastamos dos sítios centrais, nos dois tipos de próteses.

Em relação ao lado, concluímos que o lado direito era maior que o esquerdo em $0,9 \mathrm{~mm}$ com IC de 0,6 a $1,2 \mathrm{~mm}$ (Tabela 8 ).

A alteração dimensional óssea positiva, estatisticamente significante para a prótese overdenture implantossuportada desse estudo confirma os achados de Meijer et al (1999), Melo (2005) e Chung et al (2007). Meijer et al (1999) não reportaram nenhuma perda óssea 
após 5 anos de reabilitação com prótese overdenture, Melo (2005) reportou aposição óssea de 1,03mm para a prótese overdenture e Chung et al (2007) reportaram que a perda óssea para a prótese protocolo era quase duas vezes maior que para a prótese overdenture implantossuportada. Em contraposição, o trabalho de Jacobs et al (1992) demonstrou uma média de reabsorção anual de $-0,14 \mathrm{~mm}$ para o grupo overdenture e $-0,04 \mathrm{~mm}$ para a prótese protocolo, mas sua amostra consistia de $14 \%$ de indivíduos dentados e $30 \%$ de indivíduos reabilitados com próteses tipo protocolo no arco superior. Reabsorção óssea na ordem de 0,05mm para a prótese overdenture e aposição óssea de $+0,04 \mathrm{~mm}$ para a prótese protocolo foram reportados por Wright et al (2001). Estes achados podem ser suportados pela hipótese de que forças dinâmicas altas, acima do limiar do processo de remodelação, causam reabsorção óssea (Lavelle 1984).

É interessante observar que os resultados deste estudo apontaram uma aposição óssea do lado direito, dado este compatível com outros relatos da literatura (Davis et al 1999, Reddy et al 2002, Melo 2005, Lopes 2006) que, entretanto não apresentaram explicação para o fato.

Não há consenso na literatura quanto às razões desencadeantes desta aposição óssea. Imagens radiográficas e histológicas semelhantes às exostoses ou tórus, com características de osso lamelar foram observadas e desordens endógenas e genéticas foram citadas (Burkes Júnior et al 1985, Nakai et al 2000). O aumento da atividade mastigatória é citado como provável estímulo à deposição óssea, por aumentar o estímulo sobre a massa óssea edêntula (Haraldson et al 1979, Oikarinen e Siirila 1992, Nakai et al 2000, Ferrario et al 2004). Outra hipótese citada para esta causa é que forças compressivas transmitidas através das roscas dos implantes ao osso desenvolvem cargas positivas, as quais induzem mudanças nas células ósseas ativando odontoblastos (Valen 2000). Afora a informação de que todos os sujeitos que participaram desse estudo eram destros, não existe comprovação científica de que indivíduos destros ou sinistrômanos apresentam diferença de comportamento fisiológico do sistema estomatognático entre os lados direito e esquerdo.

A eletromiografia de superfície (EMG) tem seu uso aplicado à Odontologia como um eficiente método complementar de diagnóstico, avaliação de tratamento e pesquisa. Este exame permite quantificar a atividade muscular como um todo, resultando em um melhor entendimento da fisiologia do complexo Sistema Estomatognático.

A técnica eletromiográfica é utilizada para avaliar diversos parâmetros musculares presentes na mastigação, sendo frequiente o estudo da amplitude da contração voluntária 
isométrica máxima, a duração do período de silêncio, a duração do ato e do ciclo mastigatório.

O parâmetro de duração do Ato Mastigatório (DA) reflete o tempo entre o começo da atividade mastigatória até o fim desta mesma atividade. O parâmetro de duração do Ciclo Mastigatório (DC) reflete o tempo em que os músculos elevadores da mandíbula permanecem contraídos durante o processo de mastigação até o começo do ato mastigatório seguinte, incluindo o período de relaxamento. A contração voluntária isométrica máxima corresponde à média da capacidade de sustentação da força máxima de mastigação durante $5 \mathrm{~s}$ em $\mu \mathrm{V}$ (Ahlgren et al 1973, Nagasawa et al 1988, Felix 2005).

Após a instalação de prótese implantossuportadas, ocorre uma estabilização da fisiologia dos músculos mastigatórios (Haraldson e Ingervall 1979, Bakke et al 2002), dessa forma, optou-se por realizar o exame eletromiográfico dois meses após a instalação das próteses.

Para a avaliação eletromiográfica da atividade do músculo masseter foi utilizado a mastigação de cenoura e látex. A importância do uso do látex é que ele exige um esforço constante do sistema trigeminal e mantém as mesmas características durante $\mathrm{o}$ ato mastigatório. A cenoura apresenta alta resistência inicial e uma fragmentação abrupta, estimulando intensamente e em poucos milisegundos um enorme número de receptores que informam via raiz sensorial do trigêmio, o momento e a intensidade do contato dental.

Quando se solicita a mastigação unilateral se introduz um possível erro devido ao direcionamento da mastigação, que obviamente não é fisiológico. Entretanto, para a análise eletromiográfica, este efeito não pode ser desprezado, pois direciona a função muscular para o lado do estudo. Existe também a importância da realização da mastigação habitual, onde o paciente realiza a mastigação que ele faz naturalmente quando se alimenta, incluindo o lado preferencial.

Os resultados das ANOVAS do estudo da associação da medida da amplitude durante a CVIM, MH, MUD e MUE e os fatores (tipo de prótese, instante e lado) apresentados neste estudo (Tabela 13) não encontrou nenhum fator estatisticamente significante para a medida da amplitude durante a CVIM, apesar do boxplot mostrar uma tendência de aumento dos valores da amplitude para a CVIM na overdenture e uma diminuição dos valores para a prótese protocolo (Figura 16). Os valores encontrados para a medida da amplitude durante a CVIM, neste estudo, estão de acordo com os encontrados por Lopes (2006) que reportou valores 
médios de $83,4 \pm 75,39 \mu \mathrm{V}$ para o lado direito e de $50 \pm 29,4 \mu \mathrm{V}$ para o lado esquerdo, contudo valores menores e maiores foram relatados na literatura: $39 \mu \mathrm{V}$ (Haraldson et al), $160 \mu \mathrm{V}$ para overdenture e $190 \mu \mathrm{V}$ para protocolo (Jacobs et al 1995), $112 \mu \mathrm{V}$ para overdenture (Ferrario et al 2004) e $\pm 246 \mu \mathrm{V}$ para indivíduos dentados (Van der Bilt 2008). Valores menores para a amplitude da CVIM para a prótese protocolo também foram relatados por Félix (2005a) que justificou esta diminuição devido à faixa etária de sua amostra (mediana de 64 anos). Isto pode ser explicado parcialmente, pelo fato de que a precisão do exame se dá pela condução do operador, direcionando o paciente a realizar o apertamento com força, visto que há receio de fraturar a prótese ao desenvolver força intensa e pela amostra, que no caso deste estudo, foi realizado em pacientes com arco antagonista reabilitados por prótese total.

Para as medidas da amplitude durante a MH (p<0,031) e MUE ( $\mathrm{p}<0,001)$ ocorreu uma diferença estatisticamente significante apenas para o fator instante (T2-T1). A duração da medida da amplitude durante a $\mathrm{MH}$ aumentou em $9 \mu \mathrm{V}$ e durante a MUE aumentou em $19 \mu \mathrm{V}$ após um ano, para os dois tipos de próteses. Para a medida da amplitude durante a MUD $(\mathrm{p}<0,006)$ ocorreu um aumento estatisticamente significante para prótese overdenture em média de $19 \mu \mathrm{V}$ com intervalo de confiança de 8 a $30 \mu \mathrm{V}$ após um ano (Tabelas 13, 14 e 15 e Figuras 16 e 17). Não foram encontrados dados na literatura que pudessem ser comparados, mas podemos explicar este aumento como uma melhora do desempenho muscular após um ano de uso das próteses.

Os resultados das ANOVAS e post hoc neste estudo, para a duração do ato mastigatório durante a MH, MUD e MUE relataram um aumento estatisticamente significante apenas para o fator instante (T2-T1) com $\mathrm{p}<0,001, \mathrm{p}<0,033, \mathrm{p}<0,001$, respectivamente (Tabelas 19 e 20 e Figura 18). Isto significa que houve um aumento médio de 0,13s, 0,06s e 0,12s para a duração do ato mastigatório durante a MH, MUD e MUE após um ano, para os dois tipos de próteses. O aumento detectado na duração do ato mastigatório pode ser explicado como conseqüência da melhora funcional do sistema estomatognático frente à reabilitação oral promovida pelas próteses implantossuportadas. Os valores médios da duração do ato mastigatório para a prótese protocolo estão de acordo com os dados relatados por Lopes (2006) que reportou valores médios para a duração do ato mastigatório durante a MH de 0,52s, durante a MUD de 0,59s e de 0,56s durante a MUE (Tabelas 16, 17 e 18). Os valores encontrados neste estudo superaram a maioria dos valores encontrados para indivíduos com fissura labiopalatina com dentição normal variando entre 0,30s (Barco 2002) 


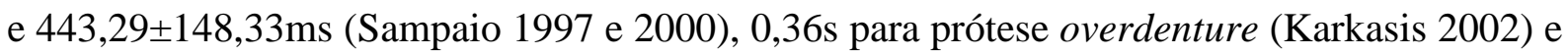
$\pm 0,43$ s (Pantaleón 2004) durante a MUD para prótese protocolo

Os resultados da duração do ciclo mastigatório neste estudo (Tabelas 24 e 25) relataram haver um aumento médio da duração do ciclo durante a MH e MUE de 0,12s e 0,11s respectivamente, após um ano (T2-T1), para os dois tipos de próteses. Este aumento era estatisticamente significante sendo $\mathrm{p}<0,010$ para $\mathrm{MH}$ e $\mathrm{p}<0,005$ para a MUE. Os valores médios apresentados nas Tabelas 21, 22 e 23 estão dentro da normalidade quando comparados aos valores encontrados para indivíduos com fissuras (Sampaio 1997, Barco 2002 e Lopes 2006).

Observamos que ocorreu um aumento tanto do ato quanto do ciclo mastigatório e isto nos leva a crer que ocorre uma maior duração do tempo para a mastigação de alimentos em indivíduos reabilitados com próteses implantossuportadas quando comparados com indivíduos dentados (Karkasis et al 2002, Ferrario et al 2004). Contudo, valores menores para a duração do ato e do ciclo mastigatório para pacientes reabilitados com próteses implantossuportadas quando comparados com indivíduos reabilitados com dentaduras convencionais têm sido reportados (Jacobs e van Steenberghe 1993, Meijer et al 1999, Pantaleón 2004). Valores maiores para o ciclo mastigatório também foram constatado por Feine et al (1994) e Pera et al (1998). Feine et al (1994) reportaram o valor de 0,70s para duração do ciclo mastigatório durante a mastigação de cenoura em indivíduos reabilitados com overdenture e Pera et al (1998) relataram encontrar a duração do ciclo aumentada, porém com padrão próximo ao de indivíduos dentados, o que justificaria a melhor eficiência mastigatória das próteses implantossuportadas quando comparadas com próteses totais. Entretanto alguns autores reportam não ocorrer mudança na duração do ciclo para pacientes reabilitados com próteses implantossuportadas (Bakke et al 2002 e van der Bilt 2006). Isto pode ser explicado pela grande variabilidade inter e intraindivíduos dos parâmetros eletromiográficos (amplitude, duração do ato e do ciclo mastigatório).

Foi possível observar uma tendência ao comportamento de aumento da atividade eletromiográfica para os músculos masseteres para os dois tipos de próteses implantossuportadas, em todos os aspectos analisados, o que confirma uma melhor atividade do músculo.

A investigação do impacto da reabilitação oral implantossuportada sobre a atividade muscular tem sido realizada por alguns autores, porém com metodologia distinta em relação ao presente estudo. A literatura consultada demonstrou que tais indivíduos apresentam-se 
satisfeitos com sua capacidade mastigatória (Haraldson et al 1979, Geertman et al 1999), tem eficiência mastigatória semelhante àqueles com dentes naturais (Haraldson e Carlsson 1979, Pera et al 1998) ou apresentam melhora da função muscular (Fontjn-Tekmp et al 2000), bem como um maior número de golpes mastigatórios por minuto e uma melhor trituração de alimentos comparativamente aos usuários de prótese total (van Kampen et al 2004).

Para estudar a relação entre as medidas ósseas verticais e as medidas da atividade muscular massetérica foram construídos modelos de regressão linear, estratificados por instante (T1 e T2) e lado e cada uma das variáveis eletromiográficas, como também estratificados por lado, pela diferença (T2-T1) das medidas ósseas e pela diferença (T2-T1) de cada uma das variáveis eletromiográficas (Tabelas 26 e 27).

Apesar de termos encontrado associações estatisticamente significantes, os resultados não parecem ser consistentes, pois foram ajustados 60 modelos de regressão e só foram encontradas associações estatisticamente significantes com as variáveis de interesse em 5 destes modelos (Tabela 28). Portanto, preferimos adotar uma postura conservadora diante dos resultados e dizer que os mesmos são inconclusivos.

Em relação a possibilidades terapêuticas e preventivas, podemos afirmar que ocorreu aposição óssea em pacientes reabilitados com próteses overdentures implantossuportadas, sendo esta considerada uma boa alternativa de tratamento em pacientes com pouca altura óssea (Feine et al 1994, Stellisngsma et al 2005 e van der Bilt 2006). Para a prótese tipo protocolo, apesar da alteração dimensional não ser estatisticamente significante, houve um equilíbrio entre os fatores de reabsorção e remodelação, nos levando a afirmar que a reabilitação oral por meio de próteses implantossuportadas pode prevenir a reabsorção contínua do rebordo mandibular residual.

Frente aos resultados encontrados, não podemos afirmar que a aposição óssea que ocorreu seja devido ao aumento de qualquer variável eletromiográfica, entretanto dados importantes que colaboram para o conhecimento da atividade muscular do masseter de indivíduos com fissura labiopalatina e sobre o comportamento ósseo mandibular em pacientes reabilitados com próteses implantossuportadas foram aqui reportados. 



\section{CONCLUSÃO}

- Ocorrem alterações dimensionais ósseas, na região posterior da mandíbula, após um ano, para o tipo de prótese inferior overdenture. No lado direito a aposição óssea foi maior.

A atividade muscular constatada pela eletromiografia, aumentou após o uso das próteses protocolo e overdenture implantossuportadas.

- Não houve correlação entre a alteração dimensional óssea e a atividade muscular, sendo atribuído ao acaso as poucas correlações encontradas. 

REFERÊTNCIAS 



\section{REFERÊNCIAS}

Adell R, Lekholm U, Rockler B, Brånemark PI. A 15-year study of osseointegrated implants in the treatment of the edentulous jaw. Int J Oral Surg 1981; 10(6):387-416.

Alhgren JCA, Ingervall BF, Thilander BL. Muscle activy in normal and post normal occlusion. Amer. J Orthodont, St Louis 1973; 64(5):445-56.

Alsaadi G, Quirynen M, Komárek A, Steenberghe D. Impact of local and systemic factors on the incidence of late oral implant loss. Clin Oral Implants Res 2008; (9):670-76.

Ávila MGA. Análise da imagem radiográfica em diferentes aparelhos panorâmicos [dissertação]. Bauru: Faculdade de Odontologia de Bauru, Universidade de São Paulo;1996.

Attard NJ, Zarb GA. Long-term treatment outcomes in edentulous patients with implant-fixed prostheses: the Toronto study. Int J Prosthodont 2004; 17(4):417-24.

Atwood DA e Coy WA. Clinical, cephalometric and densitometric study of reduction of residual ridges. J Prosthet Dent 1971; 26(3):280-95.

Atwood DA. Bone loss of edentulous alveolar ridges. J Periodontol 1979; 50(sp No):11-21.

Awad MA, Lund JP, Shapiro SH, Locker D, Klemetti E, Chehade A et al. Oral health status and treatment satisfaction with mandibular implant overdentures and conventional dentures: a randomized clinical trial in a senior population. Int J Prosthodont 2003; 16(4):390-6.

Barco J. Avaliação eletromiográfica do músculo masseter de pacientes portadores de fissura ransforame unilatera lreparada. [dissertação]. Bauru: Hospital de Reabilitação das Anomalias Craniofaciais, Universidade de São Paulo; 2002

Bakke M, Holm B, Godfredsen K. Masticatory function and patient satisfaction with implantsupported mandibular overdentures: A prospective 5-year study. Int J Prosthodont 2002; 15(6):575-81.

Bergman B e Carlsson GE. Clinical long term study of complete denture wearers. J Prosthet Dent 1985; 53(1):56-61. 
Branemark PI, Breine U, Adell R, Hansson BO, Linsdtröm J e Olsson A: Intra-osseous anchorage of dental prostheses. 1. Experimental studies. Scand J Plast Reconstr Surg 1969; 3(2):81-100.

Branemark PI, Hansson BO, Adell R, Breine U, Lindstrom J, Hallen O, Ohman A.: Osseointegrated implants in the treatment of edentulous jaw: experience from 10 years period. Scand J Plast Recontr 1977; 11(16):1-132.

Burkes Júnior EJ, Marbry DL, Brooks RE. Subpontics osseous proliferation. J Prosthet Dent 1985; 53(2):780-5.

Bresin A. Effects of masticatory muscle function and bite-rising on mandibular morphology in growing rats. Swed Dent J Suppl 2001; 150:1-49.

Carlsson GE. Response of jawbone to pressure. Gerodont 2004; 21(2):65-70

Chilvarquer I. Imageologia da Osseointegração Moderna. In: Gomes LA. Implantes Osseointegrados: técnica e arte. São Paulo: Editora Santos; 2002.p.211-9.

Chung DM, Oh TJ, Lee J, Misch CE, Wang HL. Factors affecting late bone loss: a retrospective analysis. Int J Oral Maxillofac Implants 2007; Jan-Fev 22(1):117-26.

Chuenchompoonut V, Ida M, Honda E, Kurabayashi T e Sasaki T. Accuracy of panoramic radiography in assessing the dimensions of radiolucent jaw lesions with distinct or indistinct borders. Dentomaxillofac Radiol 2003; 32(2):80-6.

Costa C, Tavano O, Junqueira JLC, Frederiksen NL. Fundamentos do planejamento radiográfico para implantes odontológicos. Rev. ABrO 2004; 59(2):63-6.

Daniels WC. Subpontic osseous hyperplasia: A five-pacient report. J Prosthodont 1997; 6(2):137-143.

Dula K, Mini R, Van Der Stelt PF, Buser D. The radiographic assessment of implant patients:decision-making criteria. Int J Oral Maxillofac Implants 2001; 16(1):80-9. 
Duyck J, Ronold HJ, Naert I, Sloten JV, Elligsen JE. The influence of static and dynamic loading on marginal bone reactions around osseointegrated implants: an animal experimental study. Clin Oral Implants Res 2001; I(2):207-18.

Ekelund JA, Lindquist LW, Carlsson GE, Jemt T. Implant treatment in edentulous mandible:A prospective study on Branemark system implants over more 20 years. Int $J$ Prosthodont 2003 Nov-Dec; 16(6):602:8.

Feine JS, Maskawai K, Grandmont P, Donohue WB, Tanguay R e Lund JP. Within-subject comparisons of implant-supported mandibular prostheses: evaluation of masticatory function. J Dent Res 1994; 73(10):1646-56.

Felix GB. Efeito da reabilitação oral implanto-suportada sobre a deglutição, o estado nutricional e a qualidade de vida de indivíduos idosos. [tese]. Botucatu: Faculdade de Medicina de Botucatu, Universidade Estadual de São Paulo; 2005

Felix GB, Genaro KF, Trindade Júnior AS, Trindade IEK. Masticatory function in temporomandibular dysfunction patients: eletromyographic evaluation. Appl Oral Sci 2005; $13: 360-5$.

Ferrario VF, Tartaglia GM, Maglione M, Simion M, Sforza C. Neuromuscular coordination of masticatory muscles in subjects with two types of implant-supported prostheses. Clin Oral Implants Res 2004; 15(2):219-25.

Fontão FNGK. Medidas lineares em radiografias panorâmicas digitalizadas, fornecidas por dois programas de imagem para planejamento de implantodontia: a correlação e análise [tese]. Bauru: Faculdade de Odontologia de Bauru, Universidade de São Paulo; 2004.

Fontijn-Temkamp FA, Slagter AP, Van Der Bilt A, Van T Hof MA, Witter Dj, Kalk W et al. Bite and chewing in overdenture, full dentures and natural dentitions. J Dent Res 2000; 79(7):1519-24

Haraldson T, Carlsson GE, Ingervall B. Funcional state, bite force and postural muscle activity in pacients with osseointegrated oral implant bridges Acta Odontol Scand 1979; 37(4):195-206 . 
Haraldson T e Ingervall B. Muscle function during chewing and swallowing in patients with osseointegrated oral implant bridges. Acta Odont Scand 1979; 37(4):207-16.

Harris D, Buser D, Dula K. et al. E.A.O. Guidelines for the use of diagnostic imaging implant dentistry: A Consensus Workshop organized by the European Association for Osseointegration in Trinity College Dublin. Clin Oral Implants Res 2002; 13(5):566-70.

Jablonski D. The comparisons of usefulness prosthetic rehabilitation with removable and fixed suprastructures on endosseous implants. Ann Acad Med Stetin 2004; 50(1):123-9.

Jacobs R, Schotte A, Van Steenberghe D, Quirynen M, Naert I . Posterior jaw bone resorption in osseointegrated implant-supported prosthesis. Clin Oral Implants Res 1992; 3(2):63-70.

Jacobs R, Schotte A, Van Steenberghe D, Naert I: Masseter muscle fatigue before and after rehabilitation with implant-supported prosthesis J Prosthet Dent 1995; 73(3):284-9.

Jacobs R e Van Steenbreghe. Masseter muscle fatigue during sustained clenching in subjects with complete dentures, implant-supported prostheses and natural teeth. J Prost Dent 1993; 69(3):305-13

Jahangiri L, Devlin $\mathrm{H}$, Ting $\mathrm{K}$ e Nishimura I. Current perspectives in residual ridge remodeling and its clinical implications: A review. J Prosthet Dent 1998; 80(2):224-37.

Karkasis HC. EMG activy of the masseter muscle in implant supported overdenture wearers during chewing of hard and soft food. J Oral Rehabil 2002; 29(10):986-91.

Lammie GA. Reduction of the edentulous ridge. J Prosthet Dent 1960; 10(2):605-11.

Langland OE, Langlais RP. Princípios do diagnóstico por imagem em Odontologia. São Paulo: Editora Santos; 2002.463 p

Lanyon LC. Functional strain as a determinant for bone remodeling. Calcif. Tissue Int 1984; 36(suppl1):456-61.

Lindquist LW, Carlsson GE. Long-term effects on chewing with mandibular fixed prostheses on osseointegrated implants. Acta Odontol Scand 1985; 43(1):39-45. 
Lindquist LW, Carlsson GE e Jemt T. A prospective 15 years follow-up study of mandibular fixed prostheses supported by osseointegrated implants. Clinical results and marginal bone loss. Clin Oral Implants 1996; 7(4):329-36. Erratum in Clin Oral Impl 1997; 8(4):342.

Lopes MMW. Atividade muscular e alterações mandibulares em usuários de prótese fixa implanto suportada [dissertação].Bauru: Hospital de Reabilitação das Anomalias Craniofaciais, Universidade de São Paulo; 2006

Meijer HJA,Raghoebar GM, Van’t HMA, Geertman ME e Van Oort RP. Implant-retained mandibular overdentures; a 5 years follow-up study of clinical aspects and patient satisfaction. Clin Oral Implants Res 1999; 10(3):238-44.

Melo, LGN. Análise das alterações dimensionais na região posterior da mandíbula em pacientes edêntulos reabilitados com prótese implantossuportada do tipo protocolo ou overdenture [monografia]. Bauru: Hospital de Reabilitação das Anomalias Craniofaciais, Universidade de São Paulo; 2005.

Moyers RE. Temporomandibular muscle contraction patterns in Angle class II, division I malocclusions: na electromyographic analysis. Am J Orthod 1949; 35(11):837-57.

Murphy W M. Clinical and experimental bone changes after intraosseous implantation. $J$ Prosthet Dent 1995; 73(1):31-5.

Nagasawa F, Yoshida K, Minagi S, Tamura H, Tsuru H. A new objective parameter for eletromyographic evaluation of masticatory function of edentulous patients. J Oral Reahab 1988; 15(6):419-24.

Nakai H, Niimi A, Ueda M. Osseous proliferation of the mandible after placement of endosseous implants. Int J Oral Maxillofac Implants 2000; 15(3):419-24.

Neter J, Kurtener M.H, Wasserman N, NACHTSHEIM C.J. Applied Linear Statistical Models. New York . $4^{\text {th }}$. McGraw-Hill/Irwin; 1996

Oikarinen VJ e Siirila HS. Reparative bone growth in an extremely atrophied edentulous mandible stimulated by an osseointegrated implant-supported fixed prosthesis: a case report. Int J Oral Maxxilofac Implants 1992; 7(4):541-44. 
Pantaleón DS, Trindade Júnior AS. Evaluación comparative de la función masticatoria en individuos rehabilitados con prótesis suportadas por implantes óseo integrados. Rev Odontl Dom 2004; 10:27-35.

Reddy MS, Geurs NC, Wang IC, Liu PR, Hsu YT, Jeffcoat Rl et al. Mandibular growth following implant restoration: Does Wolff's law apply to residual ridge resorption? Int J Periodontics Restorative Dent 2002; 22(4):315-21.

Roberts RA. A 24-year retrospective study of bone growth after implant placement. J Oral Implantol 2005; 31(2):98-103.

Sampaio ACM. Atividade dos músculos masseteres e temporais: eletromiografia integrada e força de mordida pré e pós cirurgia ortognática [tese]. Bauru: Hospital de Reabilitação de Anomalias Craniofaciais, Universidade de São Paulo; 2000.

Sampaio ACM. Período de silêncio eletromiográfico, duração do ato e do ciclo mastigatório em indivíduos com fissura labiopalatina [dissertação]. Piracicaba: Universidade Estadual de Campinas; 1997.

Standford CM e Brand RA. Towards an understanding of implant occlusion and strain adaptative bone modeling and remodeling. J Prosthet Dent 1999; 81(5):553-59.

Stellingsma K, Bouma J, Stegenga B, Meijer HJA e Raghoebar GM. Satisfaction and psychosocial aspects of patients with an extremely resorbed mandible treated with implantretained overdentures. Clin Oral Implants Res 2003; I 4(2):166-172.

Tallgren A. An eletromyographyc study of response of certain facial and jaw muscles to loss of teeth and subsequent complete denture treatment. Odontol Tidskr 1961; 69:383-430.

Tallgren A. The continuing reduction of the residual alveolar ridges in complete denture wearers: a mixed-longitudinal study covering 25 years. J Prosthet Dent 1972; 27(2):120-32 .

Taylor TD. Osteogenesis of the mandible associated with implant reconstruction: a pacient report. Int J Oral Maxillofac Implants 1989; 4(3):227-31. 
Tawil D. Peri-implant bone loss caused by occlusal overload: repair of the peri-implant defect following correction of traumatic occlusion. A case report. J Oral Maxillofac Imp 2008; 23(1):153-57

van der Bilt A, van Kampen MC e Cune M. Masticatory function with mandibular implantsupported overdentures fitted with different attachment types. Eur J Oral Sci 2006; 114(3):191-96.

van der Bilt A, Tekamp A, Van der Glas H e Abink. Bite force and electromigraphy during maximum unilateral and bilateral clenching. Eur J Oral Sci 2008; 116(3):217-22.

van Kampen FMC, van der Bilt A, Cune MS, Fontijn-Tekamp FA e Bosman F. Masticatory function with implant-supported overdentures. J Dent Res 2004; 83(9):708-11.

Vasconcelos, MHF. Avaliação de um programa de traçado cefalométrico [tese]. Faculdade de Odontologia Bauru Universidade de São Paulo; 2000

Verbeck G e Molenberg G. Linear mixed models in pratice. New York: Springer Verlag 1997; 306p.

Wright PS, Glantz PO, Randow K, Watson RM. The effects of fixed and removable implantstabilized prostheses on posterior mandibular residual ridge resorption. Clin Oral Implants Res 2002; 13(2):169-74.

Wyatt,C. The effect of prosthodontic treatment on alveolar bone loss: A review of the literature. J Prost Dent 1998; 80(3):362-66. 


Anexo 1 - Ofício recebido do Comitê de Ética em Pesquisa em Seres Humanos aprovando o projeto de pesquisa.

Ofício $n^{\circ} 380 / 2006-S V A P E P E-C E P$

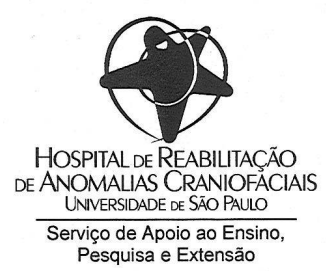

Bauru, 05 de dezembro de 2006.

Prezado(a) Senhor(a)

O projeto de pesquisa encaminhado a este Comitê de Ética em Pesquisa em Seres Humanos, denominado "Influência da eficiência mastigatória no comportamento ósseo peri-implantar de pacientes com fissuras reabilitados por próteses implanto-suportadas.", de autoria de TÂNIA MARA TASSIS MANDELLI desenvolvido sob sua orientação, foi enviado ao relator para avaliação.

$\mathrm{Na}$ reunião de 29/11/2006 o parecer do relator, aprovando o projeto, foi aceito pelo Comitê, considerando que não existem infrações éticas pendentes para início da pesquisa. Solicitamos a V.S a gentileza de comunicar o parecer à pesquisadora e anexar o presente ofício ao projeto, pois o mesmo será necessário para futura publicação do trabalho.

A pesquisadora fica responsável pela entrega no Serviço de Apoio ao Ensino, Pesquisa e Extensão dos relatórios semestrais, bem como comunicar ao CEP todas as alterações que possam ocorrer no projeto.

Informamos que após o recebimento do trabalho concluído, este Comitê enviará o parecer final para publicação.

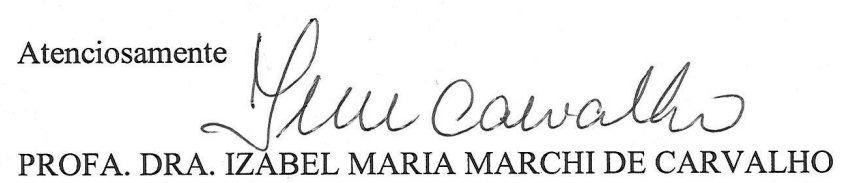

Vice-Coordenadora, em exercício, do Comitê de Ética em Pesquisa em Seres Humanos do HRAC-USP

Ilmo(a) $\operatorname{Sr}(a)$

Prof. Dr. Alceu Sergio Trindade Junior

Fisiologia - FOB/USP 
Anexo 2 - Ofício recebido aprovando alteração do nome do projeto de pesquisa.

Ofício $n^{\circ}$ 084/2007-SVAPEPE-CEP

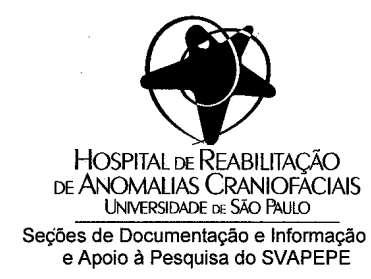

Bauru, 02 de maio de 2007.

Prezado(a) Senhor(a)

O projeto de pesquisa intitulado "Influência da eficiência mastigatória no comportamento ósseo peri-implantar de pacientes com fissuras reabilitados por próteses implanto-suportadas.", de autoria de V.S $S^{\text {a }}$, foi aprovado pelo CEP em 29 de novembro de 2006. Em reunião realizada em 25/04/2007 a solicitação de alteração do título para "Alteraçães dimensionais mandibulares e sua relação com atividade muscular em pacientes portadores de próteses implantossuportadas.", foi aprovada.

Informamos que após o recebimento do trabalho concluído, este Comitê enviará um parecer final que poderá ser utilizado para publicação.

Atenciosamente

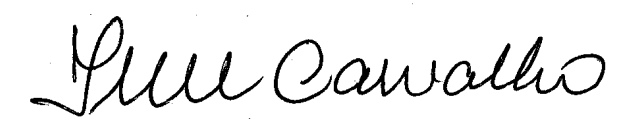

PROFA. DRA. IZABEL MARIA MARCHI DE CARVALHO

Vice-Coordenadora, em exercício, do Comitê de Ética em Pesquisa em Seres Humanos do HRAC-USP

$\operatorname{Ilmo}(\mathrm{a}) \operatorname{Sr}(\mathrm{a})$

TÂNIA MARA TASSIS MANDELLI

$\mathrm{A} / \mathrm{C}$

Prof. Dr. Alceu Sergio Trindade Junior

Fisiologia - FOB/USP 
Anexo 3 - Termo de Consentimento Livre e Esclarecido.

\section{Alterações dimensionais mandibulares e sua relação cm atividade muscular do masseter em portadores de próteses implantossuportadas}

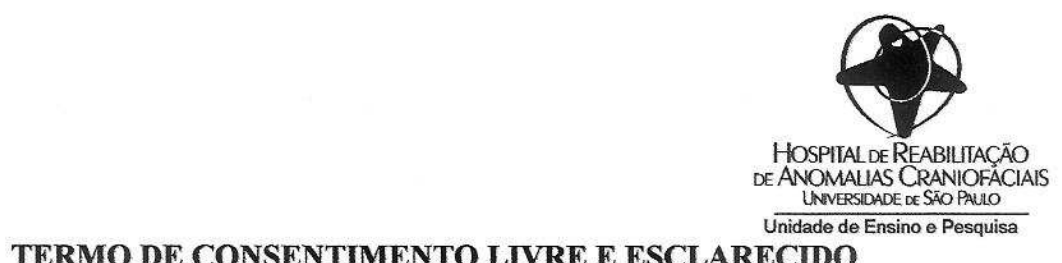

Pelo presente instrumento que atende às exigências legais, o $\mathrm{Sr}$. (a)

portador da cédula de identidade responsável pelo paciente

* _ após leitura minuciosa deste documento, devidamente explicado pelos profissionais em seus mínimos detalhes, ciente dos serviços e procedimentos aos quais será submetido, não restando quaisquer dúvidas a respeito do lido e explicado, firma seu CONSENTIMENTO LIVRE E ESCLARECIDO concordando em participar da pesquisa:Alterações dimensionis mandibulares e sua relação com atividade muscular em pacientes portadores de próteses implantossuportadas realizada por: Dra Tânia Mara de Tassis Mandelli $\mathrm{n}^{\circ}$ do Conselho: SP:54002, sob orientação do Dr Alceu Sérgio Trindade Júnior, $\mathrm{n}^{\circ}$ do Conselho:10843 SP que tem como objetivo:

avaliar o possível crescimento ósseo que ocorre em pacientes que usam prótese fixa com implantes no arco inferior.Para isto serão necessários o estudo das radiografias que o paciente já possui no hospital HRAC-USP e a realização dos seguintes testes: mastigação de cenoura, mastigação de látex e apertamento dos dentes para avaliar a atividade dos músculos da mastigação ; os testes serão realizados no setor de Fisiologia do HRAC-USP quando do retorno normal do paciente , são indolores e terão duração de uma hora. Não há benefício direto para o paciente mas , comprovado o crescimento ósseo, os resultados ajudarão a nortear a reabilitação de futuros pacientes.

"Caso o sujeito da pesquisa queira apresentar reclamações em relação a sua participação na pesquisa, poderá entrar em contato com o Comitê de Ética em Pesquisa em Seres Humanos, do HRAC-USP, pelo endereço Rua Silvio Marchione, 3-20 no Serviço de Apoio ao Ensino, Pesquisa e Extensão ou pelo telefone (14) 3235-8421".

Fica claro que o sujeito da pesquisa ou seu representante legal, pode a qualquer momento retirar seu CONSENTIMENTO LIVRE E ESCLARECIDO e deixar de participar desta pesquisa e ciente de que todas as informações prestadas tornar-se-ão confidenciais e guardadas por força de sigilo profissional (Art. 10 cap VI do Código de Ética do Conselho Federal de Odontologia).

Por estarem de acordo assinam o presente termo.

Bauru-SP, de de.

Assinatura do Sujeito da Pesquisa
ou responsável

\section{* A SER PREENCHIDO, SE O SUJEITO DA PESQUISA NÃO FOR O PACIENTE.}

Nome do Pesquisador Responsável: Dra. Tânia Mara de Tassis Mandelli

Endereço do Pesquisador Responsável (Rua, No):Rua Saint Martin ,20-26 Cidade: Bauru Estado:São Paulo CEP: 17.018.100

Telefone: (14)32358095 E-mail:tassismandelli@terra.com.br

Endereço Institucional (Rua, No): Rua Sívio Marchione, 3-20

Cidade: Bauru Estado: São Paulo CEP: 17.012.900 
Anexo 4 - Ficha de avaliação.

Nome do Paciente:

Rg do Hospital:

\section{Perguntas ao paciente:}

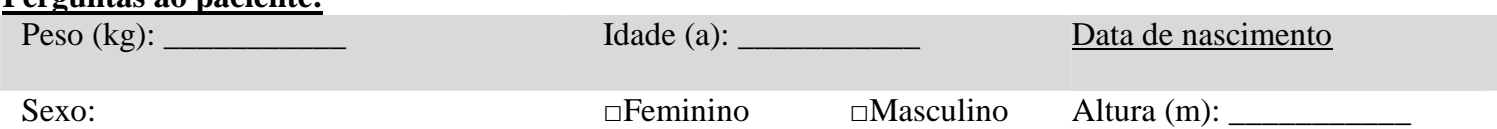

Tempo de utilizo da PT?

Tempo desdentado antes dos implantes?

Tem alguma cardiopatia, hipertensão?

Fez cirurgia Ortognática

$\square$ Sim $\square$ Não

Obs.:

Que mão você escreve?

$\square$ Sim $\square$ Não

$\square$ Direita $\square$ Esquerda

\section{$\underline{\text { Dados do Prontuário: }}$}

Arco Inferior:

Arco Superior:

Rd pré cirurgia

Tamanho do último implante do lado direito: $\mathrm{mm}$

Tamanho do último implante do lado esquerdo: $\mathrm{mm}$

Data de instalação dos implantes

Data da Instalação Prótese

Tipo de fissura

$\mathrm{N}^{\mathrm{o}}$ de implantes: arco sup

$$
\text { Arco inf }
$$

Data da Radiografia Inicial Rd 1

Data da Radiografia após instalação da prótese (controle de 1 ano) Rd 2 
Anexo 5 - Ficha de Análise Radiográfica.

Análise Radiográfica:

Medições radiográficas (mm) : Três medições $(1,23)$ e a média $(m)$.

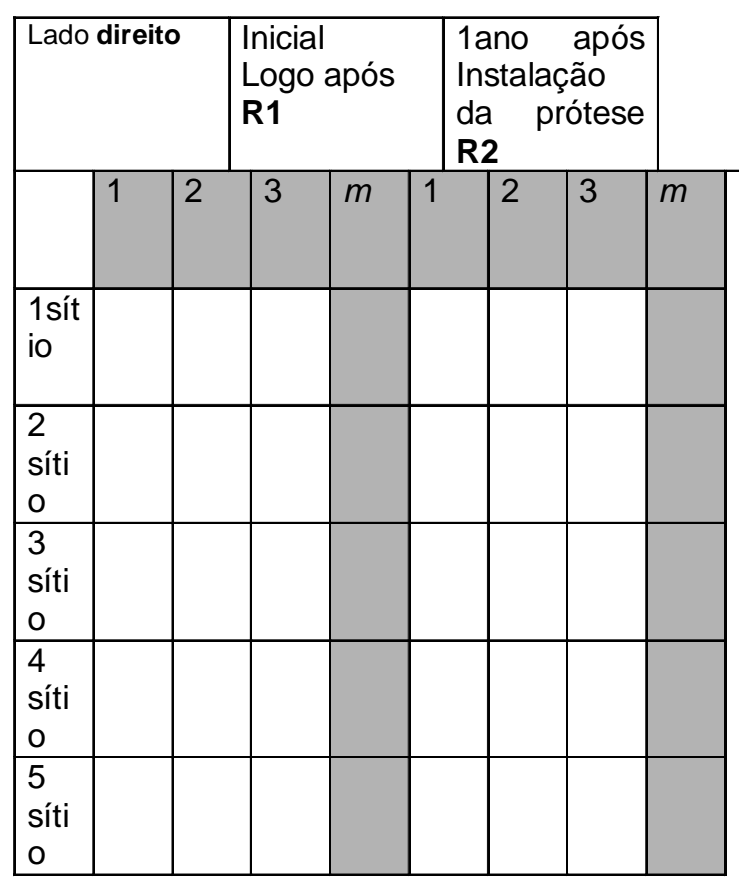

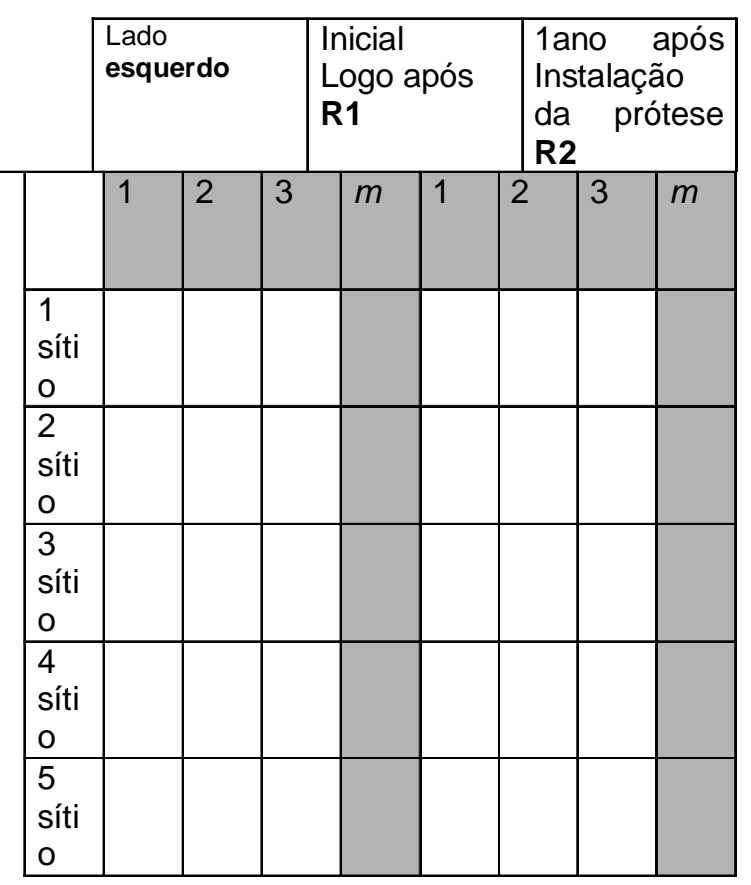

\begin{tabular}{|l|l|l|l|l|}
\hline \multicolumn{2}{|l|}{ Lado direito } & \multicolumn{3}{|l|}{$\begin{array}{l}\text { Mais de 1 ano } \\
\text { após } \\
\text { R3 }\end{array}$} \\
\hline & 1 & 2 & 3 & $m$ \\
\hline 1 sítio & & & & \\
\hline 2 sítio & & & & \\
\hline 3 sítio & & & & \\
\hline 4 sítio & & & & \\
\hline 5 sítio & & & & \\
\hline
\end{tabular}

\begin{tabular}{|l|l|l|l|l|}
\hline \multicolumn{2}{|l|}{$\begin{array}{l}\text { Lado } \\
\text { esquerdo }\end{array}$} & \multicolumn{2}{|l|}{$\begin{array}{l}\text { Mais de 1 ano } \\
\text { após } \\
\text { R3 }\end{array}$} \\
\hline & & & \multicolumn{2}{l|}{1} \\
\hline 1 sítio & & & & \\
\hline 2 sítio & & & & \\
\hline 3 sítio & & & & \\
\hline 4 sítio & & & & \\
\hline 5 sítio & & & & \\
\hline
\end{tabular}


Anexo 6 - Ficha de Análise Eletromiográfica.

\section{Mastigação Habitual com Cenoura}

Lado Direito:

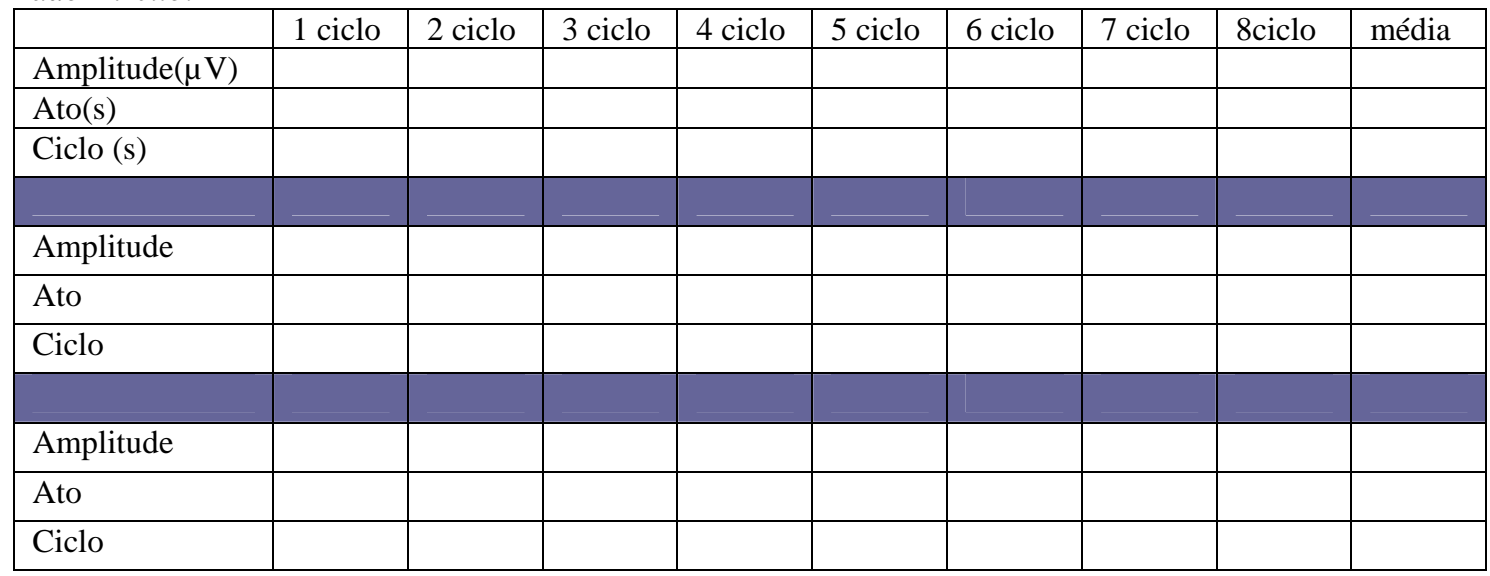

Lado Esquerdo:

\begin{tabular}{|l|l|l|l|l|l|l|l|l|l|}
\hline & 1 ciclo & 2 ciclo & 3 ciclo & 4 ciclo & 5 ciclo & 6 ciclo & 7 ciclo & 8 ciclo & média \\
\hline Amplitude $(\mu \mathrm{V})$ & & & & & & & & & \\
\hline Ato $(\mathrm{s})$ & & & & & & & & & \\
\hline Ciclo $(\mathrm{s})$ & & & & & & & & & \\
\hline & & & & & & & & & \\
\hline Amplitude $(\mu \mathrm{v})$ & & & & & & & & & \\
\hline Ato $(\mathrm{s})$ & & & & & & & & & \\
\hline Ciclo $(\mathrm{s})$ & & & & & & & & & \\
\hline & & & & & & & & & \\
\hline Amplitude $(\mu \mathrm{v})$ & & & & & & & & & \\
\hline Ato $(\mathrm{s})$ & & & & & & & & & \\
\hline Ciclo $(\mathrm{s})$ & & & & & & & & & \\
\hline
\end{tabular}

\section{Mastigação Unilateral direita com Látex}

\section{Lado Direito:}

\begin{tabular}{|c|c|c|c|c|c|c|c|c|c|}
\hline & 1 ciclo & 2 ciclo & 3 ciclo & 4 ciclo & 5 ciclo & 6 ciclo & 7 ciclo & 8 ciclo & média \\
\hline \multicolumn{10}{|l|}{ Amplitude $(\mu \mathrm{V})$} \\
\hline \multicolumn{10}{|l|}{ Ato(s) } \\
\hline \multicolumn{10}{|l|}{ Ciclo (s) } \\
\hline & & & & & & & & & \\
\hline \multicolumn{10}{|l|}{ Amplitude $(\mu v)$} \\
\hline \multicolumn{10}{|l|}{ Ato (s) } \\
\hline \multicolumn{10}{|l|}{ Ciclo (s) } \\
\hline & & & & & & & & & \\
\hline \multicolumn{10}{|l|}{ Amplitude $(\mu v)$} \\
\hline \multicolumn{10}{|l|}{ Ato(s) } \\
\hline \multicolumn{10}{|l|}{ Ciclo (s) } \\
\hline & & & & & & & & & \\
\hline
\end{tabular}


Lado Esquerdo:

\begin{tabular}{|c|c|c|c|c|c|c|c|c|c|}
\hline & 1 ciclo & 2 ciclo & 3 ciclo & 4 ciclo & 5 ciclo & 6 ciclo & 7 ciclo & 8 ciclo & media \\
\hline \multicolumn{10}{|c|}{ Amplitude $(\mu v)$} \\
\hline \multicolumn{10}{|c|}{ Ato $(\mathrm{s})$} \\
\hline \multicolumn{10}{|l|}{ Ciclo(s) } \\
\hline & & & & & & & & & \\
\hline \multicolumn{10}{|c|}{ Amplitude $(\mu v)$} \\
\hline \multicolumn{10}{|l|}{ Ato(s) } \\
\hline \multicolumn{10}{|l|}{ Ciclo(s) } \\
\hline & & & & & & & & & \\
\hline \multicolumn{10}{|c|}{ Amplitude $(\mu v)$} \\
\hline \multicolumn{10}{|l|}{ Ato (s) } \\
\hline Ciclo(S) & & & & & & & & & \\
\hline
\end{tabular}

\section{Mastigação Unilateral esquerda com Látex}

Lado Direito:

\begin{tabular}{|c|c|c|c|c|c|c|c|c|c|}
\hline & 1 ciclo & 2 ciclo & 3 ciclo & 4 ciclo & 5 ciclo & 6 ciclo & 7 ciclo & 8 ciclo & média \\
\hline \multicolumn{10}{|l|}{ Amplitude $(\mu \mathrm{V})$} \\
\hline \multicolumn{10}{|l|}{ Ato $(\mathrm{s})$} \\
\hline \multicolumn{10}{|l|}{ Ciclo (s) } \\
\hline & & & & & & & & & \\
\hline \multicolumn{10}{|l|}{ Amplitude $(\mu v)$} \\
\hline \multicolumn{10}{|l|}{ Ato (s) } \\
\hline \multicolumn{10}{|l|}{ Ciclo(s) } \\
\hline & & & & & & & & & \\
\hline \multicolumn{10}{|l|}{ Amplitude $(\mu \nu)$} \\
\hline \multicolumn{10}{|l|}{ Ato (s) } \\
\hline Ciclo(s) & & & & & & & & & \\
\hline
\end{tabular}

Lado Esquerdo:

\begin{tabular}{|l|l|l|l|l|l|l|l|l|l|l|}
\hline & 1 ciclo & 2 ciclo & 3 ciclo & 4 ciclo & 5 ciclo & 6 ciclo & 7 ciclo & 8 ciclo & média \\
\hline Amplitude $(\mu \mathrm{V})$ & & & & & & & & & \\
\hline Ato(s) & & & & & & & & & \\
\hline Ciclo $(\mathrm{s})$ & & & & & & & & & \\
\hline & & & & & & & & & & \\
\hline Amplitude $(\mu \mathrm{v})$ & & & & & & & & & \\
\hline Ato(s) & & & & & & & & & \\
\hline Ciclo(s) & & & & & & & & & \\
\hline & & & & & & & & & & \\
\hline Amplitude $(\mu \mathrm{v})$ & & & & & & & & & \\
\hline Ato(s) & & & & & & & & & \\
\hline Ciclo (s) & & & & & & & & & \\
\hline
\end{tabular}

Contração isométrica máxima

\begin{tabular}{|l|l|l|l|l|}
\hline & 1 ciclo & 2 ciclo & 3 ciclo & média \\
\hline Amplitude $(\mu \nu)$ & & & & \\
\hline Lado d & & & & \\
\hline Lado e & & & & \\
\hline
\end{tabular}




\begin{tabular}{|l|l|l|l|l|}
\hline & 1 ciclo & 2 ciclo & 3 ciclo & média \\
\hline Amplitude $(\mu v)$ & & & & \\
\hline Lado d & & & & \\
\hline Lado e & & & & \\
\hline
\end{tabular}

\begin{tabular}{|l|l|l|l|l|}
\hline & 1 ciclo & 2 ciclo & 3 ciclo & média \\
\hline Amplitude $(\mu v)$ & & & & \\
\hline Lado d & & & & \\
\hline Lado e & & & & \\
\hline
\end{tabular}


Anexo 7 - Gráficos de Dispersão.

Médias das medidas verticais vs CVIM

LD - Pré

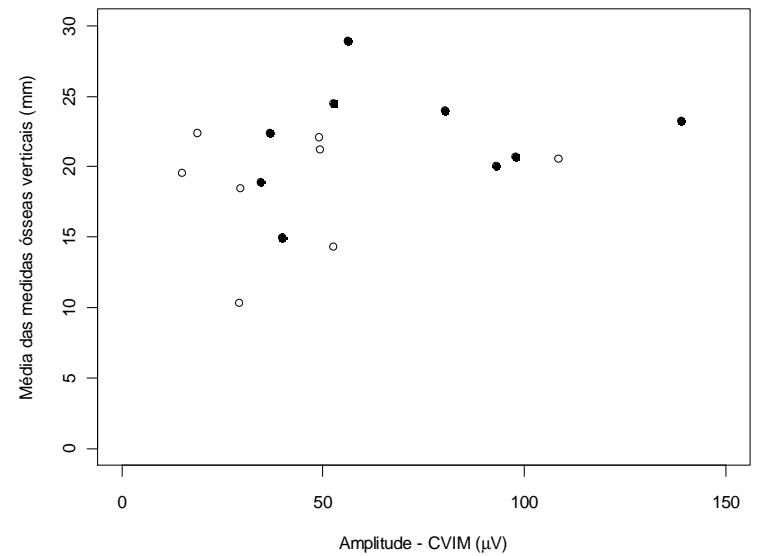

LD - Pós

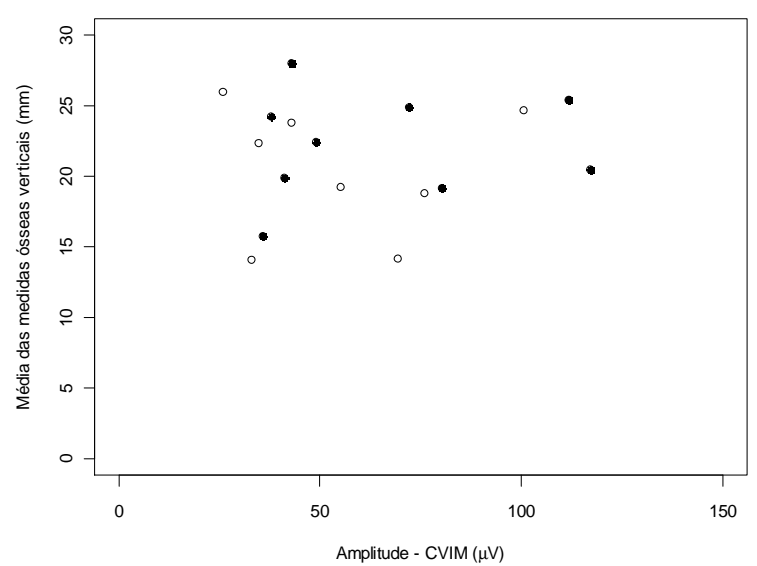

LD

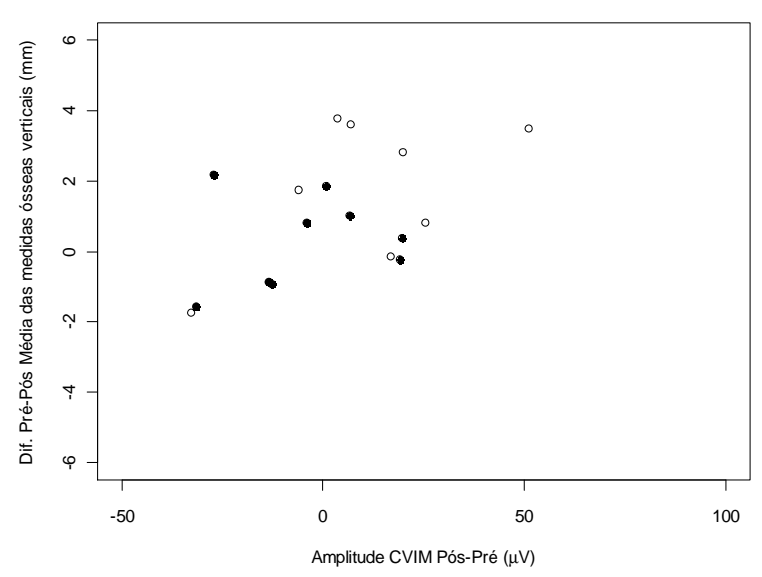

LE - Pré

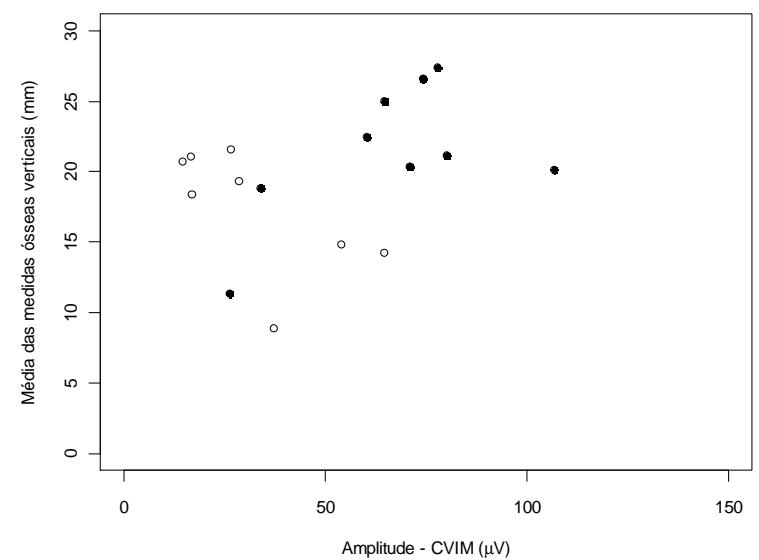

LE - Pós

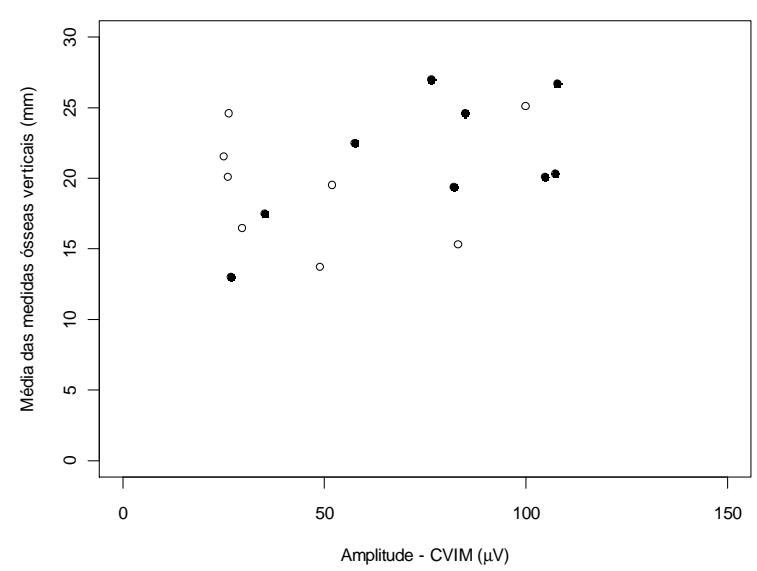

LE

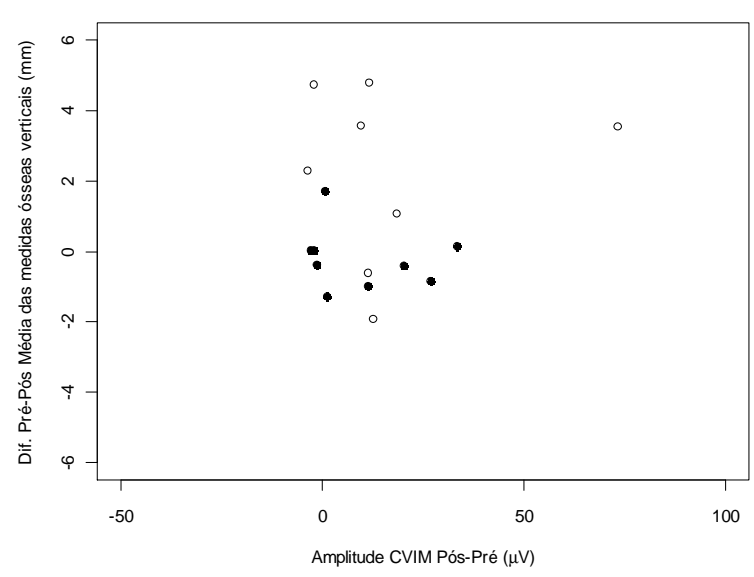


Médias das medidas verticais vs Amplitude MH
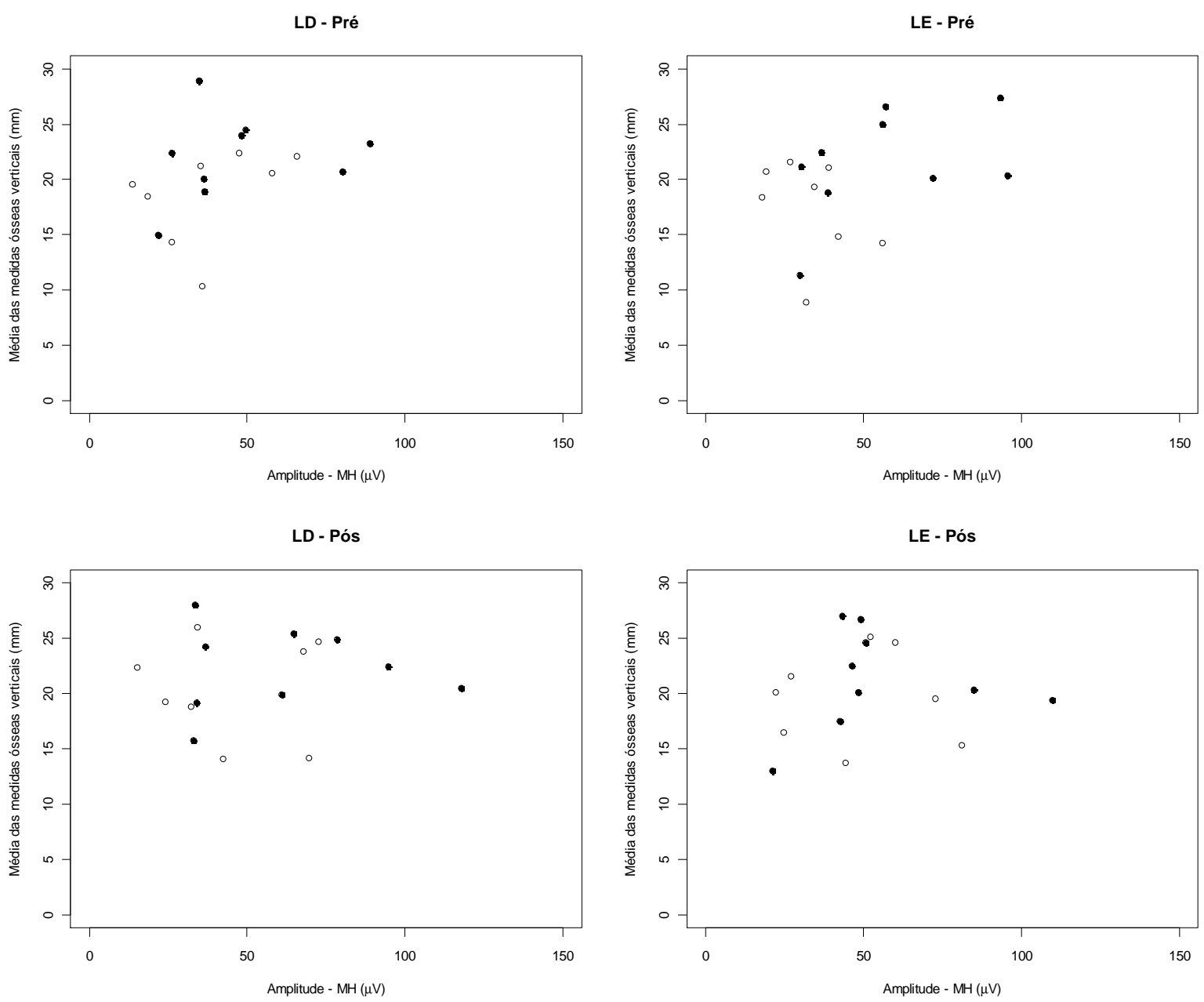

LD

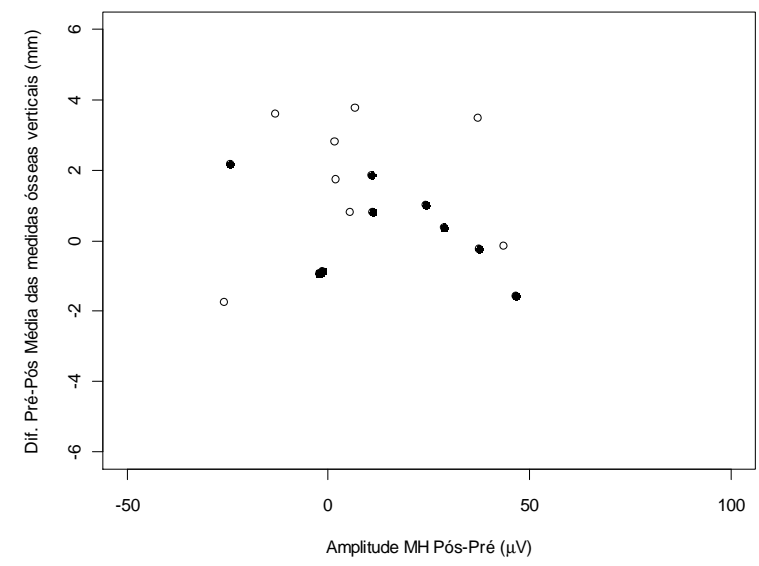

LE

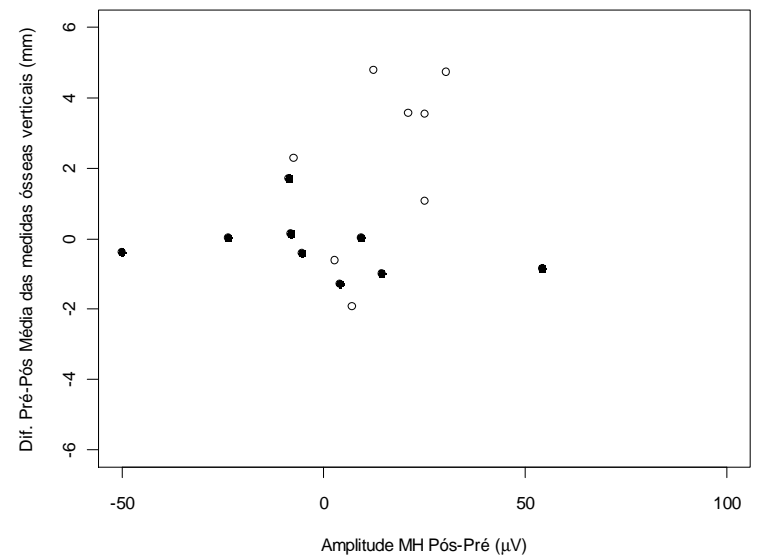


Médias das medidas verticais vs Amplitude MUD

LD - Pré

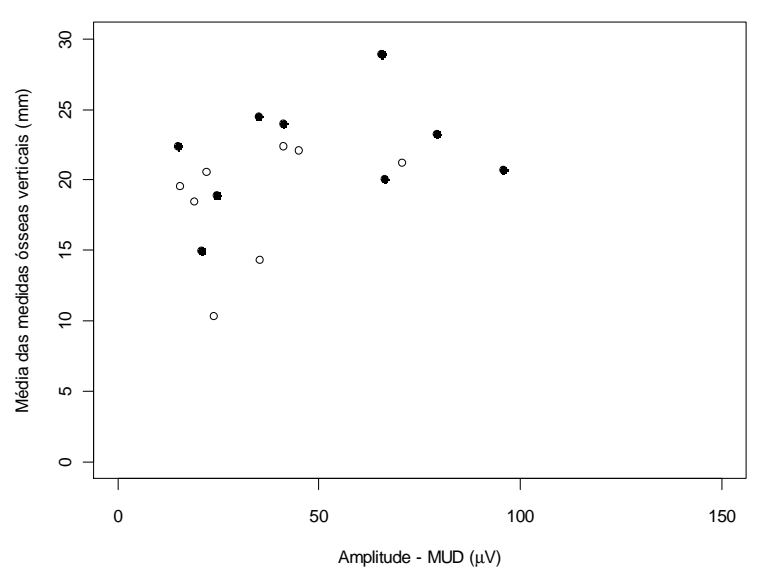

LD - Pós

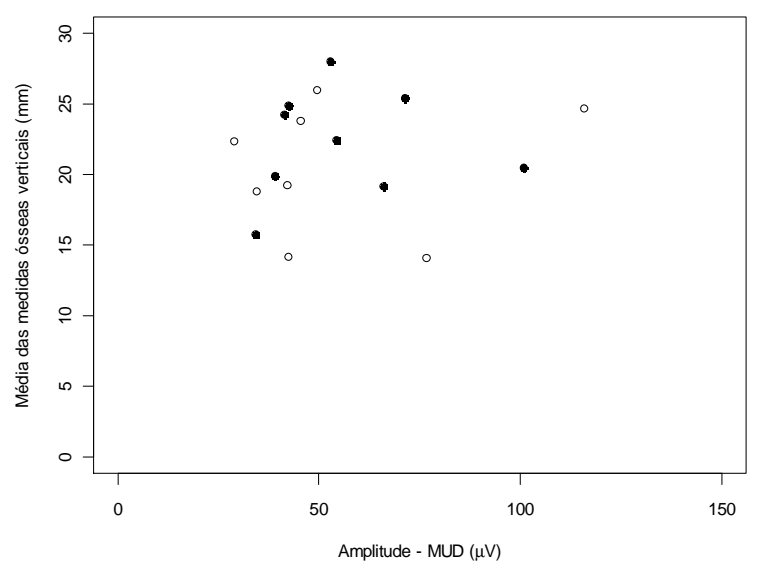

LD

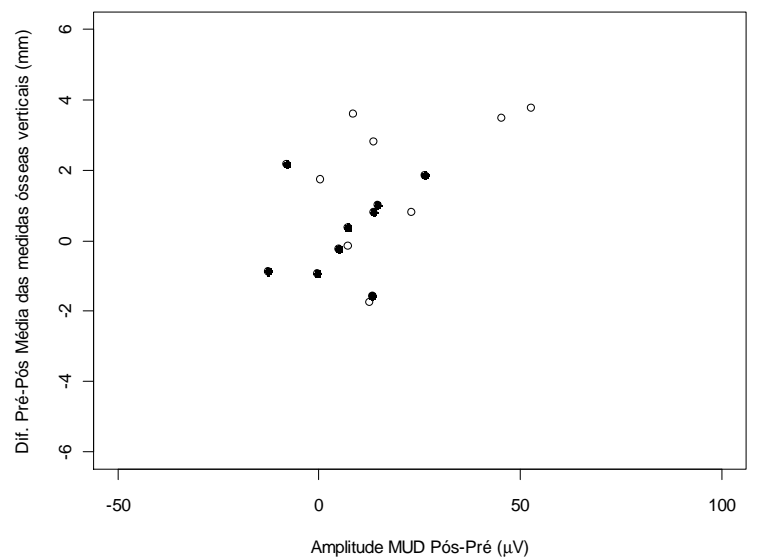

LE - Pré

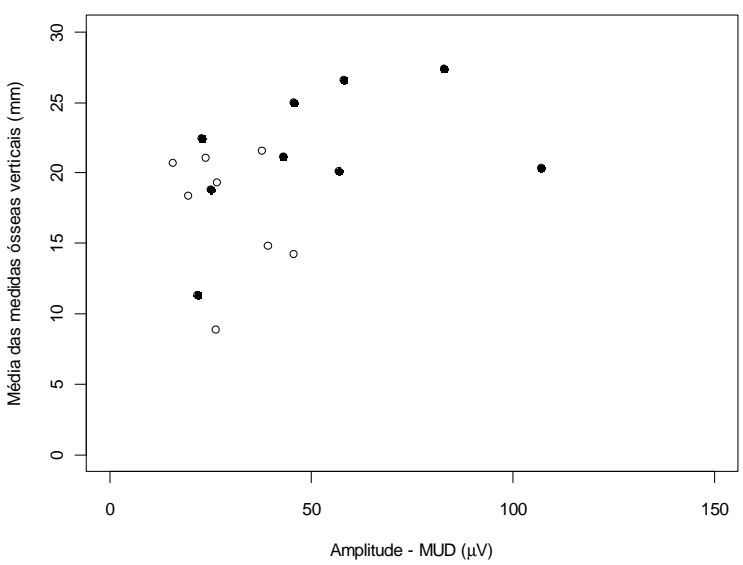

LE - Pós

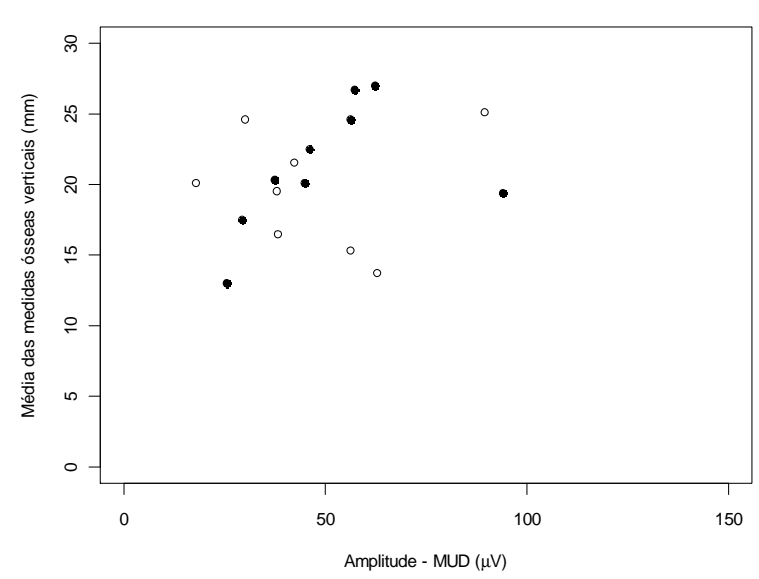

LE

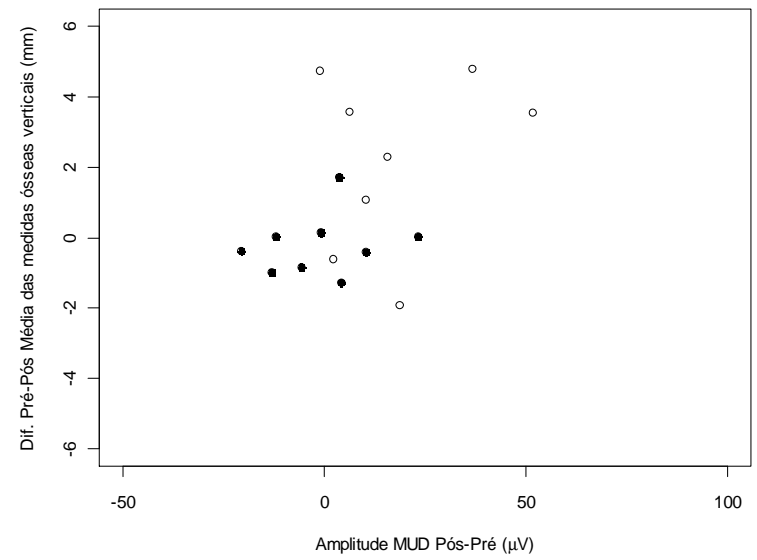


Médias das medidas verticais vs Amplitude MUE

LD - Pré

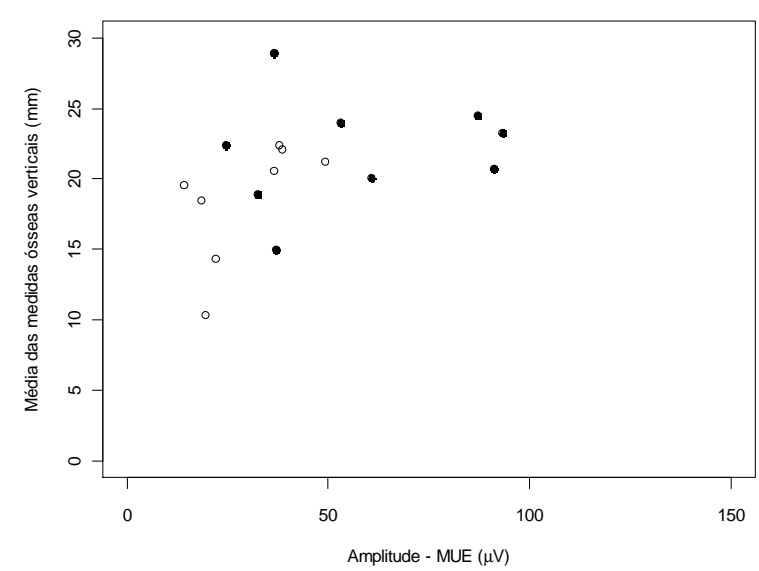

LD - Pós

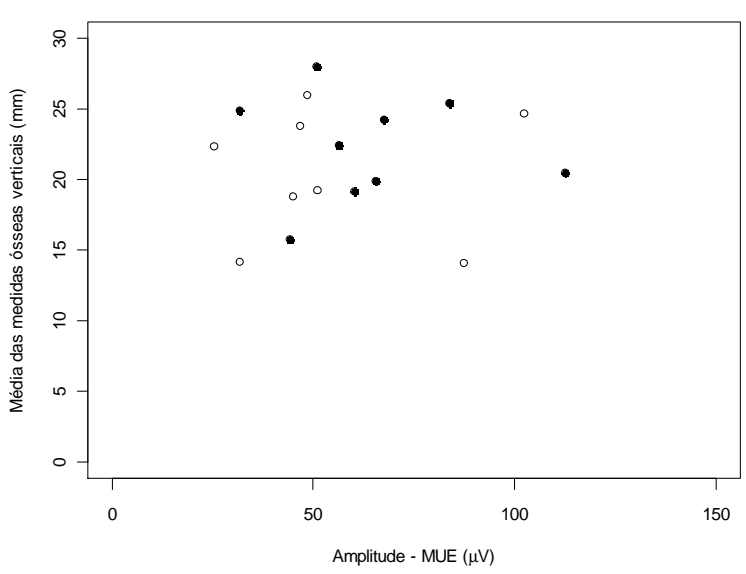

LD

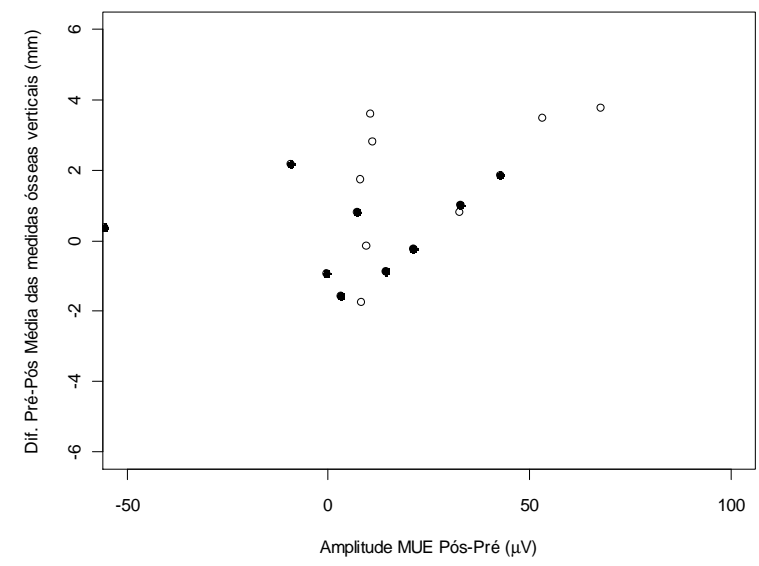

LE - Pré

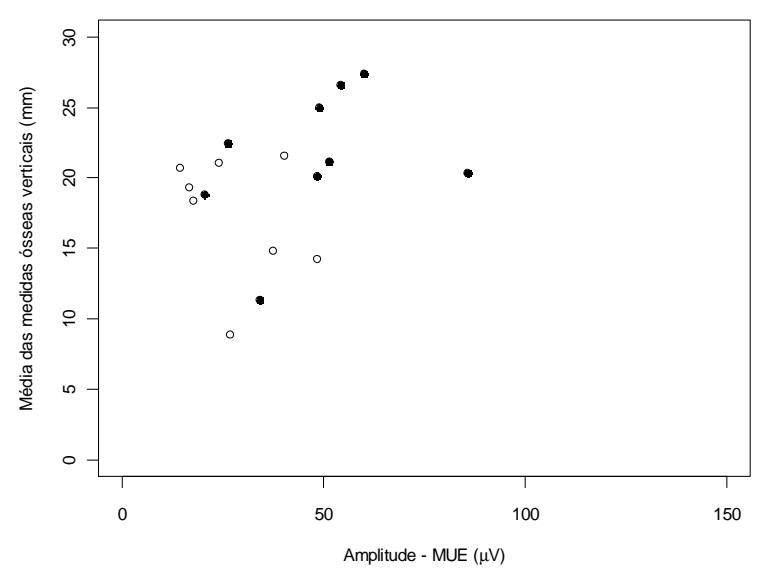

LE - Pós

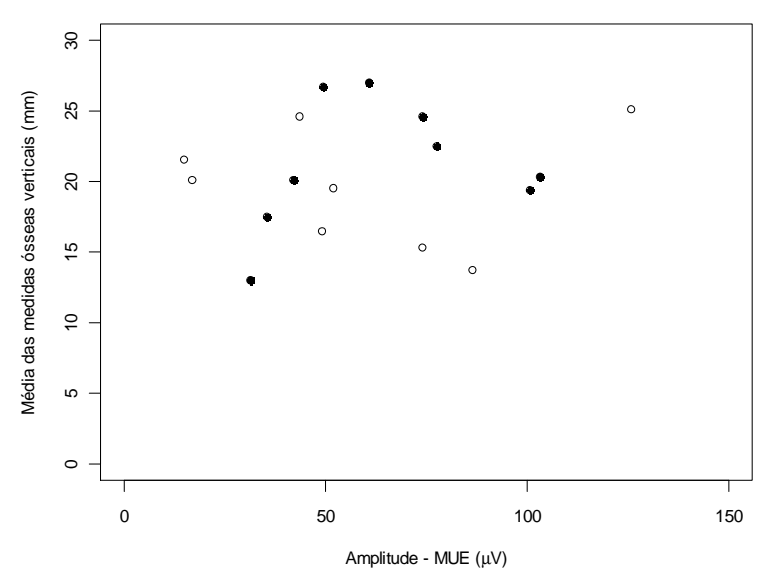

LE

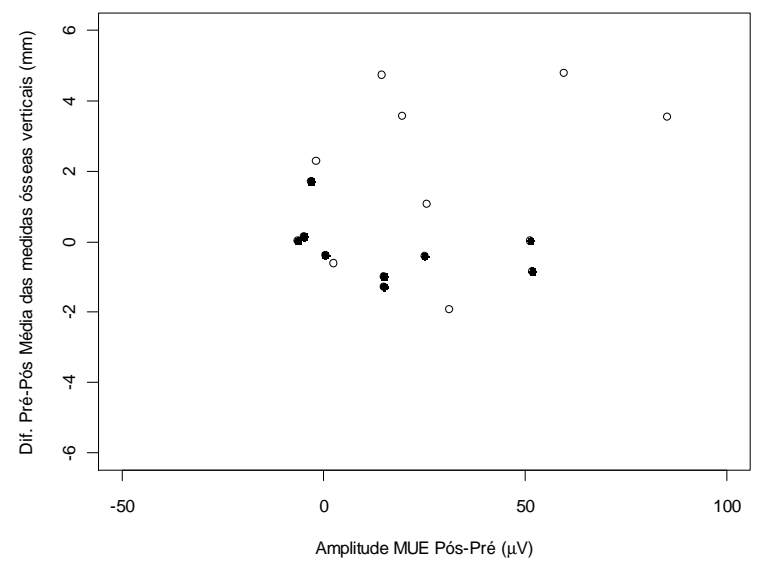


Médias das medidas verticais vs Ato MH

LD - Pré

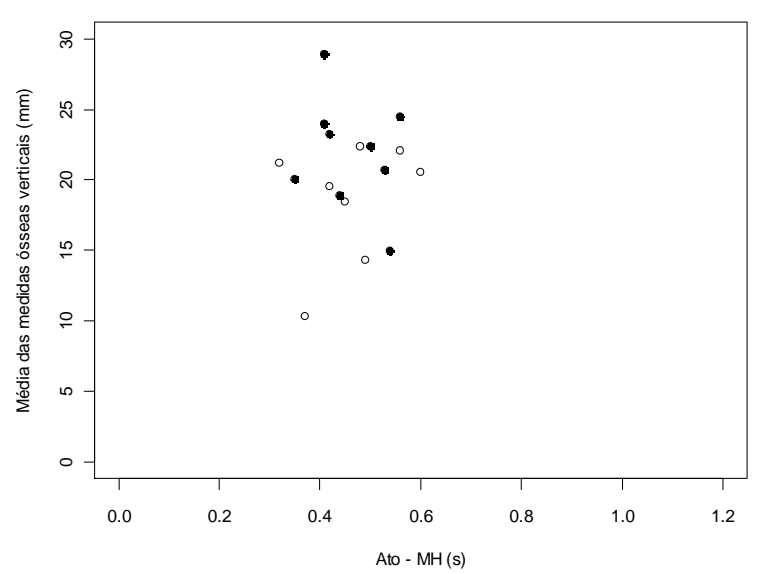

LD - Pós

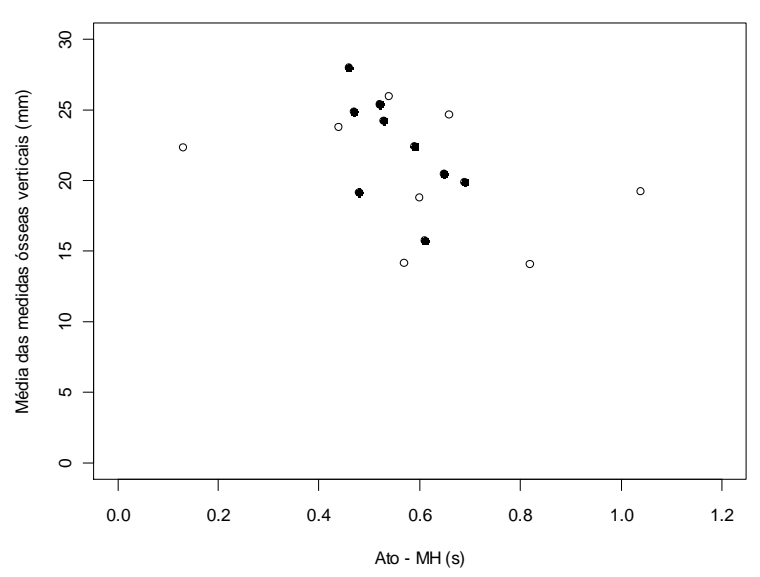

LD

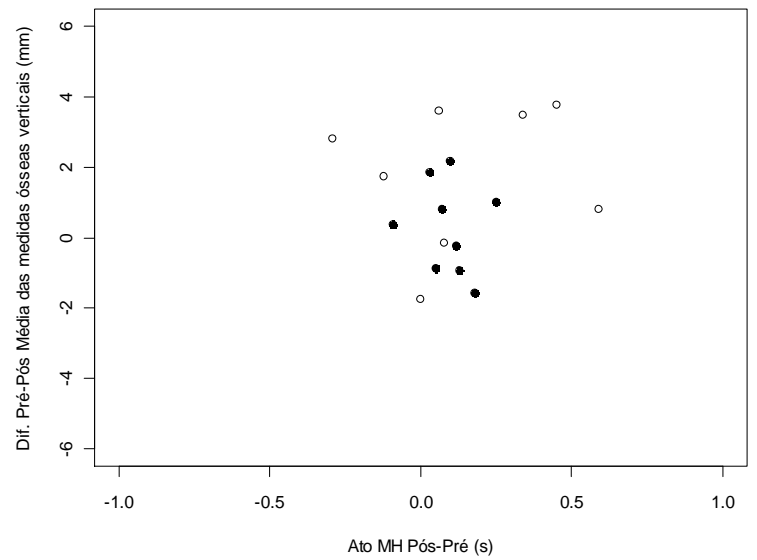

LE - Pré

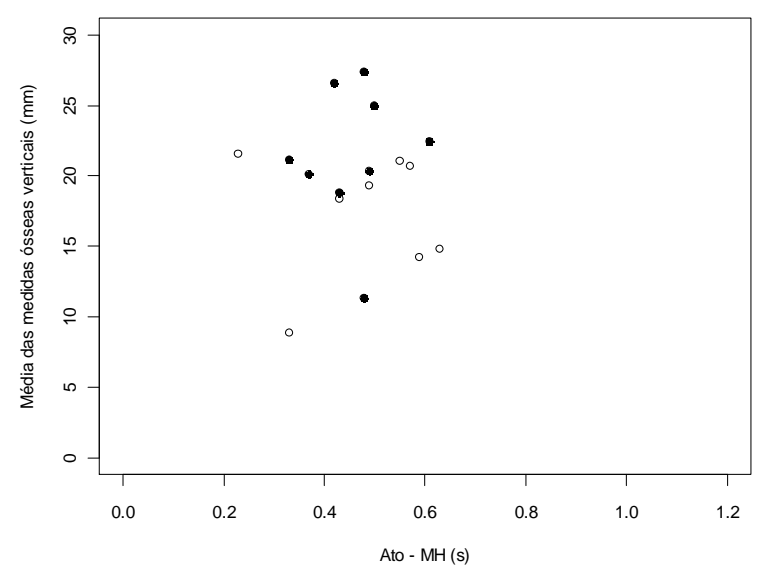

LE - Pós

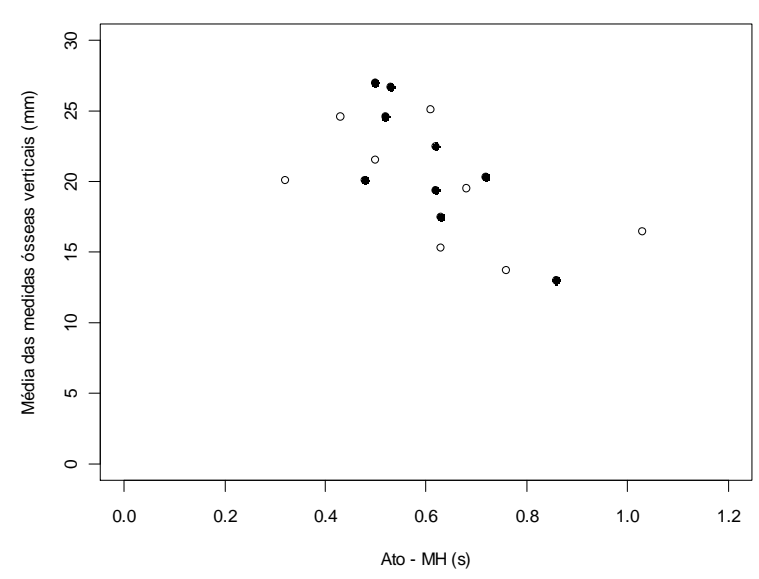

LE

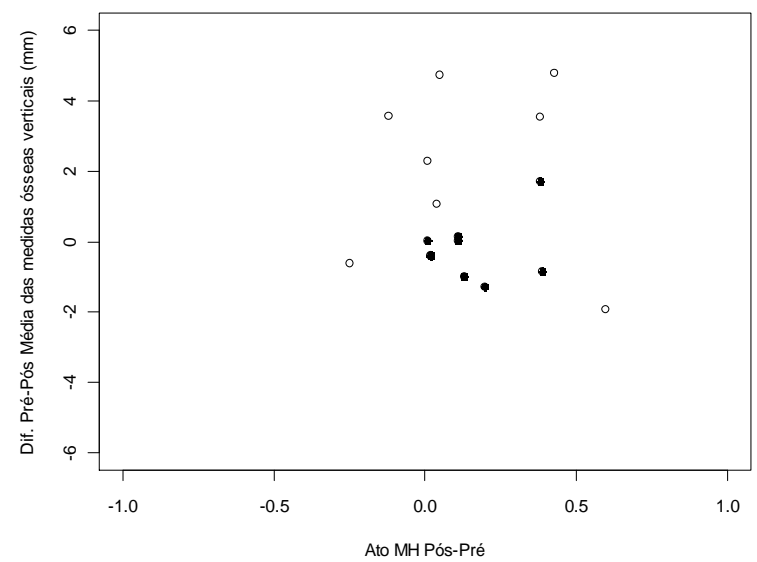


Médias verticais vs Ato MUD
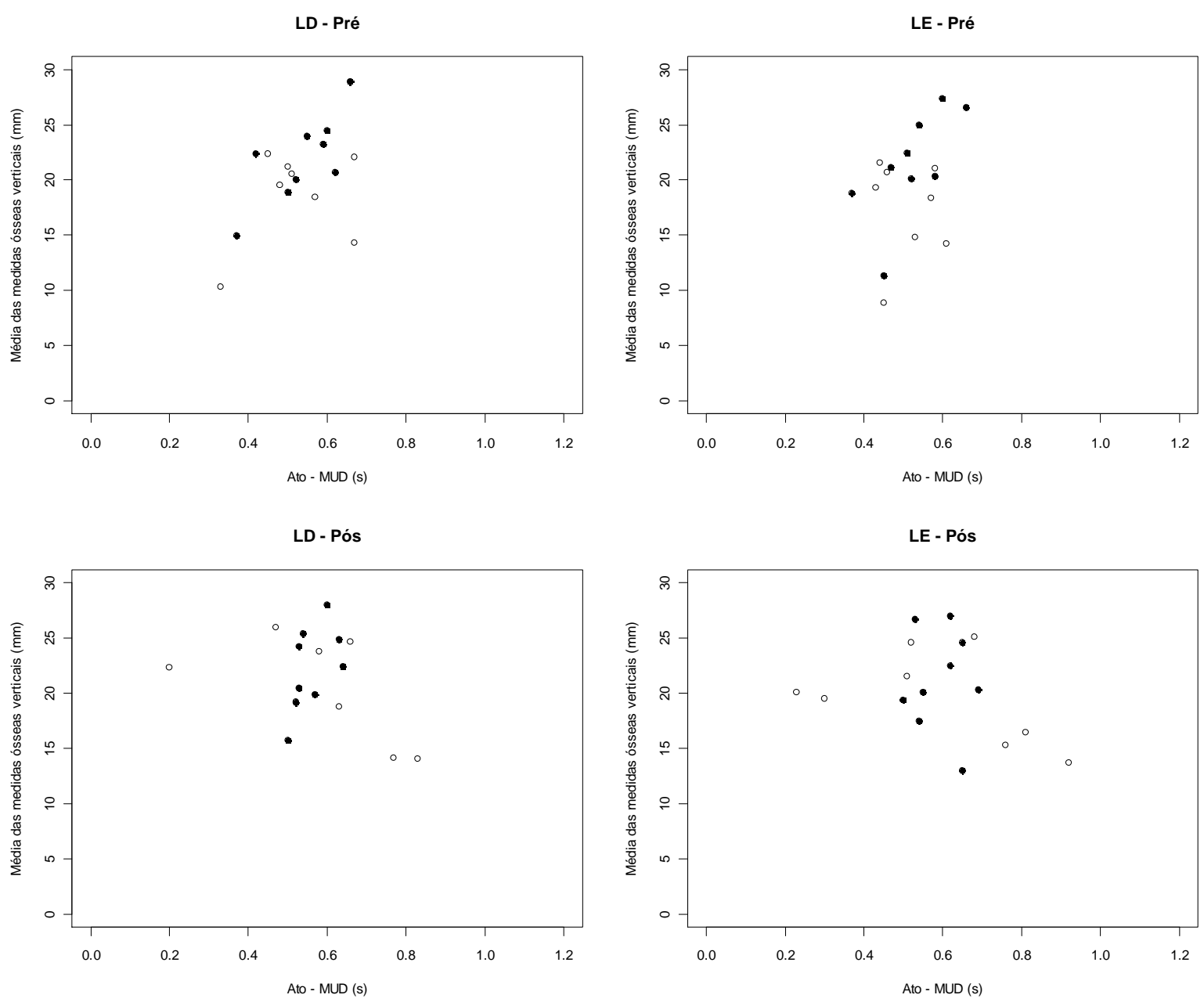

LD

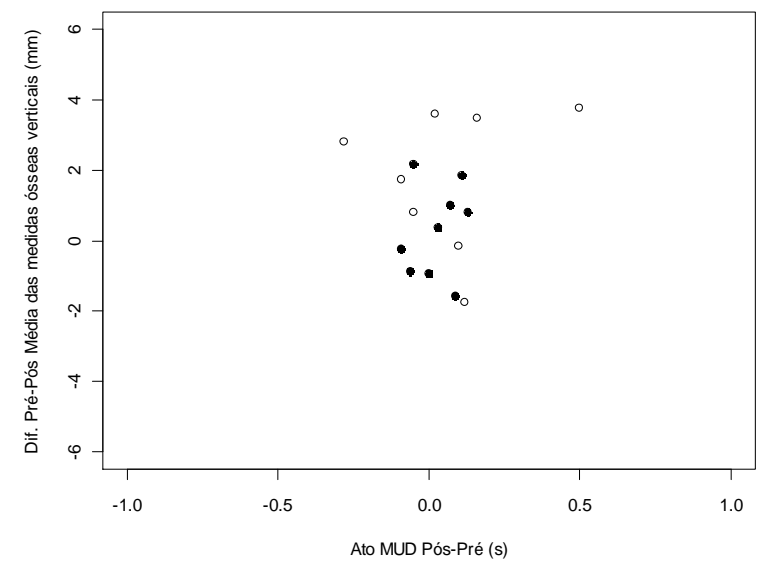

LE

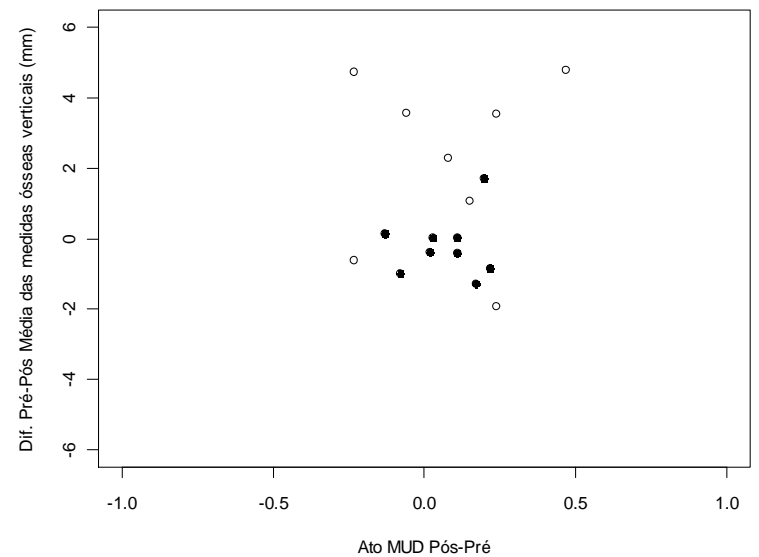


Médias verticais vs Ato MUE

LD - Pré

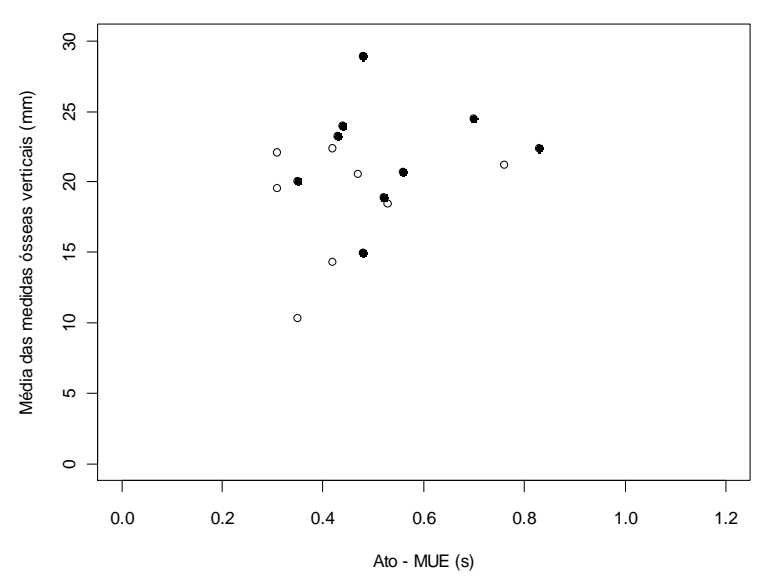

LD - Pós

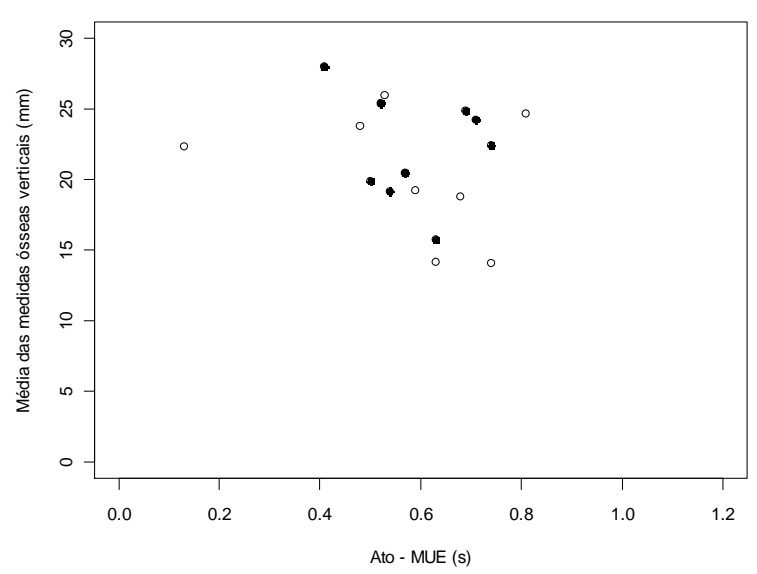

LD

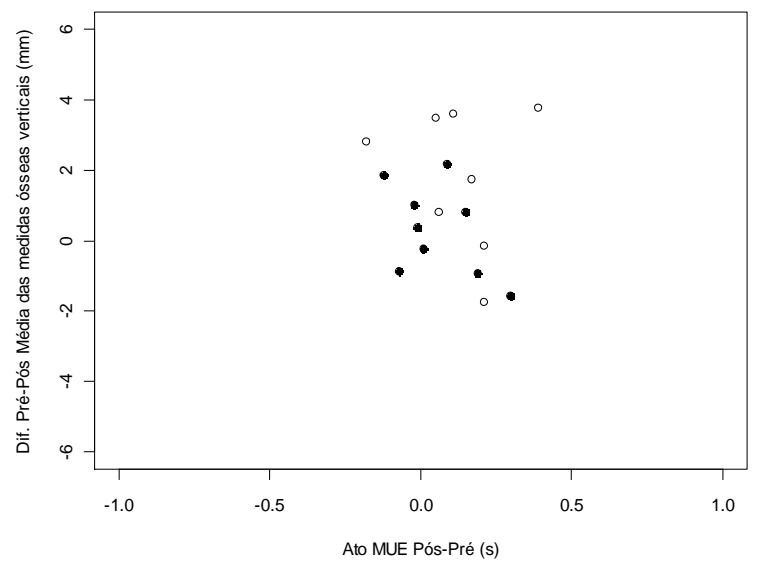

LE - Pré

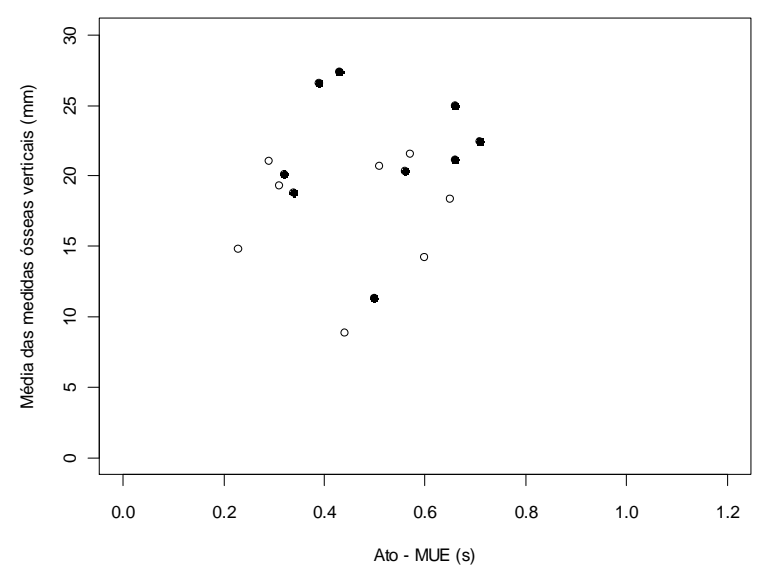

LE - Pós

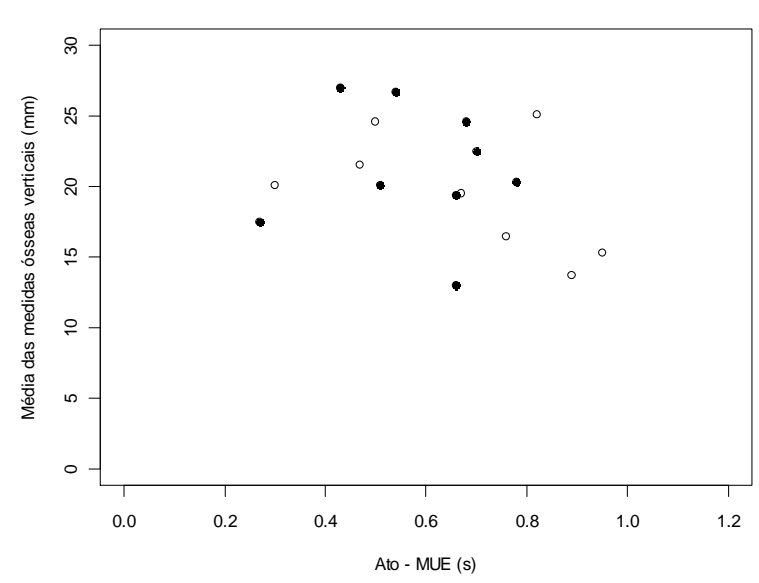

LE

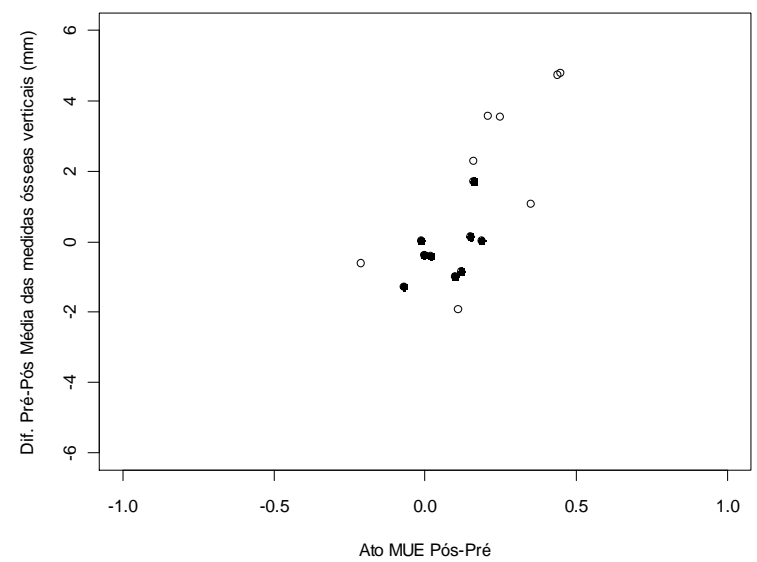


Médias verticais vs Ciclo MH
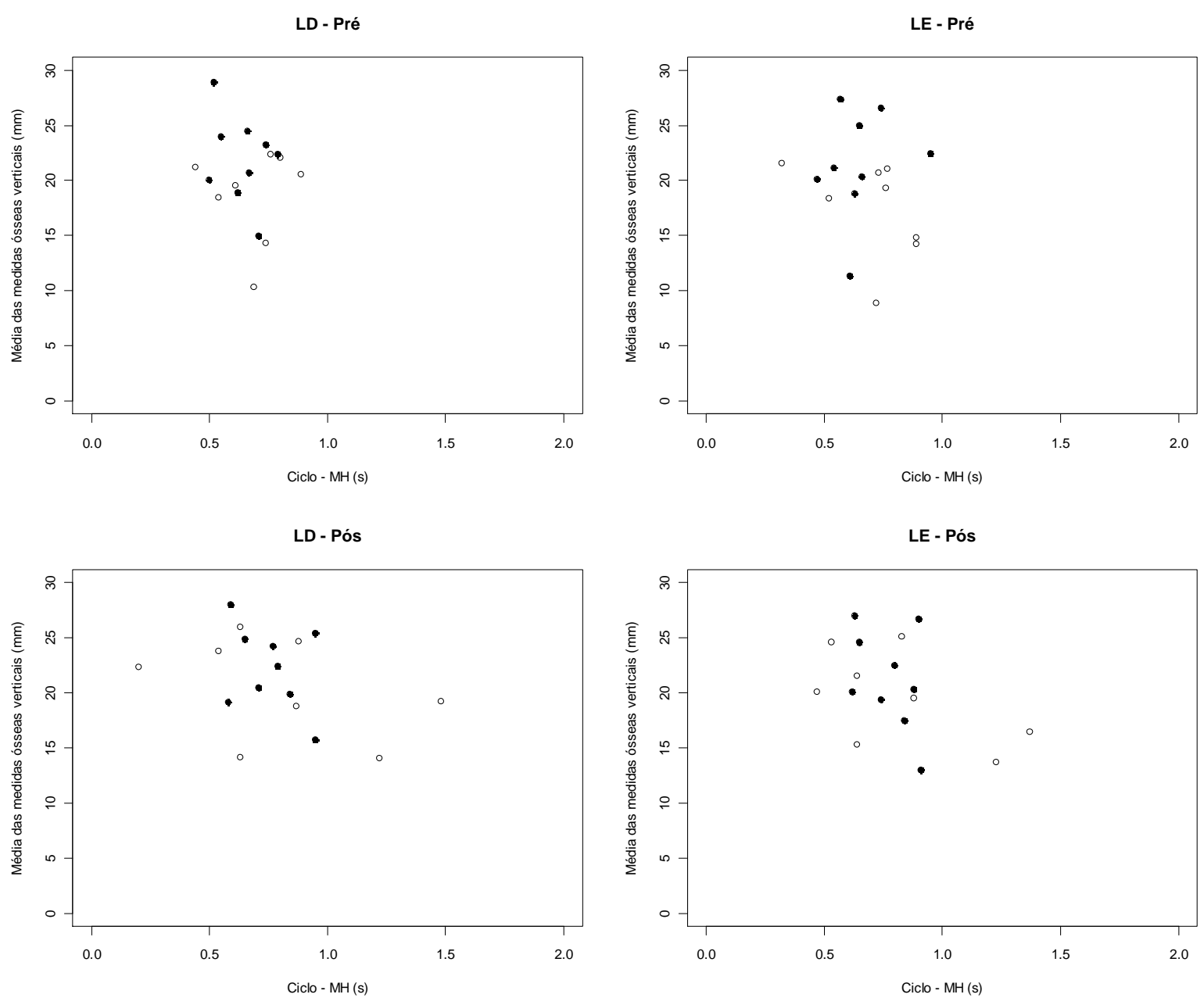

LD

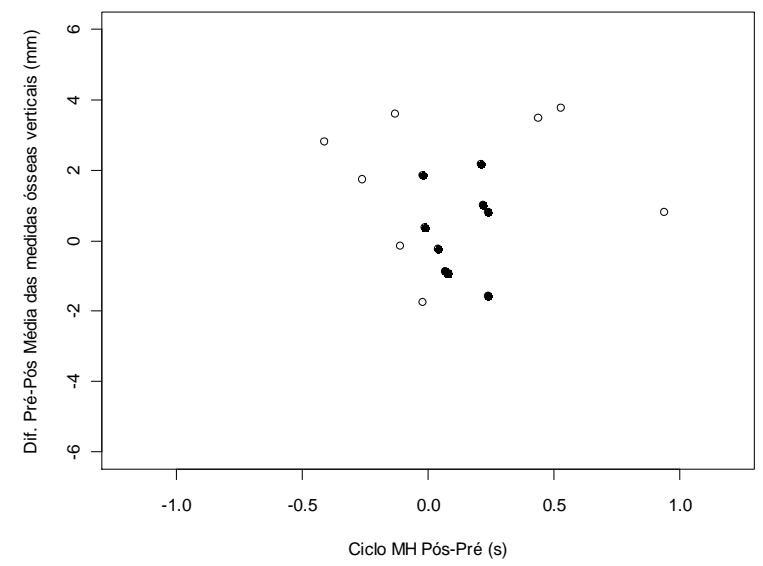

LE

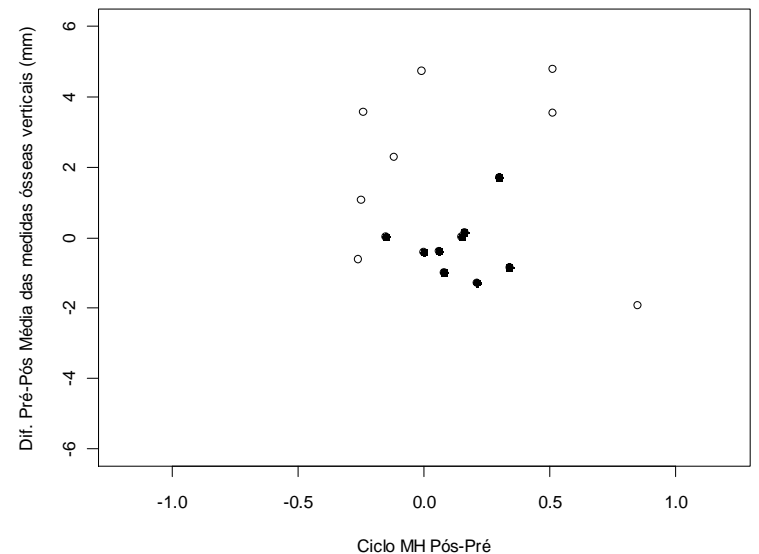


Médias verticais vs Ciclo MUD

LD - Pré

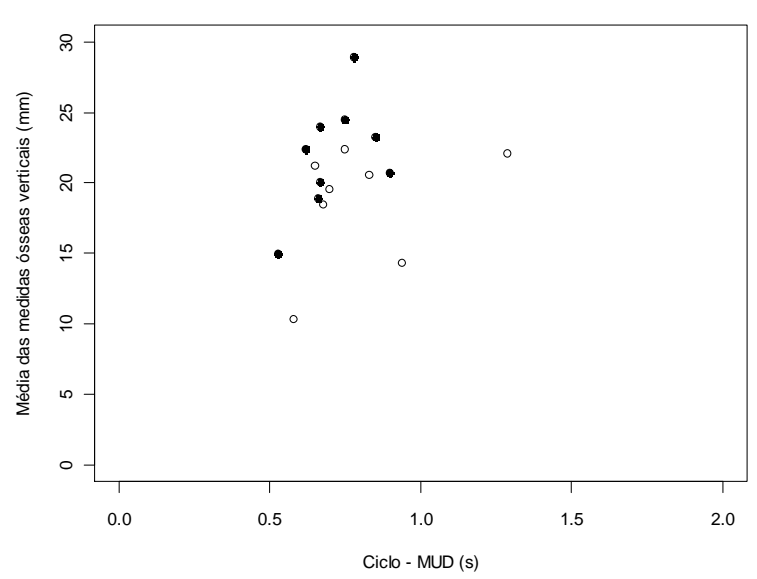

LD - Pós

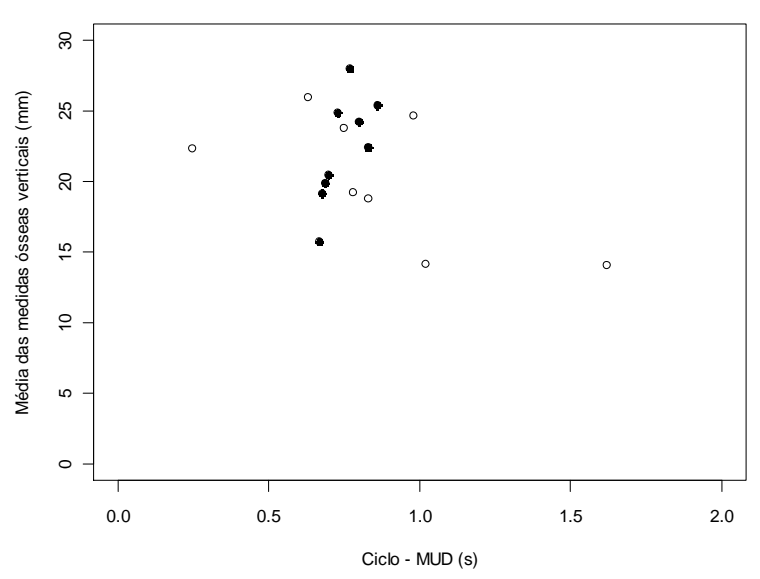

LD

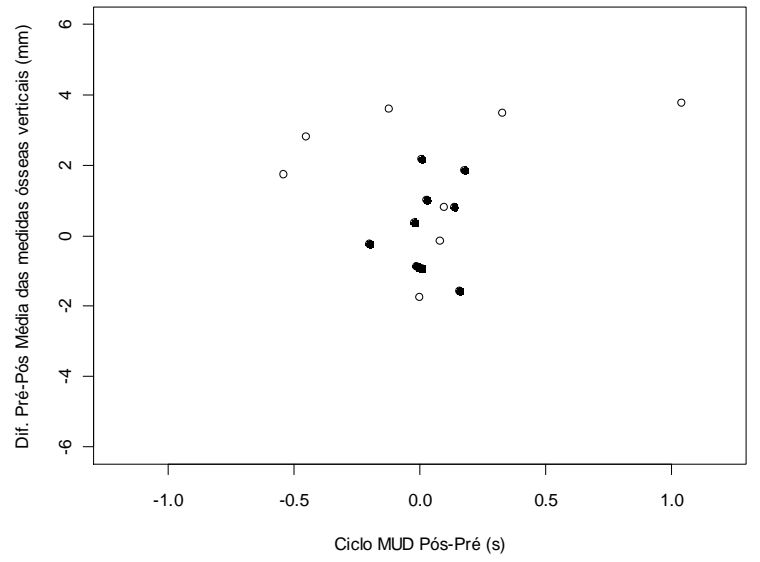

LE - Pré

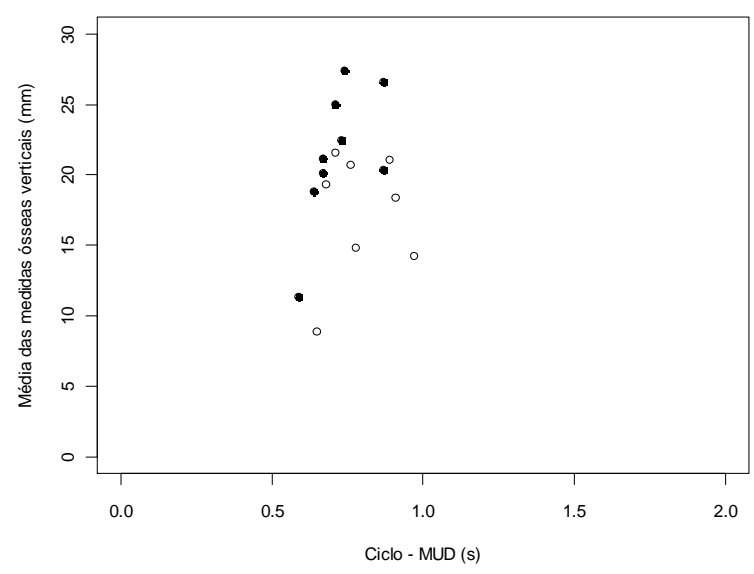

LE - Pós

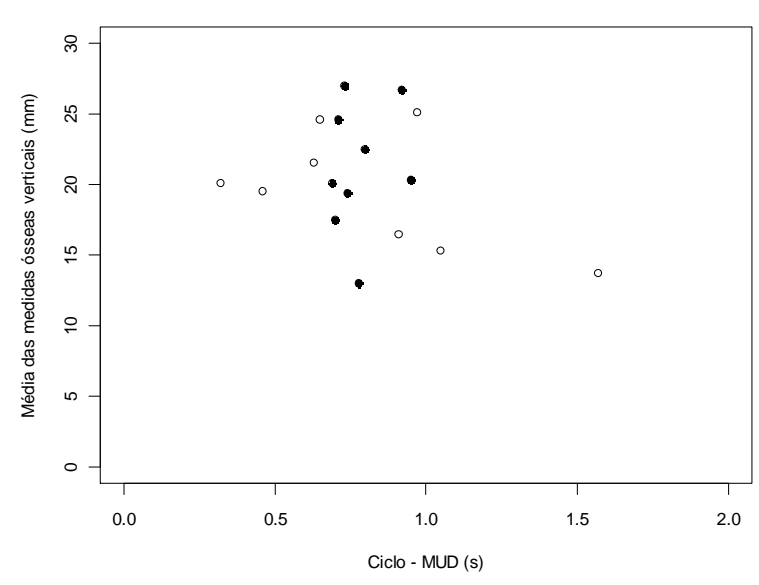

LE

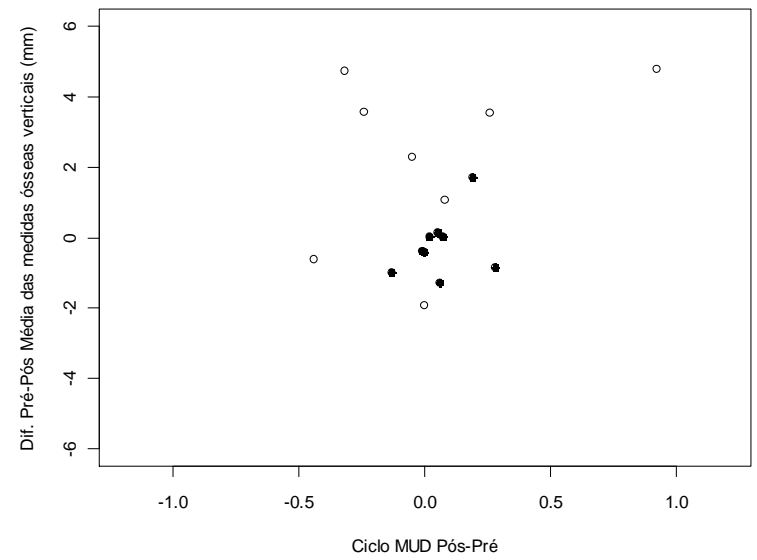


Médias verticais vs Ciclo MUE
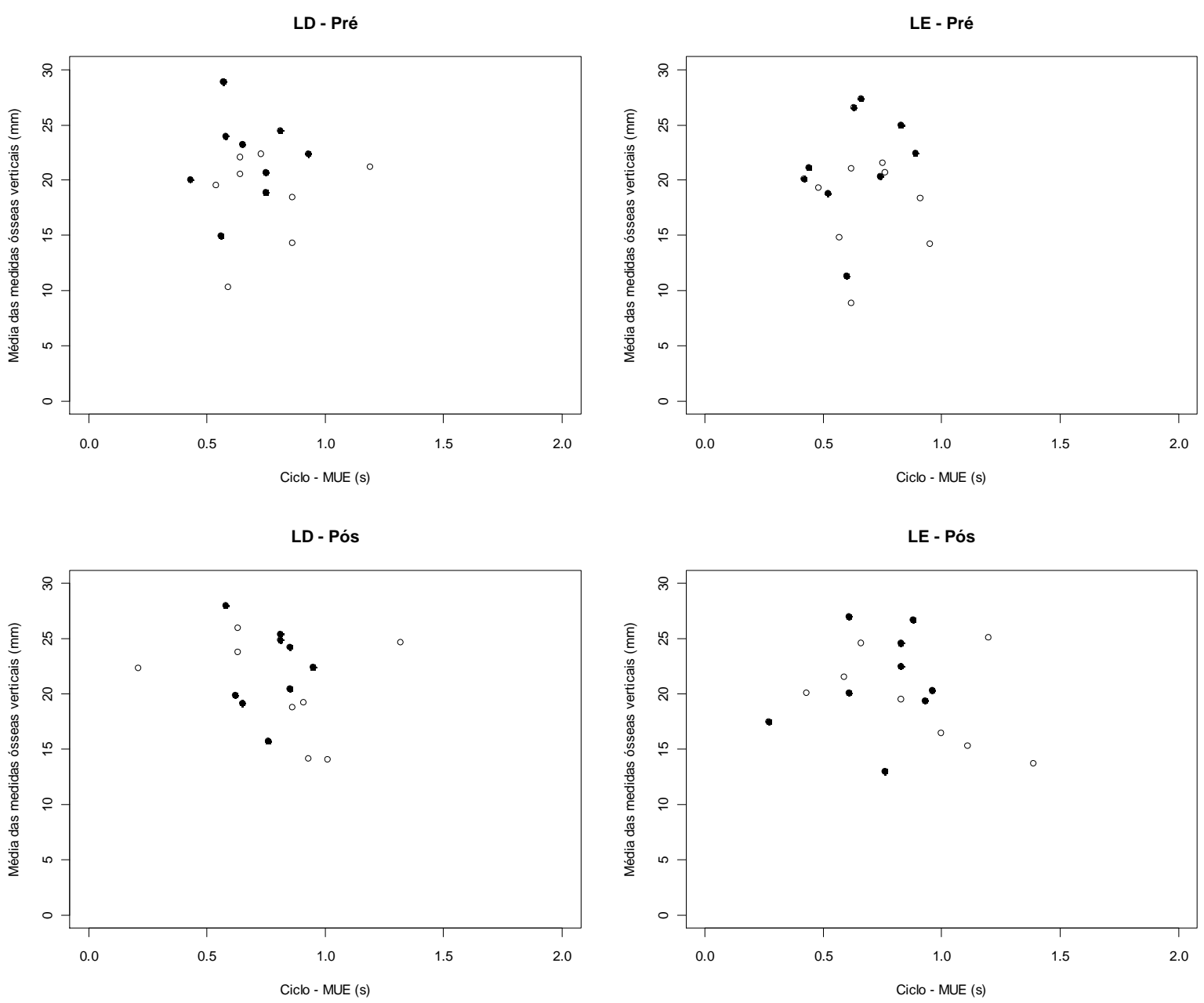

LD

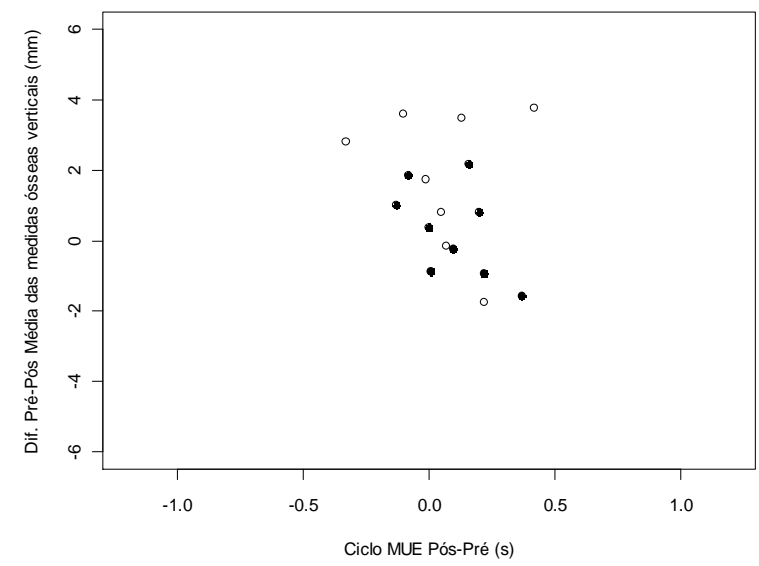

LE

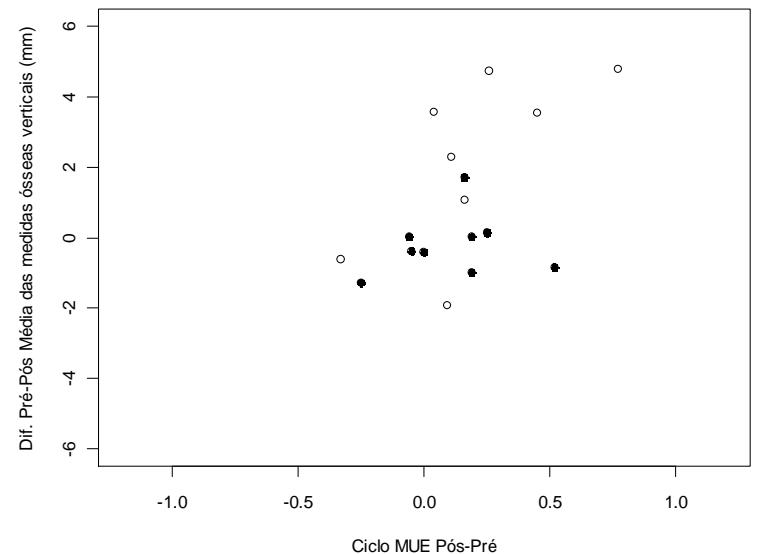


Anexo 8 - Gráficos de Perfis Individuais.
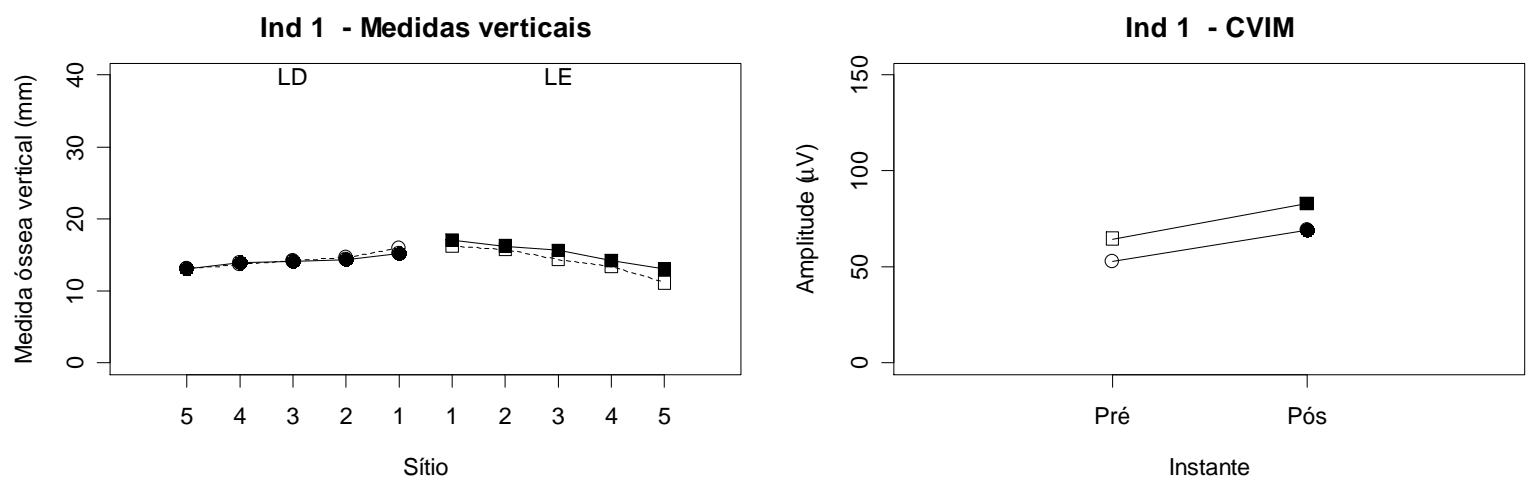

Ind 1 - MH
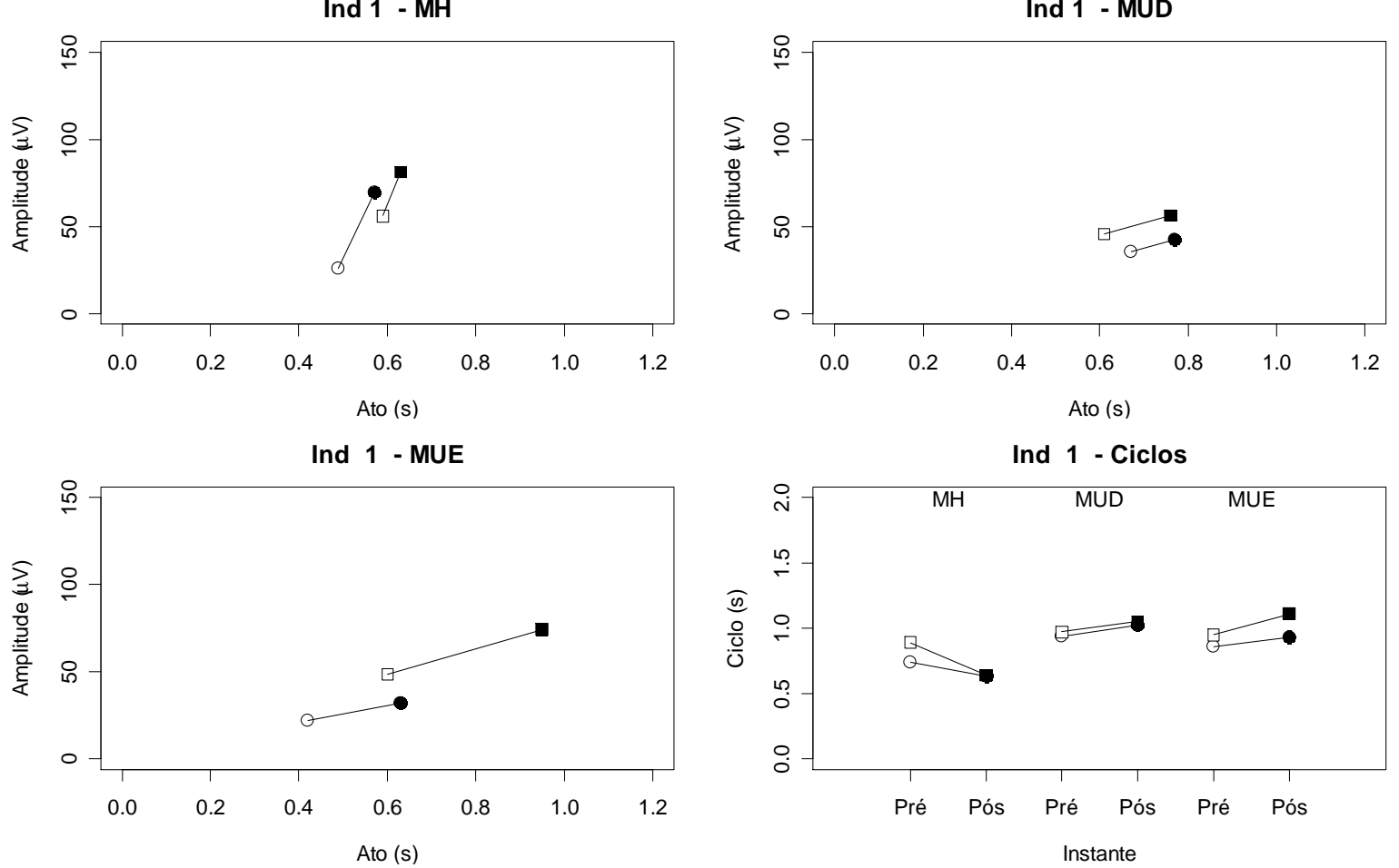

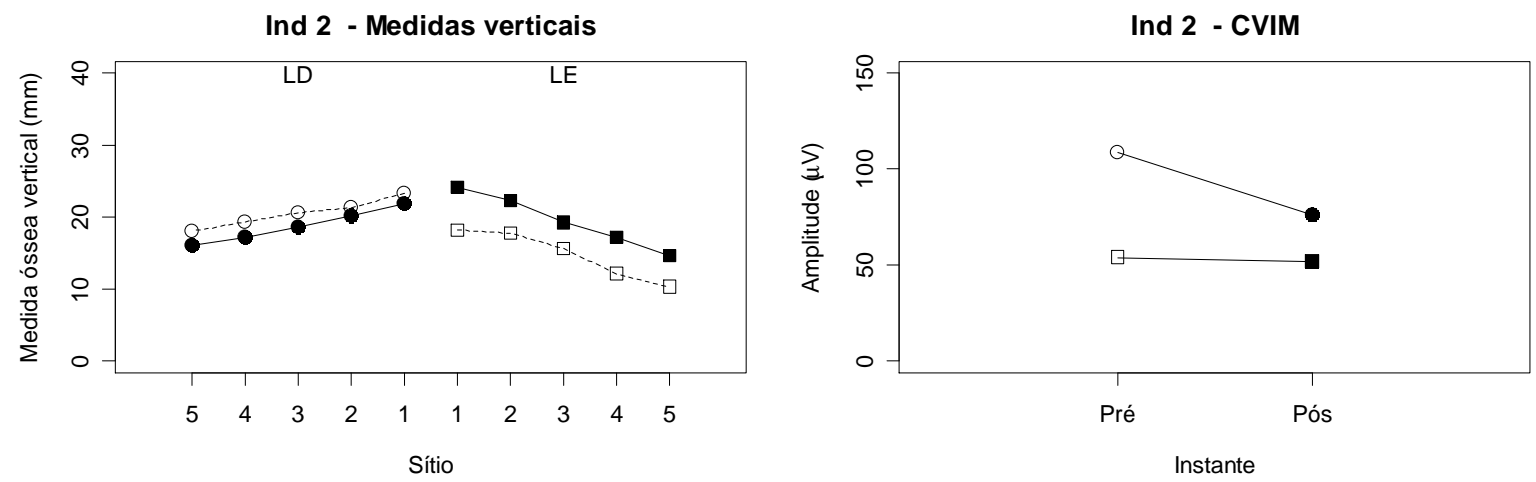

Ind 2 - $\mathrm{MH}$

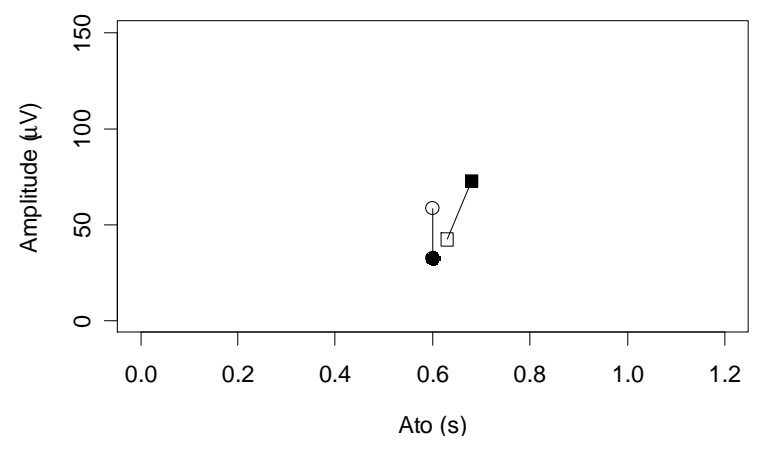

Ind 2 - MUD

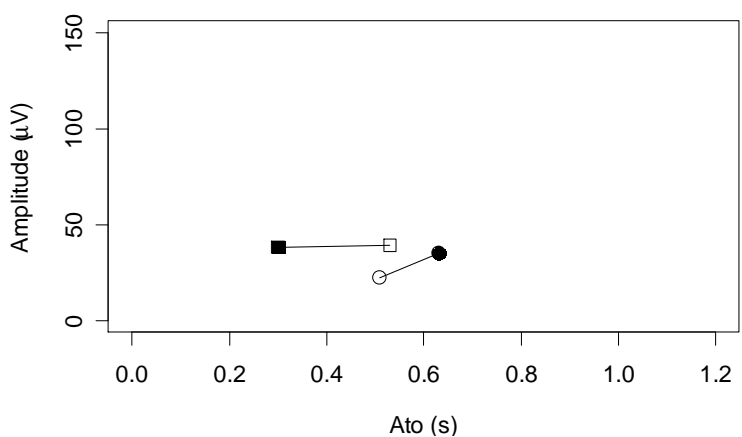

Ind 2 - MUE
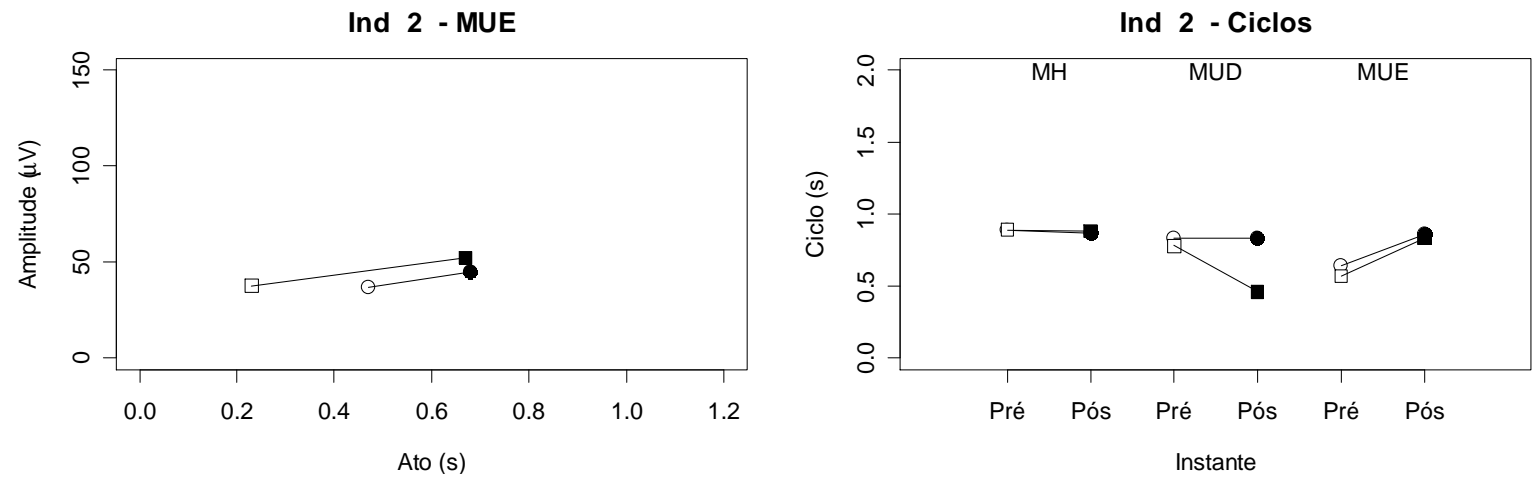

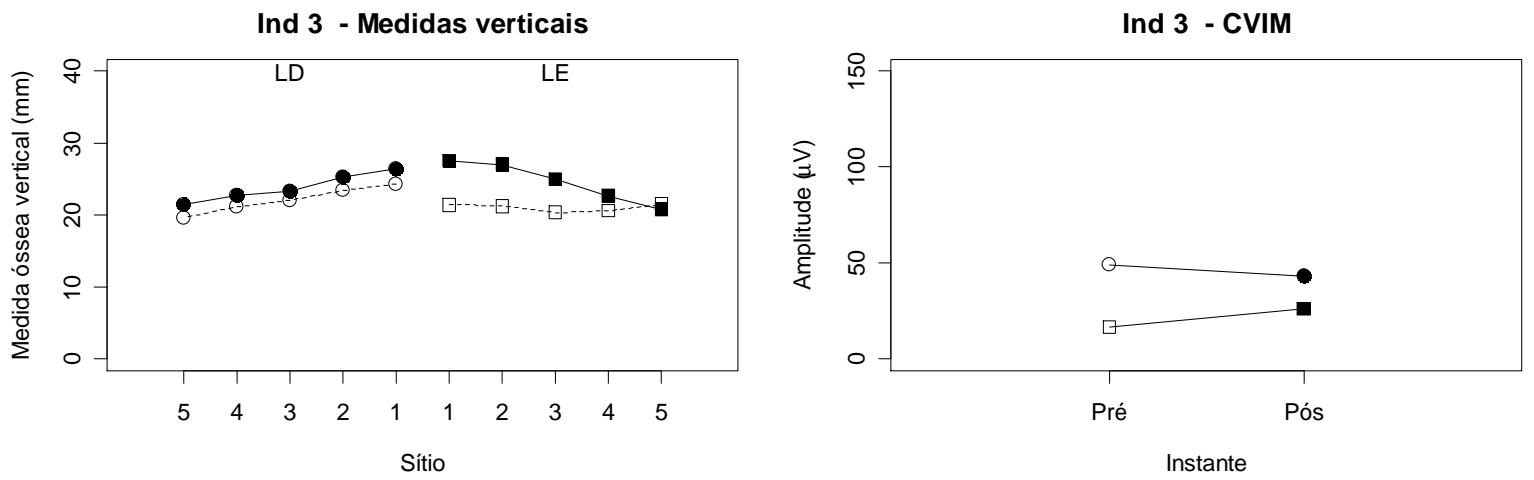

Ind 3 - MH

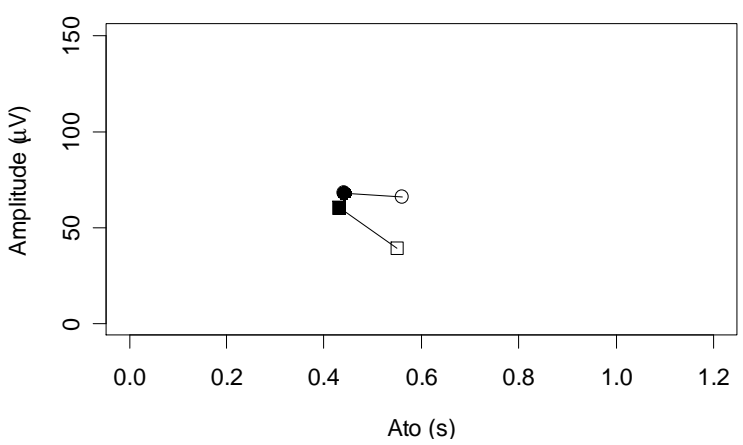

Ind 3 - MUD
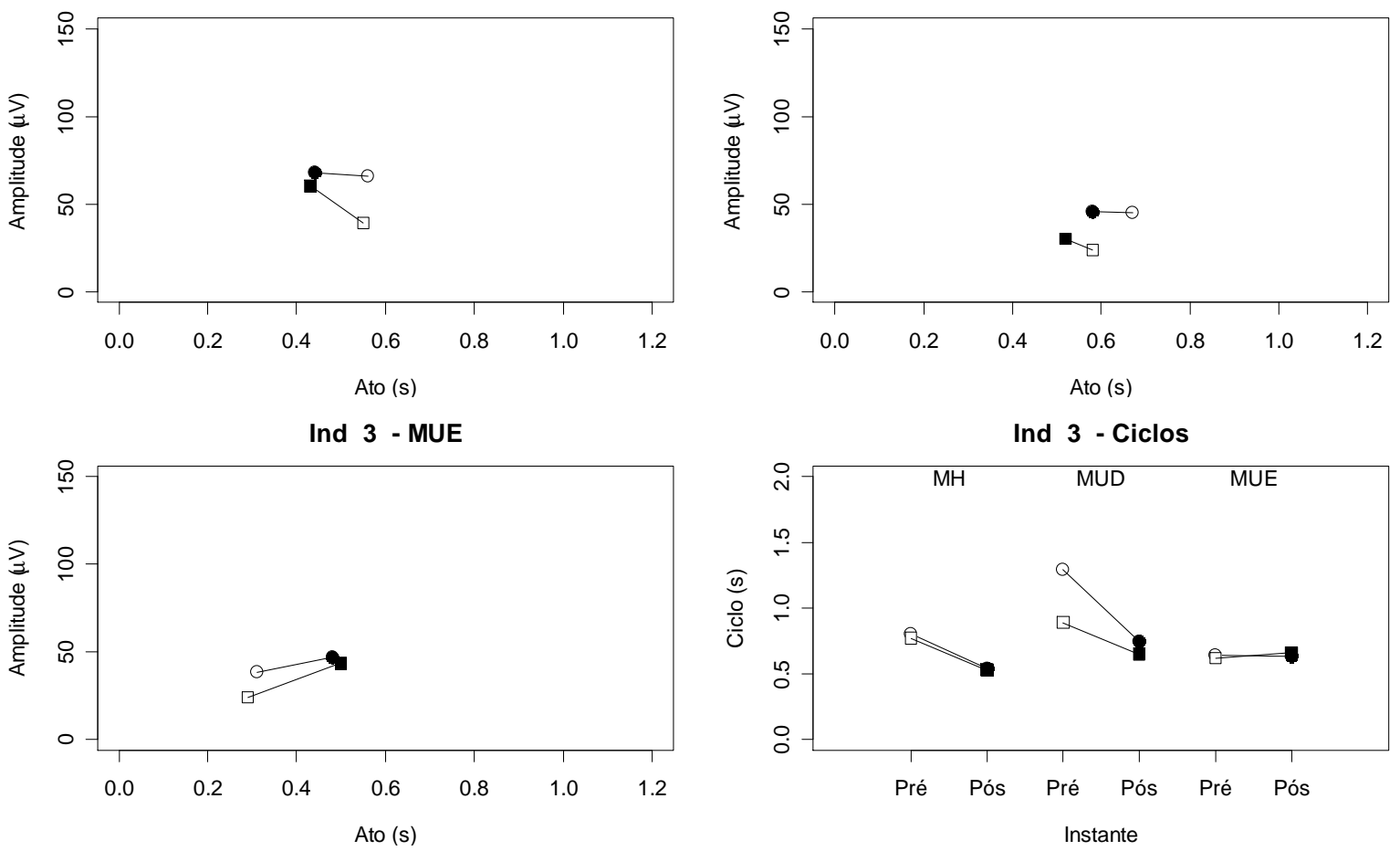

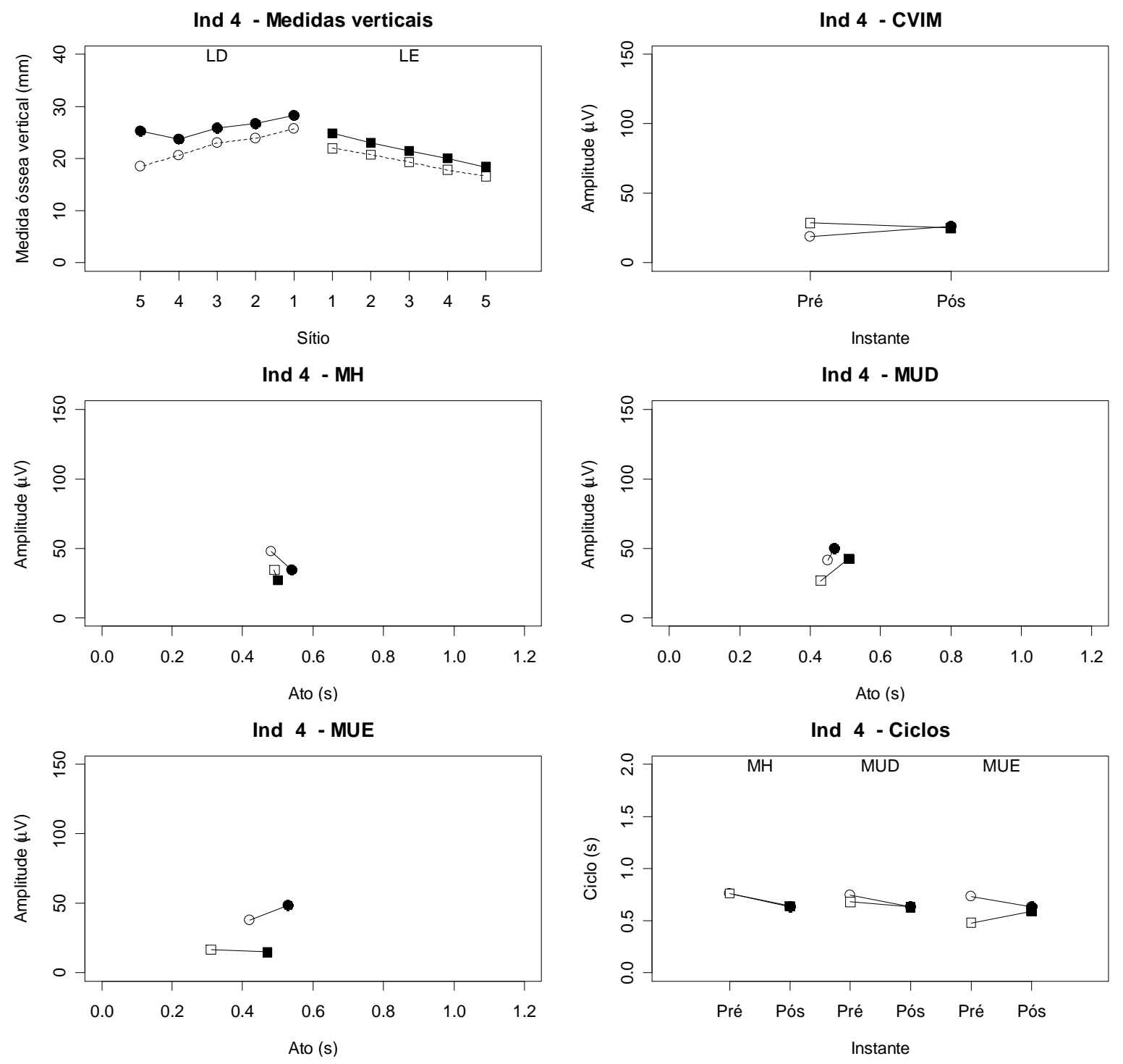

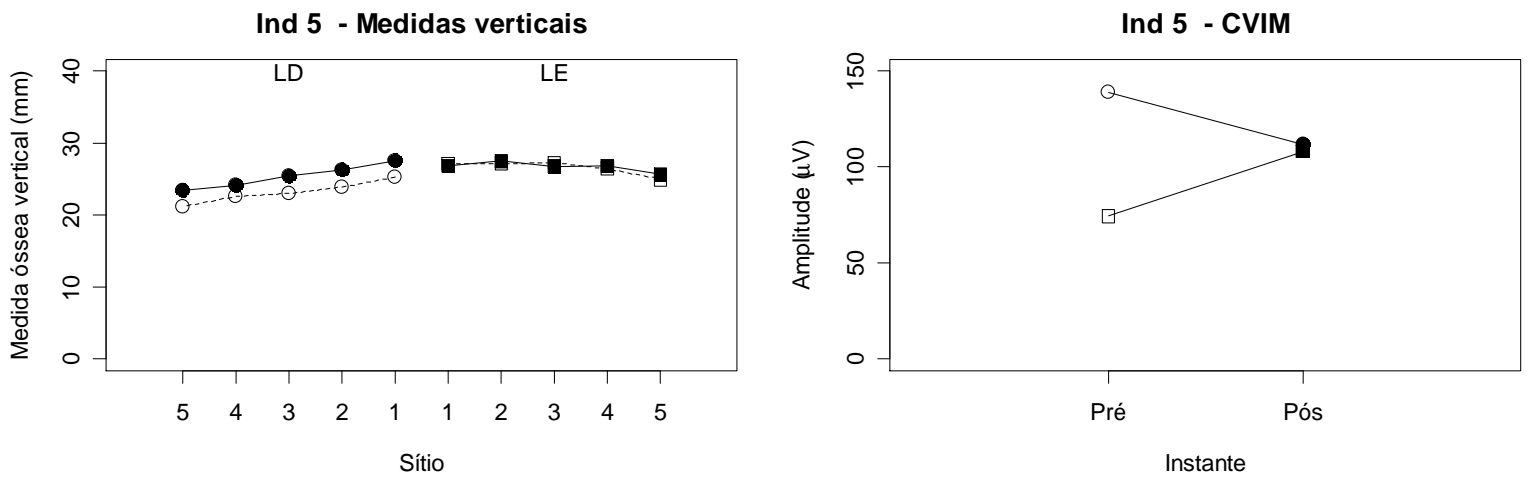

Ind 5 - MH

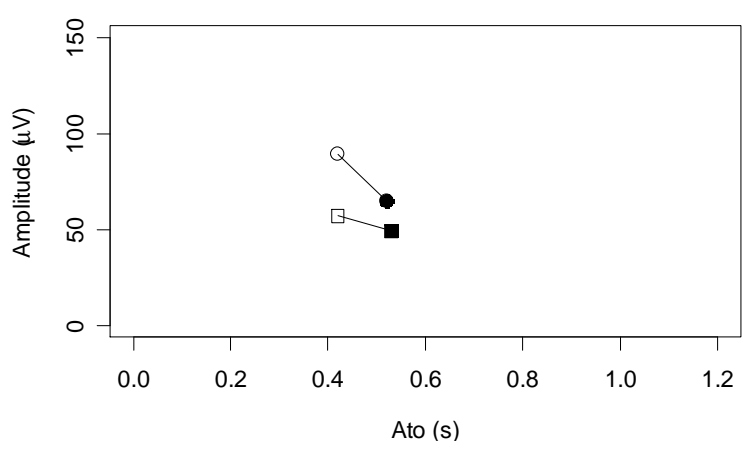

Ind 5 - MUD
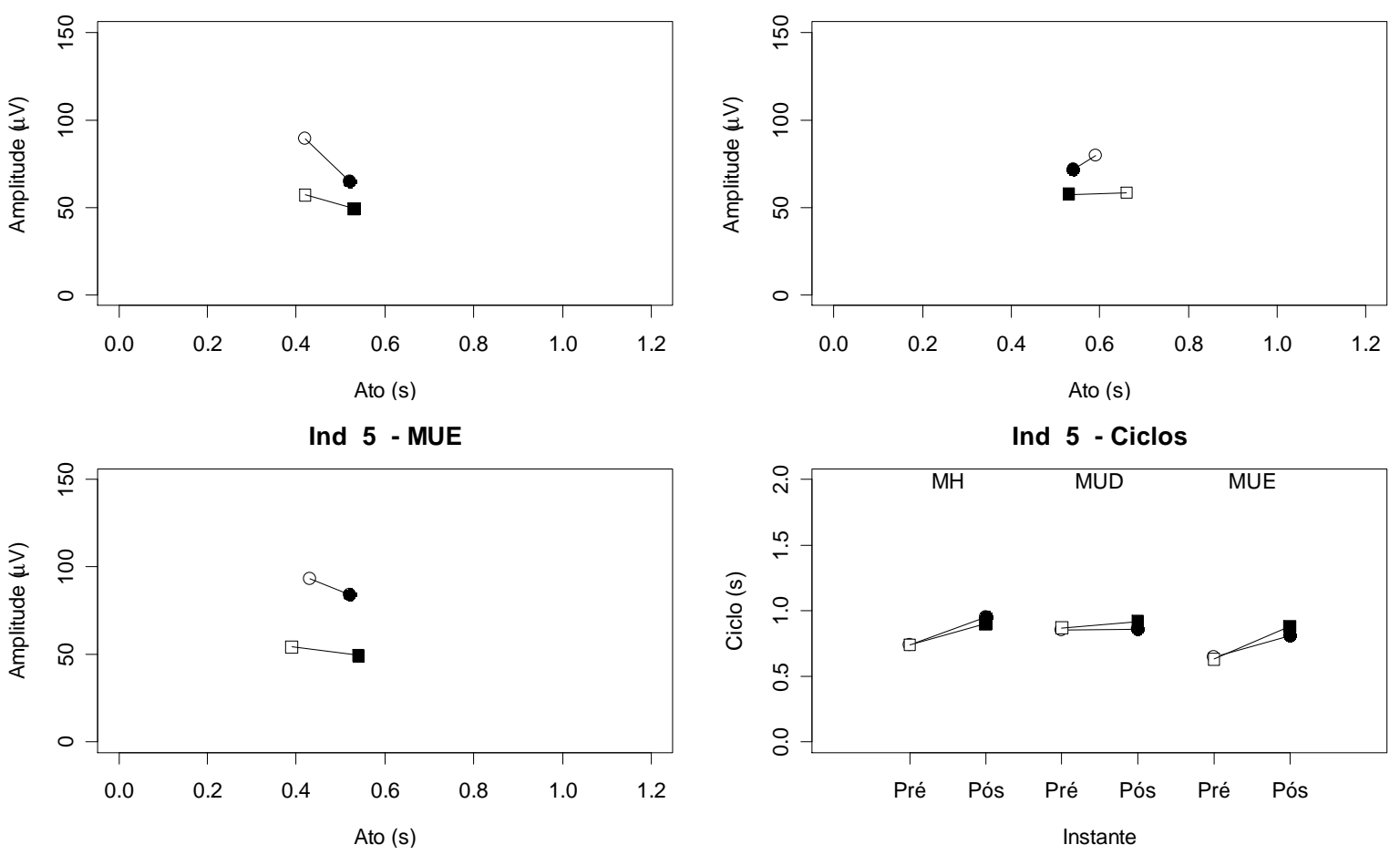

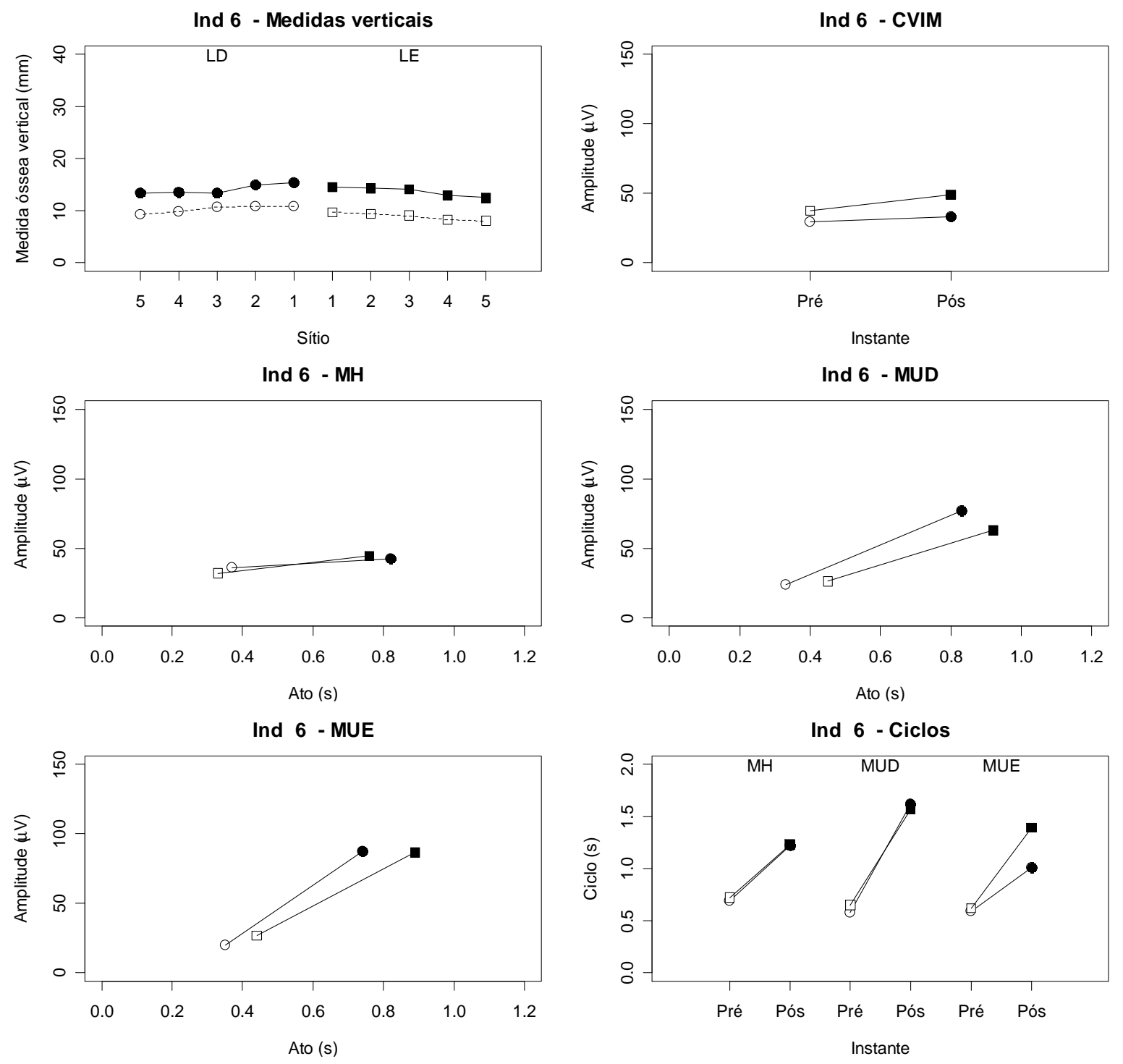

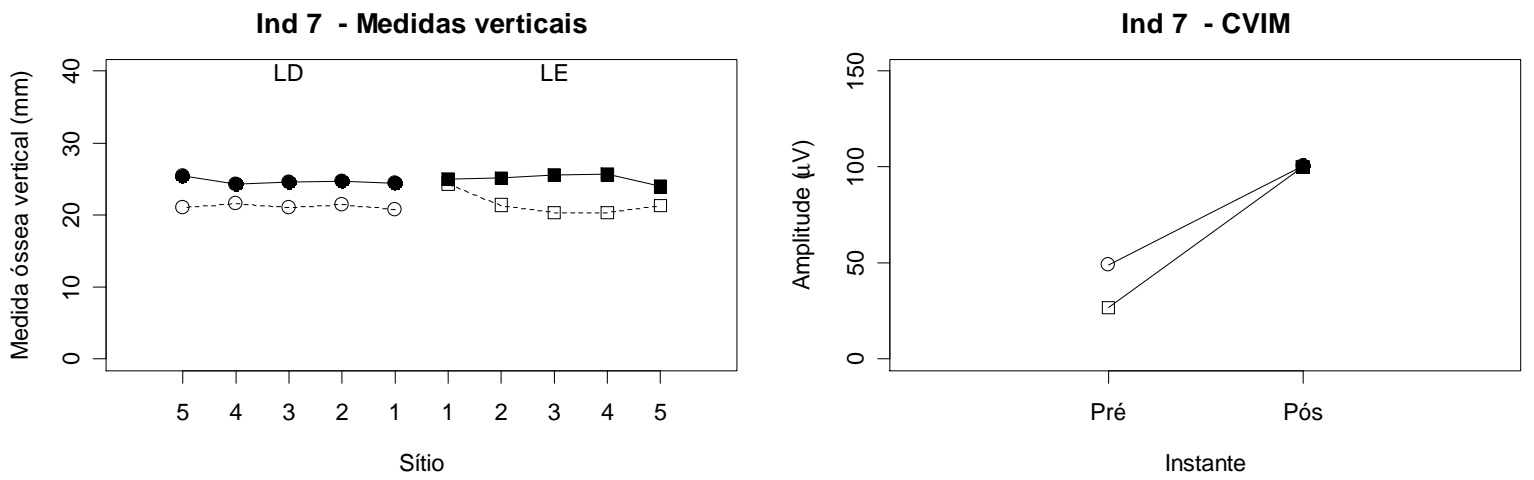

Ind 7 - MH

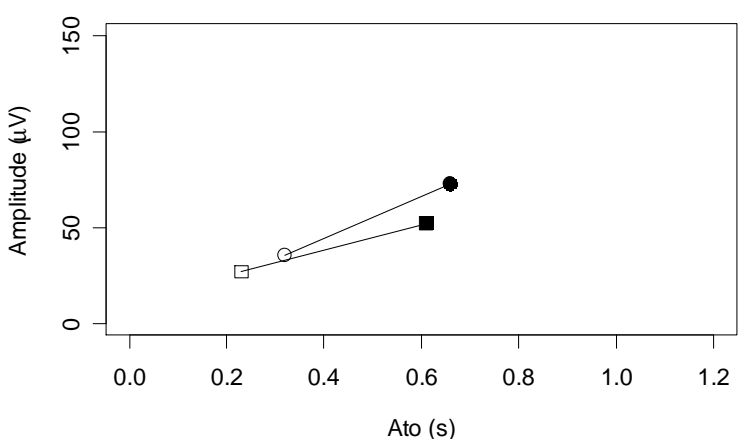

Ind 7 - MUD
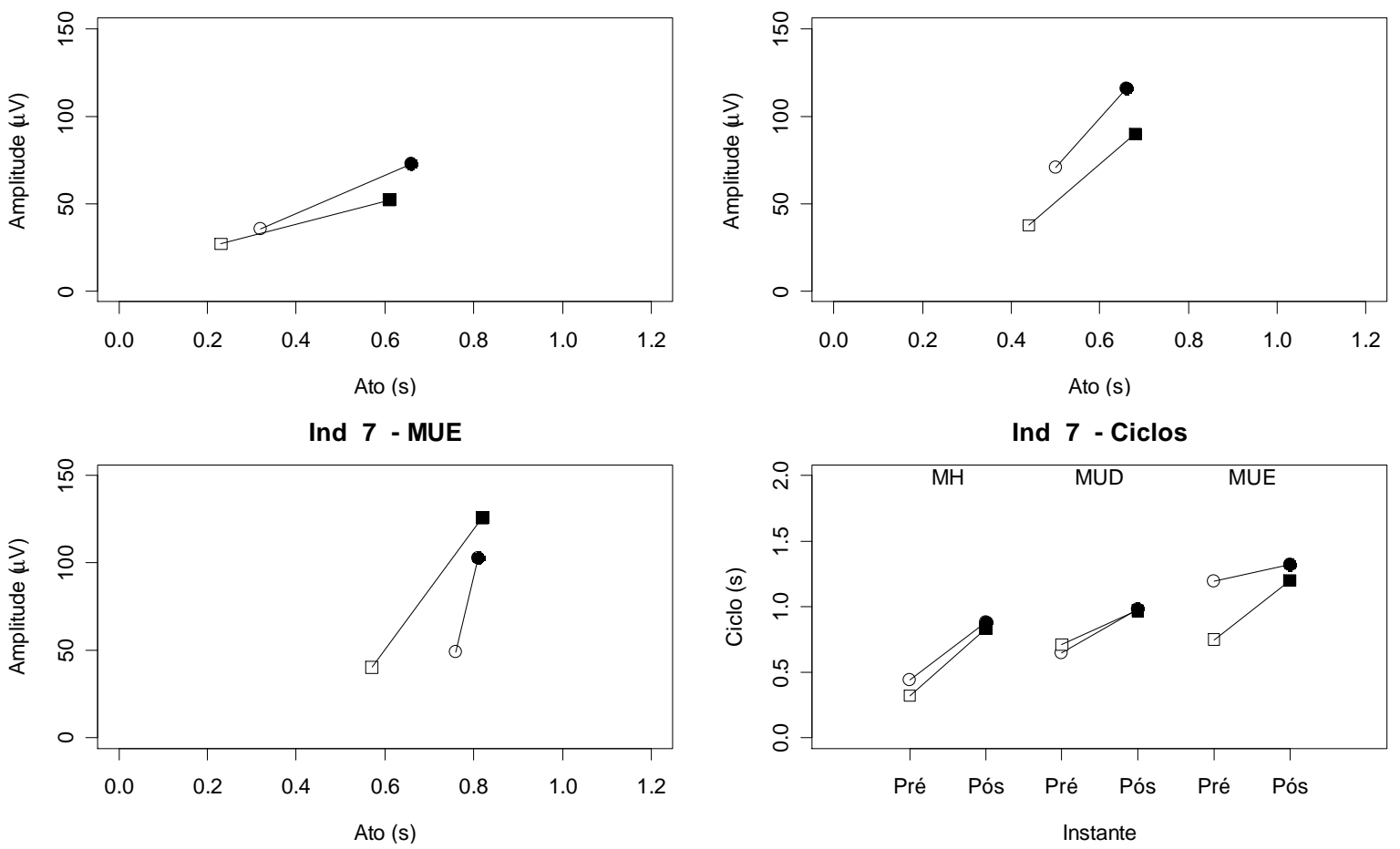

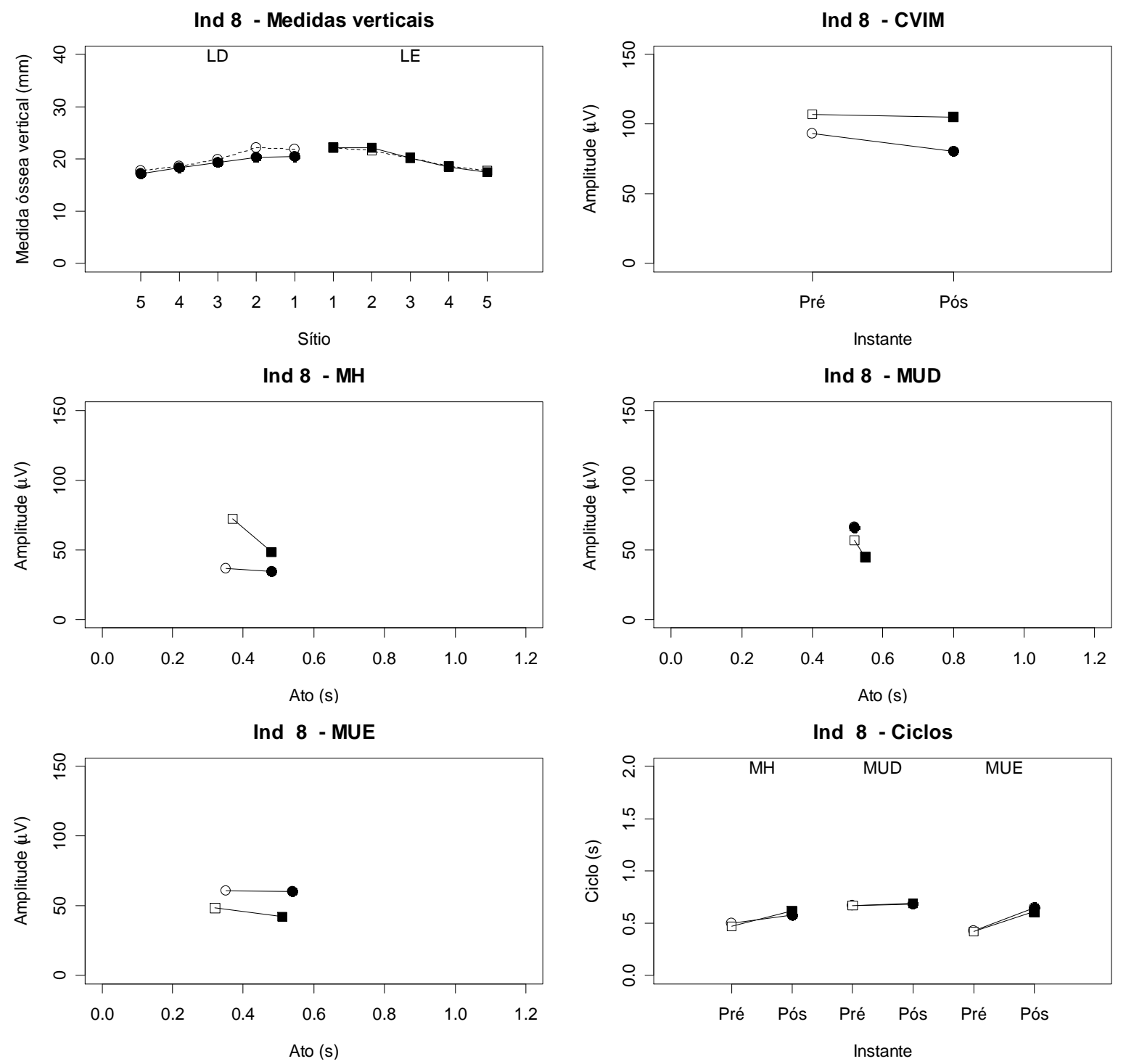

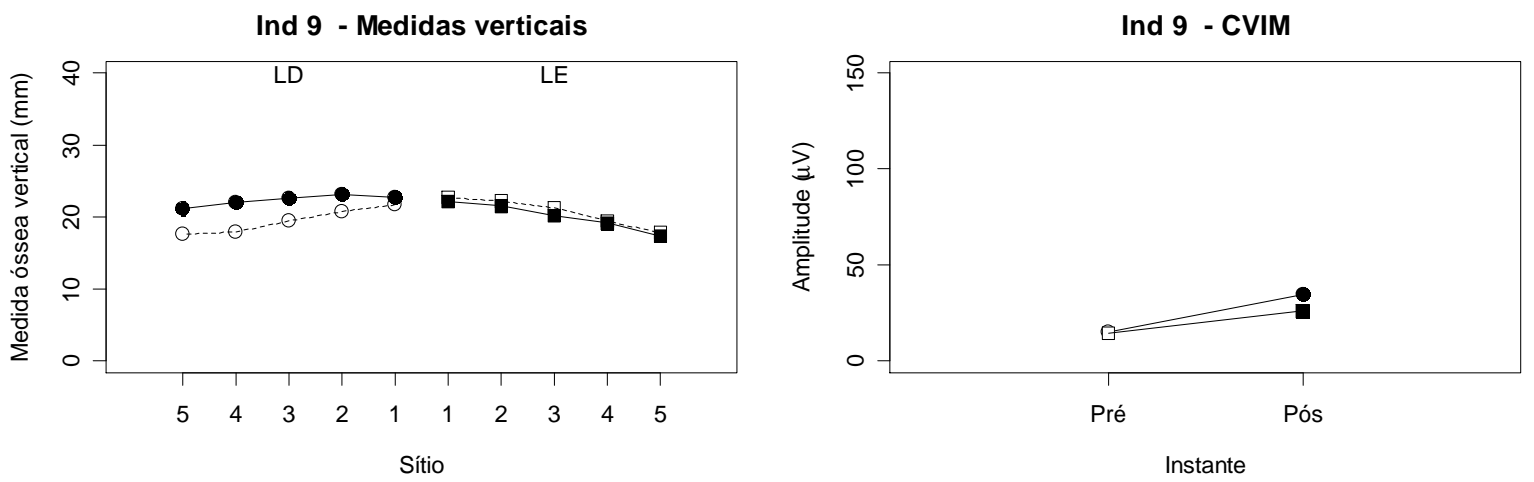

Ind $9-\mathrm{MH}$

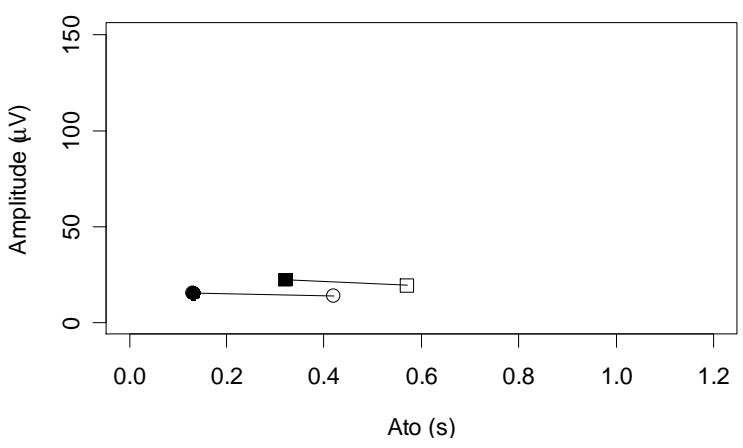

Ind 9 - MUD
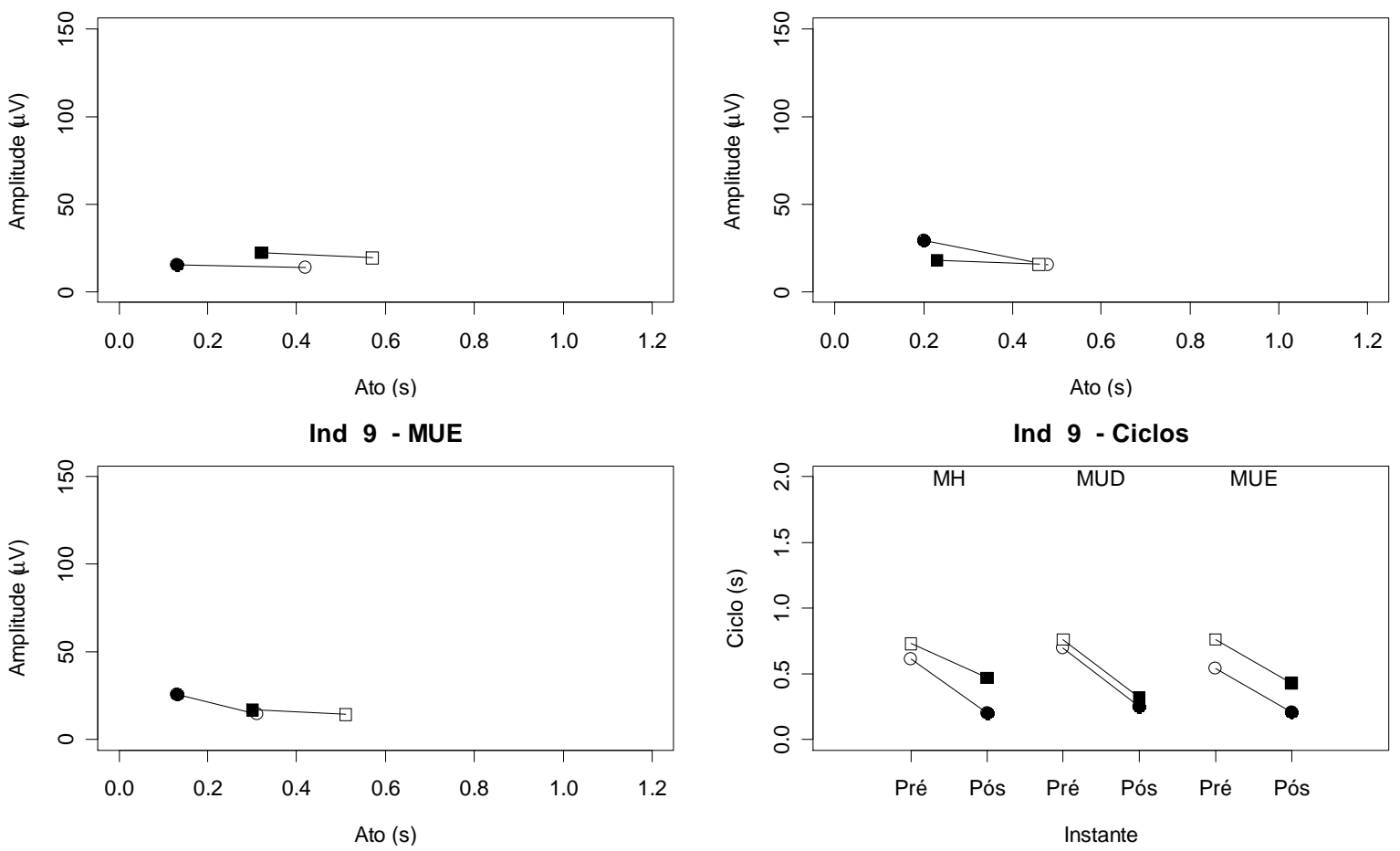

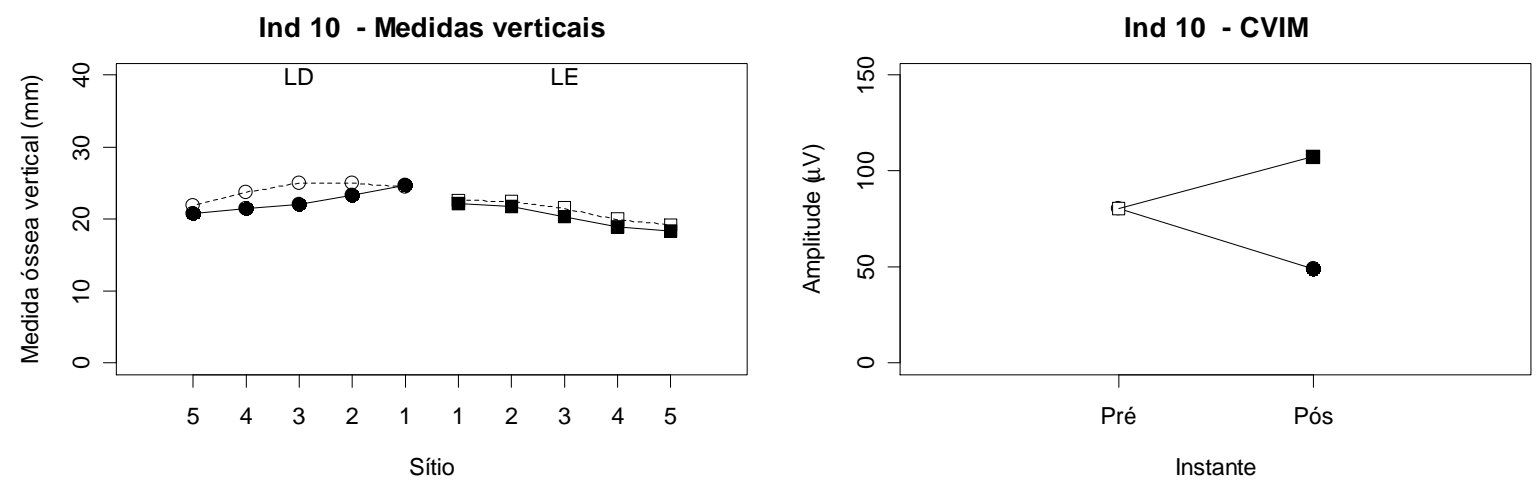

Ind 10 - MH

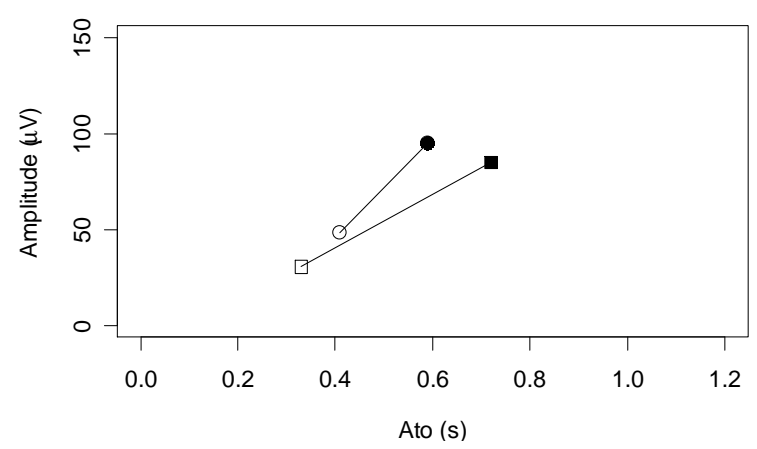

Ind 10 - MUD
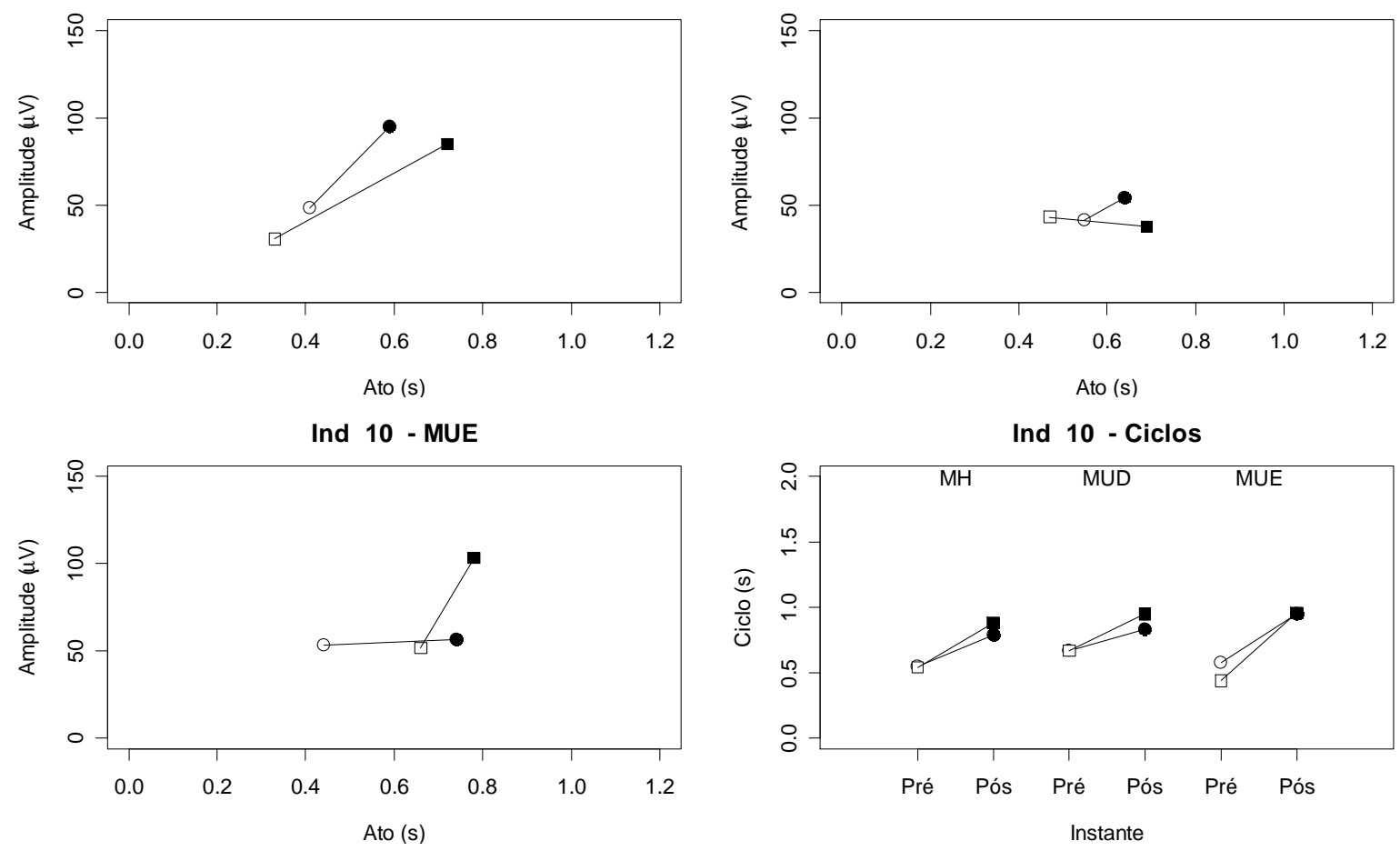

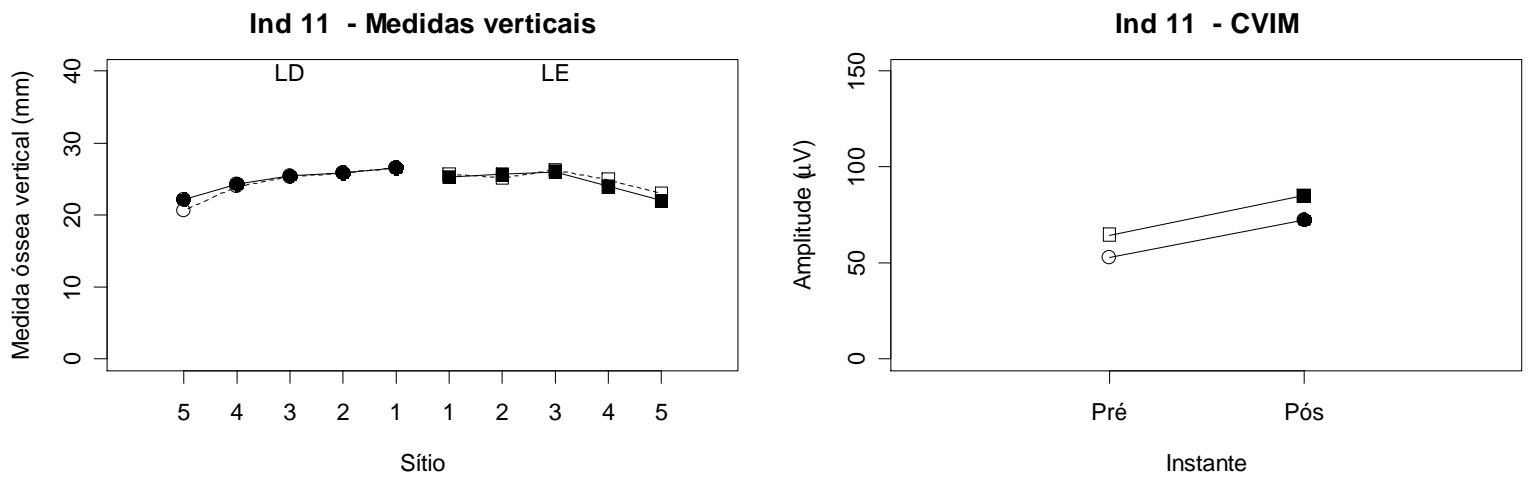

Ind 11 - MH

Ind 11 - MUD
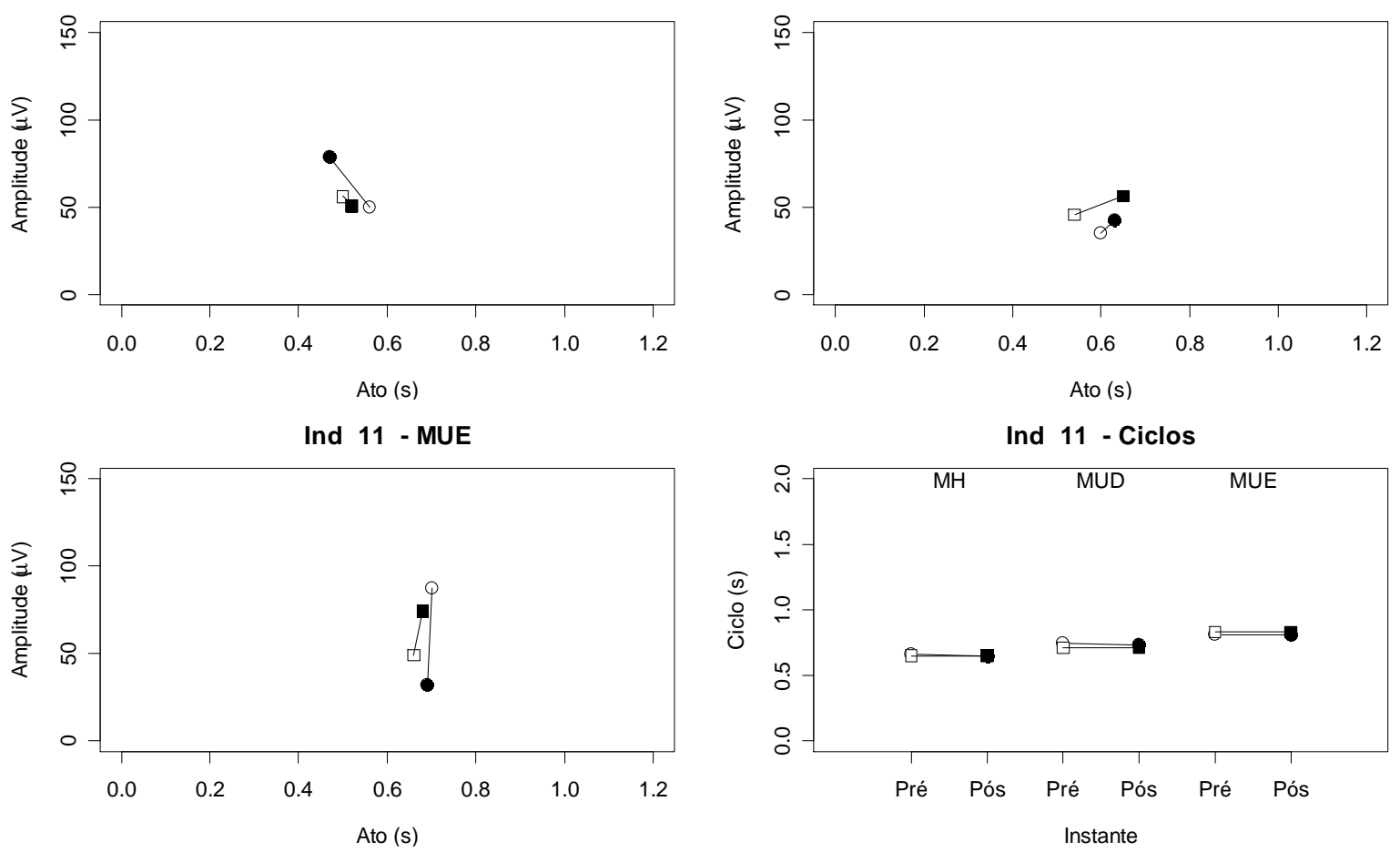

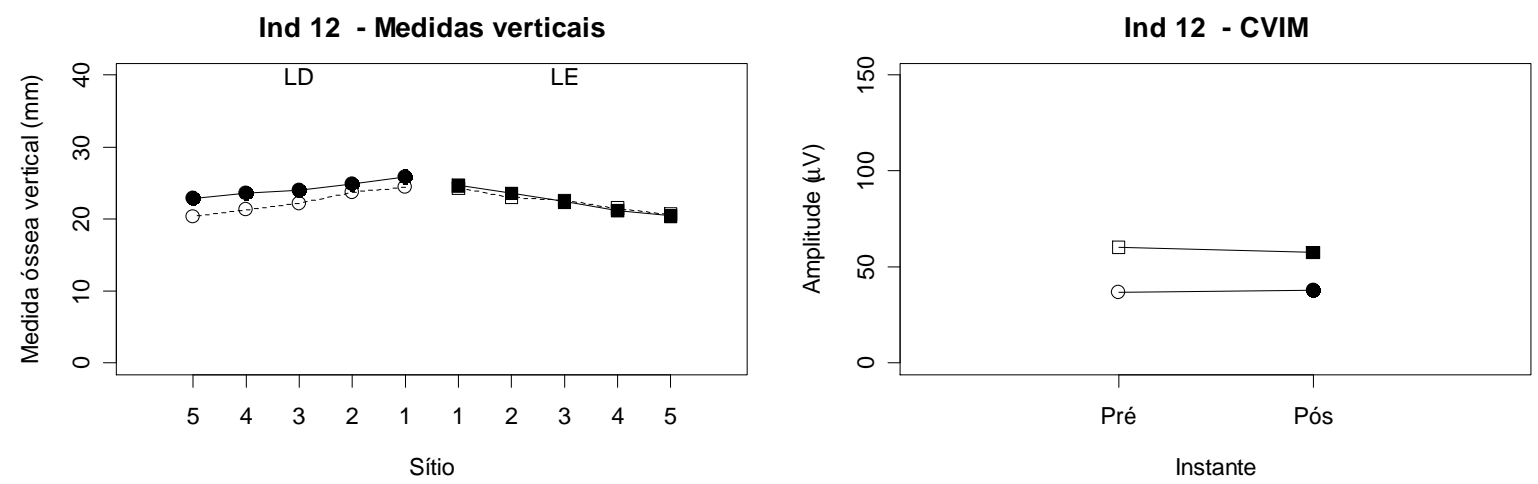

Ind 12 - MH

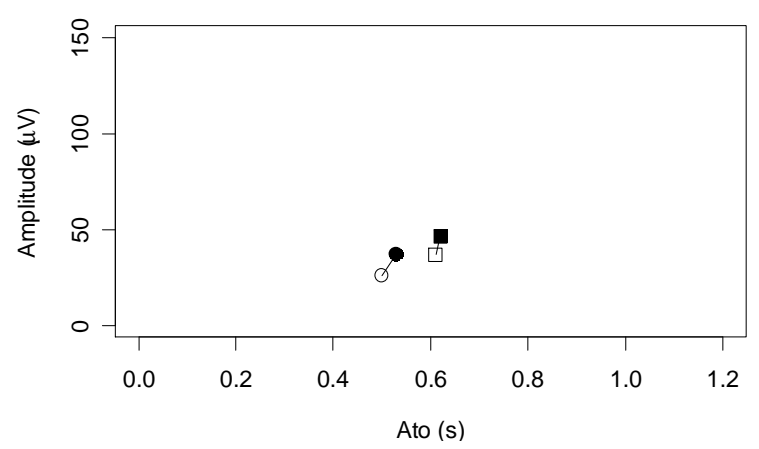

Ind 12 - MUD
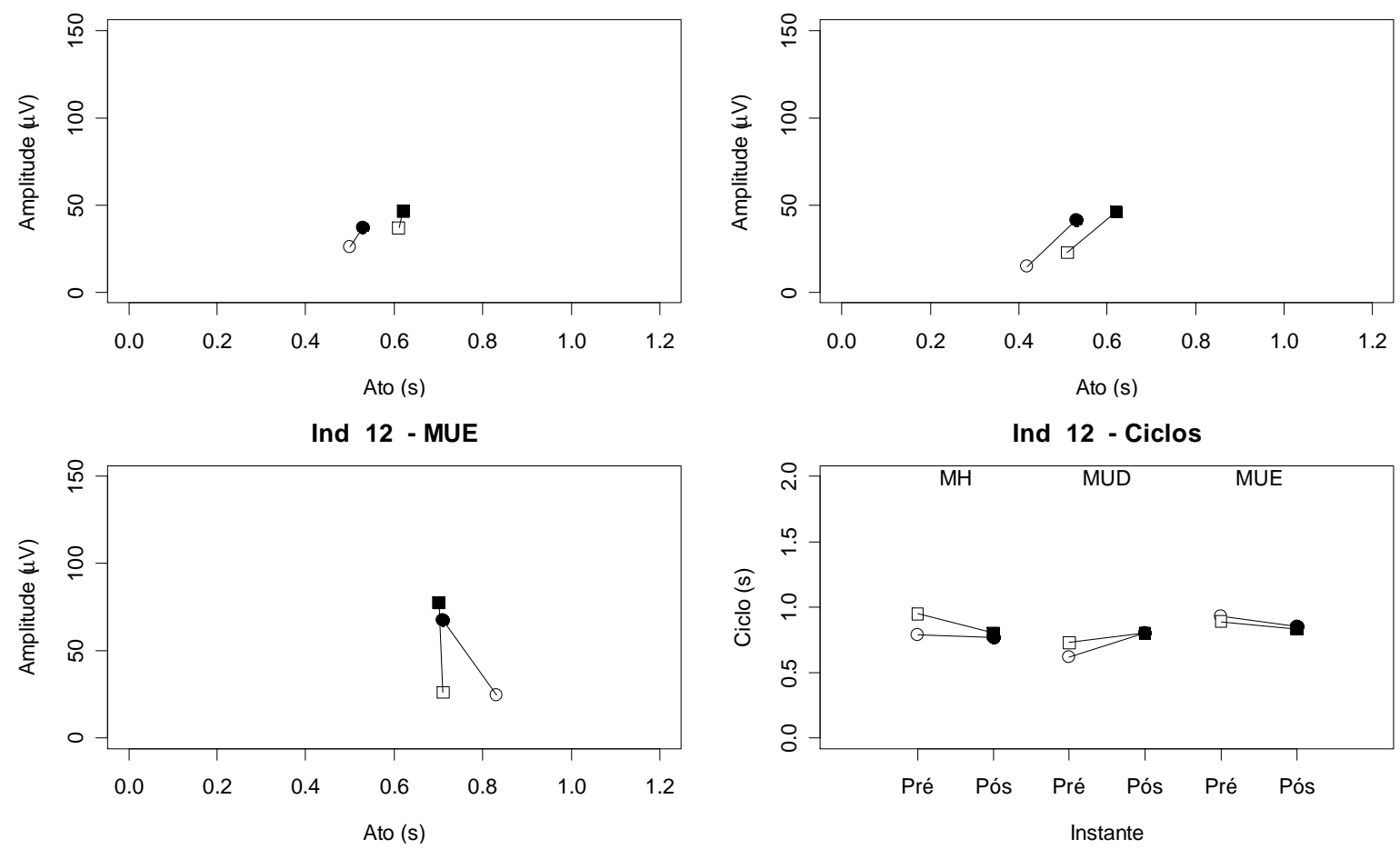

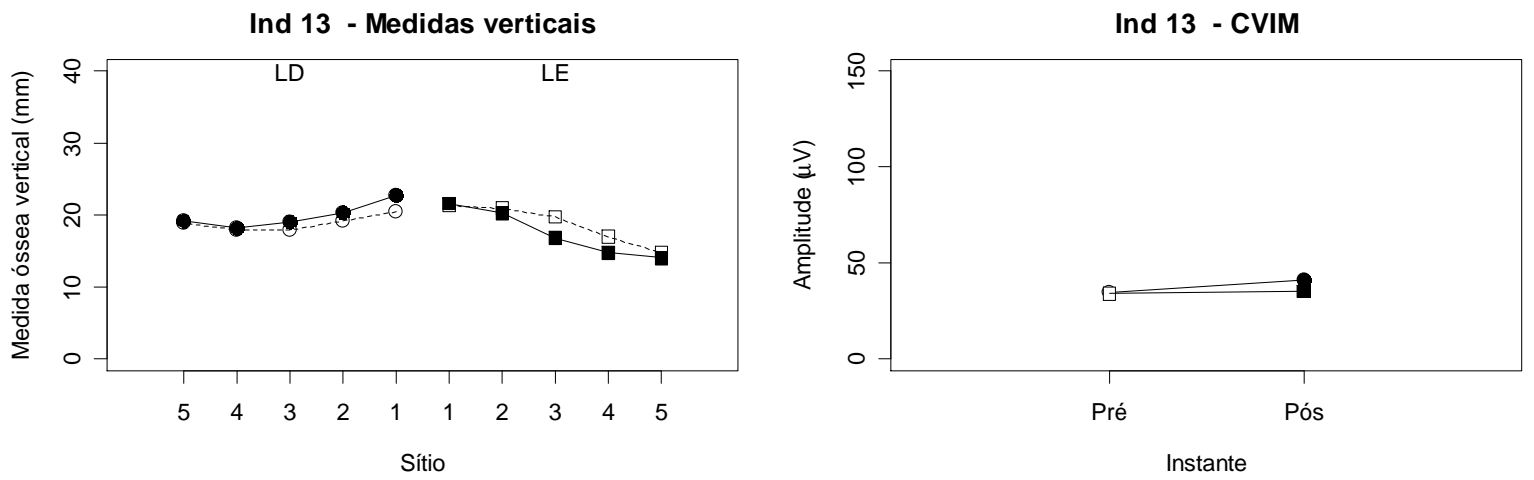

Ind 13 - MH

Ind 13 - MUD
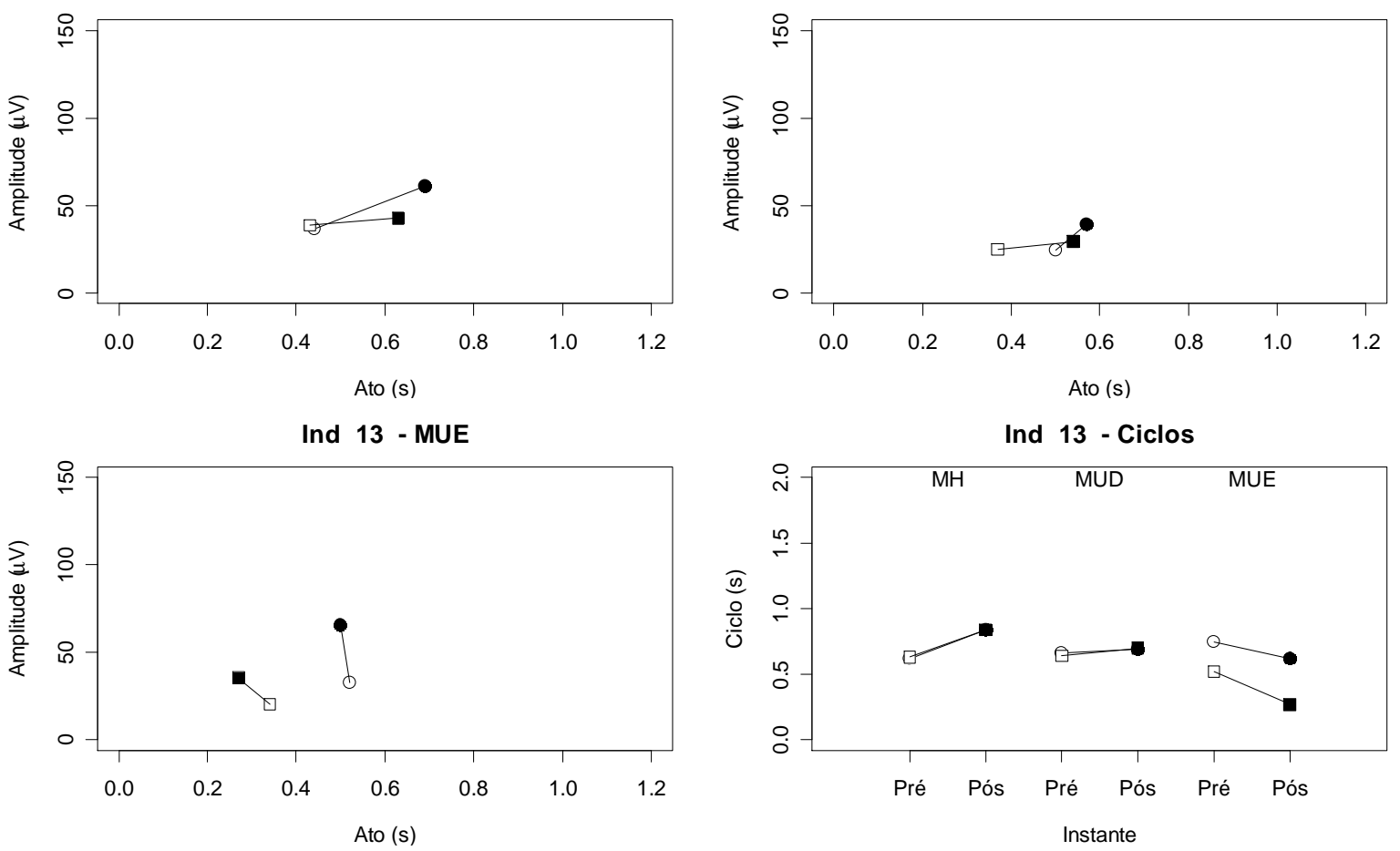

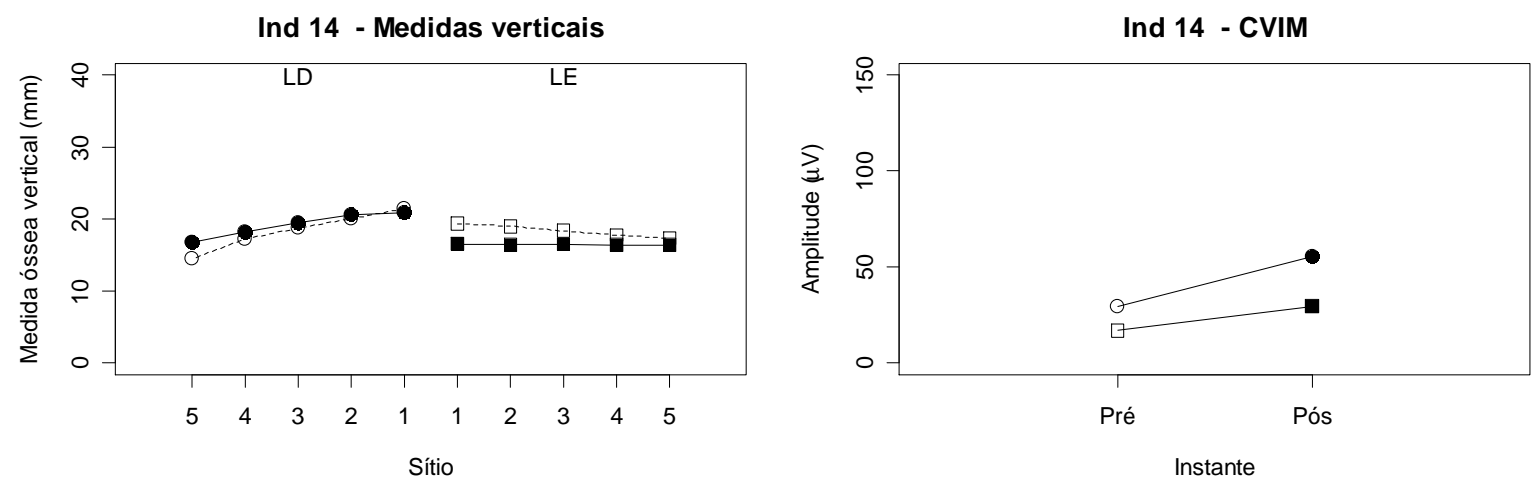

Ind 14 - MH

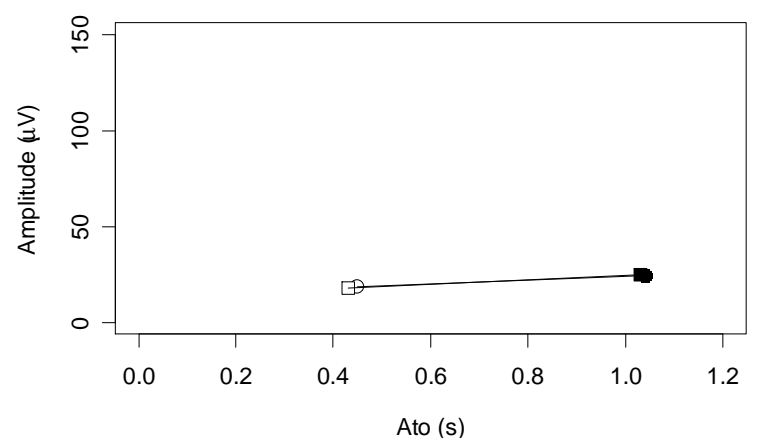

Ind 14 - MUD
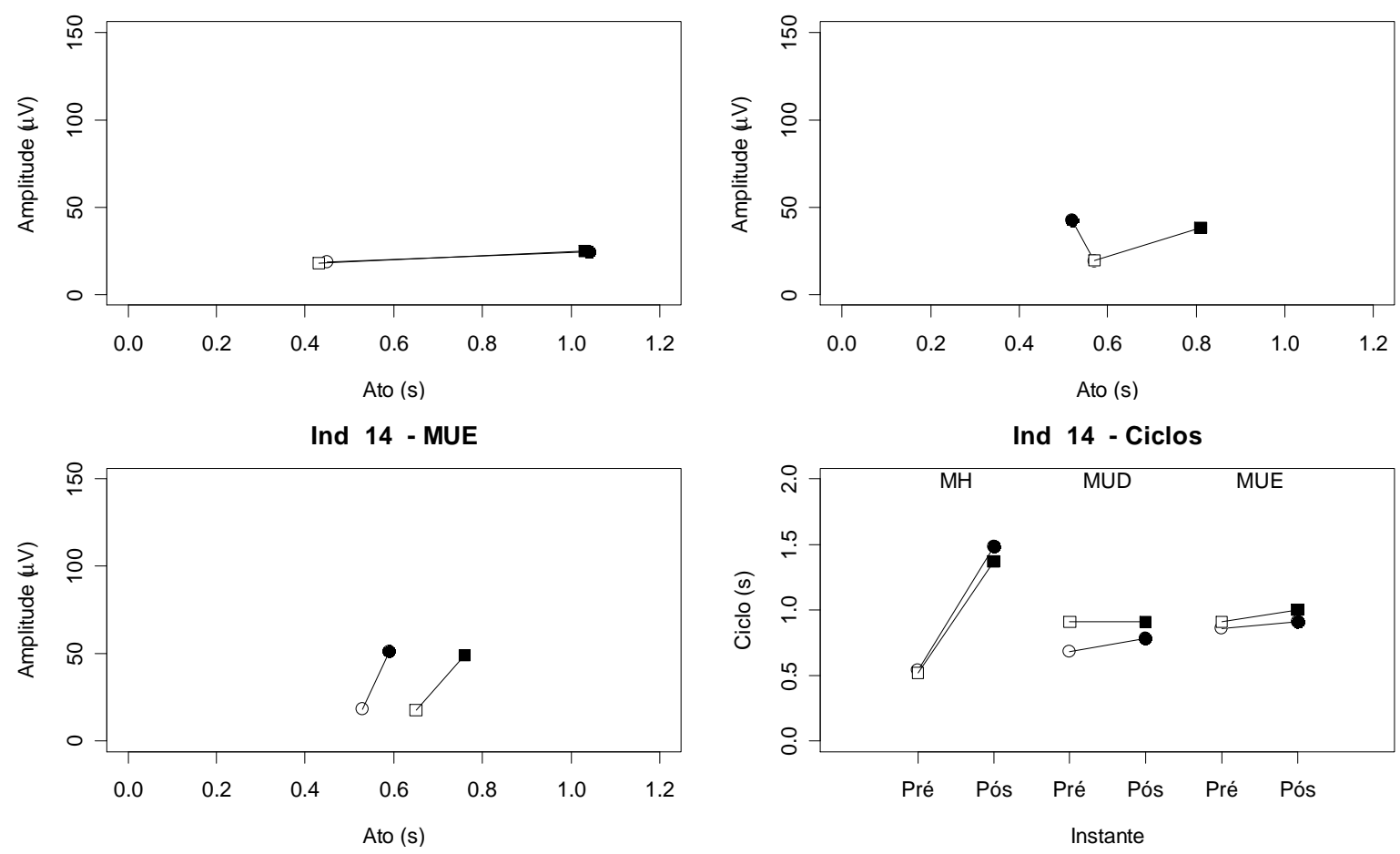

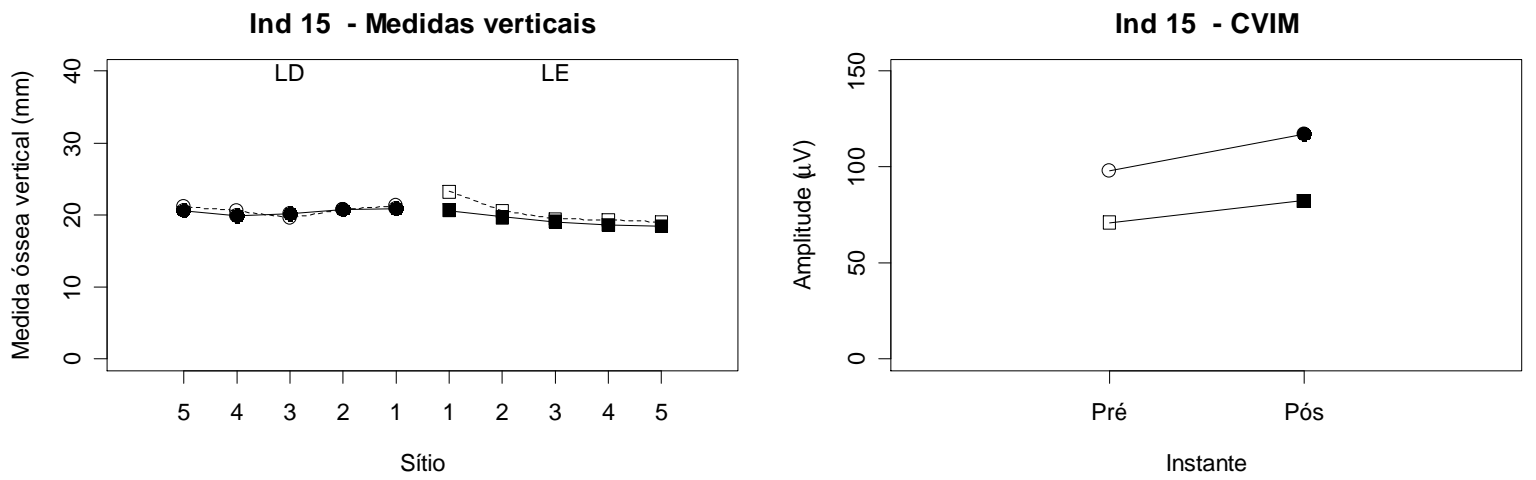

Ind $15-\mathrm{MH}$

Ind 15 - MUD
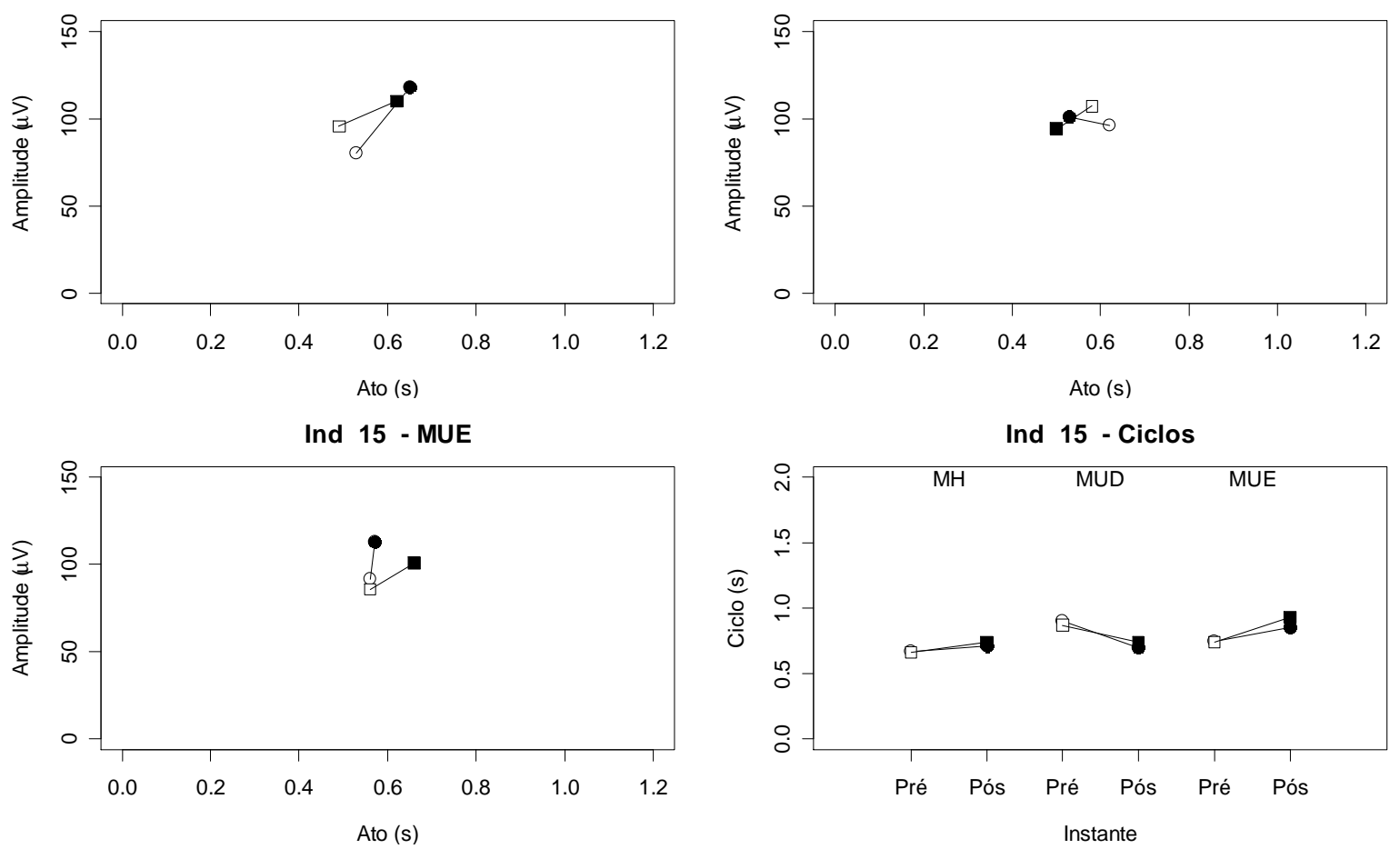

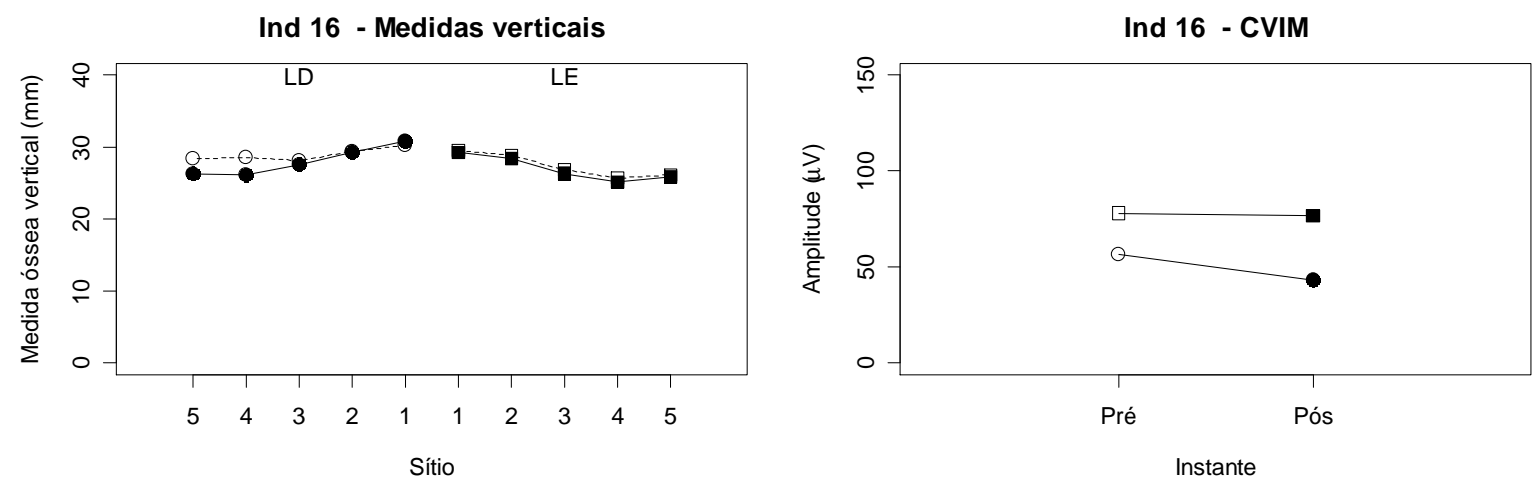

Ind $16-\mathrm{MH}$

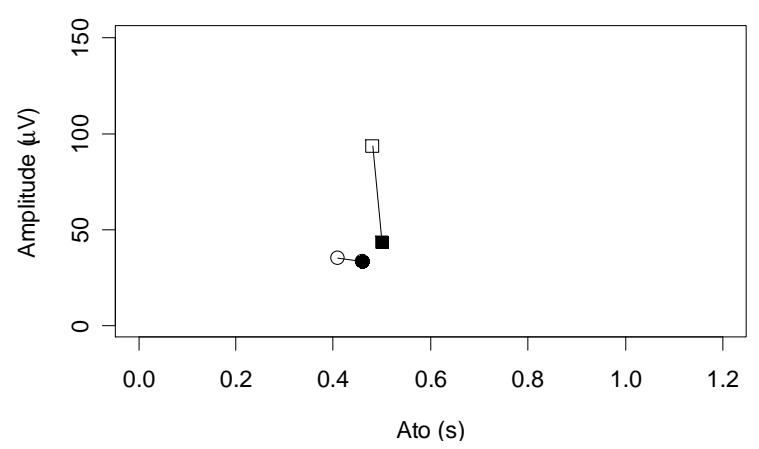

Ind 16 - MUD
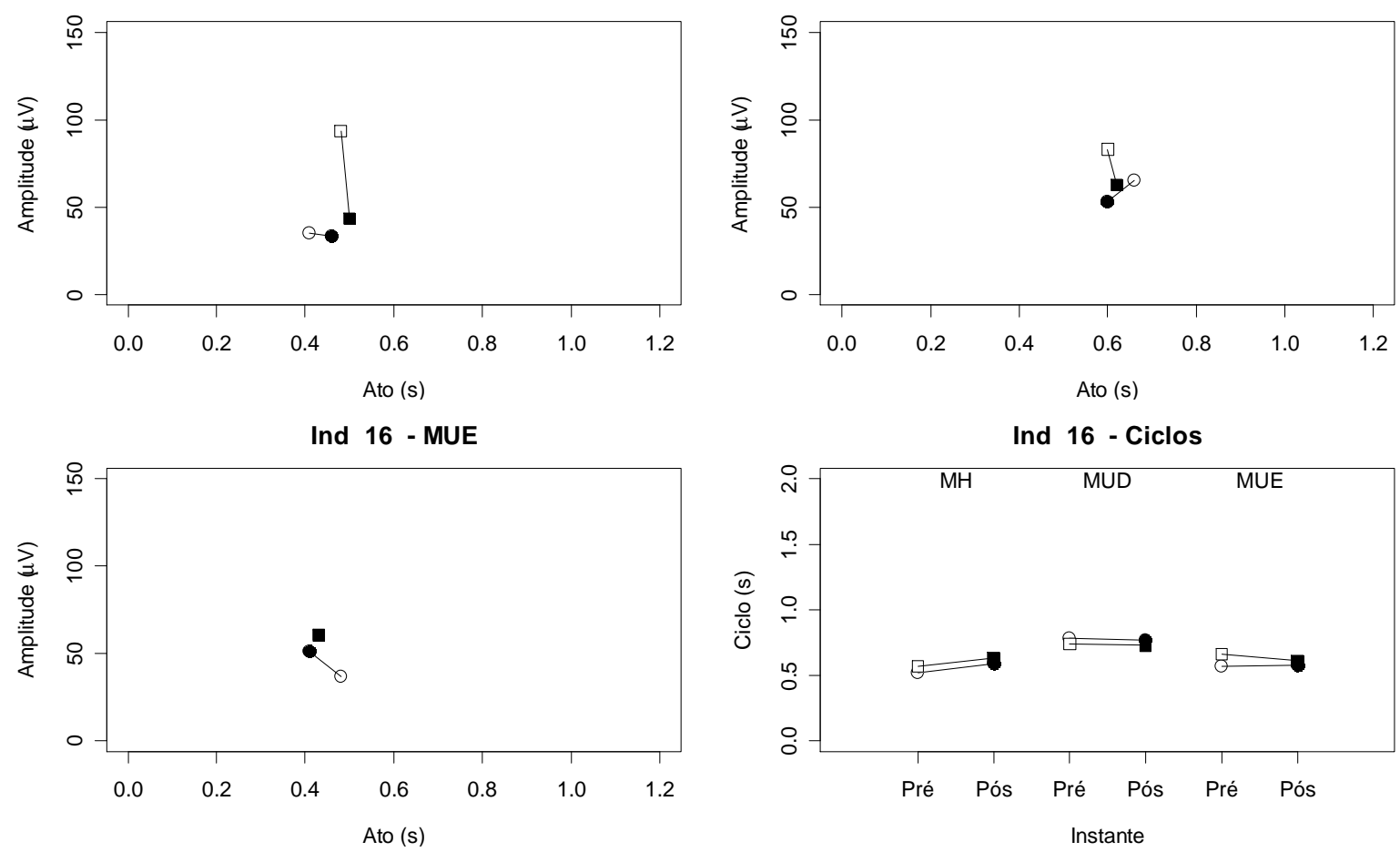

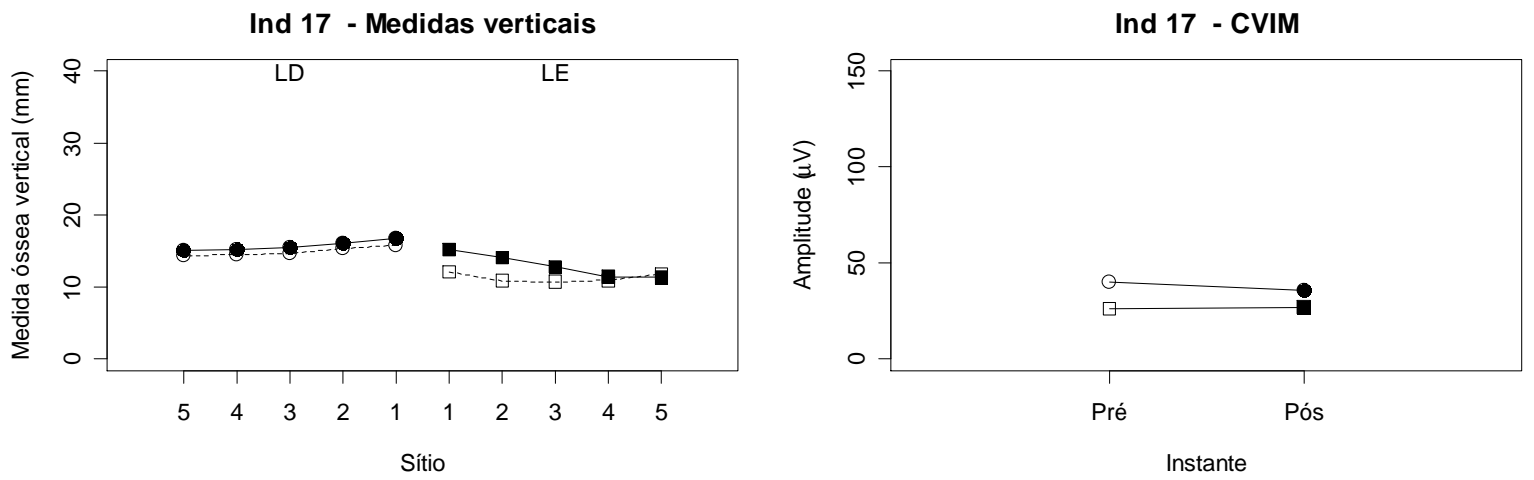

Ind $17-\mathrm{MH}$

Ind 17 - MUD
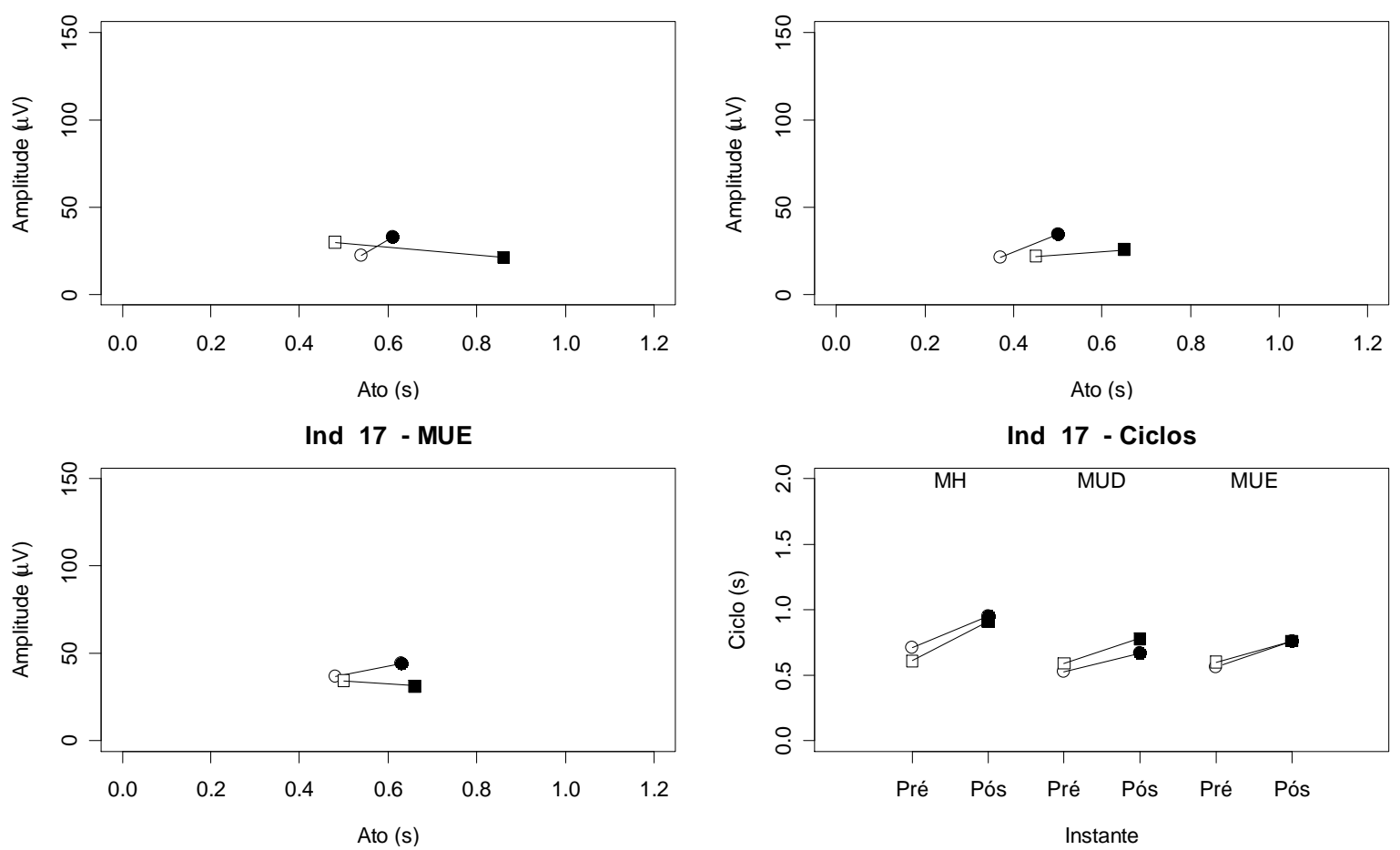